\title{
PROGRAMAS DE QUALIDADE EM HOSPITAIS DO MUNICÍPIO DE SÃO PAULO
}

\author{
VERA LÚCIA BONATO
}

Tese de Doutorado apresentada ao

Departamento de Prática em

Saúde Pública da Faculdade de

Saúde Pública da Universidade de

São Paulo para obtenção do

Grau de Doutor.

Área de concentração:

Administração Hospitalar

ORIENTADORA: PROF ${ }^{\mathrm{a}} \cdot \mathrm{DR}^{\mathrm{a}}$. VITÓRIA KEDY CORNETTA

São Paulo

2003

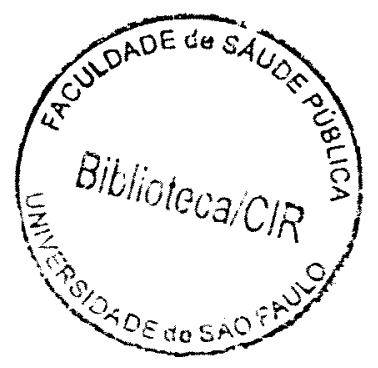


Autorizo, exclusivamente para fins acadêmicos e científicos, a reprodução total ou parcial desta tese, por processos fotocopiadores.

Assinatura:

Data:

$$
4379612003 d 00
$$


Minha homenagem à você

André Bonato, querido pai, saudades ...

Catarina Poli Bonato, querida mãe, por seu constante apoio e seus 'tempos' com o Pedro, possibilitando-me a concretização deste trabalho.

\author{
Pedro, amado filho, pelo \\ seu espírito alegre e participativo, \\ abrandando os momentos difíceis \\ deste caminho.
}




\section{AGRADECIMENTOS}

À Profa. Dra. Vitória Kedy Cornetta, querida orientadora, disponível em todos os momentos, oferecendo sua sabedoria e amizade.

Aos Professores Fernando Lefèvre e Ana Lefèvre, pelos enriquecedores encontros onde construímos conhecimento e trabalho, além de laços que transcendem este momento.

Aos Hospitais que participaram da pesquisa, criando a oportunidade de adentrarmos em seus universos, oferecendo-nos o lastro desta tese.

Ao InCor, pelas condições facilitadoras que permitiram a realização deste trabalho.

Ao Prof. Dr. José Manoel de Camargo Teixeira, pelo apoio na construção do meu caminho na área da Qualidade e, que pelo exemplo e palavras, tornou-se meu mestre e orientador.

Ao Prof. Dr. Verginelli pela cuidadosa leitura da tese, enriquecendo-a com seus apontamentos.

À Aline, Carol, Cláudia, Fernanda, Lauren, Mariana e Renata ... minha equipe de trabalho ao longo dos anos; por seu envolvimento, dedicação e disponibilidade, incentivando e participando deste desafio.

À Cátia, cuja responsabilidade, dedicação, interesse pelo trabalho e notável bom humor, tornaram mais serena esta caminhada, fazendo nascer entre nós uma amizade sincera e profunda.

À todos aqueles que por ventura não mencionei, mas que ao seu modo, me ajudaram nesta jornada. 


\section{RESUMO}

Bonato VL. Programas de Qualidade em Hospitais do Município de São Paulo.

São Paulo 2003 [Tese de Doutorado - Faculdade de Saúde Pública da USP].

Este estudo foi realizado em amostra constituída por Instituições públicas e privadas do município de São Paulo, com o objetivo de entender como os Gestores de Qualidade compreendem conceitualmente a Qualidade no Setor Saúde. Outro objetivo a destacar foi o mapeamento das práticas de Qualidade adotadas nas Instituições, e os valores atribuídos a estes Sistemas por seus Gestores. O trabalho de campo foi realizado com oito hospitais, do referido município, escolhidos intencionalmente, utilizando-se como critério fundamental a existência de Programas de Qualidade. As entrevistas ocorreram com o profissional indicado pelo hospital, ligado à Gestão de Qualidade. A método de pesquisa foi quali-quantitativa, e a estratégia metodológica para análise das entrevistas foi o Discurso do Sujeito Coletivo - DSC, além de análise quantitativa. Diferentes representações sociais foram extraídas dos discursos dos entrevistados, e demonstram os diferentes olhares existentes, no tocante à Qualidade na Saúde. Identificou-se que os métodos de certificação têm tido mais adesão dentre os pesquisados, destacando-se a ISO, na maior parte deles, seguida da Acreditação. Não foi encontrado nenhum dos hospitais trabalhando com Sistemáticas de Premiação, como o Prêmio Nacional da Qualidade - PNQ ou Programa de Qualidade do Governo Federal - PQGF. Na análise constatou-se que as Instituições iniciam seus processos de Qualidade optando por uma determinada linha de trabalho e ferramentas de caráter mais dirigido e focado. Em seguida, tendem a optar por instrumentos mais abrangentes, agregando novos elementos em seu sistema de Qualidade.

Descritores: Acreditação, Administração Hospitalar, Avaliação, Certificação, CQH, Gestão de Qualidade, ISO, Joint Commission, MBAH, Metodologias de Qualidade, PNQ, PQGF, Qualidade. 


\section{SUMMARY}

\section{Bonato VL. Programs of Quality in Hospitals of the City of São Paulo.}

São Paulo 2003 [Tese de Doutorado - Faculdade de Saúde Pública da USP].

This studyt was carried through in sample consisting of public and private Institutions of the city of São Paulo, with the objective to understand how the Managers of Quality conceptually understand the Quality in the Sector Health. Another objective was the mapping of the practical ones of Quality adopted in the Institutions, and the values attributed to these Systems for its Managers. The field work was carried through with eight hospitals, of the related city, chosen intentionally. The basic criterion used was the existence of Programs of Quality in each institution. The interviews had occurred with the professional indicated by the hospital, related with Quality. The research methodology was quali-quantitative, and the metodological strategy for analysis of the interviews was the Discurso do Sujeito Coletivo - DSC, beyond quantitative analysis. Different social representations had been extracted of the speeches of the interviewed ones, and demonstrate different ways to work with Quality in the Health. It was identified that the certification methods have had more adhesion amongst the searched ones. The ISO's certification had more adhesion, followed of the Accreditation. Wasn't found none of the hospitals working with Systematics of Awarding, as the National Award of the Quality - PNQ - or Program of Quality of the Federal Government - PQGF, both brazilian. The analysis evidenced that the Institutions iniciated its processes of Quality making an option for one determined line of work, and tools with pointed use. After that, they tend to choose more embrancing instruments, adding new elements in its System of Quality.

Key Words: Accreditation, Hospital Administration, Evaluation, Certification, $\mathrm{CQH}$, Management of Quality, ISO, Joint Commission, MBAH, Methodologies of Quality, PNQ, PQGF, Quality 


\section{ÍNDICE}

1 INTRODUÇÃO 1

1.1 Hospital - Lócus para o Desenvolvimento da Qualidade 1

1.1.1 Sobre a origem e a organização do Hospital 1

1.1.2 O Hospital e suas funções 5

1.1.3 As classificações hospitalares $\quad 7$

1.1.4 O Hospital no Brasil 11

1.1.5 A Qualidade no Hospital 15

1.2 A configuração da Qualidade na Área da Saúde: Influências e $\begin{array}{ll}\text { Determinantes } & 17\end{array}$

1.2.1 Estabelecimento de bases para a melhoria da Qualidade $\quad 17$

1.2.2 A Qualidade caminha sem informação?

1.2.3 Ampliando o conhecimento sobre o cenário da Qualidade 25

1.2.4 Reconstruindo a história da Qualidade revendo o passado

1.2.5 A nova concepção do trabalho e suas interfaces 41

1.2.6 Adequando os programas de Qualidade às organizações $\quad 42$

1.3 As sistemáticas de Qualidade na Área da Saúde 46

1.3.1 Modelo para atuar na Saúde 46

1.3.2 Acreditação hospitalar $\quad 52$

1.3.2.1 Joint Commission International 59

1.3.2.2 O Consórcio brasileiro de Acreditação 63

1.3.2.3 Manual brasileiro de Acreditação hospitalar 63

1.3.3 Certificação 65

1.3.3.1 International Standard Organization - ISO 66

$\begin{array}{lll}\text { 1.3.4 Selo } & 67\end{array}$

1.3.4.1 Controle de Qualidade Hospitalar - $\mathrm{CQH} \quad 68$

1.3.5 Premiação 69

1.3.5.1 Prêmio Nacional da Qualidade - PNQ 70

1.3.5.2 Prêmio de Qualidade do Governo Federal - PQGF $\quad 74$

2 JUSTIFICATIVA 76

3 OBJETIVO

4 MÉTODO 80

4.1 Tipo de Pesquisa 80

4.2 Desenho do estudo 82

4.3 Variáveis selecionadas 83

4.4 Instrumento e coleta de dados 84

4.5 Descrição do método de análise quantitativa e qualitativa 85 
5 RESULTADOS $\quad 87$

5.1 Apresentação comparativa dos dados entre hospitais 87

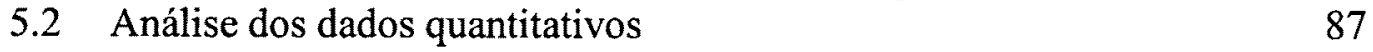

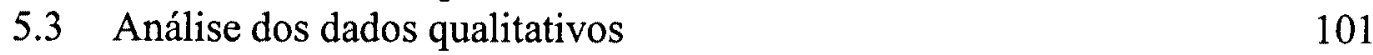

6 CONSIDERAÇÕES FINAIS 143

7 CONCLUSÃO 147

8 REFERÊNCIAS 148

ANEXO A: Termo de Consentimento

ANEXO B: Formulário de Pesquisa

ANEXO C: Compilação dos dados do Formulário de Pesquisa e Entrevistas

ANEXO D: Instrumento de Análise do Discurso do Sujeito Coletivo - DSC, Idéias Centrais e Expressões Chave 


\section{LISTA DE QUADROS/FIGURA}

\begin{tabular}{|c|c|c|}
\hline QUADRO I & - & Quanto à natureza da assistência \\
\hline QUADRO II & - & Quanto à capacidade e lotação \\
\hline QUADRO III & - & Quanto à propriedade, manutenção e controle \\
\hline QUADRO IV & - & Quanto ao procedimento do corpo clínico \\
\hline QUADRO V & - & Quanto ao tempo de estadia \\
\hline QUADRO VI & - & Quanto ao aspecto arquitetônico \\
\hline QUADRO VII & - & Quanto ao sistema de edificação \\
\hline QUADRO VIII & - & Quanto ao plano de construção \\
\hline QUADRO IX & - & Quanto à capacidade de ensino \\
\hline QUADRO X & - & Quanto ao tipo de zoneamento \\
\hline FIGURA I & - & Ciclo da Melhoria Contínua \\
\hline QUADRO XI & - & $\begin{array}{l}\text { Mudança de paradigma na implantação de } \\
\text { Qualidade no Japão }\end{array}$ \\
\hline QUADRO XII & - & Métodos de Qualidade \\
\hline QUADRO XIII & - & Critérios de Excelência no PNQ \\
\hline QUADRO XIV & - & Características da amostra \\
\hline QUADRO XV & - & $\begin{array}{l}\text { Número de colaboradores por nível } \\
\text { em relação à função exercida }\end{array}$ \\
\hline QUADRO XVI & - & Número de colaboradores por grau de escolaridade \\
\hline QUADRO XVII & - & Situação da Qualidade nos hospitais \\
\hline QUADRO XVIII & - & $\begin{array}{l}\text { Ferramentas adotadas para implementar estratégia } \\
\text { de melhoria de Qualidade }\end{array}$ \\
\hline QUADRO XIX & - & $\begin{array}{l}\text { Metodologia de avaliação, certificação, acreditação e } \\
\text { premiação adotadas }\end{array}$ \\
\hline QUADRO XX & - & $\begin{array}{l}\text { Responsáveis pela adaptação das sistemáticas de } \\
\text { Qualidade utilizadas }\end{array}$ \\
\hline
\end{tabular}


QUADRO XXI - Estruturas derivadas da implantação da Qualidade 93

QUADRO XXII - Organização dos grupos por critério de formação

QUADRO XXIII - Etapas para implantação da ISO 9000 por ordem de prioridades institucionais

QUADRO XXIV - Etapas para implantação do MBAH conforme prioridades institucionais

QUADRO XXV - Síntese das questões, Idéias Centrais e Ancoragens 


\section{SIGLÁRIO}

\begin{tabular}{|c|c|c|}
\hline $\mathbf{A B N T}$ & - & Associação Brasileira de Normas Técnicas \\
\hline APM & - & Associação Paulista de Medicina \\
\hline ASQC & - & Sociedade Americana para o Controle da Qualidade \\
\hline BSC & - & Balanced Score Card \\
\hline CBA & - & Comitê Brasileiro de Acreditação \\
\hline $\mathrm{CCIH}$ & - & Comissão de Controle de Infecção Hospitalar \\
\hline $\mathbf{C C Q}$ & - & Circulo de Controle de Qualidade \\
\hline CQH & - & Controle de Qualidade Hospitalar \\
\hline CREMESP & - & $\begin{array}{l}\text { Conselho Regional de Medicina do Estado de São } \\
\text { Paulo }\end{array}$ \\
\hline DSC & - & Discurso do Sujeito Coletivo \\
\hline $\mathbf{E C H}$ & - & Expressões Chaves \\
\hline FPNQ & - & Fundação para o Prêmio Nacional da Qualidade \\
\hline InCor-HCFMUSP & - & $\begin{array}{l}\text { Instituto do Coração do Hospital das Clínicas da } \\
\text { Faculdade de Medicina da Universidade de São Paulo }\end{array}$ \\
\hline ISO & - & Organização Internacional para Normalização \\
\hline ITT & - & International Telephone and Telegraph \\
\hline $\mathrm{JC}$ & - & Joint Commission \\
\hline JCAHO & - & $\begin{array}{l}\text { Joint Commission on Acreditation of Healthcare } \\
\text { Organizations }\end{array}$ \\
\hline JCI & - & Joint Commission International \\
\hline JUSE & - & Japanese Union of Cientists and Engeneers \\
\hline MBAH & - & Manual Brasileiro para Acreditação Hospitalar \\
\hline NBR & - & Normas Técnicas Brasileiras \\
\hline ONA & - & Organização Nacional de Acreditação \\
\hline OPAS & - & Organização Panamericana de Saúde \\
\hline PBQP & - & Programa Brasileiro de Qualidade e Produtividade \\
\hline PDCA & - & Plan Do Check Act \\
\hline PGQP & - & Prêmio Gaúcho da Qualidade e Produtividade \\
\hline
\end{tabular}




$\begin{array}{lll}\text { PIQ } & - & \text { Programa Incor da Qualidade } \\ \text { PNQ } & - & \text { Prêmio Nacional da Qualidade } \\ \text { PQGF } & - & \text { Prêmio para Qualidade do Governo Federal } \\ \text { QHR } & - & \text { Quality Healthcare Resources } \\ \text { RH } & - & \text { Recursos Humanos } \\ \text { SAC } & - & \text { Serviço de Atendimento ao Cliente } \\ \text { SEBRAE } & - & \text { Serviço Brasileiro de Apoio às Micro e Pequenas } \\ & - & \text { Empresas } \\ \text { SUS } & - & \text { Sistema Único de Saúde } \\ \text { TQS } & - & \text { Total Quality System } \\ \text { TC } & - & \text { Technical Commiteer }\end{array}$




\section{INTRODUÇÃO}

\subsection{HOSPITAL - LÓCUS PARA O DESENVOLVIMENTO DA QUALIDADE}

\subsubsection{Sobre a origem e a organização do Hospital}

Os hospitais são instituições prestadoras de serviços de grande importância social, possuindo alta complexidade e peculiaridade, onde mesmo a prática da Qualidade adquire caráter diferencial.

Conhecer a história, a evolução e o funcionamento dos hospitais, permite delinear o cenário em que se configuram as ações da Qualidade.

Atualmente, as instituições hospitalares são sistemas abertos, que além de sofrer ação do meio, são influenciadas pela própria evolução e pelas mudanças em todos os campos sociais. Tornaram-se espaço multidisciplinar de interação íntima com a sociedade (BORBA 1991, p.17).

A palavra HOSPITAL deriva da forma latina culta hospitale, que significa "relativo a hóspede e hospitalidade"; a palavra latina hospes, hóspede, originou as palavras hospitalis e hospitium, que designam o local onde se abrigavam na antigüidade os enfermos, viajantes e peregrinos, além de significar estabelecimento que se ocupava dos pobres, incuráveis e insanos, originando a palavra hospício (MICHAELIS, 1998).

Nosocômio, sinônimo de hospital, tem origem na palavra grega nosocomium que significa "lugar para tratar doentes, ou asilo de enfermos". $\mathrm{Na}$ história encontram-se citações do tipo: nosodochium, lugar para receber doentes; ptochotrophium, asilo para pobres; poedotrophium, asilo para crianças; xenotrophium, asilo e refúgio para viajantes e estrangeiros; gynetrophium, hospital para mulheres, e; gerontokomium, asilo para velhos (BORBA 1991, p.41).

Estudos relatados na Enciclopaedia Britannica (1995, p. 5855-5857), abordam que a história dos hospitais e da medicina se desenvolveram paralelamente, contudo o início da primeira é cronologicamente muito mais recente. 
As civilizações antigas, da Índia e do Egito, tiveram formas primitivas de instalações hospitalares. A literatura hindu relata que, no século VI aC, Buda nomeou um médico para cada dez vilas construindo hospitais para os aleijados e pobres. O exemplo levou seus seguidores a erigirem hospitais semelhantes, apesar de serem escassos os registros históricos de similares construções. No Sri Lanka assinala-se a existência de hospitais cinco séculos antes de Cristo.

$\mathrm{Na}$ Índia, por volta de 273-232 aC, existiu uma das mais proeminentes instalações hospitalares da Antigüidade, construída pelo rei Asoka e constituída por 18 instituições. Nelas os atendentes eram instruidos a dar tratamento carinhoso aos pacientes, servir-lhes frutas e vegetais frescos, massageá-los, mantê-los limpos e preparar medicamentos.

Nas civilizações grega e romana, os templos serviam como hospitais, impregnados pelo clima de misticismo e superstição característicos da época. Em muitos "templos-hospitais" colocavam-se os doentes à frente das estátuas dos deuses, para que a ação dos sonhos associada aos medicamentos empíricos, preparados pelos sacerdotes, pudessem efetivar a cura. Um templo de Epidauro ficaria famoso na história por esses aspectos 'hospitalares': nele os doentes eram atendidos, tanto em suas necessidades corporais como espirituais. Inscrições nas colunas deste templo podem ser consideradas como as primeiras manifestações de registros clínicos de pacientes.

Com as contribuições de Hipócrates (460-351 aC ), ilustre médico da Antigüidade, os templos passaram a assumir, mais acentuadamente, as características dos hospitais, iniciando ali a observação clínica dos pacientes apoiada mais nos fatos do que na fé. Ele ensinava que só é possível conhecer o corpo humano através do conhecimento integral do homem, constituído como unidade viva, regulada $\mathrm{e}$ harmonizada pela natureza individual.

$\mathrm{Na}$ Era Cristã, os hospitais católicos passaram a constituir parte relevante no cenário das Instituições Eclesiásticas. Um decreto do ano 355 do Imperador Romano Constantino, ordenou o fechamento das instituições médicas pagãs de origem grega, estimulando ao mesmo tempo a criação de hospitais cristãos. 
Durante a Idade Média a religião católica continuou exercendo influência dominante nos hospitais. Nestas instituições, puramente eclesiásticas, a cura não era uma meta a ser atingida, sendo apenas a alma do doente merecedora de socorro. Neste contexto a cirurgia e a dissecação eram consideradas atos sacrílegos.

O Concílio de Viena no século XIV estabeleceu que a cura do corpo caberia aos leigos e a da alma aos religiosos. O Renascimento, século $\mathrm{XV}$, trouxe um novo impulso cultural à Europa, reativando a cirurgia e a Medicina, proporcionando o desenvolvimento de estudos como o da Anatomia. Os hospitais perderam o caráter monástico, foram substituídos por hospitais municipais, futuros centros onde floresceriam grandes nomes da Medicina.

No século XVIII e primeira metade do século XIX começaram surgir os grandes hospitais, construídos sob a influência das escolas e universidades. Nessa época, tanto na Europa como nos EUA, as condições de higiene e assepsia eram muito precárias. Os cirurgiões incentivavam a supuração das feridas operatórias como um mecanismo facilitador da cura, contribuindo para que a atmosfera hospitalar se tornasse irrespirável devido a quantidade de agentes infecciosos no ambiente, resultando na elevação da mortalidade pós-operatória acima de $90 \%$.

Este quadro se reverteu na segunda metade do século XIX, com as contribuições de Pasteur, Koch e Lister, que comprovaram a importância de uma assepsia rigorosa na prevenção de infecções. Hoje a consciência da necessidade do uso da água, sabão, escova e anti-sépticos está implícita no trato das doenças.

O primeiro hospital construído na América foi o Hospital da Puríssima Conceição, fundado por Hérnan Cortés em 1524 na Cidade do México. Em 1639, em Quebec (Canadá), foi fundado pela duquesa d'Aguillon o Hôtel-Dieudu-Précieux-Sang.

O hospital norte-americano pioneiro foi edificado no ano de 1663 , na ilha de Manhattan, destinado ao atendimento de soldados feridos, e leva o nome da cidade. Em 1736, foi fundado na Luisiânia o Charity-Hospital. Sob influência do Dr. Thomas Bond e de Benjamin Franklin o Philadelphia General Hospital, foi fundado em 1755. O New York Hospital foi construído em 1771, por iniciativa privada, e o Massachusetts General Hospital, em Boston, foi inaugurado em 1811. 
TEIXEIRA (1989, p. 20) afirma que os avanços tecnológicos e o aparecimento da medicina científica no fim do século $\mathrm{XIX}$ e início do século $\mathrm{XX}$ revolucionaram o papel e as funções do hospital. Ele deixa de ser um local onde pobres e doentes eram levados para morrer, e transforma-se na mais importante instituição para tratamento das enfermidades oferecendo ao médico, condições de infra-estrutura que não podiam ser deslocadas à residência do paciente.

(....) "no século $\mathrm{XX}$, o hospital ampliou suas fronteiras e passou servir a toda comunidade".

Isso trouxe um novo conceito que aos poucos foi se instalando como o novo mecanismo de funcionamento do instrumento de saúde. Nesse contexto o hospital exibe um novo conjunto de finalidades: prestação de atenção médica ao doente e à sua comunidade, de modo integral; promoção e preocupação com ensino e pesquisa.

Conforme MEZOMO (1991), historicamente o hospital sofreu mudanças em várias direções. Sociologicamente, o hospital deixou de ser lugar para se morrer para tornar-se fonte de esperança. Legalmente, as obrigações do hospital agora incluem maiores responsabilidades pela qualidade dos cuidados que presta. Tecnologicamente, tem sido o lugar privilegiado do desenvolvimento da medicina, resultando serviços de salvação e melhoramento da vida. Economicamente, responde pelos maiores custos dos cuidados de saúde, por isso, se está diminuindo a internação, aumentando os serviços ambulatoriais, expandindo e formalizando o compromisso com a qualidade e a satisfação do usuário.

A configuração do cenário hospitalar atual caracteriza-se como um sistema mais humano do que mecânico, apesar de, paradoxalmente, ser uma organização bastante burocrática, com regras e regulamentos para o controle do comportamento e trabalho de seus membros. Perdeu quase que totalmente suas características de paternalismo e autoritarismo, assumindo o caráter de uma organização funcional-racional-burocrática (TEIXEIRA 1989, p. 23-24). 
Segundo TEIXEIRA, a eficiência do hospital moderno está vinculada à adequação de diferentes fatores. A racionalização e o controle rígido das tarefas, a coordenação organizacional e a profissionalização, são atividades necessárias na garantia do produto final, sendo este último processado num ambiente multiprofissional, multifuncional e de alta interatividade (1989, p. 24).

\subsubsection{O Hospital e suas Funções}

A Organização Mundial de Saúde, através de seu Relatório número 122 de 1957, esclarece que: "O hospital é um elemento de organização de caráter médico-social, cuja função consiste em assegurar Assistência Médica completa, curativa e preventiva à determinada população e cujos serviços externos se irradiam até a célula familiar considerada em seu meio; é um centro de medicina e de pesquisa bio-social."

Apesar dessa definição ter quase cinqüenta anos, ela não tem sido aplicada ao hospital ao longo de sua história. A partir das contribuições de GONÇALVES, com o decorrer dos anos a Medicina e os médicos foram se aprimorando na fisiopatologia (ciência das mudanças das funções fisiológicas, causadas pela doença) e na etiopatogenia (estudo das causas das doenças ou do seu desenvolvimento), o que permitiu um segundo momento na evolução dos hospitais. Estes passaram a ser o local de encaminhamento dos doentes que necessitavam de cuidados oferecidos por pessoal e equipamento especializados $(1989$, p. 4).

Mais recentemente o conhecimento sobre agentes microbianos, e mecanismos imunológicos, permitiram novas evoluções no quadro da saúde, principalmente desenvolvendo programas de natureza preventiva. Por causa de uma visão errônea dos fatos, os hospitais pouco participaram desta conquista. Isso gerou como conseqüência uma divisão no aparelho assistencial para com a saúde da população. 
As atividades de natureza curativa ficaram destinadas aos hospitais públicos ou privados. $\mathrm{E}$ as de natureza preventiva acabaram por gerar os conceitos básicos de Saúde Pública.

Por algum tempo esse quadro acabou limitando a postura de ambas as 'medicinas', a curativa e a preventiva. Contudo essa divisão artificial vem sendo superada, uma vez que todos os organismos que atuam no processo de atenção à saúde vêm percebendo a importância e a positiva contribuição que existe na formação de um sistema integrado, capaz de dividir as atividades e distribuir as responsabilidades de maneira racional. Vislumbra-se então o terceiro momento de evolução dos hospitais, o da medicina integral, cujo atendimento passa buscar desde a prevenção até a reabilitação do paciente e de toda a população.

Segundo o mesmo autor, aliado às contribuições de BORBA pode-se dizer que o hospital moderno tem diferentes funções, sendo elas: restaurativa, preventiva, educativa, pesquisa e integração (1991, p. 47).

A função restaurativa compreende o diagnóstico (em ambulatório e internação), o tratamento de doenças, seja de forma curativa, paliativa, por procedimentos médicos, cirúrgicos ou especiais, a reabilitação física, mental e social e o atendimento de emergência.

A segunda função refere-se ao desenvolvimento de atividades de natureza preventiva, incluindo: supervisão da gravidez e do nascimento, do crescimento normal e do desenvolvimento da criança e do adolescente; controle das doenças contagiosas; prevenção das doenças prolongadas, invalidez física e mental; educação sanitária; saúde ocupacional e higiene no trabalho.

A função educativa envolve aspectos do ensino médico, vinculado à idéia de hospital universitário, apesar da enorme importância em promover conferências, cursos, palestras, seminários, ou qualquer atividade que qualifique e recicle tal ensino. Representa também a participação em programas de natureza comunitária. O hospital deve procurar atingir o contexto sócio-familiar dos doentes atendidos. A educação sanitária, além de preventiva é educativa pois, aprimora a cultura do povo, uma vez que a higiene e o saneamento são fundamentais para a qualidade da saúde e da educação. 
Vale ressaltar que estes programas também devem ser destinados aos colaboradores da instituição, por fazerem parte da comunidade e poderem se tornar ótimos multiplicadores das orientações recebidas.

A última função dos hospitais diz respeito à participação no desenvolvimento de pesquisa em todos os terrenos de sua atividade, testando e aplicando técnicas para o seu desenvolvimento e para o progresso da sociedade. Com isso, proporciona a formação de uma consciência e uma mentalidade voltada para a indispensável coordenação dos recursos potenciais.

\subsubsection{As Classificações Hospitalares}

A classificação hospitalar também sofreu mudanças e se desenvolveu ao longo do tempo. Segundo BORBA (1991), hoje existem diferentes categorias que definem tipos distintos de Instrumentos de Saúde, apresentadas a seguir:

\section{QUADRO I - QUANTO À NATUREZA DA ASSISTÊNCIA}

\begin{tabular}{|c|l|}
\hline TIPO & \multicolumn{1}{|c|}{ DEFINIÇÃO } \\
\hline GERAL & Atende doentes de várias especialidades \\
\hline ESPECIALIZADO & Atende portadores de doenças específicas ou predominantes \\
\hline
\end{tabular}

QUADRO II - QUANTO À CAPACIDADE OU LOTAÇÃO

\begin{tabular}{|c|c|}
\hline TIPO & DEFINIÇÃO \\
\hline PEQUENO & de 25 a 49 leitos \\
\hline GRANDE & de 50 a 149 leitos \\
\hline MÉDIO & de 150 a 500 leitos \\
\hline ESPECIAL ou EXTRA & acima de 500 leitos \\
\hline
\end{tabular}




\section{QUADRO III - QUANTO À PROPRIEDADE, MANUTENÇÃO E CONTROLE}

\begin{tabular}{|l|l|}
\hline \multicolumn{1}{|c|}{ GOVERNAMENTAIS } & PARTICULARES \\
\hline - Federais: das Forças Armadas, Assistência & - Filantrópicos; \\
Pública e Universidades; & - De fins lucrativos; \\
- Estaduais: de Saúde Pública, & - Sem fins lucrativos. \\
Universidade, Polícia e outros; & \\
- $\begin{array}{l}\text { Municipais: dos Municípios; } \\
\text { - Para-Estatais: de Institutos. }\end{array}$ \\
\hline
\end{tabular}

\section{QUADRO IV - QUANTO AO PROCEDIMENTO DO CORPO CLÍNICO}

\begin{tabular}{|c|l|}
\hline TIPO & \multicolumn{1}{c|}{ DEFINIÇÃO } \\
\hline FECHADO & $\begin{array}{l}\text { Possuem um corpo clínico efetivo, que executa todo o serviço } \\
\text { médico, onde os médicos estranhos só podem participar em } \\
\text { casos especiais ou por cortesia }\end{array}$ \\
\hline ABERTO & $\begin{array}{l}\text { Não dispõe de corpo clínico efetivo e qualquer médico pode } \\
\text { exercer sua profissão e tratar de doentes particulares }\end{array}$ \\
\hline MISTO & Associação das duas formas descritas anteriormente \\
\hline
\end{tabular}

\section{QUADRO V - QUANTO AO TEMPO DE ESTADIA}

\begin{tabular}{|c|c|}
\hline TIPO & DEFINIÇÃO \\
\hline $\begin{array}{c}\text { CURTA } \\
\text { PERMANÊNCIA }\end{array}$ & $\begin{array}{c}\text { Período médio de permanência inferior a quinze dias } \\
\text { (hospitais gerais) }\end{array}$ \\
\hline $\begin{array}{c}\text { LONGA } \\
\text { PERMANÊNCIA }\end{array}$ & \begin{tabular}{c} 
Período médio de permanência superior a quinze dias \\
\hline
\end{tabular} \\
\hline
\end{tabular}


QUADRO VI - QUANTO AO ASPECTO ARQUITETÔNICO

\begin{tabular}{|c|c|}
\hline TIPO & DEFINIÇÃO \\
\hline BASILICAL & Em forma de catedral \\
\hline CRUCIFORME & Em forma de cruz \\
\hline PALACIANO & De forma quadrada ou em U \\
\hline
\end{tabular}

QUADRO VII - QUANTO AO SISTEMA DE EDIFICAÇÃO

\begin{tabular}{|c|l|}
\hline \multicolumn{1}{|c|}{ TIPO } & \multicolumn{1}{|c|}{ DEFINIÇÃO } \\
\hline PAVILHONAR & Constituídos de várias edificações \\
\hline MONOBLOCO & Bloco único \\
\hline MISTO & Combinam blocos e pavilhões \\
\hline VERTICAIS & Vários pavimentos \\
\hline HORIZONTAIS & $\begin{array}{l}\text { Blocos dispostos, predominantemente, em } \\
\text { superficie }\end{array}$ \\
\hline
\end{tabular}

\section{QUADRO VIII - QUANTO AO PLANO DE CONSTRUÇÃO}

\begin{tabular}{|c|l|}
\hline TIPO & \multicolumn{1}{|c|}{ DEFINIÇÃO } \\
\hline $\begin{array}{l}\text { DEFINITIVO ou } \\
\text { INALTERÁVEL }\end{array}$ & A planta fisica não permite alterações \\
\hline PROGRESSIVO & $\begin{array}{l}\text { Construído em etapas, que prevêem } \\
\text { alterações futuras }\end{array}$ \\
\hline FLEXÍVEL & $\begin{array}{l}\text { Possibilita mudanças internas sem } \\
\text { prejuizo na funcionalidade }\end{array}$ \\
\hline
\end{tabular}




\section{QUADRO IX - QUANTO À CAPACIDADE DE ENSINO}

\begin{tabular}{|c|l|}
\hline TIPO & \multicolumn{1}{|c|}{ DEFINIÇÃO } \\
\hline & Tipo Grande, com todas especialidades clínicas, com funções de \\
HOSPITAL DE & coordenação dos serviços médico-hospitalares de uma zona, e de \\
ENSINO & $\begin{array}{l}\text { aperfeiçoamento profissional. Inclui atividades de ensino } \\
\text { médico, escolas-médicas, e pode TER ou NÃO TER residência } \\
\text { médica regulamentada }\end{array}$ \\
\hline
\end{tabular}

\section{QUADRO X - QUANTO AO TIPO DE ZONEAMENTO}

\begin{tabular}{|c|l|}
\hline TIPO & \multicolumn{1}{|c|}{ DEFINIÇÃO } \\
\hline UNIDADE SANITÁRIA & $\begin{array}{l}\text { Pequeno, com aproximadamente 40 leitos, assistência } \\
\text { médica, cirúrgica, obstétrica e de emergência, e com } \\
\text { desenvolvimento de programas de Saúde Pública }\end{array}$ \\
\hline COMUNITÁRIO & $\begin{array}{l}\text { Aproximadamente 100 leitos, com assistência médica, } \\
\text { pediátrica, cirúrgica, obstétrica e de emergência, e com } \\
\text { encargos de Saúde Pública }\end{array}$ \\
\hline REGIONAL ou & $\begin{array}{l}\text { Aproximadamente 250 leitos, e com todas as } \\
\text { especialidades clínicas }\end{array}$ \\
\hline DISTRITAL & $\begin{array}{l}\text { Mais de 250 leitos, com todas especialidades clínicas, } \\
\text { com funções de coordenação dos serviços médico- } \\
\text { hospitalares de uma zona, e de aperfeiçoamento } \\
\text { profissional }\end{array}$ \\
\hline DE ENSINO MÉDICO & $\begin{array}{l}\text { Igual ao de base, incluindo as atividades de ensino } \\
\text { médico, escolas-médicas }\end{array}$ \\
\hline
\end{tabular}




\subsubsection{O Hospital no Brasil}

No século $\mathrm{XV}$ foram fundadas em Portugal as catorze Obras de Misericórdia agrupadas em duas categorias: Sete Espirituais e Sete Corporais. No grupo destas últimas uma se destinava ao atendimento assistencial dos enfermos originando a "Irmandade das Santas Casas de Misericórdia"(BORBA 1991, p. 41).

No periodo colonial o Brasil herdou esse tipo de organização, trazido pelos padres jesuítas no processo de catequização dos índios. Dessa forma, as Santas Casas foram os primeiros hospitais brasileiros. Acredita-se que a primeira a ser fundada tenha sido a de Olinda em 1540, depois a de Santos em 1543 ou 1551. Apesar de alguns historiadores admitirem que esta última tenha sido a precursora, por iniciativa de Brás Cubas.

O maior centro hospitalar do Brasil é o Hospital das Clinicas da Faculdade de Medicina da Universidade de São Paulo, cuja construção teve início em 1938 e término em abril de 1944.

No Rio de Janeiro funciona desde 1946 o Hospital dos Servidores do Estado, com 600 leitos. Tendo sido classificado, na época, no padrão A, pela Associação Americana de Hospitais.

De acordo com CASTELAR (1995, p.38) "a organização sanitária brasileira, até a década de 80 , caracterizou-se pela diversidade de instituições prestadoras de cuidados de saúde e pela profunda dicotomia observada entre as práticas de promoção e prevenção de saúde e a medicina chamada curativa".

Dentro desta organização, era de responsabilidade do Ministério da Saúde: os programas referentes à atenção básica, o atendimento às emergências, programas de Saúde Materno-Infantil e o controle de processos infecto-parasitários de maior prevalência ou gravidade, por exemplo, Hanseníase e Malária, e de responsabilidade das Secretarias estaduais e municipais, com o apoio do Ministério da Saúde, elaboração e condução de programas educacionais e atividades de imunização. 
A Previdência Social oferecia atendimento aos seus assegurados em Postos de Assistência Médica e Hospitais da Previdência, sendo que o setor privado atuava, principalmente, na área hospitalar, fazendo interface com a previdência e atendendo os casos particulares.

Em virtude de uma boa arrecadação da Seguridade Social na década de 70, houve mudanças dentro da estrutura de atendimento previdenciário. Inicialmente caracterizou-se a fusão de diversos Institutos, sob a denominação de Instituto Nacional de Previdência Social, INPS, mais tarde substituído pelo Instituto Nacional de Assistência Médica da Previdência Social, INAMPS.

Assinala-se que na década de 70 existiram várias outras tentativas de universalizar o acesso aos cuidados de saúde, como o PIASS, Programa de Interiorização à Assistência à Saúde e Saneamento, o PREV-SAÚDE, o PAIS, Programa de Ações Integradas de Saúde, e finalmente o SUDS, Sistema Único e Descentralizado de Saúde, que antecede o SUS, Sistema Único de Saúde.

"É importante relatar que na década de 90 ocorreu a mudança da vinculação do INAMPS com o Ministério da Previdência e Assistência Social, MPAS, para o Ministério da Saúde, MS, precursor do Sistema Único de Saúde SUS" (CASTELAR 1995, p.39).

Foi através do movimento da Reforma Sanitária, tendo como expoente a $8^{a}$ Conferência Nacional de Saúde, em 1986, que se deu a definição do Sistema Único de Saúde. É importante salientar que esta Conferência representou o evento mais significativo em termos de debate da política de saúde já acontecido na história do Brasil, pois possibilitou a participação de todos os segmentos da sociedade brasileira e estabeleceu princípios e diretrizes que posteriormente formaram a base do Capítulo da Saúde na Constituição Federal de 1988 (AMARAL 2000).

Antes desta data o acesso aos serviços de saúde não era universal, sendo que o atendimento gratuito era prestado apenas em alguns hospitais estatais e universitários, instituições filantrópicas, ou em postos e hospitais de institutos de previdência para seus associados. Dessa forma, o intuito da criação do SUS visava a integração das ações e serviços de saúde na perspectiva de um sistema único, como o próprio nome explicita. 
Os princípios norteadores que compõe o SUS são:

- Universalização do atendimento;

- Eqüidade no acesso;

- Integralidade dos serviços e ações de saúde.

As diretrizes segundo as quais o SUS se organiza são:

- Descentralização, os municípios são os principais administradores;

- Participação da comunidade através de conselhos de saúde;

- Atendimento integral, promoção, prevenção, cura e reabilitação.

Para isso ocorrer, pressupõe-se que haja:

- Comando único em cada esfera de governo;

- Regionalização e hierarquização da rede de serviços;

- Papel complementar da rede privada na cobertura assistencial.

A hierarquia traçada pelo sistema segue o modelo da pirâmide baseado no sistema nacional inglês de saúde. Neste modelo a assistência é dividida em três grandes eixos. Na base está a atenção primária voltada para a promoção, prevenção de saúde e as doenças mais corriqueiras, seguida pela secundária que tem como foco o atendimento das especialidades básicas e no pico a atenção terciária, que atende as situações de maior complexidade (AMARAL 2000).

A Lei Orgânica da Saúde, 8080 de 1990, dispõe sobre as condições para a promoção, proteção e recuperação da saúde, organização e funcionamento dos serviços, enquanto a Lei 8142 dispõe sobre a participação popular, através das Conferências e dos Conselhos de Saúde (www.saude.pr.gov.br).

Para que o Sistema Único de Saúde fosse devidamente implementado passou-se a editar Normas Operacionais Básicas - NOB. A NOB 01/91 deu início a descentralização, bem como a implantação dos Conselhos e Fundos Estaduais e Municipais de Saúde. Manteve os municípios limitados ao papel de prestadores de serviços, recebendo recursos mediante a fatura de procedimentos, conforme a mesma tabela aplicada pelos serviços contratados. 
Para definir, mais claramente o papel e as responsabilidades do gestor, foi editada a NOB 01/93, que estabeleceu as condições de gestão tanto para a esfera estadual, quanto municipal.

A NOB 01/96, além de ampliar o processo de transferência de recursos, trouxe uma nova proposta de financiamento do Sistema, que passou, no caso da Atenção Básica, a utilizar o critério per capita e de responsabilidade do gestor pelas ações básicas de saúde em cada município (AMARAL 2000).

O financiamento do SUS é de responsabilidade dos governos Federal, Estadual e Municipal. Uma das dificuldades que se apresenta para a eficaz implantação desse sistema é a questão da distribuição adequada das verbas necessárias, e da colaboração efetiva, por parte dos governos. Os recursos aplicados têm sido insuficientes para atender os princípios da universalidade e integralidade.

$\mathrm{Na}$ tentativa de subsidiar o SUS, ou alimentar o orçamento busca-se realocar recursos. Assim a criação da CPMF, operando como fonte substitutiva, permitiu a regularização do fluxo dos recursos ao longo dos exercícios financeiros. A instituição do Piso de Atenção Básica também permitiu o repasse fundo a fundo de recursos destinados às ações e serviços básicos, feitos com critérios assentados em bases populacionais.

Isso introduziu importante elemento de redução de desigualdades na distribuição dos recursos federais, permitindo aos gestores iniciar um processo de reorganização da rede de serviços.

Mesmo buscando alternativas de reajuste financeiro, a manutenção do SUS enfrenta dificuldades referentes a crescente evolução científica e tecnológica, que eleva cada vez mais o volume de recursos aplicados, desequilibrando a relação de custos com os procedimentos básicos, feitos cada vez mais em maior quantidade.

Outro fator comprometedor envolve o atendimento que o SUS presta aos usuários de Planos e Seguros Privados de Saúde, sem o devido ressarcimento.

Atualmente a última medida tomada na tentativa de minimizar os problemas com o mecanismo de financiamento do Sistema Único de Saúde encontrase na Emenda Constitucional 29/2000. 
Por esta emenda, desde 2001, nenhum estado ou município pode gastar menos de $7 \%$ de sua receita líquida com a Saúde. Sendo que no período de 2001 a 2005, os estados são obrigados a aumentar progressivamente seus gastos de $7 \%$ para $12 \%$, e os municípios de $7 \%$ para $15 \%$.

Ainda que não represente a forma ideal desejada pelo setor, cria horizontes mais favoráveis quanto aos montantes destinados à saúde e coloca desafios para o controle social quanto ao melhor e mais adequado destino dos recursos acrescidos. As principais restrições à Emenda Constitucional 29/00 estão associadas ao fato de não vir acompanhada de uma regulamentação imediata que garanta significativo aumento dos recursos na área da saúde, principalmente pelas indefinições sobre o que será admitido como gastos em ações e serviços de saúde (www.saude.pr.gov.br).

\subsubsection{A Qualidade no Hospital}

Tendo em vista que muitas das condições elementares das organizações hospitalares ainda não foram alcançadas, o estabel4ecimento da Qualidade consiste num grande desafio a ser enfrentado. Envolve alocação de recursos materiais, a gestão de pessoas, avaliação da capacidade técnica e utilização adequada das mesmas. No entanto, o que tem demonstrado ser o ponto central desta questão diz respeito ao compromisso efetivo dos tomadores de decisão com os princípios da Qualidade.

Esta lacuna não é recente. Foram necessárias algumas atitudes, às vezes drásticas, para a percepção da necessidade de olhar o usuário e os processos de trabalho, assim como verificar o lugar da qualidade, principalmente na atenção médica. Esta reflexão mobilizou os norte-americanos, que iniciaram práticas como: o relatório Abraham Flexner, que resultou no fechamento de 60 das 155 escolas médicas, entre 1910 e 1920, devido à má qualidade na formação de seus profissionais. 
O estabelecimento dos princípios sobre a importância da Certificação do médico e da Acreditação das instituições, que resultaram em 1918 no Programa Nacional de Padronização Hospitalar, apresentando um índice de $87 \%$ de reprovação dos candidatos da época, e o estabelecimento em 1951 da Comissão Conjunta de Acreditação de Hospitais, buscando assegurar a introdução e a ênfase da análise qualitativa dos mecanismos assistenciais (GILMORE, NOVAES 1997).

Estes fatos podem ser identificados como um conjunto de ações precursoras na introdução e disseminação da 'Cultura da Qualidade'. Demonstram também que o caminho americano na consolidação de uma instituição de saúde com qualidade é extenso e progressivo.

A observação dos hospitais brasileiros traz a percepção de que este processo é novo, e que seus resultados acompanham sua pouca idade e cultura predominante. Assim, as contribuições advindas dos Programas de Qualidade são bastante favoráveis e poderão contribuir na reflexão sobre o estabelecimento de melhorias intrínsecas e extrínsecas às instituições.

Para que a Qualidade se configure de acordo com as demandas atuais, deve ser incentivada e estimulada pela alta direção. A implantação desta política ocorrerá com sucesso na medida em que for incorporada na rotina do trabalho e no comportamento dos colaboradores, visando a busca de melhoria nos processos e procedimentos, pela sua constante revisão e reciclagem.

É importante o monitoramento freqüente orientado ou indicação de eficácia e eficiência, para obtenção de produtos ou serviços que atendam às necessidades e expectativas dos usuários. 


\subsection{A CONFIGURAÇÃo DA QUALIDAdE NA ÁREA DA SAÚDE: INFLUÊNCIAS E DETERMINANTES}

\subsubsection{Estabelecimento de bases para a melhoria da Qualidade}

"Excelência é uma habilidade conquistada através de treinamento e prática.

Nós somos aquilo que fazemos repetidamente. Excelência, então, não é um ato, mas um hábito."

(Aristóteles- 384-322 aC)

Este estudo aborda a Qualidade como escolha decorrente da experiência no campo hospitalar, onde constatou-se que as práticas de saúde só se realizam completamente através da ação humana, responsável pela organização do trabalho.

A Qualidade é portanto uma praxis, iluminada pela crítica e vice-versa que, se entendida e tratada nesta perspectiva, pode representar importante contribuição para a existência, concretude e historicidade do setor saúde. Sendo historicidade entendida como recurso metodológico de investigação, que se reporta ao passado para auxiliar na compreensão do presente e do futuro.

A pesquisa e suas premissas fazem parte da evolução do conhecimento adquirido pela autora no decorrer dos anos dedicados à prática de Implementação de Programa e Sistema de Qualidade, em Instituição Pública de Saúde, especializada em cardiologia; levando a mapear e conhecer as metodologias escolhidas para a implantação dos Programas de Qualidade em outros hospitais.

Buscou-se compreender como a Qualidade e os diferentes Sistemas de Avaliação são entendidos na área da saúde, qual a percepção destes pelos atores sociais que conduzem este processo nos diferentes níveis e unidades em que operam.

A atuação da pesquisadora no campo da Qualidade em hospital teve início nos idos de 1993 e vem sofrendo constantes revisões, pois a praxis pode ser transformada pelas contribuições dos atores que, interagindo com o tema, constroem novas visões e podem agregar valor aos processos vividos, além de resignificar os conceitos de acordo com a sua realidade. 
A Gestão pela Qualidade e o monitoramento dos dados levantados por este estudo, convictamente representam fatores críticos deste exercício, constituindo um dos alvos específicos de interesse da análise.

FORTES alerta que a noção de Qualidade não deve estar centrada apenas nas vertentes organizacionais, tecnicistas ou econômicas, mas orientada para a preservação dos direitos da cidadania dos usuários, destacando o importante papel dos profissionais encarregados da administração de instituições e serviços de saúde, para a garantia deste direito. (....) são apresentados aos administradores dilemas éticos relacionados à garantia da vontade dos usuários - direito à informação, privacidade, reclamação e liberdade de locomoção - por vezes negligenciado pelos profissionais da saúde. Enquanto a maior preocupação de cada profissional de saúde é com seu paciente, o administrador deve preocupar-se com a clientela do estabelecimento como um todo, em seus diferentes níveis e necessidades (1995,1996, p.48-49).

Portanto, os mecanismos de Qualidade e sua estruturação conceitual poderão ser aliadas dos dirigentes na missão de administrar as instituições de saúde, uma vez que o sucesso deste empreendimento reside na condução exemplar da alta gestão, como um modelo inspirador dos participantes neste movimento.

Assim, dentro do campo da Qualidade na saúde, o recorte feito focou especialmente em como se estabelece a compreensão conceitual da Qualidade pelos atores sociais que conduzem o processo neste cenário, a partir de sistemáticas de Qualidade vivenciadas no trabalho, cuja evolução torna-se visível pelos dados apresentados.

A compreensão de como os atores sociais interagem e se posicionam frente às diversas dimensões, presentes no cotidiano dos serviços de saúde, constituíram também interesse da análise. 
Nas décadas de 80 e 90 o conceito de Qualidade passou a circular nos meios de comunicação, como forma de transformação empresarial projetada para o futuro. Sua difusão fez com que as organizações adotassem Sistemas de Qualidade para se posicionarem no mercado, buscando a competitividade pela eficiência e eficácia de seus processos.

Este movimento refletiu mudanças na gestão das organizações, cujo olhar dirigiu-se à reestruturação organizacional, focando na visão sistêmica dos processos, na transformação dos indivíduos, na busca de auto-realização, como pessoas capazes, criativas e produtivas. Nestas décadas verificou-se tendência à valorização dos talentos humanos, atuando como agentes participativos do replanejamento e resignificação do trabalho.

Com isso, o profissional sofreu influências diversas. O trabalho contribuiu intensamente para mudanças, tanto no plano profissional quanto no pessoal, exigindo do trabalhador postura ativa, participativa e transformadora, afetando diretamente a relação de trabalho.

Estas considerações levam a refletir sobre a abrangência e influência da Qualidade nos diferentes setores da sociedade e sua aproximação também no setor saúde.

Pode-se atribuir o início da sistematização dos primeiros modelos voltados à gestão da Qualidade da assistência médica e hospitalar ao cirurgião norte-americano Ernest Armory Codman. Entre 1913 e 1918, publicou os primeiros trabalhos sobre a necessidade e importância de garantir a qualidade dos resultados das intervenções médicas e os "resultados finais" das ações de saúde. Propugnou a utilização dos conceitos da Teoria da Administração Científica (Taylorismo) ao modo de gerir, administrar e classificar os hospitais, bem como avaliar e controlar a prestação dos serviços e os resultados da atenção. De sua ação precursora surgiu o modelo de Acreditação Hospitalar nos EUA, gerido pela Comissão Conjunta para Acreditação de Hospitais e Organizações de Saúde (NETO e GASTAL, 1997, p.14). 
O estudo da Qualidade no campo da saúde, envolve além de um conjunto de técnicas, uma dimensão mais ampla de ações como processo social, cujos elementos principais para seu desenvolvimento são aqueles que atuam e exercem seu papel nesta cadeia.

Desta maneira, o conjunto de práticas e ações desenvolvidas pelos sujeitos são construídas a partir de uma história pessoal e social com autonomia, embora estimulada institucionalmente.

Baseia-se, portanto, no pressuposto que os indivíduos fazem parte de uma cadeia de trabalho, onde a Qualidade influencia o processo social. Estão imersos num contexto histórico, participam com diversos outros atores sociais, interagindo entre si e no espaço que define e constitui o sistema de saúde, orientado por políticas do Estado.

Para BOURDIEU (1990, p.7) “(....) a teoria dos campos - e que poderia se chamar a pluralidade dos mundos - terminará com uma reflexão sobre a pluralidade das lógicas correspondentes aos diferentes mundos, ou seja aos diferentes campos enquanto lugares onde se constroem sensos comuns, lugares comuns, sistemas de tópicos irredutíveis uns aos outros".

SIMIONI (1996), ORTIZ (1990) e BOURDIEU (1990), afirmam que o campo pode ser compreendido não como o resultado de ações individuais, e sim como um conjunto de estratégias daqueles que o compõem. É um espaço onde se manifestam relações de poder. O que significa que sua estruturação ocorre a partir da posição que cada agente ocupa no campo. Tal distribuição é desigual e interfere na sua configuração final.

O cenário da saúde tratado neste estudo tem características próprias. A Área da Saúde pressupõe lidar com situações de saúde-doença, vida-morte, sofrimento, situações penosas e fatores de risco, que afetam tanto quem é atendido, quanto quem atende. A organização hospitalar deve considerar que o profissional é instrumento de seu trabalho, dando a este tonalidades particulares e especiais.

“A transformação individual é importante, mas não suficiente, pois o indivíduo não consegue transformar a organização do trabalho sozinho. As mudanças ocorrerão à medida em que perceba a si e ao mundo externo, passando trocar essas percepções e desejar mudanças" (BONATO DE SOUZA 1994, p.23). 
No âmbito do trabalho as transformações só podem acontecer pela ação coletiva dos trabalhadores, que através da participação ativa poderão transfigurar a organização e a divisão das tarefas, dando nova feição ao clima e à cultura organizacional.

Esta concepção baseia-se numa visão de homem integrado em diferentes aspectos, dentro de um contexto social, político, econômico e cultural, sendo responsável pela sua história de vida, além de resignificar valores e conceitos do mundo que o cerca.

VALLE (1992, p.32) afirma que a melhoria da Qualidade não pode ser vista como um programa de duração limitada, mas como processo contínuo, gradual e permanente.

O esforço de construção e organização de um sistema produtivo, que contemple relações mais claras e definidas entre os diversos atores sociais, tem se constituído como o desafio dos pensadores da administração, da psicologia, entre outros.

Frente ao mundo acelerado, repleto de turbulências e transformações tanto tecnológicas, quanto econômicas e sociais, encontra-se no conhecimento e na informação a vantagem competitiva para o indivíduo e para as organizações.

A este cenário alia-se a necessidade de revisão da forma de estar no mundo e das relações entre os indivíduos uma vez que os paradigmas antigos estão sendo questionados. Encontrou-se mudanças fundamentais nos modelos de ação, como a exigência de olhar o mundo de uma nova maneira, por uma nova ótica, reciclando os modelos mentais. Até então, os indivíduos assumiam posturas passivas, ficando a espera de mudanças externas, querendo ver para crer, buscavam estabilidade e segurança. Os chefes eram imperativos e os subordinados passivos; o planejamento linear e o controle era rigoroso sobre o trabalho e os indivíduos.

O novo paradigma exige dos profissionais posturas que reflitam a internalização de valores e conceitos revistos. Descentralizar autoridade, planejar por interação, dar ênfase na transformação individual, e estimular o autodesenvolvimento são pontos inovadores. 
As pessoas são o diferencial e os líderes influenciam de maneira saudável os colaboradores, enfocando a participação da força humana dentro da organização. A evolução para este novo modelo de pensar e agir, aliado a outros fatores da gestão, constituem a base deste aprendizado.

Para SENGE (1995, p.12) “O aprendizado faz parte da nossa natureza e, além disso, todo ser humano gosta de aprender."

Criar um ambiente de trabalho estimulador para que o conhecimento seja compartilhado, onde as relações entre as pessoas se manifestem, gerando novos conhecimentos e o desenvolvimento de novas competências, é o desafio que se coloca para a organização focada na gestão das pessoas e preocupada com a Qualidade. Ao potencializar o saber dos indivíduos a organização estará realizando saltos em busca de um crescimento.

Assim, um programa de Qualidade, que exista mais por escrito do que na prática, dará poucos resultados e será considerado pelos trabalhadores como um capricho da direção.

É preciso conhecer e entender as mudanças atuais nos seus diferentes âmbitos: social, econômico, organizacional e psicológico, para poder administrá-las. Este é o caminho para a construção de uma organização que evolui em paralelo com o desenvolvimento social e estimula seus trabalhadores rumo à cidadania.

As organizações tendem cristalizar-se no seu funcionamento. Resistem ao novo, através de barreiras criadas para manter o "status" vigente. Cabe à alta direção das empresas estabelecer com transparência seus planos de mudanças, oferecendo diretrizes que orientem o corpo funcional quanto ao novo caminho a ser trilhado e projete os esforços a serem empreendidos por todos os colaboradores.

Este direcionamento aberto e compartilhado, orientado pela definição do planejamento estratégico, possibilitará o alcance dos objetivos pretendidos pela sinergia das pessoas e da organização

Este processo de co-participação fortalece a empresa e congrega seus colaboradores a superarem crises e dificuldades comuns num mercado em constante mudança, especialmente num setor complexo como o da saúde. 
Neste cenário, as organizações vencedoras serão aquelas que conseguirem criar alternativas com maior rapidez, para avançar e melhorar, identificando suas fragilidades e estabelecendo oportunidades para a criação de mecanismos inovadores nas situações do cotidiano. Outro aspecto importante é a definição e identificação dos seus concorrentes, para estabelecer a forma como lidar com eles.

A Qualidade Total surge como ferramenta de apoio para tratar esta realidade. Assume diferentes significados tais como: qualidade de trabalho, serviço, informação, processo, estrutura e pessoas. Implica na total satisfação das expectativas e necessidades dos clientes por meio de uma gestão científica dos processos, baseada em fatos e dados, voltada para a correção e prevenção de erros. Tem como base a manutenção e a melhoria dos padrões de desempenho atuais, com produtos e serviços cada vez melhores e mais competitivos, com a participação e o envolvimento de todos os membros da organização, considerando aspectos éticos que envolvem a prestação dos serviços de saúde.

Planejamento e inovação são caminhos sem volta e a organização, através da Qualidade, vivenciará a apropriação do atual estado da arte deste segmento, projetando suas melhorias futuras.

Esta via de diversas mãos interage com os diferentes sujeitos que atuam em hospitais. Estabelece uma relação dinâmica, onde influencia e é influenciada em seu planejamento e execução, fato que possibilita contribuições, construções e reconstruções que podem agregar valor e resignificar conceitos, aproximando cada vez mais as ações do hospital à realidade do sistema de saúde e mobilizando para a busca da transformação deste segmento.

A multiplicidade de aspectos que envolvem a questão da Qualidade na saúde é constatada na vivência institucional, o que garante a convicção da importância do tema. 


\subsubsection{A Qualidade caminha sem informação?}

Segundo BITTAR (1996), apesar dos avanços que vêm ocorrendo na administração da Área da Saúde, ainda identifica-se poucos hospitais brasileiros mobilizados para a discussão: da Qualidade; dos indicadores gerenciais e de serviço; das metas institucionais, e; do estabelecimento de mecanismos de avaliação e acreditação neste ambiente.

Observou-se empiricamente que muitos hospitais estão iniciando esta busca de organização e acompanhamento de suas informações devido ao crescimento do interesse neste segmento e pela competitividade que vem se instalando, tornando o mercado mais desafiador e exigente.

A consciência criada pelos colaboradores, pela apropriação do trabalho que os Programas de Qualidade possibilitam, faz com que os indivíduos constantemente realizem leituras tanto dos movimentos objetivos, quanto subjetivos, das instituições, e consigam com relativa clareza entender seus reais caminhos.

Os anos 90 são marcados por melhores sistemas e métodos à disposição das diferentes instituições para que elas possam melhorar a Qualidade da atenção médica e dos serviços prestados. Esta melhoria hoje converteu-se em obrigação, por isso muitos países propuseram iniciativas de reforma dos seus sistemas de saúde. Grande parte dos pacientes e dos profissionais desta área sabem que os serviços prestados, especialmente aqueles voltados a atenção médica, poderiam ser melhorados.

Entre os fatores que contribuíram para a busca do atendimento destas necessidades, identifica-se:

- A maior conscientização dos pacientes, como usuários diretos dos serviços de saúde;

- Maior atenção para a Qualidade em todos os ramos da economia, ao reconhecer que esta é a chave para o êxito a longo prazo;

- A necessidade de controlar os custos da saúde. 
"Dentre as inúmeras questões que envolvem este setor, a informação ao usuário apresenta-se como um ponto a ser melhorado. Freqüentemente ela é sonegada ao paciente, porém isto não decorre de má-fé, mas da postura paternalista prevalente no setor saúde. Pensando em beneficiá-lo, a informação adequada é ocultada, acreditando-se que esta possa acarretar conseqüências adversas à sua esfera psicológica" (FORTES 1995,1996; p.49).

Informação é fundamental para que o individuo possa manifestar seu consentimento de forma esclarecida sobre as ações que modificarão sua integridade física ou psíquica. É preciso que a informação revelada, seja por ele compreendida.

Além da responsabilidade individual de cada profissional por informar aos usuários sobre questões que lhes são mais afeitas, cabe ao administrador dar condições à equipe de saúde o fornecimento de informações necessárias a cada caso, disponibilizar informações dos direitos que terão ao serem atendidos, elaborar prontuários adequados e facilitar seu acesso aos usuários (FORTES 1995,1996; p.50).

\subsubsection{Ampliando o conhecimento sobre o cenário da Qualidade}

A pauta básica da melhoria da Qualidade é que tudo são processos, ou uma série de passos, e o propósito é basicamente analisá-los e melhorá-los. A garantia da Qualidade é importante para medir o verdadeiro desempenho do nível individual e do sistema. Uma distinção importante entre a garantia da Qualidade e a sua melhoria, está na concentração nos processos, em vez de nos indivíduos.

É importante que os administradores examinem os problemas do sistema com tanto, ou mais rigor, do que fazem com o desempenho individual. 
O pediatra norte-americano Donald Berwick, preocupado com as questões relativas ao gerenciamento da Qualidade, envolveu-se com estes conceitos aplicando-os na Área da Saúde e implantando nela ferramentas da Qualidade Total. Todo este interesse no assunto veio mobilizado pelo Plano Nacional de Demonstração. Esta experiência foi inspiradora para que ele escrevesse, juntamente com colaboradores, o livro "Melhorando a qualidade dos serviços médicos, hospitalares e da saúde".

BERWICK e col. (1994, p.75) mostraram algumas questões também presentes no Brasil:

- Poderia a indústria da saúde, martelada pelas reações a seus crescentes custos e a seu desempenho variável, encontrar nos métodos de melhoria da Qualidade pelo menos uma resposta promissora a seus persistentes problemas?

- Poderiam os hospitais, administrados por métodos de melhoria da Qualidade, também atingir novos níveis de eficiência, satisfação do paciente, segurança, efetividade clínica e lucratividade?

- A administração da Qualidade não se aplica somente quando há um padrão, um produto uniforme? Como ela pode ajudar nos serviços médicos quando cada paciente é diferente?

- Onde se encontra a linha de montagem na assistência à saúde? A Qualidade não é principalmente uma questão de o médico tomar a decisão correta?

- A administração da Qualidade certamente ajudou sob as normas culturais do Japão, mas como ela pode funcionar na cultura individualista do Brasil? 
- Os médicos não gostam de ver a si mesmos como participantes de uma equipe nas organizações. Como a administração da Qualidade pode dar certo com os médicos?

- A administração da Qualidade exige que ela seja medida. Como podemos possivelmente medir ou até mesmo definir algo tão sutil como "Qualidade" nos serviços de saúde?

- O problema real não seria Qualidade, mas custo? O problema é que médicos e pacientes querem usar toda a tecnologia disponível enquanto o setor público e a indústria estiverem dispostos a pagar por ela. Uma Qualidade mais elevada não significará custos mais elevados?

Todas essas questões estão presentes quando se trabalha com a Qualidade na saúde, podendo constituírem-se em forças mobilizadoras ou restritivas para a aceitação e o desenvolvimento deste trabalho. A missão dos serviços públicos de saúde visa o atendimento às demandas da população, neste campo e no da doença.

Para tanto, é necessário que a gestão dos serviços deva ser eficiente e eficaz, implicando na efetivação de ações humanas através de todo corpo funcional da instituição hospitalar.

JUNQUEIRA (1992) coloca que a interação de todos os recursos da instituição afeta o desempenho organizacional, mas são essas ações humanas que determinam especialmente este processo. As ações configuram uma relação que é construída no exato momento do seu "fazer", caracterizando-se como um produto intangível, pois não é possível tocá-lo ou armazená-lo. Tais situações podem ser observadas na realização da consulta médica, onde a ação de saúde se dá, sobretudo, pela interação direta médico-paciente, o mesmo ocorrendo no momento em que o farmacêutico dispensa o medicamento, quando a enfermeira orienta, ou quando o psicólogo o atende.

Enquanto os produtos diferenciam-se pelo modo de produção, os serviços destacam-se pela forma de sua prestação. 
A definição de Qualidade na saúde depende da perspectiva, conhecimentos, valores e recursos de quem a define. Para os clientes e seus familiares, significa obter diagnóstico correto e tratamento satisfatório de acordo com suas próprias percepções. Para os profissionais, prevalecem os critérios estritamente técnicos de melhorar a qualidade de vida e saúde dos pacientes, os quais são definidos pelo contexto de onde trabalham, da escola médica responsável pela sua formação e seus valores intrínsecos.

Quando o assunto é serviço, a interferência do cliente é absoluta. Ele observa todo o processo, podendo emitir sua opinião no ato do recebimento do serviço. Acontece que nem sempre o fornecedor demonstra interesse pelo parecer do consumidor, que por isso não irá recomendá-lo e ainda divulgará a má qualidade dos serviços que encontrou. De um modo geral, produtos e serviços interrelacionam-se o tempo todo. No entanto, estudos realizados demonstram que a insatisfação gera as seguintes situações:

- Dos clientes insatisfeitos, $96 \%$ não reclamam;

- Cliente muito insatisfeito: conta para 14 pessoas;

- Cliente muito satisfeito: conta somente para quatro pessoas;

- Problema resolvido: $82 \%$ dos que reclamam, voltam;

- Custa cinco vezes mais conseguir um novo cliente.

Cerca de $94 \%$ dos problemas de prestação de serviços decorrem de falhas no processo e os $6 \%$ restantes são atribuídos a causas especiais, como pessoas, acidentes ou eventos fortuitos. Isso prova que antes de tentar achar o "culpado" de um erro, é preciso rever todas as etapas do atendimento oferecido, e detectar os pontos desfavoráveis (CRUZ 1996, p.22).

Segundo SIMIONI (1996, p.3), "Recursos Humanos, são a área viva dos sistemas de saúde, pois é a única que, no momento mesmo em que funciona, se representa, ou seja, é capaz de pensar sobre si mesma, sobre suas inter-relações, sobre o gerenciamento e sobre as ações que realizam e que uma vez tomadas, "encarnam" os sistemas de saúde como algo além de uma máquina de produção de bens e serviços." 
Pode-se caracterizar os atores deste sistema como fator crítico das instituições de saúde, ao mesmo tempo em que são elementos essenciais para a operacionalização e concretização do sistema. São, portanto, ponto fundamental para a Área da Qualidade, e devem ser tratados como um investimento das organizações. Neles se concentram a condição para transformar a organização, fazê-la diferente e capaz de enfrentar novos desafios, que consequentemente resultará em melhorias e evolução de ambos.

A velocidade para aderir às inovações, ̀̀ iniciativa e ao comprometimento para a mudança, residem na motivação desses indivíduos, sem os quais, os resultados buscados, a geração de idéias e a alavancagem para novos processos ficam prejudicados.

\subsubsection{Reconstruindo a história da Qualidade}

Revendo o passado para entender o presente e projetar o futuro

As indagações sobre Qualidade se iniciam quando procura-se compreender as diferentes concepções nela envolvidas.

A questão da Qualidade é antiga, tomando tempo dos filósofos em suas discussões conceituais sobre o homem no mundo. Permeia a ética, a moral e a religião, no tocante aos atributos que levam o homem à perfeição, qualificando-o.

No mundo industrializado de hoje, com múltiplas áreas de produção de bens e serviços, esta questão deixa de ser apenas filosófica, passando a ser caráter de sobrevivência econômica das empresas produtoras de bens e prestadoras de serviços.

Pode-se dizer que Qualidade compreende um conjunto de características relativas a determinado produto ou serviço, ou a um indivíduo, ou a um grupo deles.

A Qualidade é tudo aquilo que agrega valor ao nosso trabalho ou às nossas relações. Está diretamente ligada à produtividade da instituição, envolvendo o relacionamento humano e o desenvolvimento profissional e pessoal. 
No hospital, pode-se avaliar características que definem a Qualidade: de produtos - radiografias, exames de laboratório, refeições, etc; de serviços psicologia, serviço social, financeiro, etc, e; de grupos de indivíduos - médicos, enfermeiros, pessoal de apoio, etc., configurando desta forma um 'nivel de Qualidade do hospital'.

As bases para a construção de uma 'Teoria da Qualidade em Saúde', tem como principal expoente Avedis Donabedian. Com uma vertente metodológica distinta da utilizada na administração empresarial, o autor demonstra em seus estudos que a qualidade dos serviços médicos, hospitalares e de saúde, transita por três macrovertentes ou fundamentos operacionais: estrutura, processo e resultados, explicados a seguir:

- Estrutura - trata do número de especialistas, adequação da área e estrutura fisica, seguindo determinados padrões, manutenção e atualização de registros médicos e não médicos, etc. Compreende características referentes aos tipos de serviços prestados, entre eles: recursos materiais, tais como instalações, equipamentos e dinheiro; recursos humanos, como número e qualificação do pessoal; estrutura institucional, tal como a organização do pessoal médico, métodos para avaliação de colegas e métodos de reembolso;

- Processo - avalia como os cuidados são prestados. Exemplos: número de encaminhamentos para especialistas; tempo de espera para marcação de consultas, e; número de exames. Inclui ainda, o processo que se realiza para prestar e receber serviços, as ações com o paciente que solicita atenção médica e as ações do profissional para apresentar um diagnóstico, recomendar ou instrumentalizar o tratamento;

- Resultados - obtidos através dos indicadores. Inclui, entre outros, taxa de infecção hospitalar, e compreendem os efeitos da atenção para o estado de saúde dos pacientes e população. 
DONABEDIAN (1980), o grande líder mundial da Qualidade em saúde, diz que:

- "Há muitas definições ou muitas variáveis de uma só definição de Qualidade, e cada uma é legítima no seu contexto apropriado" (p.132);

- "A Qualidade na atenção médica consiste na obtenção dos maiores benefícios com os menores riscos para o paciente, e ao menor custo" (p.140).

A II Guerra Mundial foi o grande laboratório para utilização do gráfico de controle pelas indústrias norte-americanas que, premidas pela necessidade de produção em massa de suprimentos militares, não tinham tempo para se reorganizarem. Ela foi vencida, também, graças a utilização do controle estatístico de Qualidade nas linhas de produção dos aviões e das bombas utilizadas pelo exército aliado.

O embrião do moderno controle estatístico da Qualidade surgiu em 1930, nos Estados Unidos, com a aplicação industrial do gráfico de controle estatístico da Qualidade, inventado pelo Dr. WA Shewhart da empresa Bell Laboratories, proporcionando uma produção quantitativa e qualitativamente satisfatória (ISHIKAWA 1997).

O movimento da Gestão pela Qualidade Total tem seu início no Japão do pós guerra (1951), com as missões de cooperação internacional para a reconstrução do país, nas quais alguns cientistas norte-americanos se engajaram, entre eles Deming e Juran (DEMING 1990).

O Japão tomou conhecimento dessa tecnologia para controle da Qualidade durante o período que antecedeu a guerra e, imediatamente, traduziu para o idioma japonês suas descobertas, deslocando um número significativo de especialistas para estudá-las mais profundamente. Porém, estes acabaram expressando seus trabalhos numa linguagem matemática de difícil entendimento, acabando por impedir sua aceitação popular (ISHIKAWA 1997). 
Quando derrotado na II Guerra Mundial, o Japão teve suas indústrias destruídas, não havendo mais comida, roupa e moradia para a população. Este era o retrato de um país ocupado, frente a sérios obstáculos técnicos ligados à infraestrutura de telecomunicações.

O sistema de telefonia japonês falhava muito acima daquilo que poderia ser considerado como normal. O telefone não era uma ferramenta de comunicação confiável e isto dificultava a ação do exército norte-americano no território japonês (ISHIKAWA 1997).

$\mathrm{A}$ indústria japonesa apresentava produtos de baixo nível de qualidade e confiabilidade. A partir dessa constatação, as forças de ocupação ordenaram que a indústria japonesa de telecomunicações passasse a utilizar controles estatísticos de Qualidade e, em paralelo, educaram e treinaram os trabalhadores japoneses em cursos de estatística básica, com o apoio de especialistas norte-americanos.

A literatura disponível estabelece o ano de 1946 para o início do controle de Qualidade no Japão. Seus resultados foram tão surpreendentes que aquele método se espalhou rapidamente pela indústria japonesa. Desse modo, o Japão incorporou os primeiros conceitos de Qualidade que, ironicamente, serviram para que o 'exército empresarial japonês' ocupasse o mercado norte-americano a partir da década de 70, não pelo uso da força, mas da competência (ISHIKAWA 1997).

Essa competência cristalizou-se pela busca incessante da Qualidade, palavra muito utilizada atualmente, mas que esconde algumas armadilhas que podem ser evitadas quando se busca o seu real significado.

Com a finalidade de traçar um panorama com as idéias dos mais conceituados pensadores da Qualidade contemporânea, segue alguns conceitos por eles formulados.

JOSEPH JURAN, engenheiro e advogado, contribuiu decisivamente no movimento japonês em prol da Qualidade. Organizou os temas de forma rigorosa, formulou conceitos claros, descreveu seus métodos de forma nítida e destaca-se por um posicionamento mais 'científico'. Sugere que a Qualidade deve ser planejada estrategicamente com metas de curto, médio e longo prazo. Dá ênfase aos termos cliente interno e externo. 
Sugere princípios filosóficos e propõe tarefas concretas de organização, responsabilização e recompensas com base em resultados alcançados.

Criou a "Trilogia Juran - Planejamento, Controle e Melhoria" como instrumento de implementação de processos de Qualidade, definindo etapas como: estabelecimento e avaliação de metas e planos; ações corretivas, se necessário; melhorias contínuas e inovações constantes.

“Qualidade é a satisfação do cliente e a ausência de deficiências".

“(...) Algumas pessoas pensam que um hotel que cobra mais, é melhor do que outro que cobra menos" (JURAN 1990, p.16).

Embora seja esperado um serviço de melhor Qualidade de quem cobra mais, nem sempre isto ocorre, porque preço alto não é sinônimo de qualidade.

PHILIP CROSBY, técnico em Qualidade, ganhou experiência na ITT Corporation. Considera-se um pensador pragmático de negócios, entendendo a Qualidade como um conceito de razoável simplicidade. Criou a concepção do "zero defect" (defeito zero) e popularizou o conceito de "fazer certo da primeira vez".

Introduziu a noção de que a decisão do que fazer em Qualidade deve levar em conta aqueles setores da empresa que "fazem mais coisas erradas" e procurar as ações corretivas que mais economizarão nestes setores. Esse ponto de vista faz com que as empresas pensem na Qualidade com relação ao custo.

Seus passos para programas de aperfeiçoamento da Qualidade constam de um guia de 14 pontos práticos, que sugerem medidas concretas de como fazer.

Sua filosofia de estândares para alcançar a ausência total de defeitos considera que as instituições devem estabelecer objetivos claros para seus esforços de melhoramento da Qualidade.

"O primeiro pressuposto errôneo implica a Qualidade como sinônimo de virtude, luxo, brilho ou peso. A palavra Qualidade é usada no sentido do valor relativo das coisas, como nas frases boa Qualidade ou má Qualidade" (CROSBY 1986, p.31). 
No mundo dos negócios, os requisitos pretendidos devem ser claramente expostos para que não haja confusão conceitual. A não conformidade detectada é a ausência de Qualidade. Os problemas de Qualidade tornam-se problemas de não conformidade, e assim a Qualidade passa a ser, finalmente, definível. Por exemplo, se um automóvel BMW satisfaz todos os requisitos de um BMW, ele é um carro de Qualidade. Ao mesmo tempo, se um Fusca está de acordo com os requisitos de Fusca, ele também poderá ser considerado um automóvel de Qualidade. Qualidade é "Conformidade com os Requisitos".

KAORU ISHIKAWA, foi professor de engenharia da Universidade de Tóquio. Sua maior contribuição foi mostrar que Qualidade se faz através das pessoas, que não são, necessariamente, especialistas no assunto. Ao simplificar a linguagem, criou instrumentos e ferramentas que podem ser utilizadas por todos os trabalhadores. Criou os Círculos de Qualidade e algumas ferramentas importantes como o diagrama de causa e efeito. Qualidade "é um sistema que produz economicamente, coisas ou serviços que atendem às exigências dos consumidores".

SHEWHART, concebeu a Teoria das Cartas ou Gráficos de Controle. Estes ajudam a entender a amplitude que permeia as ações de busca da Qualidade, explicitando um universo dinâmico, constituído pelos clientes, concorrentes, matéria prima, mercado e processo de fabricação. A satisfação do consumidor é sustentada por três aspectos da Qualidade:

- No seu sentido amplo, que objetiva a satisfação das pessoas, incluindo a Qualidade do produto ou serviço, constitui o primeiro pilar;

- Custo do produto ou serviço. Quanto menor for o preço, maior a satisfação do consumidor. O preço é função do mercado, e este aspecto da Qualidade se reflete internamente no custo, este é o segundo pilar;

- Atendimento no prazo e local certos e na quantidade certa, baseia-se o terceiro pilar da satisfação total do consumidor, formando o conceito de Qualidade. 
A Qualidade de um produto ou serviço está diretamente ligada à satisfação total do consumidor e consta dos fatores: Qualidade ampla, custo e atendimento.

EDWARD DEMING, físico e matemático, trabalhou a partir de 1942 na indústria da guerra nos EUA, aplicando o controle estatístico de processo. Em 1947, passou assessorar o processo de reconstrução do Japão.

Dá nome ao prêmio que os japoneses conferem às suas empresas que se destacam pela sua Qualidade.

Pode ser considerado um filósofo da Qualidade. Alerta sobre as dificuldades e o longo tempo necessário à implementação de suas recomendações, que pressupõem profundas transformações no relacionamento entre empresa, clientes, fornecedores e empregados.

Seu método de implementação da gestão da Qualidade possui 14 pontos onde se destacam proposições como: constância de propósitos a longo prazo; acabar com a decisão sobre compras apenas no critério preço; eliminar o medo através da comunicação eficiente, e; remover barreiras que impeçam o trabalhador a ter orgulho de realizar um trabalho bem feito.

Coube principalmente a Deming, discípulo de Shewhart, personificar e consolidar conceitualmente, junto aos engenheiros e cientistas japoneses da União Japonesa de Cientistas e Engenheiros (JUSE), o arcabouço da teoria que hoje se denomina Gestão pela Qualidade Total (QUINTO NETO,GASTAL 1997).

Para ele Qualidade é algo que "só pode ser definido em termos do agente (....) Na cabeça do trabalhador, ele produz Qualidade se possuir orgulho de seu trabalho".

Os fundamentos da Gestão pela Qualidade Total baseiam-se:

- Na busca do controle total, utilizando modelos matemáticos e estatísticos para prevenção de falhas e erros;

- No planejamento estratégico da organização, de produtos, processos e melhorias/aprendizagem (PDCA); 
- Na busca da radical redução de desperdícios, re-trabalho e custos;

- No tempo certo e com tal adequação e qualidade, que gerem a total satisfação dos clientes.

A literatura reporta alguns autores que, ao discutirem o conceito de Qualidade aplicado aos serviços de saúde, apontam que os instrumentos utilizados não são necessariamente novos, mas que periodicamente voltam à moda, estabelecendo ciclos de alternância, variáveis sob a influência de diferentes denominações e concepções de mundo em relação ao trabalhador e ao usuário (MALIK 1996b).

Qualidade é o reconhecimento de um termo ao qual se atribui valor subjetivo, sendo hoje vendido como algo que varia praticamente de interlocutor para interlocutor.

No entanto, situando essa discussão no Brasil no final do século XX, isso não invalida critérios mais objetivos, como aqueles da Associação Brasileira de Normas Técnicas e/ou do início da aceitabilidade das normas ISO.

Em francês, a definição de Qualidade tem conotação de excelência, superioridade ou mérito, apresentando a noção do homem de qualidade como sendo nobre de nascença. Em inglês, mesmo o dicionário sendo o mais antigo consultado, o termo também traz entre seus significados, o de grau de excelência (MALIK 1996a, p.7).

Outro aspecto comum no conceito de Qualidade é a percepção de que qualidade é luxo. Pesquisa divulgada no $2^{\circ}$ Fórum Brasileiro de Qualidade, em 1991, revelou que $69 \%$ das pessoas não sabem reconhecer a qualidade dos produtos e a confundem com sofisticação.

Sob esse enfoque, qualidade custa caro, uma vez que está associada à quantidade de atributos de um produto e ao status que ele traz ao seu possuidor. 
No início dos anos 90 as organizações apresentavam formas de gerenciamento valorizando a redução-rejeição dos produtos, iniciativas que destacavam auditorias, visando o controle administrativo das organizações. $O$ advento do gerenciamento com foco na Qualidade tem se mostrado um conector altamente bem sucedido, integrador de realidades e com capacidade para acompanhar resultados e estabelecer ciclos de melhoria.

A maior preocupação desta abordagem é a ocorrência da falta de unidade na empresa, gerando ações desconectadas das novas expectativas dos clientes, tornando-se cada vez mais vulnerável à sua insatisfação, ficando prejudicada a eficácia dos sistemas de Qualidade Total, sujeita ao alto custo da falta de Qualidade e à inaceitável lentidão do desenvolvimento do produto.

A Qualidade não é mais essencialmente um assunto técnico, tornandose em diversos países, a base de expressão da liderança para o gerenciamento das empresas. Qualidade é um processo, podendo ser entendida a partir dos conceitos de melhoria, tomando para si vantagens como as representadas na figura I .

\section{FIGURA I - CICLO DA MELHORIA CONTÍNUA}
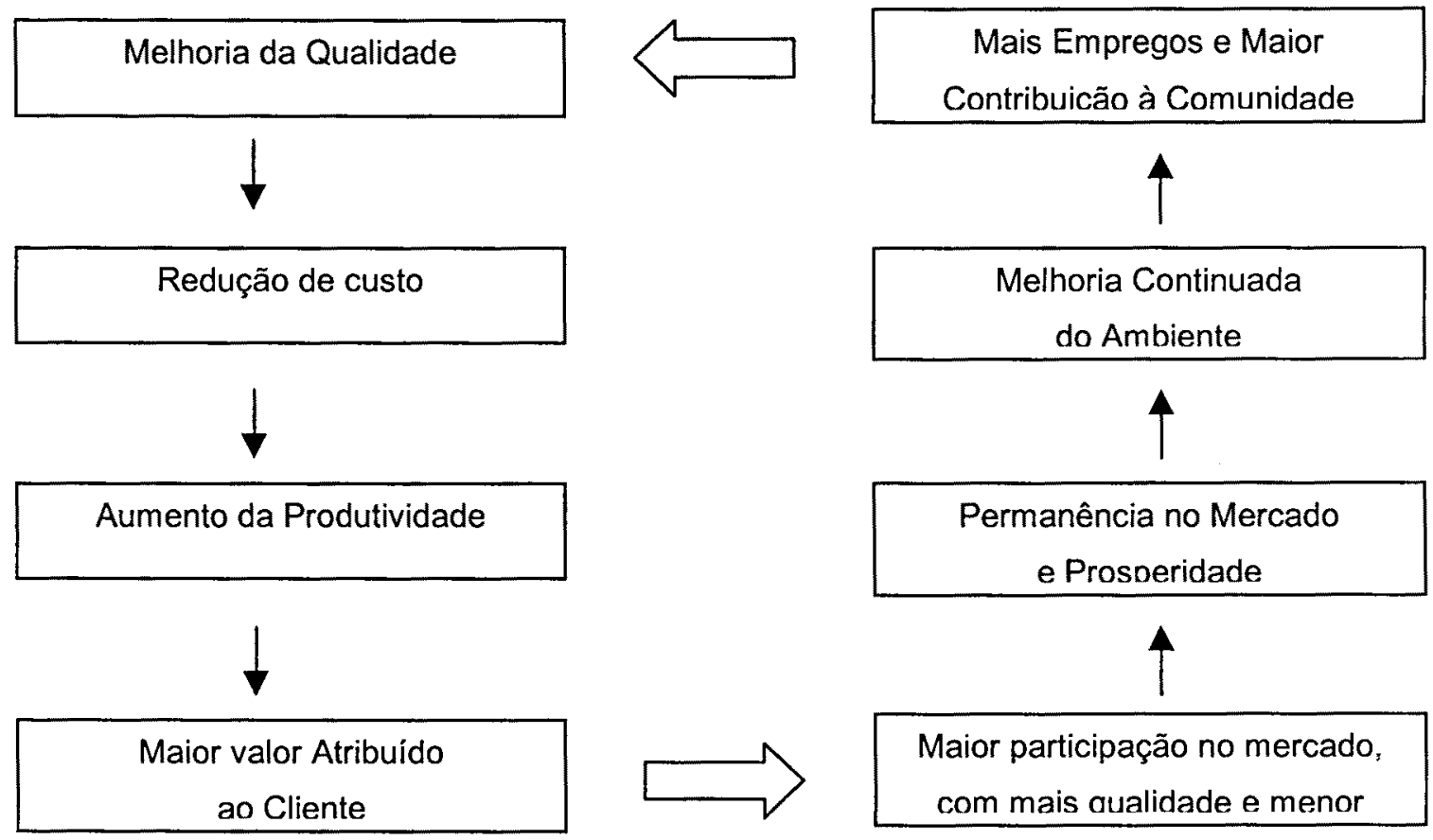

Fonte: GAUCHER e COFFEY 1991 citado em MEZOMMO 1992, p.66

Maior participação no mercado, com mais oualidade e menor 
Algumas organizações produzem mais e com mais qualidade do que outras, e isto não se deve apenas aos aspectos de tecnologia, mas sobretudo à cultura inerente ou subjacente ao modelo administrativo adotado, que se reflete no envolvimento dos recursos humanos, bem como sua participação no processo produtivo, e na conseqüente garantia ou não da satisfação do cliente.

Alguns aspectos da administração de recursos humanos no Japão figuram no quadro a seguir, retratando comparativamente a lógica presente na administração nos períodos pré e pós-guerra. Este cenário descreve o momento em que se torna mais favorável o despontar de novos desafios para a sociedade oriental, uma vez que ela precisa ressurgir da destruição sofrida.

\section{QUADRO XI - MUDANÇA DE PARADIGMA NA IMPLANTAÇÃO DE QUALIDADE NO JAPÃO}

\begin{tabular}{|c|c|}
\hline PRÉ - GUERRA & PÓS - GUERRA \\
\hline 1. Trabalho Individual & 1. Trabalho em grupo \\
\hline 2. Política de controle e motivação externa & $\begin{array}{l}\text { 2. Política de solidariedade, confiança e } \\
\text { motivação interna }\end{array}$ \\
\hline 3. Relação de proteção, subordinação e medo & $\begin{array}{l}\text { 3. Relação de parceria, lealdade e co- } \\
\text { responsabilidade }\end{array}$ \\
\hline $\begin{array}{l}\text { 4. Administração burocrática baseada na } \\
\text { autoridade }\end{array}$ & $\begin{array}{l}\text { 4. Administração participativa com alto } \\
\text { envolvimento dos funcionários }\end{array}$ \\
\hline $\begin{array}{l}\text { 5. Individualismo e alta mobilidade no } \\
\text { trabalho }\end{array}$ & $\begin{array}{l}\text { 5. Visão corporativa e baixa mobilidade no } \\
\text { trabalho }\end{array}$ \\
\hline $\begin{array}{l}\text { 6. Tensão nas relações com o empregador e } \\
\text { falta de compromisso com o cliente }\end{array}$ & 6. Lealdade ao empregador e ao cliente \\
\hline 7. Enfase na tecnologia & $\begin{array}{l}\text { 7. Ênfase na dependência dos recursos } \\
\text { humanos }\end{array}$ \\
\hline 8. Ênfase na produtividade e no custo & $\begin{array}{l}\text { 8. Ênfase na qualidade e na satisfação do } \\
\text { cliente. }\end{array}$ \\
\hline 9. Pensamento Vertical & 9. Pensamento horizontal \\
\hline 10. Visão perfeccionista limitada & 10. Visão perfeccionista clara e absoluta \\
\hline
\end{tabular}

Fonte: Revista Exame - ano $24-n^{\circ} 5(04 / 03 / 1992)$ 
Somente após os resultados positivos obtidos pelos países orientais, que os impulsionavam na superação da crise econômica do pós guerra, é que os princípios da Qualidade tiveram destaque nos Estados Unidos da América, sendo aplicados em s4uas indústrias.

O Brasil, bastante afeito à cultura americana, apenas nas últimas décadas vem aderindo a estes princípios. Iniciou sua aplicação na indústria automobilística, e aos poucos migrou para os outros setores, chegando à área de serviços, particularmente à saúde, no final da década de 80 .

Todos os esforços de transformação têm sido dirigidos para a construção de organizações de saúde que:

- Atendam aos variados interesses e necessidades dos envolvidos, sejam eles consumidores, acionistas, empregados ou sociedade;

- Sejam eficazes no atendimento às expectativas dos participantes interessados, e cuja função crítica seja coordenada pela lealdade e comprometimento dos participantes;

- Desenho organizacional define fronteiras mais permeáveis entre unidades, papéis e organizações;

- A tecnologia não pode ser separada dos "inputs" humanos e do contexto organizacional;

- Os colaboradores e outros participantes sejam os melhores avaliadores de seus próprios interesses;

- As participações individuais e coletivas sejam fundamentais para as mudanças e efetividade nas modernas organizações de saúde.

A organização de saúde empreendedora deve procurar vantagem competitiva pela flexibilidade organizacional na solução de problemas, persistência em detalhar e integrar pensamento e o fazer, promovendo a realização de um trabalho integrado e prazeroso. 
No Brasil, percebe-se crescimento no uso de técnicas como $5 \mathrm{~S}$, PDCA, CCQ, Kanban e TQS, embora a política industrial e o Programa de Qualidade e Produtividade (PBQP) continuem no papel, longe de aplicação sistêmica e regular, sem avaliações constantes. Identifica-se constantes redirecionamentos das ações de Qualidade, causadores de resultados descontinuados, os quais geram ações espasmódicas, tendo por conseqüência programas que nunca alcançam sucesso.

A busca de flexibilidade, polivalência, aumento das qualificações profissionais, participação dos colaboradores nos processos de inovações tecnológicas e outras decisões, dá-se no trabalho em equipe, cuja ênfase vem sendo dada nas ações cotidianas.

O grupo tende a ser mais criativo do que o indivíduo, trazendo maior comprometimento das pessoas com as metas, principalmente, quando definidas por elas mesmas. O controle das atividades é também realizado pelo grupo, na verificação do cumprimento das metas estabelecidas e pela forma de pressão sóciotécnica, na qual os membros dos próprios grupos realizam controle de desempenho. Trabalho em grupo é raramente enfatizado nas empresas brasileiras, uma vez que pressupõe certa estabilização da força de trabalho, alto nível de qualificação e formação, condições não verificadas na maior parte da força de trabalho, no país.

A valorização do talento humano na organização, quando evidenciada, possibilita resultados favoráveis. Outras características importantes propiciam clima positivo para a Qualidade, tais como:

- Carreiras flexíveis e não atreladas a estrutura rígida de cargos;

- Treinamento intensivo e contínuo;

- Recrutamento de pessoal com ênfase no potencial para o desenvolvimento;

- Trabalho em equipes.

Para ser competitiva a organização necessita de corpo gerencial e de trabalhadores com nível de educação, formação e qualificação profissional cada vez maior. Nessa concepção da organização competitiva, tecnologia e RH qualificados andam juntos, à procura de inovações, qualidade dos serviços e produtividade. 
Em função de mudanças na tecnologia, elevação no nível do trabalho e tendência do trabalho em grupo, emerge um profissional dirigido à multifuncionalidade, com exigências educacionais e de formação, voltados aos parâmetros fundamentais do novo modelo de relações de trabalho e gestão de RH nas empresas.

\subsubsection{A nova concepção do trabalho e suas interfaces}

Na nova concepção, os investimentos em educação e treinamento só trarão resultados caso o profissional possa aplicar o aumento de qualificação obtido na própria situação do trabalho, para tanto a organização deve propiciar o desenvolvimento de ação profissional polivalente.

O trabalhador deve sentir-se valorizado como pessoa participante de um grupo, enfrentando desafios comuns. Essa valorização traduz-se em relações de trabalho e políticas de Recursos Humanos, que proporcionem de modo contínuo, o seu envolvimento e desenvolvimento completo.

As comunicações internas tendem a ser muito mais efetivas nas organizações com culturas participativas e uso intensivo do trabalho em grupo, representam pré-condição para o sucesso das atividades em equipes, evitando mecanismos paralelos de veiculação das informações.

A discussão interna das metas tem papel fundamental no sentido da clarificação e do comprometimento de todos os membros, enquanto a divulgação final do desafio superado, representa o clímax da satisfação psicológica do grupo.

A questão da comunicação interna está intimamente relacionada ao funcionamento dos grupos de trabalho e à participação dos trabalhadores. Deve receber atenção e ser destaque nos planos de trabalho da alta direção, convergindo as forças para uma mesma direção. 


\subsubsection{Adequando os Programas de Qualidade às Organizações}

A integração dos segmentos econômico e administrativo são vitais para as organizações. Elas, quando bem sucedidas, enfrentarão o futuro adequando seus programas de Qualidade a nova era administrativa, direcionando-os para sua sustentação no mercado. Alguns fatores tornarão as organizações mais competitivas, a saber:

- Qualidade Total na satisfação dos clientes, com pesquisas sobre a apresentação de dados, esperando que a Qualidade seja essencialmente perfeita, economicamente viável, e que possa ser determinada pelos usuários, em seus próprios termos;

- Controle dos custos, com ênfase na maior redução daqueles causados pela perda de qualidade;

- Desenvolvimento contínuo dos trabalhadores visando seu envolvimento na formação do conceito de Qualidade;

- Estreitamento da parceria e da cooperação com os fornecedores na melhoria dos controles de qualidade e de tempo, em toda a cadeia de suprimento da organização.

Nas organizações em que a Qualidade tornou-se o ponto central para a eficácia dos negócios, suas iniciativas têm estabelecido processos de trabalho em equipe, visando reduzir os custos da perda e contribuir de maneira significativa para o alcance dessa economia de custo exigida com tanta urgência.

A medição é fundamental no controle da Qualidade e requer dois tipos: dos resultados e das variáveis de processo monitorando os passos intermediários. $\mathrm{Na}$ área da saúde, encontram-se alguns exemplos onde esta prática vem sendo exercida, ou ao menos buscada.

A equipe do serviço de terapia respiratória, do Butterworth Hospital, citada por BERWICK e col. 1990, necessitava de contínuas medições, visando o aperfeiçoamento de seus serviços, mas percebeu que na época ainda não havia disponível uma forma para medir os resultados obtidos. 
No Jonhs Hopkins Hospitals, a equipe inicialmente pretendia melhorar os processos clínicos de três diferentes unidades de cirurgia ambulatorial. $\mathrm{O}$ pressuposto inicial assinalava que as informações referentes à medida da eficiência clínica e administrativa, ainda não se encontravam prontamente disponíveis para avaliação.

A equipe encontrou como barreira: "As informações referentes às medidas de eficiência eram fragmentadas $\mathrm{e}$ casuais, sem nenhum sistema para avaliar esses dados, muito menos para identificar as áreas de preocupação para que fossem tomadas ações corretivas. Cada localidade media diferentes parâmetros de diferentes modos, tornando impossível que se desenvolvesse uma análise de como o programa de cirurgias ambulatoriais estava funcionando" (BERWICK e col. 1994, p.114).

A equipe do Jonhs Hopkins descobriu que os processos de tratamento clínico e os serviços ao paciente deveriam ser monitorados porém, seria difícil fazêlo, sem um sistema de medição mais preciso. O grupo decidiu trabalhar da seguinte maneira: em vez de se envolver num projeto de melhoria da Qualidade específico, preferiu estudar e reestruturar seus procedimentos.

Segundo BERWICK e col., o sistema de garantia da qualidade proposto, diferia do sistema existente em três grandes áreas. Buscou inicialmente parâmetros da influência para o sistema que incluía o cancelamento de casos, grandes atrasos e mudança de "status" do paciente, da internação efetuada no mesmo dia para o ambulatório e vice-versa. A segunda recomendação era que o sistema fosse projetado como uma avaliação em perspectiva tanto dos procedimentos clínicos como administrativos, pela equipe envolvida no tratamento de pacientes (....) 
(...) para identificar as questões à medida que elas ocorrem em vez de esperar pela provável revisão realizada (....) por terceiros. A recomendação final acarretava o estabelecimento de grupos de garantia da qualidade dentro de cada área, incluindo representantes de todos os grupos de "staff"(....) (1994, p.128).

Os exemplos do Butterworth Hospital, Jonhs Hopkins e muitos outros hospitais, sugerem que o desenvolvimento e a disposição de sólidos e eficientes sistemas para medir o desempenho de processos não serão fáceis nas organizações de saúde. As instituições que optarem pelos processos de melhoria, e quiserem estabelecer controle formal da Qualidade, terão que responder aos vazios que ocupam a instituição neste momento, gerando ineficiência, desperdício e insatisfação.

A equipe do Massachusetts General Hospital, relata situação em que busca melhorar a precisão das contas hospitalares enviadas ao Medicare. Este fato demonstra a existência de contínua falta de medições ou indicadores de Qualidade, dentro e entre os departamentos. Muitos dos dados que descrevem o processo de faturamento não são rotineiramente analisados, gerando atrasos neste serviço. As notificações de rejeição, por parte do Medicare, chegam atrasadas, dificultando feedback rápido e preciso do hospital como um todo.

Em muitas organizações, como ocorreu no Jonhs Hopkins, será necessário que os gerentes e as equipes façam uma pausa suficientemente longa para perguntar: O que este processo pretendia realizar? Como medir os resultados? Como rastrear seu desempenho de baixo para cima a partir desses resultados? E quem é responsável por fazer, avaliar e pôr em prática ações baseadas nessas medições?

Os governos, os organismos de Acreditação e outras partes interessadas em garantia da Qualidade têm tratado de desenhar medidas válidas e confiáveis para avaliar a competência clínica de maneira objetiva, como por exemplo, os estândares para a prática médica, as verificações genéricas para revisar os prontuários, o sistema para notificar os acontecimentos adversos, pautas práticas ou caminhos críticos padronizados para seguir e, indicadores de desempenho. 
A Qualidade deve ser de interesse de todos, começando pelos dirigentes. É essencial que emerjam como protagonistas de todo o programa da Qualidade, porque se não existir esse compromisso o único produto será a propaganda.

Todos aqueles que trabalham em hospitais, como nos demais serviços de saúde, têm contribuições a oferecer, tanto para sua melhoria intrínseca, como às necessidades das próprias comunidades. 


\subsection{AS SISTEMÁTICAS DE QUALIDADE NA ÁREA DA SAÚDE}

\subsubsection{Modelo Para Atuar na Saúde}

A implementação de um programa de Qualidade Total pressupõe que a instituição seja vista como um todo e que a necessidade de cada serviço seja compartilhada por todos, onde as equipes de trabalho estejam suficientemente preparadas para este grande desafio. Os indicadores de Qualidade dos eventos de maior freqüência e risco, ou mais propensos a problemas, devem ser identificados com base em padrões de referência, apontando assim a direção inicial do trabalho.

$\mathrm{O}$ uso de protocolos para descrever as ações médicas, desde o diagnóstico até o estabelecimento da terapêutica, tem sido apontado como forma de tornar a prática médica mais compreensível e inteligível para os demais profissionais da saúde. A sistematização dos procedimentos permitirá análise mais objetiva e poderá incluir outros profissionais da saúde nesta discussão, minimizando a subjetividade do processo. Esta situação é bastante complicada pelas inúmeras variáveis que podem ocorrer na evolução clínica ou tratamento de uma determinada patologia, como também em relação a idade, sexo e co-morbidade dos doentes.

Apesar de alguns avanços obtidos, na maioria dos hospitais, a sistematização dos procedimentos se mantém abaixo do desejado.

Pode-se neste percurso identificar alguns hospitais que vêm se preocupando com o desenvolvimento da Qualidade e será destacado um deles como exemplo.

No Brasil, dos anos 70, houve a iniciativa do Instituto do Coração do Hospital das Clínicas da Faculdade de Medicina da Universidade de São Paulo (InCor-HC.FMUSP) de implementar um programa de Qualidade Total, que iniciouse naquela oportunidade e se mantém até o momento. Nesta proposta estabeleceu-se alguns pontos essenciais para a implantação da Qualidade nesta instituição, conforme segue:

- A melhor equipe multiprofissional para trabalhar em um hospital complexo; 
- Para cada atividade foram identificados os 'agentes' e as 'tarefas' correspondentes. Durante a rotina operacional podem ocorrer falhas de processamento em qualquer ponto, ocasionando problemas gravíssimos ao doente;

- Ao recomendação aos "agentes" envolvidos no processo de discutir suas rotinas, em hora e dias fixos, constituiu o que chamou-se de "Grupos de Qualidade” ou “Círculos de Qualidade” (GILMORE, NOVAES 1997).

Esta concepção de desenvolver Qualidade foi incorporada desde o início da organização do hospital. Em meados de 1993, o InCor definiu, em parceria com um grupo de líderes da instituição, pela estruturação de um programa de Qualidade - Programa InCor da Qualidade - com linhas que foram se desenhando ao longo de sua trajetória.

O programa teve por objetivo o envolvimento de todos os colaboradores e, embora parte deles não tenha aderido plenamente, aqueles que o fizeram permitiram ao instituto alavancar melhorias em seus processos de trabalho, além de promover melhor entrosamento entre os colaboradores das diferentes funções e cargos.

No desenvolvimento desse programa, vários caminhos foram experimentados visando encontrar a melhor forma de congregar os esforços das equipes para realização dos objetivos pretendidos, sustentando as metas institucionais.

O conceito de Qualidade prevalente estabelecia dois focos principais: o cliente externo e o cliente interno. Portanto, tudo o que orbitava em torno destas prioridades merecia destaque e dedicação dos grupos de Qualidade.

Os profissionais da instituição sabiam que, dentre outras medidas, melhorar processos de trabalho, diminuir filas e agilizar internações eram essenciais para a melhoria das relações internas e externas.

Em 1994, teve início a sensibilização do corpo diretivo do InCor para a importância da Qualidade em diferentes ramos da atividade e também na área da saúde. Nesta fase, recorreu-se a empresas com experiências consolidadas para relatar e discutir os trabalhos realizados. 
Contou-se com a Editora Abril, a Johnson \& Johnson, além dos hospitais Albert Einstein, Maternidade São Luís e o Instituto da Criança do HCFMUSP. A contribuição, através dos programas de Qualidade dessas Instituições foi o ponto inicial para os trabalhos do Programa InCor da Qualidade - PIQ. O relato das vivências destas empresas certamente estimulou as lideranças à reflexão sobre a Qualidade e mobilizou a análise sobre a adequação de um programa específico desta natureza.

No ano de 1995, realizou-se treinamento para a Qualidade com os grupos de diretores, cujo processo já havia sido iniciado no ano anterior. Esta etapa incluiu também chefias e encarregados além de ter contado com o apoio de consultoria externa.

Neste ano, as ações do PIQ foram de natureza teórico-práticas, através de seminários onde foram discutidos os conceitos da Qualidade Total na área da saúde. Ocorreu também a discussão do Planejamento Estratégico do InCor, onde buscou-se analisar durante os seminários realizados: a intenção estratégica; a missão; visão; filosofia, e; políticas da instituição. Discutiu-se a dinâmica do hospital frente às mudanças tecnológicas e as novas demandas sociais, além de vislumbrar alternativas para uma administração estratégica, buscando a elaboração de um plano funcional para o InCor, atendendo a uma demanda antiga da direção do instituto.

Em paralelo, no período de agosto a dezembro de 1995, foram discutidos com os diferentes níveis de comando, os principais conceitos da Qualidade Total, seus vários aspectos e aplicações, o que proporcionou uma visão global da Qualidade. O treinamento teve como público alvo os sete níveis de gerenciamento do InCor - Encarregados e Chefias (de nível universitário, médio e operacional) e Diretores. Ficaram ausentes deste trabalho, principalmente, os profissionais envolvidos na assistência direta ao paciente, destacando-se a área médica.

Como resultado desta fase implantou-se os times de melhoria que atuaram sobre diferentes pontos críticos da instituição. Merece destaque a implantação dos 5S, como uma prática de fácil aplicação e com boa adesão pelos colaboradores, gerando ótimos resultados para a organização das áreas. 
Evidenciou-se diminuição do desperdício, favorecendo o descarte de material obsoleto, propiciando reorganização do espaço físico e melhorando o envolvimento do grupo, principalmente quando a liderança local apoiou e participou.

A estrutura do PIQ, conforme descrita, se manteve até 1999. A partir daí, as ações de Qualidade se voltaram para a implantação de método de certificação, tendo como área inicialmente escolhida o Laboratório de Análises Clínicas e áreas de interface. Desta experiência o InCor estuda sua ampliação para outras áreas.

A Qualidade não é um processo passivo de cima para baixo, mas sim uma dinâmica, ininterrupta e exaustiva atividade de permanente identificação de falhas nas rotinas e procedimentos, os quais precisam ser periodicamente revisados, atualizados e difundidos, com grande participação, desde a mais alta direção do hospital, até seus colaboradores mais básicos.

O hospital, para implementar um programa de garantia de Qualidade, deve estar permanentemente sob análise gerencial, redistribuindo recursos segundo as prioridades contingenciais dos serviços, mantendo um equilíbrio constante entre os objetivos em curto e longo prazo. O estabelecimento destes, e seu freqüente monitoramento, orientarão os planos para a ação, a estratégia da organização e a implementação de programas.

Há também outros hospitais brasileiros que têm investido fortemente na busca do conhecimento e aprofundamento dos diversos sistemas de avaliação no âmbito da saúde, visando aproximar suas instituições destes modelos.

A seguir será apresentado o Quadro XII - Metodologias da Qualidade, que oferece uma visão sistematizada dos métodos de: Certificação; Acreditação; Selo e Premiação, que estão sendo utilizados na Área da Saúde. Posteriormente, será discutido cada uma deles. 


\section{QUADRO XII - MÉTODOS DE QUALIDADE}

\begin{tabular}{|c|c|c|c|}
\hline $\begin{array}{c}\text { TIPO DE } \\
\text { AVALIAÇÃO }\end{array}$ & $\begin{array}{l}\text { INSTRU- } \\
\text { MENTO }\end{array}$ & CARACTERIZAÇÃO & $\begin{array}{c}\text { ÁREA DE } \\
\text { ABRANGÊNCIA }\end{array}$ \\
\hline \multirow{3}{*}{ Acreditação } & $\mathrm{JC}$ & $\begin{array}{l}\text { São usados padrões ótimos para a verificação } \\
\text { dos hospitais, através de indicadores } \\
\text { quantitativos clínicos e banco de dados } \\
\text { incorporados ao processo de acreditação. }\end{array}$ & Institucional \\
\hline & $\overline{\mathrm{CBA}}$ & $\begin{array}{l}\text { São usados padrões mínimos para a verificação } \\
\text { dos hospitais, através de indicadores } \\
\text { quantitativos que estão em fase de construção e } \\
\text { testagem em hospitais federais do Rio de } \\
\text { Janeiro. }\end{array}$ & Institucional \\
\hline & MBAH & $\begin{array}{l}\text { Busca classificar os hospitais em niveis, } \\
\text { estabelecidos a partir de padrões conforme os } \\
\text { itens de verificação. } \\
\text { O instrumento construído estabelece o padrão e } \\
\text { o item de verificação que devem ser } \\
\text { considerados. }\end{array}$ & Institucional \\
\hline Certificação & ISO & $\begin{array}{l}\text { Permite garantir o sistema de qualidade, através } \\
\text { da verificação das normas estabelecidas pela } \\
\text { ISO. }\end{array}$ & Setorial \\
\hline Selo & $\begin{array}{l}\text { Programa } \\
\text { do } \\
\mathrm{CQH}\end{array}$ & $\begin{array}{l}\text { Baseia-se no registro e análise de dados e } \\
\text { aferição da adequação dos serviços às suas } \\
\text { normas e critérios. }\end{array}$ & Institucional \\
\hline \multirow[t]{2}{*}{ Premiação } & PNQ & $\begin{array}{l}\text { Busca estimular a melhoria da Qualidade e } \\
\text { produtividade da gestão das organizações } \\
\text { produtoras de bens e serviços, estabelecendo } 07 \\
\text { critérios e itens de avaliação que permitem o } \\
\text { diagnóstico baseado em metas de pontuação, } \\
\text { sendo que este instrumento não é prescritivo. }\end{array}$ & Institucional \\
\hline & PQGF & $\begin{array}{l}\text { É um instrumento de transformação da Gestão } \\
\text { Pública, no campo específico da promoção da } \\
\text { Qualidade, dos serviços prestados aos cidadãos. }\end{array}$ & Institucional \\
\hline
\end{tabular}

Fonte: Primária / Autor: Vera Bonato 
O termo Avaliação, para a Real Academia Espanhola, significa "assinalar o valor de uma coisa". Para SCRIVENS (1995) Avaliação é um processo através do qual busca-se estimar o mérito ou valor de algo. Como primeira aproximação pode-se dizer que avaliar é uma forma de estimar, apreciar, calcular, e ainda, um processo que consiste em emitir um juízo de valor.

Embora o conceito de avaliação esteja muito ligado a idéia de medição, não se trata da mesma coisa. A medição é o ato de verificar a extensão e quantificação de algo, a avaliação, por outro lado, faz referência ao ato de verificar o valor desse algo. Pode-se medir algo sem valorar, e valorar sem medir. Deve-se levar em conta que, em muitos casos, a medição ajuda na tarefa de avaliar.

Considerando a definição de TYLER que, embora mais antiga, expressa o pensamento do mais importante precursor ou "pai" da pesquisa avaliativa, pode-se constatar que avaliação é o "processo que visa determinar até que ponto foram alcançados os objetivos previamente estabelecidos" (TYLER 1942).

Nesta mesma linha, encontram-se definições mais recentes: KAUFMAN e ENGLISH (1979) consideram que a avaliação consiste em analisar as discrepâncias entre o que é e o que deve ser, ou, em outras palavras, a disparidade entre uma situação desejada ou esperada e outra existente ou real.

A avaliação só tem sentido na medida em que serve para tomar decisões concretas. Outros autores se expressam da seguinte maneira:

- "(...) a avaliação é um estudo sistemático, dirigido e realizado com o fím de ajudar um grupo de clientes a julgar e/ou aperfeiçoar o valor e/ou o mérito de algum objeto (....)" (STUFFLEBEAM e SHINKFIELD 1987);

- "(...) processo sistemático de coleta e valoração de informação útil para uma eventual tomada de decisões (....)" (CRONBACH 1983);

- "(...) a avaliação é, primeira e necessariamente, uma coleção de conceitos e práticas que provaram sua utilidade no campo das Ciências Sociais e que se aplicam de modo tal que podem contribuir para o aperfeiçoamento das atividades práticas (....)" (HAYES, SHAW 1994). 
Em geral a avaliação da Qualidade depende quase que exclusivamente das medidas de estrutura e processos da atenção. Os organismos governamentais de acreditação e os grupos profissionais têm considerado mais fácil estabelecer estândares para a atenção, pertinente à estrutura e ao processo, dando pouca importância aos resultados, quando monitora-se a Qualidade das instituições sanitárias.

\subsubsection{Acreditação Hospitalar}

A Acreditação, método de avaliação externa da Qualidade dos serviços de saúde, muito difundida em paises de língua inglesa, antecedeu em muito o movimento do gerenciamento da Qualidade Total. Seu desenvolvimento se confunde com aquele dos serviços de saúde nos Estados Unidos, exemplo mais conhecido e divulgado desta vertente da Qualidade. Justamente por ter sido desenvolvida para a saúde e dentro da sua realidade, envolveu sobretudo a corporação médica, e seu jargão é familiar aos vários atores da área. Estas características tendem a diminuir as resistências observadas no setor para a adoção de métodos de avaliação.

O modelo de Acreditação vem marcando a medicina americana com a tentativa de assegurar a excelência dos procedimentos médicos e garantir a segurança das ações de saúde, respondendo assim, com a prestação de serviços com Qualidade para uma sociedade organizada e consciente de seus direitos.

O dicionário FERREIRA (1999, p.38) refere que o termo acreditar significa: "conceder reputação a; tornar digno de confiança". É neste sentido que se utiliza os termos acreditado (que merece ou inspira confiança), acreditador (que ou aquele que acredita) e acreditação (procedimento que viabiliza alguém ou algo a ser acreditado).

Consequentemente, um hospital que se submete ao processo de Acreditação poderá ser acreditado por uma instituição oficial credenciada para esse fim. 
O processo de Acreditação propõe a participação voluntária das instituições envolvidas com a saúde, estimulando-as a um comportamento de procura da melhoria contínua da Qualidade, criando e desenvolvendo positivamente a integração com a sociedade e estimulando a cidadania.

Segundo o Manual de Acreditação Hospitalar para a América Latina e o Caribe - OPAS (1996) - e conforme NOVAES e PAGANINI (1992, p.41) Acreditação é definida como: “(....) o procedimento de avaliação dos recursos institucionais, voluntário, periódico e reservado, que tende a garantir a qualidade da assistência através de padrões previamente aceitos. Os padrões podem ser mínimos ou mais elaborados e exigentes, definindo diferentes níveis de satisfação (....)"

Acreditação constitui um método desenvolvido para apreciar a qualidade da assistência médico-hospitalar em todos os serviços de um hospital, com base em duas importantes variáveis:

- Avaliação dos padrões de referência desejáveis, construídos por peritos e previamente divulgados;

- Os indicadores, isto é, os instrumentos que o avaliador/visitador usará para constatar se os padrões foram observados ou estão presentes na instituição.

Para PAGANINI e NOVAES (1992), Acreditação Hospitalar desenvolve uma dimensão nova no hospital, que resulta em auto-avaliação e revisão intema. Estas, determinam um processo de intercomunicação entre os diversos setores do hospital, que se empenham em melhorar o trabalho da equipe, no sentido de alcançar um importante objetivo: oferecer assistência médica integrada, continuada e de qualidade ao paciente hospitalizado.

A Acreditação Hospitalar não constitui auditoria ou procedimento de habilitação institucional, pois estas são funções do Estado. Ela é uma maneira consistente de regular a qualidade dos serviços de saúde na medida em que os parâmetros de avaliação se modificam ao longo do tempo, além do que, globalmente, o instrumento contém ítens que são 'puxados' para cima da média, a fim de servir de estímulo para a contínua melhoria dos serviços (QUINTO NETO, GASTAL 1997). 
Reproduzindo o Manual Brasileiro de Acreditação Hospitalar (MINISTÉRIO DA SAÚDE 1999), o Grupo Técnico de Acreditação, formado por profissionais envolvidos com o tema definiu que: "Acreditação significa um sistema de avaliação periódica, voluntária e reservada, para o reconhecimento da existência de padrões definidos na estrutura, processo e resultado, com vistas a estimular o desenvolvimento de uma cultura de melhoria contínua da qualidade da assistência médico-hospitalar e na proteção da saúde da população".

Acreditação é um sistema de verificação de Qualidade, medindo de acordo com sua conformidade uma série de padrões. Estes constituem expectativas de desempenho que minimizam riscos para pacientes e profissionais e aumentam as probabilidades de sucesso.

A América Latina e o Caribe como um todo, e o Brasil em particular, apresentam cerca de $70 \%$ de seus hospitais com menos de 70 leitos. Mesmo existindo grandes centros médicos públicos e privados, comparáveis aos mais avançados de qualquer outro continente, uma quantidade razoável destes nosocômios não resistiria a mínima avaliação para garantir uma qualidade permanente (GILMORE e NOVAES 1997, p.135).

Preocupada com estas questões e embuida do propósito de melhorálas, a Organização Pan-Americana de Saúde e a Organização Mundial de Saúde, juntamente com a Federação Latino-Americana de Hospitais, desenvolveu um modelo de Acreditação hospitalar apropriado às características desta região, suficientemente flexível, de maneira a adaptar-se às pronunciadas diferenças entre uma sub-região e outra, para ser amplamente discutida.

A medida em que a sociedade brasileira evolui e participa dos diferentes segmentos, passando a exigir o que é de direito, as organizações começam a inquietar-se com seu desempenho e sua forma de prestação de serviços. Estas preocupações são recentes, assim como a mobilização e participação social mais intensa, diferente da sociedade americana que já trabalha com o conceito de Acreditação há 75 anos. 
A curto prazo, a existência de um Programa de Acreditação Hospitalar, estimula a melhoria da atenção ao paciente, fortalece a confiança da comunidade, apoia a educação do pessoal dos serviços de saúde e favorece o seu recrutamento. A longo prazo, poderá agilizar o pagamento das agências de saúde, melhorar o acesso à cobertura de seguro e permitir o acesso a mercados financeiros (QUINTO NETO, GASTAL 1997).

Em 1913, o Dr. Ernest Codman apresentou uma dissertação à Sociedade Médica do Condado de Filadélfia (EUA), intitulada "O Produto dos Hospitais". Pretendia estimular a reflexão e o debate em torno da padronização dos hospitais.

Para ele, a palavra padronização incluía um movimento geral cujo objetivo era "melhorar a qualidade dos produtos em que se investem os fundos alocados aos hospitais" (WHITE 1992, p.24).

Opinava que não seria fustigando os atrasados, mas estimulando os melhores que se conseguiria elevar a qualidade da atenção à saúde como um todo (QUINTO NETO, GASTAL 1997).

Esta idéia adquiriu força e contribuiu para a formação do Colégio Americano de Cirurgiões, em 1913. Cinco anos depois, padrões oficiais para a prestação de cuidados hospitalares são implantados passando a ser conhecidos como "Padrão Mínimo" constando dos seguintes itens:

- Os médicos que trabalham em hospitais devem estar organizados como grupo (corpo médico);

- Os médicos e cirurgiões devem dispor de certificados e licenças reconhecidas, caráter e ética profissional;

- O corpo médico deve reunir-se pelo menos uma vez por mês para revisar e analisar todos os registros e serviços médicos;

- Os médicos devem fazer registros exatos dos casos de todos os pacientes;

- Disponibilidade de instalações de diagnóstico e terapêutica, incluindo patologia, radiologia e serviços de laboratório (QUINTO NETO, GASTAL 1997). 
O "Padrão Mínimo" foi o precursor do processo de Acreditação Hospitalar nos Estados Unidos. Em 1951, o Colégio Americano de Cirurgiões une-se a quatro outras instituições - Colégio Americano de Médicos, Associação Médica Americana e Associação Médica Canadense, e surge a Comissão Conjunta de Acreditação Hospitalar. Em 1959, a Associação Médica Canadense retira-se para formar o Conselho Canadense de Acreditação de Instalações de Saúde. Em 1980, a Associação Odontológica Americana torna-se membro da Comissão Conjunta (QUNTTO NETO, GASTAL 1997).

Em 1913, o Dr. Codman concluiu sua exposição com as seguintes palavras: Devemos formular algum método para elaborar relatórios dos hospitais que nos permitam conhecer, da forma mais exata possível, os resultados obtidos com o tratamento de pacientes nas diferentes instituições. Este documento deve ser elaborado e publicado pelo hospital, segundo um sistema uniforme, para possibilitar as comparações. Com um relatório deste tipo como ponto de partida, quem estiver interessado poderá começar a formular perguntas sobre administração e eficiência (WHITE 1992, p.25).

O estabelecimento de padrões mínimos de Qualidade não é um tema novo no Brasil. Em 1979, a Dra. Lourdes Carvalho mencionava as vantagens advindas da existência de padrões mínimos de organização dos hospitais:

- Para os pacientes: receberiam uma assistência eficiente através da melhor organização do Corpo Clínico, da assistência de pessoal competente e de serviços complementares de diagnóstico e tratamento;

- Para os médicos: os hospitais proporcionariam um ambiente de trabalho adequado; 
- Para os hospitais: a padronização daria os princípios fundamentais a um melhor funcionamento de toda a instituição;

- Para os residentes e corpo de enfermagem: os hospitais ofereceriam melhor experiência, sob supervisão, em vista da organização, equipamento e pessoal existentes;

- Para a comunidade: confiança no hospital e a vontade de ser atendida por ele, caso viesse a necessitar da atenção hospitalar (CARVALHO 1979).

Desde 1989, quando houve a primeira reunião coordenada pelo Dr. Humberto Novaes, membro da Organização Pan-Americana de Saúde, discutiu-se em vários níveis, nos diversos países da América Latina, a questão da Acreditação Hospitalar.

O entendimento de que este processo é lento e que a mudança de cultura gerencial do Sistema de Saúde, que não se traduz em meses, mas em anos, foi consenso.

Um dos instrumentos básicos utilizados no Brasil foi o Manual de Acreditação Hospitalar proposto pela Organização Pan-Americana de Saúde e Federação Latino-Americana de Hospitais. Este trabalho resultou na elaboração do Manual de Avaliação da Qualidade Assistencial Hospitalar. O esforço no sentido de construir um instrumento adaptado à realidade nacional (QUINTO NETO, GASTAL 1997), deu-se com base em cinco aspectos:

- O impacto dos programas de garantia de Qualidade é absolutamente insignificante onde não existem programas de Acreditação;

- Falta de uma tradição de auto-avaliação e rigorosa revisão interna nos hospitais;

- Dificuldade dos administradores hospitalares em tomarem decisões orientadas para procedimentos inadequados, realizados pelo pessoal técnico;

- Carência de informações concretas sobre a eficiência, a adequação e a eficácia dos serviços de saúde;

- Pressão externa sobre os serviços de saúde. 
A existência de um Programa de Acreditação Hospitalar no ambiente dos negócios da saúde, proporciona quatro efeitos relevantes nos hospitais (HAYES e SHAW 1994):

- Busca voluntária da qualidade: Este é um dos principais incentivos para a Acreditação de serviços de saúde. É um sistema que permite à instituição uma demonstração de sua eficácia, de forma mais construtiva possível, através do desenvolvimento organizacional voluntário. Um sistema compulsório conduzido pelo governo adquire um caráter de julgamento e torna-se uma ameaça para algumas instituições. $O$ processo voluntário encoraja as instituições a funcionarem de acordo com a Acreditação, e representa, acima de tudo, um compromisso com a Qualidade que livremente desejam.

- Construção de equipe: A preparação para a Acreditação é uma fase chave do desenvolvimento para todos os funcionários e profissionais envolvidos. A construção de uma equipe para a melhoria dos serviços, como um prérequisito, é um processo que encoraja a motivação para alcançar melhores resultados.

- Função educativa para a equipe de funcionários, profissionais e aplicadores: O processo é instrutivo para os participantes das instituições e para os aplicadores do instrumento de Acreditação. Oferece às instituições a oportunidade de revisar suas práticas correntes, olhar com novos olhos o que estão fazendo, e a maneira pela qual isto pode ser melhorado. Uma compreensão de aspectos da gestão da assistência, numa situação de prática diária, freqüentemente proporciona aos aplicadores idéias novas e abundante informação que podem ser utilizadas em suas instituições.

- Instrumento útil de gerenciamento: a Acreditação pode servir como um instrumento de gerenciamento, o que vem contribuindo para aumentar sua popularidade. No processo de Acreditação a auto-análise ou auto-avaliação, proporciona uma base para o desenvolvimento organizacional. O adicional da revisão externa coloca objetividade à auto-avaliação. 
Avaliar é diagnosticar uma realidade para poder estabelecer a intervenção. A avaliação é um poderoso instrumento de mudança social que serve de lastro para uma ação modernizadora. Há uma crescente ênfase na avaliação direcionada à melhoria permanente da Qualidade, voltada ao atendimento das necessidades, expectativas e satisfação da população que recorre aos hospitais e serviços de saúde.

Qualquer discussão a respeito de Qualidade traz, implícita ou explicitamente, a noção de avaliação. $O$ processo de avaliação determina o valor de algo. Um julgamento é então realizado, e a explicitação dos critérios utilizados, aumenta a legitimidade da avaliação. O conhecimento dos critérios permite saber se o julgamento pode ou não ser considerado válido pelo observador (MALIK e SCHIESARI 1998).

A avaliação de determinado programa de saúde pode ser feita com diferentes olhares. Os interesses do observador como ator influenciam diretamente sua visão de um fato qualquer, fazendo que valorize mais, determinados aspectos. A avaliação não é, portanto, neutra, o avaliador influi na avaliação e sofre as influências de quem a encomendou. Deve esclarecer o objetivo da avaliação, os critérios, os atores envolvidos no processo, e divulgar seus resultados. A avaliação é um processo com início e fim, com limites que atravessam diversos momentos. A decisão por um determinado tipo depende, sobretudo, dos propósitos e interesses dos envolvidos a cada momento.

\subsubsection{Joint Commission International - JCI}

A Joint Commission on Accreditation of Healthcare Organizations (JCAHO) é uma organização sem fins lucrativos, formada por profissionais de diversas áreas, tem como objetivo desenvolver padrões de Qualidade em cuidados de saúde e avaliar instituições de saúde quanto a sua adequação a estes padrões tidos como o 'estado da arte' em Qualidade de serviços. 
Atualmente, mais de 18.000 prestadores de serviços em saúde nos Estados Unidos, são certificados pela JCAHO, voluntariamente, atendendo aos seus padrões de Qualidade (JOINT COMMISSION INTERNATIONAL 1998).

Desde 1994, a Joint Commission International vem prestando consultoria a governos, hospitais e outras instituições de saúde em mais de 35 países, na: Europa Ocidental, Central e Oriental; Oriente Médio; África; América Latina; Caribe; Ásia e áreas do Pacífico, e; em novos países independentes. Alia conhecimento técnico especializado de avaliação na área da saúde com o conhecimento específico de cada país e da sua cultura. Tem reconhecida a sua liderança na implementação de programas de melhoria de desempenho e de sistemas de avaliação nesta área. (JOINT COMMISSION INTERNATIONAL 1998).

As atividades internacionais da Joint Commission são prestadas pela JCI (Joint Commission International) e pela QHR (Quality Healthcare Resources).

A Joint Commission estimula instituições de saúde a alcançarem e excederem padrões, através da Acreditação e da educação voltada para a melhoria da Qualidade.

São usados padrões ótimos, e não mínimos, para a verificação dos hospitais, através de indicadores quantitativos clínicos e banco de dados nacionais, que também estão sendo incorporados ao processo de Acreditação. Trata-se de um processo aberto, onde se fornecem perguntas e são analisadas respostas .

As características da acreditação envolvem:

- Programas educacionais e publicações facilmente disponíveis;

- Processo participativo durante a visita;

- A organização durante todo o processo é representada por um membro designado;

- Avaliadores são respeitados por anos de experiência em suas áreas e pela formação teórica;

- O método de avaliação e o processo decisório são justos;

- Agenda programada com horários rígidos é cumprida para maximizar o uso do tempo dos representantes do hospital e da equipe; 
- Relatórios de desempenho dos hospitais são públicos. (JOINT COMMISSION 1996, p.15-18)

A organização da visita pelos avaliadores segue os seguintes passos:

- Agenda genérica que define o que cada avaliador deverá fazer a cada hora;

- A agenda é modificada conforme as necessidades dos hospitais;

- Cada encontro ou entrevista, em caderno separado, está descrito com detalhes incluindo exemplos de questões que o avaliador irá perguntar;

- A Joint Commission sugere quem do “staff” do hospital poderá participar em cada aspecto da investigação;

- Proporcionar à equipe, diariamente, oportunidade para se reunir e para rever os achados com o "staff" administrativo do hospital;

- Ao término da avaliação, é feita uma apresentação final para a equipe do "staff” administrativo do hospital. (JOINT COMMISSION 1996, p.2.2-2.4)

A Acreditação pela Joint Commission é reconhecida nos EUA como um "Símbolo de Qualidade" indicando que a organização encontrou certos padrões de desempenho, possibilitando que ela melhore suas habilidades para prover a Qualidade no cuidado aos pacientes. Também é usada para requerer licença ou certificação junto ao Medicare. É também condição de reembolso para este sistema.

A Acreditação deve ser um dos valores do cuidado à saúde.

Os serviços acreditados ajudam a informar e proteger o consumidor, oferecem melhoria na educação e no sistema de cuidados com a saúde.

Dos cerca de 6.800 hospitais norte-americanos, aproximadamente $80 \%$ deles são acreditados pela Joint Commission.

As organizações participam da J.C. para:

- Melhorar a assistência ao paciente;

- Fortalecer a confiança da comunidade;

- Oferecer consultoria profissional e aumentar a cultura do 'staff'; 
- Obter suporte técnico;

- Estimular programas internos de melhoria da Qualidade;

- Estimular o envolvimento do "staff";

- Preencher os requisitos de alvarás em muitos Estados;

- Ser reconhecida pelas companhias de seguros e outras;

- Atrair referências profissionais;

- Obter maiores facilidades junto a financiadores;

- Melhorar o acesso e reduzir o custo da cobertura do seguro de responsabilidade civil;

- Apressar os pagamentos de terceiros.

Os padrões da Joint Commission são voltados para os resultados e para a melhoria contínua dos processos de cuidado ao paciente, contemplando os direitos e deveres de cada indivíduo, garantindo que os cuidados prestados sejam os mais adequados, onde priorizam-se o conhecimento e participação do paciente nas decisões. Dá-se importância à continuidade até que suas necessidades estejam totalmente atendidas.

Estes mesmos padrões também se relacionam com a infra-estrutura e o ambiente nos quais os cuidados são prestados. Os profissionais responsáveis devem ser qualificados e os processos definidos.

A Acreditação em hospitais típicos, segue os seguintes passos:

- Avaliação no mínimo a cada três anos;

- Equipe de avaliadores formada por médico, enfermeiro e administrador;

- A equipe faz entrevistas, apresentações, educação em saúde, consultoria e revisão de documentos para avaliar o grau de cumprimento dos padrões;

- Para avaliação, a equipe elabora minuta de relatório e decisão sobre a Acreditação com o uso de "laptop" e "software";

- Relatório final é emitido pelo Comitê de Acreditação do escritório central;

- Monitoramento posterior é feito durante os três anos que se seguem, se surgirem problemas. 


\subsubsection{Consórcio Brasileiro de Acreditação - CBA}

No Brasil, no ano de 1997, foi criado o Consórcio Brasileiro de Acreditação de Serviços de Saúde - o CBA. Este consórcio foi integrado: pela Fundação CESGRANRIO, por sua experiência em avaliação educacional; pela Universidade Estadual do Rio de Janeiro, através do Instituto de Medicina Social; pelo Colégio Brasileiro de Cirurgiões, e; pela Academia Nacional de Medicina, por sua tradição e capacidade técnica.

A união das quatro instituições teve por finalidade possibilitar, na área da saúde, o desenvolvimento de avaliações e ações de aprimoramento da Qualidade, trabalhando em estreita cooperação. Ao mesmo tempo visou assegurar: a participação das entidades que representam os prestadores de serviços; os financiadores do atendimento à saúde; os representantes dos usuários; da comunidade; dos profissionais da saúde, e; das instituições técnico-científicas ligadas a esta área.

O CBA (1999) vem trabalhando para adequar os padrões da Joint Commission à cultura brasileira e refletir sobre a melhor forma de aplicação dos estândares para nossa realidade. Este instrumento já foi utilizado por algumas instituições no país (FUNDAÇÃO CESGRANRIO 1999, p.V-VI).

\subsubsection{Manual Brasileiro de Acreditação Hospitalar MBAH}

O Manual Brasileiro de Acreditação Hospitalar é um instrumento para estimular a melhoria da Qualidade dos hospitais brasileiros, através da análise de alguns indicadores a serem observados.

O método busca classificar os hospitais em níveis estabelecidos a partir de padrões a serem avaliados conforme os ítens de verificação indicados, e estes serão orientadores para o avaliador. 
Visa a avaliação da Qualidade institucional, é composto de seções e subseções. Nas subseções existem os padrões definidos segundo três níveis, do mais simples ao mais complexo. Para cada nível são definidos ítens de verificação que orientam o processo de visita e a preparação do hospital para a Acreditação.

Os níveis, conforme o MBAH (MINISTÉRIO DA SAÚDE 1999, p.7), centram pontos a serem avaliados pelo hospital e servirão de orientador para os visitadores. Segue seus amplos objetivos:

Nível 1 - as exigências deste nível contemplam o atendimento aos requisitos básicos da qualidade na assistência prestada ao cliente, nas especialidades e serviços do hospital, com os recursos humanos compatíveis com a complexidade, qualificação adequada dos profissionais e responsável técnico com habilitação correspondente para as áreas de atuação institucional.

Nível 2 - presença de evidências de adoção do planejamento na organização da assistência hospitalar, referentes à: documentação, corpo funcional, treinamento, controle, estatísticas básicas para a tomada de decisão clínica e gerencial e práticas de auditoria interna.

Nível 3 - evidências de politicas institucionais de melhoria contínua em termos de estrutura, novas tecnologias, atualização técnico-profissional, ações assistenciais e procedimentos médico-sanitários. Evidências objetivas de utilização da tecnologia da informação, disseminação global e sistêmica de rotinas padronizadas e avaliadas com foco na busca da excelência.

O instrumento construído estabelece o padrão e o ítem de verificação que deve ser considerado. Pode-se perceber que o instrumento busca identificar se há ou não o solicitado. $O$ foco do instrumento está na presença ou ausência do ítem a ser verificado em relação ao padrão estabelecido.

Está voltado prioritariamente para a área de resultados dos serviços prestados, não tendo como objetivo de trabalho a avaliação da gestão da instituição e suas políticas. $O$ instrumento apresenta-se como um avanço importante na busca da melhoria dos serviços de saúde, que deverá sofrer reformulações ao longo de seu uso. 
O processo de avaliação e visita é composto por duas grandes etapas: a pré-visita e a visita propriamente dita. A primeira está relacionada com a preparação da instituição para o processo de Acreditação, na qual o hospital toma conhecimento desse processo e se prepara para solicitar a visita de avaliadores.

A visita somente ocorrerá após a solicitação voluntária do hospital à instituição acreditadora.

\subsubsection{Certificação}

Segundo PRAZERES (1996, p.65), Certificação é Atividade de comprovação da qualificação de ítens, materiais, produtos, serviços, procedimentos, processos, pessoal ou de sistema da qualidade, no todo ou em parte. A certificação da qualidade necessariamente será executada por entidade especificamente designada para tal (organismo certificador), com base em requisitos previamente estabelecidos e documentados, podendo ou não resultar em emissão de certificados.

A Certificação ISO, também por PRAZERES (1996, p.65), é definida como: Declaração emitida por um organismo de certificação credenciado, que atesta que a organização solicitante cumpre com os requisitos das normas ISO série 9000. Trata-se de uma prova pública. Para ser certificada, a organização precisa comprovar que tem um sistema da qualidade implantado e em funcionamento. A comprovação é feita através de uma auditoria de certificação conduzida pelo organismo de certificação contratado, via análise da documentação do sistema da qualidade (procedimentos, instruções de trabalho, documentos e registros da qualidade) $\mathrm{e}$ as evidências objetivas de sua implementação e funcionamento. 


\subsubsection{International Standard Organization - ISO}

A ISO (Organização Internacional para Normalização) é uma federação mundial atualmente com 90 membros, composta pelos organismos nacionais de normalização da cada país. No Brasil é representada pela ABNT (Associação Brasileira de Normas Técnicas).

A ISO começou a funcionar oficialmente em 23/2/1947, com sua sede em Genebra - Suíça. Tem por objetivo promover o desenvolvimento da normalização e de atividades mundiais correlacionadas, com vistas a facilitar o comércio internacional de bens e serviços, bem como desenvolver cooperação na esfera de atividade intelectual, científica, tecnológica e econômica (MELLO e CAMARGO 1998, p.271).

O sistema de garantia da Qualidade ISO 9000, chegou ao Brasil em 1987. Dez anos depois, apontava mais de 1.400 empresas certificadas.

As terminologias das normas, na versão vigente, são mais facilmente correlacionadas à realidade da indústria, e por isso, é recomendado ao usuário de outros setores minuciosa leitura e interpretação de seus elementos. Vale ressaltar que a tradução das normas ISO para a língua portuguesa baseou-se na versão em inglês, que por apresentar características gramaticais peculiares, dificulta em várias partes do texto a tradução fiel de expressões e terminologias e a manutenção do significado original. Na revisão de 1994, várias correções foram realizadas a fim de melhorar o texto traduzido, mas, apesar disso, sugere-se que no caso de dúvidas seja consultada a norma na versão original. Muito da abordagem apresentada baseia-se no desenvolvimento de importante trabalho em equipe.

A implantação do Sistema ISO 9000 para as áreas produtivas é favorável, trazendo resultados imediatos e preparando a área para outros avanços.

As normas ISO incrementam a ordem e a disciplina interna, incentivam a identificação e monitorização de indicadores da Qualidade, aumentando a consistência dos serviços prestados e facilitando a análise do desempenho dos processos por parte da administração. 
Apesar dos termos técnicos da Norma, com treinamento adequado é possivel transmitir aos colaboradores seu papel e suas responsabilidades na elaboração e condução dos processos que afetam diretamente o atendimento ao cliente. A ISO é passo importante na educação e preparação dos colaboradores para o trabalho em equipe e participação no sistema de melhoria contínua da Qualidade.

A norma ISO, como muitos críticos querem afirmar, não significa a burocratização da área, nem tampouco o alcance da Qualidade Total. Estar embasado nas normas ISO significa um patamar importante de identificação, otimização, qualificação, padronização e monitorização dos processos, além de ser um fantástico exercício de visão multifuncional, compartilhada com toda a equipe profissional.

No setor saúde encontra-se 167 instituições certificadas, segundo dados da ABNT. Em 2002, houve a emissão da nova versão da norma ISO. As organizações já certificadas terão até 15 de dezembro de 2003 para readequarem-se à nova versão. Dentre as mudanças realizadas, passa-se a ter os principais focos: gerenciamento por processos, com a identificação de indicadores de eficiência e eficácia; satisfação do cliente, e; melhoria contínua.

\subsubsection{Selo}

Selo é um emblema, símbolo ou marca usado para identificar, substituir ou autenticar a assinatura ou escritos de um indivíduo ou organização. Possuir um selo significa estar certificado, em conformidade com uma norma ou outro documento normativo, especificado pelo órgão emissor deste selo (MICHAELIS 1998).

Uma organização que possui um Selo de Qualidade traduz na sua maneira de funcionar as normas, procedimentos e regulamentos exigidos na obtenção da qualidade esperada, e seu produto ou serviço está adequado ao uso e às exigências estabelecidas.

Dessa forma, além de significar a regulamentação da organização dentro dos parâmetros prescritos, o Selo significa também que o usuário tem a garantia da qualidade na obtenção de um produto e/ou serviço oferecido por uma organização, instituição, etc (PRAZERES 1996). 


\subsubsection{Controle de Qualidade Hospitalar - CQH}

Conforme referido no "Manual de Orientação aos Hospitais Particulares 1998", o CQH é um sistema de informações que visa a avaliação da qualidade do atendimento médico hospitalar, baseado no registro, análise de dados, aferição da adequação dos serviços às suas normas e critérios.

A finalidade da avaliação é contribuir para o aperfeiçoamento e melhoria dos hospitais, abrindo perspectivas modernizantes, nas quais a Qualidade, a racionalidade e a eficiência constituam os objetivos máximos pretendidos.

Espera-se que as normas e procedimentos apresentados contribuam para o apoio e desenvolvimento de ações que visem a melhoria contínua da Qualidade. Para isto segue os seguintes objetivos:

- Estimular o comprometimento da alta direção dos hospitais com a busca da melhoria contínua da Qualidade;

- Sensibilizar os trabalhadores de saúde para a necessidade de mudança cultural, no sentido de incorporar ações de melhoria contínua da Qualidade do atendimento;

- Estimular o pessoal das instituições de saúde à participar de palestras, cursos e reuniões sobre temas referentes a Qualidade hospitalar;

- Estimular a formação de equipes multiprofissionais para controle da Qualidade nos hospitais, voltadas para a auto - avaliação ( $\mathrm{CQH}$ - Manual de Orientação aos Hospitais - 1994).

Para a implementação do programa no hospital, é necessário verificar e analisar as condições da estrutura hospitalar, a capacitação profissional e técnica, os processos, os resultados do atendimento, as opiniões dos consumidores e prestadores dos serviços, além de:

- Desenvolver estudos e modelos de administração em saúde nas unidades médico-hospitalares, a partir da participação no $\mathrm{CQH}$; 
- Incentivar a formação de equipes, com representantes do corpo clínico, de enfermagem, administração e de outros profissionais e serviços, para o desenvolvimento de um programa de melhoria, que envolva a cooperação de todos na busca contínua da Qualidade;

- Desenvolver estudo e aperfeiçoamento dos atuais indicadores, padrões e parâmetros de avaliação;

- Desenvolver e aperfeiçoar método de participação do usuário no sistema de prestação de serviços;

- Divulgar ou possibilitar a divulgação do $\mathrm{CQH}$ nos hospitais. (CQH - Manual de Orientação aos Hospitais - 1994).

$\mathrm{O} \mathrm{CQH}$ é administrado pela Associação Paulista de Medicina (APM) e Conselho Regional de Medicina do Estado de São Paulo (CREMESP), ligadas ao ambiente médico-hospitalar do Estado de São Paulo. Estas entidades designam o nível executivo responsável pela parte operacional do programa. Também colocam à disposição do nível executivo os recursos necessários para a implementação do mesmo.

O nível executivo atua como núcleo técnico do programa para recebimento e encaminhamento dos relatórios a cada hospital participante, bem como, processamento de dados, manutenção de arquivos, concessão do Selo de Conformidade e outras atividades pertinentes.

$\mathrm{O} \mathrm{CQH}$ possui um sistema para captação, validação e registro de dados de um universo definido de hospitais do Estado de São Paulo. A extração das informações permite avaliar a situação de cada um dos participantes frente às suas expectativas internas e da comunidade usuária.

\subsubsection{Premiação}

Premiação é uma distinção ou recompensa conferida por certo trabalho ou mérito, sendo constituída por um diploma ou troféu (MICHAELIS 1998, p.1.688) 
A Premiação estimula a melhoria contínua da qualidade de produtos e serviços, estabelecendo amplo entendimento dos requisitos de excelência e desempenho, promove a imagem e reputação internacionais da excelência dos produtos e serviços brasileiros, conferindo à organização que o recebe o 'estado da arte'.

Desta forma, garante: melhoria da competitividade, e; ampla troca de informações, sobre métodos e sistemas de gestão que alcançaram sucesso, e sobre os benefícios decorrentes da utilização dessas estratégias.

Seus critérios constituem um modelo sistêmico de gestão adotado por inúmeras organizações de classe mundial. Dessa forma, uma organização pode modelar seu sistema de gestão, realizar uma auto-avaliação ou se candidatar ao Prêmio Nacional da Qualidade.

Criado em 1992, na categoria Administração Pública (1996), o Prêmio Nacional da Qualidade representou um diferencial para a melhoria da gestão pública, estimulando e preparando o setor público para condições adequadas de concorrência, dentro de um mercado competitivo mundial (RUTA e col. 2002).

As estratégias do programa da Qualidade no serviço público têm a finalidade de reconhecer e premiar as organizações públicas. Estas devem comprovar, mediante avaliação feita por uma banca examinadora, desempenho institucional, estando sujeita a premiação.

Os prêmios President's Quality Award (específico para organizações públicas), Malcolm Balbridge National Quality Award, dos Estados Unidos, e o Prêmio Nacional da Qualidade (PNQ), do Brasil., são exemplos de Premiação baseados nos critérios, anteriormente, citados.

A seguir será apresentado, com mais detalhe, o PNQ e o PQGF (Prêmio de Qualidade do Governo Federal).

\subsubsection{Prêmio Nacional da Qualidade - PNQ}

O Prêmio Nacional da Qualidade é um reconhecimento à excelência na gestão, das organizações sediadas no Brasil, na forma de troféu. É administrado 
pela Fundação para o Prêmio Nacional da Qualidade - FPNQ, entidade privada, sem fins lucrativos, criada em 1991, por organizações privadas e públicas.

Sua missão visa: promover a conscientização para a qualidade e produtividade das empresas produtoras de bens e serviços, e; facilitar a transmissão de informações e conceitos, relativos às práticas e técnicas modernas e bem sucedidas da gestão da qualidade, inclusive com relação aos órgãos da administração pública.

Em função da sua flexibilidade, da simplicidade da linguagem utilizada e, principalmente, por não prescrever ferramentas e práticas de gestão específicas, o modelo é útil para avaliação, diagnóstico e orientação de qualquer tipo de organização, no setor público ou privado, com ou sem finalidade de lucro e de porte pequeno, médio ou grande (FPNQ 1996).

O Prêmio está baseado em um conjunto de critérios para a excelência do desempenho. Esses critérios permitem um diagnóstico da organização referente ao sistema de gestão de desempenho.

A principal característica dos critérios de excelência do PNQ é uma orientação para os resultados do negócio, definidos pela composição dos seguintes aspectos: "Liderança, Estratégias e Planos, Clientes, Sociedade, Informações e Conhecimento, Pessoas, Processo e Resultados" (FPNQ 1996).

Os critérios de excelência realizam uma detalhada 'varredura' por todos os aspectos relativos ao funcionamento, desempenho e operacionalização das organizações, bem como interagem e enfatizam alguns aspectos que merecem maior destaque:

- Melhorias incrementais e revolucionárias;

- Estratégia de decisões organizacionais;

- Desempenho financeiro;

- Inovação e criatividade.

As organizações candidatas ao Prêmio devem fornecer informações sobre seu sistema de gestão, sobre seus processos de melhoria e sobre os resultados alcançados, de acordo com o que é solicitado por estes critérios. 
Essas informações têm por objetivo demonstrar que a candidata utiliza enfoques eficazes e exemplares, que podem ser úteis também para outras organizações.

Estes critérios estão desenhados não somente para servir como fundamento para a premiação, mas, principalmente, para permitir um diagnóstico, qualquer que seja o tipo de organização, no que se refere ao sistema de gestão do desempenho.

Os critérios foram construídos a partir de um conjunto de valores $\mathrm{e}$ conceitos que são fundamentais para a integração dos requisitos principais da organização, dentro de uma estrutura de gestão orientada para resultados.

Os principais valores e conceitos são:

- Liderança e constância de propósitos;

- Visão de futuro;

- Foco no cliente e no mercado;

- Responsabilidade social e ética;

- Decisões baseadas em fatos;

- Valorização das pessoas;

- Abordagem por processos;

- Foco nos resultados;

- Inovação;

- Agilidade;

- Aprendizado organizacional;

- Visão sistêmica. 
Quanto à estrutura, os principais valores e conceitos são incorporados em 8 critérios, subdivididos em 27 ítens conforme Quadro XIII - Critérios de Excelência do $P N Q$ a seguir.

\section{QUADRO XIII - CRITÉRIOS DE EXCELÊNCIA DO PNQ}

\begin{tabular}{|c|c|}
\hline \begin{tabular}{|ll}
1 & Liderança \\
1.1 & Sistema de Liderança \\
1.2 & Cultura de excelência \\
1.3 & Análise crítica do desempenho global
\end{tabular} & 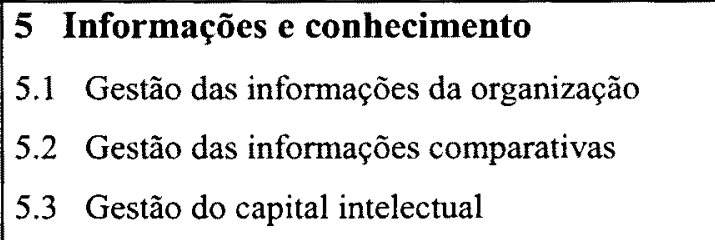 \\
\hline \begin{tabular}{|ll}
2 & Estratégias e planos \\
2.1 & Formulação das estratégias \\
2.2 & Desdobramento das estratégias \\
2.3 & Planejamento da medição do desempenho
\end{tabular} & $\begin{array}{ll}6 & \text { Pessoas } \\
6.1 & \text { Sistemas de trabalho } \\
6.2 & \text { Capacitação e desenvolvimento } \\
6.3 & \text { Qualidade de vida }\end{array}$ \\
\hline $\begin{array}{ll}\text { 3 } & \text { Clientes } \\
\text { 3.1 } & \text { Imagem e conhecimento de mercado } \\
3.2 & \text { Relacionamento com clientes }\end{array}$ & $\begin{array}{ll}7 & \text { Processos } \\
7.1 & \text { Gestão de processos relativos ao produto } \\
7.2 & \text { Gestão de processos de apoio } \\
7.3 & \text { Gestão de processos relativos aos } \\
& \text { fornecedores } \\
7.4 & \text { Gestão econômico-financeira }\end{array}$ \\
\hline $\begin{array}{l}4 \text { Sociedade } \\
4.1 \text { Responsabilidade sócio-ambiental } \\
4.2 \text { Ética e desenvolvimento social }\end{array}$ & \begin{tabular}{|ll}
8 & Resultados \\
8.1 & Resultados relativos aos clientes e ao \\
& mercado \\
8.2 & Resultados econômico-financeiros \\
8.3 & Resultados relativos às pessoas \\
8.4 & Resultados relativos aos fornecedores \\
8.5 & Resultados dos processos relativos ao \\
& produto \\
8.6 & Resultados relativos à sociedade \\
8.7 & Resultados dos processos de apoio e \\
organizacionais
\end{tabular} \\
\hline
\end{tabular}

A avaliação, observando os critérios de excelência do PNQ, é aplicável em qualquer organização. A estrutura dos critérios é flexível e adaptável a todos os ramos de atividade. Permite à organização medir seu desempenho pelos indicadores financeiros, relativos ao cliente, ao produto e aos processos. 
Além disso, é possível identificar seus pontos fortes e se concentrar nas principais oportunidades para melhoria. Com os recursos alinhados para alcance das metas, a organização poderá melhorar seu desempenho.

Ao se candidatar, a instituição recebe um relatório de avaliação detalhado, relacionando pontos fortes e oportunidades para melhoria, com base numa avaliação externa independente, executada por profissionais de reconhecida competência. Esse relatório permite uma análise das observações efetuadas pela própria organização, levando a reflexão de alguns aspectos favoráveis, tais como:

- Revisão do modelo de gestão;

- Clareza dos principais processos institucionais;

- Mudança do foco na tarefa para foco no cliente;

- Pensamento sistêmico;

- Diagnóstico situacional da instituição;

- Favorecimento da sinergia grupal.

Em 1999, o Relatório PNQ 98 foi reformulado. Na primeira versão foi possível conhecer este instrumento de avaliação da gestão e obter visão global da instituição onde se trabalha, porém, outras versões terão que ser realizadas. Hoje está vigente a versão 2002 (www.mct.gov.br).

\subsubsection{Prêmio de Qualidade do Governo Federal - PQGF}

O PQGF faz parte do plano do governo Federal para o incentivo à Qualidade dos setores públicos. Este programa vem se desenvolvendo desde 1991, estimulando a administração pública para uma gestão empreendedora, valorizando os serviços prestados aos usuários e aos servidores. Busca agilizar seus processos e fazer com que a organização pública passe a considerar o cidadão como parte interessada e essencial ao sucesso da gestão e, em função disso, que a avaliação do desempenho institucional somente é considerada aceitável se incluir a satisfação do cidadão como item de verificação. 
Melhorar a qualidade dos serviços prestados ao cidadão e, ao mesmo tempo, tornar o cidadão mais exigente em relação aos serviços públicos a que tem direito, é o grande desafio da Qualidade na administração pública e o foco da atuação do PQGF.

Para isso, as ações do programa se desenvolvem, principalmente, no espaço em que a organização pública se relaciona diretamente com o cidadão, ou seja, na condição de executora da ação do Estado.

Cabe às lideranças da organização buscar e estimular as contribuições individuais que possam viabilizar o alcance de objetivos comuns. $O$ instrumento PQGF valoriza a prática da gestão participativa que requer ainda: diálogo e confiança para delegar respeito mútuo entre todos; compartilhamento de informações, estimulando a capacidade para tomar decisões, e; a criatividade, melhorando o clima organizacional, contribuindo para a realização das pessoas. 


\section{JUSTIFICATIVA}

As organizações têm constantemente se transformado para poder gerir seus negócios. Muitos fatores vêm influenciando esta situação, mas, sem dúvida, a ampliação do espectro de prestação de serviços tem se tornado fator relevante, influindo nesta realidade.

Este cenário gera a necessidade das organizações se prepararem para enfrentar um ambiente competitivo, que afeta sua sobrevivência atual e futura.

O aprendizado e a disseminação do conhecimento são compulsórios e também são os pilares para o crescimento e desenvolvimento das organizações. Deve-se buscar satisfazer o mercado quanto ao fornecimento dos serviços, condições de preço, prazo e qualidade cada vez melhores, antecipando-se às expectativas e necessidades dos clientes.

As organizações que assim atuam, reaprendem, inovam e oferecem novos serviços, a partir das informações obtidas e das solicitações identificadas. Este clima propicia a modernização das organizações, servindo para aprimorar suas gestões, fortalecendo-as e tornando-as referenciais umas para as outras, estimulando mercados abertos.

Dentre os diversos mecanismos de aperfeiçoamento, vinculados às estratégias e políticas organizacionais, será dado ênfase ao mapeamento de sistemas de Qualidade, como métodos de suporte às gestões.

O estabelecimento de valores claros e a definição da razão de ser da organização constituem a força central para o engajamento de todos. Para tanto, será necessário o desenvolvimento de métodos de trabalho e processos bem executados, voltados para a aprendizagem, refletindo a Qualidade inerente ao sistema. Estudos desta natureza são mais comuns em países americanos e europeus, que abordam a discussão das melhores práticas de Qualidade na saúde e seus indicadores, norteando caminhos mais adequados.

Dentre os diversos atores sociais envolvidos na prática das ações de Qualidade, procurou-se conhecer o ponto de vista dos gestores e profissionais da equipe de Qualidade que trabalham diretamente neste âmbito nas organizações e na prática destas ações, como sujeitos deste cenário específico. 
O conhecimento das percepções e expectativas destes atores sociais influenciam e interferem na tomada de decisões sobre as políticas de Qualidade, e nas sistemáticas mais eficazes para a área da saúde e para aquelas adotadas pelas instituições pesquisadas.

A carência de estudos nacionais sobre esta temática, acrescido de seu espectro original e inovador no tocante a gestão de Qualidade, em instituição de saúde, foi o mote para esta pesquisa. Sua relevância social e científica se concretiza quando verifica-se sua importância tanto para os gestores de saúde quanto para os usuários.

A autora, orientada pelas premissas expostas anteriormente e mobilizada pela necessidade de contribuir com a melhoria da Qualidade da instituição onde trabalha - InCor - assumiu em 1993 a coordenação da área da Qualidade, cuja proposta inicial era de agregar áreas que já vinham desenvolvendo ações com características de excelência e competência. Até o momento, a proposta exige constante revisão dos processos de trabalho, definição de indicadores e uma constante atitude de melhoria por parte dos colaboradores.

Diante de um cenário externo altamente competitivo, onde as mudanças ocorrem rapidamente, foi necessário refletir sobre a importância da sistematização das ações de Qualidade que já ocorriam em diversas áreas do hospital, mas de maneira isolada. O start para a organização deste programa foi dado pela Diretoria Executiva do InCor, mobilizada para melhorar o atendimento prestado à população, alinhando pessoas e serviços, para manter a instituição no seu patamar de destaque.

Em 1998, devido a este trabalho na área de Qualidade no InCor, a autora participou de uma missão de estudos em Chicago (EUA) a convite do Ministério do Planejamento do Governo Brasileiro. Para isso contou com o apoio da Diretoria Executiva do instituto.

O objetivo desta viagem foi o treinamento dos participantes na Joint Commission, visando conhecer esta proposta de trabalho, além de discutir sua adequação à realidade brasileira. 
Também fez parte deste programa visita a alguns hospitais que aderiram ao uso deste método e estavam em fase de avaliação pelas equipes técnicas da Joint Commission. No retorno, pôde-se acompanhar a estruturação do Consórcio Brasileiro de Acreditação e a adaptação do manual da Joint Commission às necessidades brasileiras.

No ano de 1999, em contato com o Ministério da Saúde, a autora teve conhecimento da evolução do Manual Brasileiro de Acreditação Hospitalar MBAH. A partir disso, realizou parceria com a Organização Nacional de Acreditação - ONA - para cooperar no desenvolvimento da aplicação deste instrumento. Tratouse de um projeto abrangente, que envolveu as áreas do InCor contempladas neste instrumento. A auto-avaliação institucional proposta favoreceu que cada área fizesse seu auto-retrato, identificando assim seus pontos fortes e aqueles que necessitavam de melhoria. Estabeleceu-se parceria com os gestores deste processo, os quais tiveram participação direta na experiência, auxiliando nas diferentes etapas trabalhadas, desde a discussão do planejamento proposto, até a apresentação final dos resultados.

Após a realização deste piloto, a autora participou, com o Ministério da Saúde e ONA, da divulgação dos resultados desta prática em algumas capitais do Brasil. Tal processo fazia parte da intenção de ampliar a divulgação deste instrumento para os gestores de hospitais, das diferentes regiões do país. Internamente, no InCor, os resultados fizeram com que cada área investisse energia na superação daqueles pontos a serem melhorados, estabelecendo ações preventivas e corretivas.

Após este trabalho sistêmico, que envolveu grande parte do hospital, aconteceu o redirecionamento do foco das ações de Qualidade, as quais ficaram mais voltadas para áreas específicas.

A trajetória deste trabalho esteve permeada por desafios, pela constante ampliação do interesse e busca de conhecimento do tema. Estes fizeram surgir inúmeras questões inquietantes, dirigindo ao aprofundamento científico, visando conhecer a realidade de outras instituições de saúde que já vinham implantando programas de Qualidade. 


\section{OBJETIVO}

- Entender como os diversos sujeitos entrevistados articulam conceitualmente a Qualidade na Saúde;

- Identificar como os atores sociais da saúde entendem as diferentes sistemáticas da Qualidade, e quais valores são atribuídos a estes sistemas, na esfera do trabalho;

- Mapear as práticas de Qualidade adotadas na amostra pesquisada;

- Resgatar e analisar as percepções relativas ao tema em evidência, que refletem a essência da praxis da Qualidade para os atores sociais. 


\section{MÉTODO}

\subsection{TIPO DE PESQUISA}

SELLTIZ e col. (1967, p.59-90) esclareceram que os estudos exploratórios têm, dentre outras funções: aumentar o conhecimento do pesquisador acerca do fenômeno que deseja investigar ou da situação em que pretende realizar tal estudo; o esclarecimento de conceitos; o estabelecimento de prioridades para futuras pesquisas, e; a obtenção de informações sobre possibilidades práticas de avaliação de pesquisa em situação de vida real.

Para analisar os dados que seguem utilizou-se a Pesquisa Qualitativa, como uma das estratégias.

MINAYO (2000, p.10) enuncia que “(...) o objeto de estudo, é entendido como aquele capaz de incorporar a questão do significado e da intencionalidade, como inerente aos atos, às relações e às estruturas."

A opção pelo Discurso do Sujeito Coletivo (DSC) ocorreu por entender-se que a abordagem qualitativa permite reconstruir as representações sociais, através da análise dos discursos de indivíduos num dado campo social (SIMIONI 1996).

Alguns autores defendem esta forma de pesquisa científica relatando:

Partindo do princípio de que o ato de compreender está ligado ao universo existencial humano, as abordagens qualitativas não se preocupam em fixar leis para se produzir generalizações. Os dados da pesquisa qualitativa objetivam uma compreensão profunda de certos fenômenos sociais apoiados no pressuposto da maior relevância do aspecto subjetivo da ação social, (....) enfatizam as particularidades de um fenômeno em termos de seu significado para o grupo pesquisado (GOLDENBERG 2000, p.49). 
A principal característica das pesquisas qualitativas é o fato de que elas seguem a tradição compreensiva ou interpretativa, (....) partem do pressuposto de que as pessoas agem em função de suas crenças, percepções, sentimentos e valores e que seu comportamento tem sempre um sentido, um significado que não dá a conhecer de modo imediato precisando ser desvelado (....)" (MAZZOTTI-ALVES 1999).

Os autores da técnica esclarecem que o Discurso do Sujeito Coletivo implica a utilização de quatro figuras metodológicas a saber:

\section{- Expressões Chave}

As expressões chave $(\mathrm{ECH})$ são pedaços, trechos ou transcrições literais do discurso do conteúdo discursivo dos segmentos em que se divide o depoimento.

Busca-se o resgate integral do depoimento, julgando a pertinência ou não da seleção e da tradução dos depoimentos.

As expressões chave são uma espécie de 'prova discursivo empírica' da 'verdade' das idéias centrais e das ancoragens e vice-versa, que podem ser resgatadas nas entrevistas originais.

\section{- Idéias Centrais}

Diz respeito as afirmações que permitem traduzir os conteúdos essenciais do discurso dos sujeitos, explicitado pelo sujeito.

\section{- Ancoragem}

A ancoragem de um discurso ocorre quando é possível encontrar nele, traços lingüisticos explícitos de teorias, hipóteses, conceitos, ideologias, existentes na sociedade e na cultura, e que estão internalizadas nos indivíduos (LEFEVRE, LEFEVRE e VIEIRA 2000). 


\section{- Discurso do Sujeito Coletivo}

Utilizou-se como técnica de tabulação de dados qualitativos o DSC. Este modelo tem o intuito de "reconstruir, com pedaços de discursos individuais, como em um quebra-cabeças, tantos discursos síntese quanto se julgue necessário para expressar uma dada figura, ou seja, um dado pensar ou representação social" (LEFEVRE e col. 2000, p.19).

A proposta do DSC, como forma de conhecimento ou redução da variabilidade discursiva empírica, implica em um radical rompimento com a lógica quantitativo-classificatória, na medida em que se busca resgatar o discurso como signo de conhecimento dos próprios discursos. É assim, uma estratégia metodológica que, utilizando a estratégia discursiva, visa a mais clara representação social e o conjunto das representações que conformam um dado imaginário.

Para a elaboração do DSC, parte-se dos discursos em estado bruto, que são submetidos a um trabalho analítico inicial. Segundo LEFEVRE e col. (2000, p.20) "depois da decomposição e seleção das principais ancoragens e/ou idéias centrais de discursos individuais, o Discurso do Sujeito Coletivo é a forma sintética onde se busca (....) a reconstituição discursiva da representação social."

Associado a este método foi também utilizada análise quantitativa do material coletado.

\subsection{DESENHO DO ESTUDO}

Solicitou-se a Listagem Jurídica dos hospitais do município de São Paulo para a Agência Nacional de Vigilância Sanitária, o que possibilitaria a definição da amostra, visto que a mesma constitui parte fundamental do processo de construção da pesquisa.

No exame de qualificação a banca examinadora orientou para que fosse dispensada a listagem referida. A hipótese levantada foi a de que a maior parte destes hospitais não possuiria programas de Qualidade implantados. 
Sendo assim, os membros da banca indicaram que fosse utilizado como critério, hospitais que já possuíssem programas de Qualidade sistematizados e que fossem previamente conhecidos, a fim de poder alcançar os objetivos pretendidos na pesquisa.

Assim, o desenho proposto para este estudo envolveu oito hospitais pertencentes ao município de São Paulo, sendo eles públicos e privados, independente de fatores como: especialidade atendida; número de leitos e número de funcionários. Para garantir o sigilo acordado com eles, os mesmos foram identificados pelas letras A, B, C, D, E, F, G e H. Foram entrevistados os atuais coordenadores das áreas de Qualidade de cada hospital.

Aos hospitais selecionados foi enviado Termo de Consentimento (Anexo A) para certificar-se que estavam dentro dos critérios estabelecidos. Para fazer parte da amostra foi solicitado a indicação de profissionais capacitados para responderem sobre o tema em destaque, a partir do instrumento da pesquisa.

\subsection{VARIÁVEIS SELECIONADAS}

\section{- Definição da amostra}

A população entrevistada foi constituída pelos atuais responsáveis pelas áreas de Qualidade dos hospitais escolhidos. Estes tinham diferentes níveis e cargos, idade, gênero, área de formação, tempo na instituição e no cargo.

\section{- Definição das variáveis a serem estudadas}

- Cargo - Objetivou medir em quais das várias áreas que compõem a organização está situada a instância organizacional que trabalha com a formalização da Qualidade.

- Tempo no Cargo - Investigou a experiência do indivíduo na função específica que desempenha, expresso em número de meses.

- Tempo na Instituição - Indicado em número de meses, por refletir a experiência específica do indivíduo, subdividido em dois ítens: em funções de outra natureza e na área da Qualidade. 
A análise das informações possibilitou traçar um quadro sobre os sistemas de avaliação escolhidos pelos hospitais, além de permitir a identificação da percepção dos entrevistados.

Outro aspecto relevante do estudo foi a possibilidade de sistematização das práticas de implantação de Qualidade como elemento orientador para instituições e organizações privadas, fundacionais e/ou governamentais com interesse no tema.

Este estudo de natureza exploratória, quali-quantitativo, tem como unidade de análise um grupo de individuos, constituído por atores sociais da saúde, da área da Qualidade, também definidos geograficamente pelo lócus do trabalho.

O principal uso deste elemento possibilita análises comparativas, a fim de construir o mapa das práticas de avaliação que vem sendo utilizadas no setor saúde, além de identificar qual a percepção de Qualidade dos que atuam neste segmento, tanto em hospitais públicos como privados.

As entrevistas foram conduzidas por pesquisador chefe que realizou orientações pertinentes, juntamente com o auxílio de um pesquisador colaborador, cujo papel foi o de registrar as informações/pareceres apresentados durante esta ocasião.

\subsection{INSTRUMENTO E COLETA DE DADOS}

O estudo foi realizado por meio de Formulário de Pesquisa (Anexo B) individualizado, aplicado em forma de entrevista semi-estruturada, combinando perguntas abertas e fechadas, onde o entrevistado teve a possibilidade de discorrer sobre os pontos propostos, fornecendo informações relativas ao tema pesquisado, de acordo com sua visão, percepção e experiência.

As questões versaram sobre: conceito de Qualidade, metodologia de avaliação, resultados dos programas aplicados, importância do desenvolvimento de Políticas de Qualidade, dificuldades do processo de implantação e pontos a serem melhorados. 
$\mathrm{O}$ entrevistado teve contato prévio com o instrumento. Este foi enviado para que ocorresse o levantamento de dados quantitativos e específicos, exigidos por algumas questões e cuja informação dependeria de diferentes áreas do hospital. Tal prática objetivou assegurar que as informações solicitadas fossem pesquisadas a priori.

Foram realizados na pesquisa os passos descritos a seguir, referentes a interação do pesquisador com as instituições pesquisadas:

- A constituição da amostra foi intencional;

- Comunicação com a instituição via telefone para solicitação de participação no estudo;

- Quando aceito, houve envio do termo de consentimento e solicitação de indicação de profissional da Qualidade a ser entrevistado;

- Envio de Formulário de Pesquisa para o entrevistado, visando levantamento de dados quantitativos a serem entregues no ato da entrevista;

- Visitas aos hospitais previamente definidos, para entrevista orientada;

- Compilação dos dados do Formulário de Pesquisa e entrevistas (Anexo C).

\subsection{DESCRIÇÃO DO MÉTODO DE ANÁLISE QUANTITATIVA E QUALITATIVA}

Os dados foram organizados segundo aspectos qualitativos $\mathrm{e}$ quantitativos.

Os primeiros compreenderam variáveis relativas a caracterização dos hospitais, estratégias de melhoria e mecanismos de Qualidade. Para apresentação destes aspectos utilizou-se o sistema de processamento de texto, banco de dados e a sistematização das informações, em forma de quadros. O conteúdo das questões quantitativas abordaram pontos relacionados a escolha da método de Qualidade, tempo de implantação e resultados obtidos. Conhecer o universo das instituições pesquisadas, suas opções metodológicas e seus caminhos de trabalho, permitiu a construção de um panorama da área da saúde, onde delineou-se como a Qualidade se coloca neste âmbito. 
As abordagens de corte qualitativo permitem a compreensão mais aprofundada dos campos sociais e dos sentidos neles presentes, remetendo a uma teia de significados de difícil recuperação, em estudo de corte quantitativo.

Escolheu-se para a análise dos dados, concepções teóricas que sustentam as sistemática de Qualidade e referenciais teóricos de pensadores do assunto, que ancoram as escolhas de cada hospital.

A Idéia Central que permeia cada escolha foi buscada no processo de entrevista, permitindo identificar os critérios que influenciaram a implantação dos programas de Qualidade.

A elaboração da análise qualitativa compreendeu as seguintes etapas:

- Sistematização das respostas oferecidas pelas instituições por meio das pessoas entrevistadas;

- Montagem de instrumento de avaliação de resultados, que permitiu visualização das Idéias Centrais. Objetivou-se criar mecanismos de comparação das informações levantadas;

- Construção do cenário da Qualidade representado pelos hospitais pesquisados, por meio dos sujeitos que foram entrevistados e atuam nesta área. 


\section{RESULTADOS}

\subsection{APRESENTAÇÃO COMPARATIVA DOS DADOS ENTRE HOSPITAIS}

A apresentação comparativa dos dados entre os hospitais pesquisados possibilitou a compreensão da situação específica de cada universo, assim como permitiu o desenvolvimento de idéias a cerca de questões que envolvem tanto as ações de Qualidade, quanto o funcionamento das instituições hospitalares incluídas nesta pesquisa.

O estudo dos dados favoreceu o entendimento das diferentes possibilidades contidas na utilização de uma mesma sistemática de Qualidade. Dessa forma, valorizou-se a condição de flexibilização permitida em cada uma destas situações, como elemento agregador, a partir das características de cada equipamento de saúde.

Com isto evidenciou-se que a implantação de ações de Qualidade, passa, necessariamente, pela construção de um diagnóstico situacional, onde é valorizada a cultura institucional, seus meios de comunicação, a forma como as relações de poder estão estruturadas, o envolvimento dos colaboradores nos processos institucionais e o comprometimento da alta direção.

Aspectos como organização e acesso à informação constituem também elementos importantes no curso da análise da pesquisa, uma vez que sua ausência fala da forma como a instituição está estruturada.

\subsection{ANÁLISE DO DADOS QUANTITATIVOS}

Várias das questões respondidas pelos entrevistados resultaram em informações relevantes, estas foram transformadas em quadros, objetivando uma melhor visualização dos mesmos. Encontrados a seguir. 
O quadro XIV apresenta a caracterização dos hospitais de acordo com sua força de trabalho, estrutura funcional e jurídica. Entende-se neste contexto que os colaboradores são aqueles indivíduos, que atuam nos diferentes segmentos de prestação de serviço, ou seja, constituem a força de trabalho da instituição.

\section{QUADRO XIV - CARACTERÍSTICAS DA AMOSTRA}

\begin{tabular}{|c|c|c|c|c|}
\hline HOSP. & $\begin{array}{c}\text { PERSONALIDADE } \\
\text { JURÍDICA }\end{array}$ & $\begin{array}{c}\text { TIPO DA } \\
\text { INSTITUIÇÃo }\end{array}$ & $\begin{array}{c}\mathbf{N}^{\circ} \text { DE } \\
\text { LEITOS }\end{array}$ & $\begin{array}{c}\mathbf{N}^{\circ} \text { DE } \\
\text { COLABORADORES }\end{array}$ \\
\hline A & Privado & Geral & 85 & 200 à 499 \\
\hline B & Fundação & Geral & 220 & 500 à 999 \\
\hline C & Privado & Geral & 241 & 1000 à 2499 \\
\hline D & Privado/Filantrópico & Geral & 411 & 2500 ou mais \\
\hline E & Privado & Geral & 160 & 500 à 999 \\
\hline F & Público & $\begin{array}{c}\text { Especializado/ } \\
\text { Pediátrico }\end{array}$ & 119 & 500 à 999 \\
\hline G & Público/Fundação & $\begin{array}{c}\text { Especializado/ } \\
\text { Cardiologia }\end{array}$ & 247 & 1000 à 2499 \\
\hline H & Privado & Geral & 183 & 1000 à 2499 \\
\hline
\end{tabular}

Os Quadros XV e XVI foram preenchidos pelo setor da instituição responsável por estas informações. Buscou-se com eles mostrar o levantamento do quadro de colaboradores que trabalham nestes hospitais.

No Quadro XV pretendeu-se identificar em que níveis ocorrem maiores concentrações de profissionais. O quadro XVI apresenta a distribuição dos colaboradores quanto ao grau de escolaridade.

Vale ressaltar que em ambos os quadros, as células que se encontram vazias significam que a própria Instituição não forneceu as informações correspondentes, seja pela inexistência do dado ou fator não revelado. 
QUADRO XV - NÚMERO DE COLABORADORES POR NÍVEL EM RELAÇÃO À FUNÇÃO EXERCIDA

\begin{tabular}{|c|c|c|c|c|}
\hline HOSP. & OPERACIONAL & TÉCNICO & UNIVERSITÁRIO & TERCEIROS \\
\hline A & 81 & 132 & 45 & \\
\hline B & 220 & 369 & 96 & \\
\hline C & 1.120 & 155 & 249 & \\
\hline D & 1.144 & 1.436 & 1.081 & \\
\hline E & & & & \\
\hline F & 203 & 357 & 340 & 1250 \\
\hline G & 309 & 453 & 329 & \\
\hline H & 200 & 450 & 350 & \\
\hline
\end{tabular}

QUADRO XVI - NÚMERO DE COLABORADORES POR GRAU DE ESCOLARIDADE

\begin{tabular}{|c|c|c|c|c|c|c|c|c|}
\hline HOSP. & $\begin{array}{l}\text { COMPL } \\
\text { INCOMPL }\end{array}$ & $\begin{array}{c}1^{\circ} \\
\text { GRAU }\end{array}$ & $\begin{array}{c}2^{\circ} \\
\text { GRAU }\end{array}$ & $\begin{array}{c}3^{\circ} \\
\text { GRAU }\end{array}$ & MESTR. & DOUTOR. & $\begin{array}{c}\text { PÓS- } \\
\text { DOUTOR. }\end{array}$ & ESPEC. \\
\hline $\mathbf{A}$ & $\begin{array}{l}\text { Compl. } \\
\text { Incompl. }\end{array}$ & 28 & 102 & 30 & 0 & 0 & & 0 \\
\hline B & $\begin{array}{l}\text { Compl. } \\
\text { Incompl. }\end{array}$ & $\begin{array}{c}47 \\
0\end{array}$ & $\begin{array}{c}461 \\
0\end{array}$ & $\begin{array}{c}177 \\
0\end{array}$ & $\begin{array}{l}0 \\
0\end{array}$ & $\begin{array}{l}0 \\
0\end{array}$ & & $\begin{array}{c}41 \\
0\end{array}$ \\
\hline C & $\begin{array}{l}\text { Compl. } \\
\text { Incompl. }\end{array}$ & $\begin{array}{c}207 \\
0\end{array}$ & $\begin{array}{c}587 \\
0\end{array}$ & $\begin{array}{c}223 \\
0\end{array}$ & $\begin{array}{c}34 \\
0\end{array}$ & $\begin{array}{l}0 \\
0\end{array}$ & & $\begin{array}{l}0 \\
0\end{array}$ \\
\hline D & $\begin{array}{l}\text { Compl. } \\
\text { Incompl. }\end{array}$ & $\begin{array}{c}897 \\
0\end{array}$ & $\begin{array}{c}1618 \\
0\end{array}$ & $\begin{array}{c}1146 \\
0\end{array}$ & $\begin{array}{l}0 \\
0\end{array}$ & $\begin{array}{l}0 \\
0\end{array}$ & & $\begin{array}{l}0 \\
0\end{array}$ \\
\hline $\mathbf{E}$ & $\begin{array}{l}\text { Compl. } \\
\text { Incompl. }\end{array}$ & & & & & & & \\
\hline $\mathbf{F}$ & $\begin{array}{l}\text { Compl. } \\
\text { Incompl }\end{array}$ & & & & & & & \\
\hline G & $\begin{array}{l}\text { Compl. } \\
\text { Incompl. }\end{array}$ & $\begin{array}{l}173 \\
114\end{array}$ & $\begin{array}{c}331 \\
62\end{array}$ & $\begin{array}{c}328 \\
38\end{array}$ & $\begin{array}{l}16 \\
04\end{array}$ & $\begin{array}{l}32 \\
08\end{array}$ & $\begin{array}{c}09 \text { (livre } \\
\text { docência) }\end{array}$ & 0 \\
\hline H & $\begin{array}{l}\text { Compl. } \\
\text { Incompl. }\end{array}$ & $\begin{array}{c}200 \\
0\end{array}$ & $\begin{array}{c}450 \\
0\end{array}$ & $\begin{array}{c}350 \\
0\end{array}$ & $\begin{array}{c}30 \\
0\end{array}$ & $\begin{array}{l}5 \\
0\end{array}$ & & $\begin{array}{c}50 \\
0\end{array}$ \\
\hline
\end{tabular}

$\left({ }^{*}\right) \mathrm{Compl}=$ completo/Incompl $=$ incompleto 
Concentrou-se no Quadro XVII informações que possibilitaram visualizar a situação da Qualidade nos hospitais pesquisados. Os dados levantados auxiliaram no entendimento de como as estratégias de Qualidade foram implantadas e o comprometimento da instituição para o alcance da construção deste objetivo. A lógica para as duas células vazias é a mesma dos Quadros XV e XVI.

\section{QUADRO XVII - SITUACÃO DA QUALIDADE NOS HOSPITAIS}

\begin{tabular}{|c|c|c|c|}
\hline HOSP. & $\begin{array}{c}\text { TEMPO DE } \\
\text { IMPLEMENTAÇÃO DE } \\
\text { ESTRATÉGIAS DE } \\
\text { QUALIDADE }\end{array}$ & ABRANGÊNCIA & $\begin{array}{l}\text { COLABORADORES } \\
\text { ENVOLVIDOS }\end{array}$ \\
\hline $\mathbf{A}$ & $>08$ anos & Toda organização & 20 \\
\hline B & De 01 a 03 anos & $\begin{array}{l}\text { Algumas áreas. Com } \\
\text { previsão de } 2 \text { anos para } \\
\text { certificar todo o hospital }\end{array}$ & Média 250 \\
\hline C & $>08$ anos & Toda organização & 2000 \\
\hline D & De 05 a 07 anos & Toda organização & $\begin{array}{c}\text { Todos os colaboradores em } \\
\text { diferentes momentos do } \\
\text { processo }\end{array}$ \\
\hline $\mathbf{E}$ & & Toda organização & $\begin{array}{c}\text { Todas as gerências, } \\
\text { encarregados, } 60 \% \\
\text { multiplicadores e os terceiros }\end{array}$ \\
\hline $\mathbf{F}$ & & Toda organização & $\begin{array}{c}\text { Todos os colaboradores em } \\
\text { diferentes momentos do } \\
\text { processo }\end{array}$ \\
\hline G & De 05 a 07 anos & $\begin{array}{l}\text { Toda organização } \\
\text { menos os médicos }\end{array}$ & $\begin{array}{c}80 \text { (diretores de serviços e } \\
\text { chefes) }\end{array}$ \\
\hline $\mathbf{H}$ & De 01 a 03 anos & Toda organização & $\begin{array}{l}43 \text { apoio, mais todos os } \\
\text { colaboradores }\end{array}$ \\
\hline
\end{tabular}

Os Quadros XVIII e XIX, demonstrados adiante, foram elaborados com a finalidade de mapear as ferramentas usadas pelos hospitais, bem como as sistemáticas que orientaram as ações de Qualidade.

Os respondentes apontaram, além das alternativas sugeridas no Formulário da Pesquisa, outras que melhor retrataram a situação do hospital. 
QUADRO XVIII - FERRAMENTAS ADOTADAS PARA IMPLEMENTAR ESTRATÉGIA DE MELHORIA DE QUALIDADE

\begin{tabular}{|c|c|c|c|}
\hline HOSP. & 5S & PDCA & OUTROS. QUAIS? \\
\hline A & & $\mathrm{X}$ & $\begin{array}{c}\text { Metodologia própria (treinamento, conscientização em relação } \\
\text { ao atendimento) }\end{array}$ \\
\hline B & & & ISO 9002 e Joint Comission \\
\hline C & & $\mathrm{X}$ & Cada área usou ferramentas próprias \\
\hline D & & $\mathrm{X}$ & Gestão Estratégica \\
\hline E & & & Funções gerais de adm/compras de livros \\
\hline F & & & Manual Brasileiro de Acreditação Hospitalar e CBA \\
\hline G & $\mathrm{X}$ & $\mathrm{X}$ &
\end{tabular}

QUADRO XIX - METODOLOGIA DE AVALIAÇÃO, CERTIFICAÇÃO, ACREDITAÇÃO E PREMIAÇÃO ADOTADAS

\begin{tabular}{|c|c|c|c|c|c|c|c|c|c|}
\hline \multirow{2}{*}{ HOSP. } & \multicolumn{2}{|c|}{ PRÊMIO } & \multirow{2}{*}{$\begin{array}{c}\text { SELO } \\
\text { CQH }\end{array}$} & \multirow{2}{*}{$\begin{array}{c}\text { CERTIF. } \\
\text { ISSO }\end{array}$} & \multicolumn{3}{|c|}{ ACREDITAÇÃO } & \multirow{2}{*}{ PRÓPRIA } & \multirow{2}{*}{ Outras } \\
\hline & PNQ & PQGF & & & CBA & $\mathbf{J C}$ & MBAH & & \\
\hline $\mathbf{A}$ & & & & $\mathrm{X}$ & & & $\mathrm{X}$ & & \\
\hline B & & & & $\mathrm{X}$ & & & & & \\
\hline C & & & $\mathrm{X}$ & $\mathrm{X}$ & & & & & \\
\hline D & & & & $\mathrm{X}$ & & $\mathrm{X}$ & & & \\
\hline $\mathbf{E}$ & & & & & & & $\mathrm{X}$ & & \\
\hline $\mathbf{F}$ & & & & & & & & $\mathrm{X}$ & \\
\hline G & & & $\mathrm{X}$ & $\mathrm{X}$ & & & $\mathrm{X}$ & & 5S/PDCA \\
\hline H & & & & & $\mathrm{X}$ & & & & \\
\hline Total & $\mathbf{0}$ & $\mathbf{0}$ & 2 & 5 & 1 & 1 & 3 & 1 & \\
\hline
\end{tabular}

O Quadro XX, que se encontra na página seguinte, releva aquelas informações fornecidas, referentes ao apoio externo e interno para a condução do trabalho de implantação de sistemáticas de Qualidade. 


\section{QUADRO XX - RESPONSÁVEIS PELA ADAPTAÇÃO DAS \\ SISTEMÁTICAS DE QUALIDADE UTILIZADAS}

\begin{tabular}{|c|c|c|c|}
\hline \multirow{2}{*}{ HOSP. } & \multicolumn{2}{|c|}{ CONSULTORIA EXTERNA } & \multirow{2}{*}{ INSTITUCIONAL } \\
\cline { 2 - 3 } & TIPO & TEMPO DE ATUAÇÃO & Gestores \\
\hline A & Nacional & De 24 a 30 meses & Superintendente \\
\hline B & Nacional & De 18 a 24 meses & Gerente da Qualidade \\
\hline D & Nacional & De 24 a 30 meses & Coordenador Administrativo \\
\hline E & Nacional & $\begin{array}{c}\text { De } 06 \text { a } 12 \text { meses (ISO) e } \\
\text { de } 18 \text { a } 24 \text { meses (JCI) }\end{array}$ & Comissão \\
\hline F & Não Houve & De 06 a 12 meses & Diretor Executivo \\
\hline G & Nacional & De 01 a 06 meses & Assistente Técnico de Saúde \\
\hline H & Nacional & De 18 a 24 meses & Superintendentes e Gerentes \\
\hline
\end{tabular}

O Quadros XXI e XXII dizem respeito a como os hospitais montaram suas estruturas de Qualidade.

Destacam-se em particular:

- Os Times - entendidos como estrutura que tem como objetivo identificar problemas relacionados com o trabalho, medir a frequência desses, seus impactos no cliente e na organização, seus custos e recomendar ações corretivas;

- A Comissão Executiva - considerada como grupo encarregado de colocar em execução as resoluções tomadas pelos representantes da reunião a que ela pertence, e;

- A Força Tarefa - como a equipe multidisciplinar com o objetivo de analisar problemas considerados crônicos e propor soluções. 
QUADRO XXI - ESTRUTURAS DERIVADAS DA IMPLANTAÇÃO

DA QUALIDADE

\begin{tabular}{|c|c|c|c|c|}
\hline HOSP. & $\begin{array}{c}\text { TIMES DE } \\
\text { MELHORIA }\end{array}$ & $\begin{array}{c}\text { COMISSÕES DE } \\
\text { QUALIDADE }\end{array}$ & $\begin{array}{r}\text { FORÇA } \\
\text { TAREFA }\end{array}$ & OUTROS \\
\hline A & $\mathrm{x}$ & & & \\
\hline B & & & & Comitês \\
\hline C & $\mathrm{X}$ & $\mathrm{X}$ & $\mathrm{X}$ & \\
\hline D & $\mathrm{x}$ & $\mathrm{X}$ & $\mathrm{x}$ & $\begin{array}{c}\text { Reorganização } \\
\text { institucional }\end{array}$ \\
\hline $\mathbf{E}$ & & & $\mathrm{X}$ & \\
\hline$F$ & $\mathrm{X}$ & & & \\
\hline G & & & & $\begin{array}{c}\text { Sensibilização e } \\
\text { motivação dos } \\
\text { profissionais }\end{array}$ \\
\hline H & $\mathrm{X}$ & $\mathrm{X}$ & & Grupo Executivo \\
\hline
\end{tabular}

QUADRO XXII - ORGANIZAÇÃO DOS GRUPOS POR CRITÉRIO DE FORMAÇÃO

\begin{tabular}{|c|c|c|c|c|}
\hline HOSP. & TAREFA & FUNÇÃO & $\begin{array}{c}\text { INTERESSE } \\
\text { PESSOAL }\end{array}$ & ÁREA \\
\hline A & $\mathrm{X}$ & & & \\
\hline B & & & & $\mathrm{X}$ \\
\hline C & $\mathrm{X}$ & & & \\
\hline D & & $\mathrm{X}$ & & \\
\hline E & & $\mathrm{X}$ & & \\
\hline F & $\mathrm{X}$ & & & \\
\hline G & & & $\mathrm{X}$ & \\
\hline H & $\mathrm{X}$ & & & \\
\hline
\end{tabular}


Os Quadros XXIII e XXIV foram construídos visando compreender a lógica de implantação de instrumentos, como a ISO e o MBAH, exclusivamente para aqueles hospitais que fizeram uso destas.

\section{QUADRO XXIII - ETAPAS PARA IMPLANTAÇÃO DA ISO 9000 POR ORDEM DE PRIORIDADES INSTITUCIONAIS}

\begin{tabular}{|c|c|c|c|c|c|c|c|c|}
\hline \multirow[b]{2}{*}{ ETAPAS } & \multicolumn{8}{|c|}{ HOSPITAIS } \\
\hline & $\mathbf{A}$ & $\mathbf{B}$ & $\mathbf{C}$ & D & $\mathbf{E}$ & $\mathbf{F}$ & G & $\mathbf{H}$ \\
\hline Conscientização da Alta Administração & 1 & 1 & 1 & 1 & - & - & 1 & - \\
\hline Organização do Planejamento do Trabalho & 2 & 2 & 4 & 2 & - & - & 2 & - \\
\hline $\begin{array}{l}\text { Diagnóstico dos Fluxos Operacionais pela Consultoria } \\
\text { Externa }\end{array}$ & 3 & 3 & 2 & 2 & - & - & - & - \\
\hline $\begin{array}{l}\text { Mapeamento dos Macro - Processos e sua inter - } \\
\text { relação }\end{array}$ & 9 & 5 & 3 & 2 & - & - & 3 & - \\
\hline Treinamento ISSO 9000 para Pessoal Operacional & 10 & 4 & 7 & 3 & - & - & 8 & - \\
\hline $\begin{array}{l}\text { Aprovação do Cronograma Geral e de Elaboração de } \\
\text { Procedimentos }\end{array}$ & 5 & 6 & 5 & 3 & - & - & 4 & - \\
\hline Visão de Processo para Gestores & 4 & 8 & 6 & 3 & - & - & 11 & - \\
\hline Assessoria às áreas para Elaboração de Procedimentos & 6 & 7 & 9 & 4 & - & - & 6 & - \\
\hline Procedimentos de Melhoria e Auditoria Interna & 19 & 9 & 15 & 4 & - & - & 9 & - \\
\hline Estratégia para Melhoria Contínua & 20 & 13 & 8 & 4 & - & - & 12 & - \\
\hline Sensibilização ISO 9000 e Política de Qualidade & 8 & 14 & 10 & 4 & - & - & 10 & - \\
\hline Manual da Qualidade e Comunicação Interna & 7 & 10 & 14 & 4 & - & - & 5 & - \\
\hline Monitoramento dos Objetivos da Qualidade & 18 & 11 & 12 & 5 & - & - & 13 & - \\
\hline Realização de Auditoria Interna & 17 & 12 & 17 & 6 & - & - & 7 & - \\
\hline Diagnóstico Independente & 11 & 13 & 13 & 7 & - & - & 14 & - \\
\hline Análise Crítica pela Administração & 12 & 17 & 16 & 4 & - & - & 15 & - \\
\hline Contratação - Contato com a Certificação & 13 & 14 & 11 & 2 & - & - & * & - \\
\hline Realização da Pré Auditoria & 14 & 15 & 18 & 8 & - & - & * & - \\
\hline Realização da Auditoria de Certificação & 15 & 16 & 19 & 9 & - & - & * & - \\
\hline Reconhecimento aos envolvidos & 16 & 18 & 20 & 10 & - & - & * & - \\
\hline
\end{tabular}




\section{QUADRO XXIV - ETAPAS PARA IMPLANTAÇÃO DO MBAH CONFORME PRIORIDADES INSTITUCIONAIS}

\begin{tabular}{|c|c|c|c|c|c|c|c|c|}
\hline \multirow[b]{2}{*}{ ETAPAS } & \multicolumn{8}{|c|}{ HOSPITAIS } \\
\hline & $\mathbf{A}$ & $\mathbf{B}$ & $\mathbf{C}$ & $\mathbf{D}$ & $\mathbf{E}$ & $\mathbf{F}$ & $\mathbf{G}$ & $\mathbf{H}$ \\
\hline $\begin{array}{l}\text { Definição institucional da aplicação do instrumento } \\
\text { como metodologia de Qualidade e integração } \\
\text { institucional }\end{array}$ & 2 & - & - & - & - & - & 1 & - \\
\hline $\begin{array}{l}\text { Manifestação institucional da alta direção da meta } \\
\text { definida de aplicação do MBAH }\end{array}$ & 1 & - & - & - & - & - & 4 & - \\
\hline $\begin{array}{l}\text { Sensibilização das áreas envolvidas no manual pela área } \\
\text { da Qualidade, sobre a importância de atender aos itens } \\
\text { de verificação solicitados. }\end{array}$ & 3 & - & - & - & - & - & 2 & - \\
\hline $\begin{array}{l}\text { Capacitação de avaliadores internos e gerentes pela } \\
\text { Instituição Acreditadora ou Entidades Associativas para } \\
\text { liderar as atividades de preparação para visita e } \\
\text { auditoria }\end{array}$ & 4 & - & - & - & - & - & 3 & - \\
\hline $\begin{array}{l}\text { Auto avaliação das áreas, segundo os itens de } \\
\text { verificação, liderado pelos coordenadores locais do } \\
\text { processo, com apoio da área da Qualidade, que poderá } \\
\text { funcionar como uma visita pré auditoria. }\end{array}$ & 5 & - & - & - & - & - & - & - \\
\hline Marcação de visita dos avaliadores pelo hospital & 7 & - & - & - & - & - & 5 & - \\
\hline $\begin{array}{l}\text { Visita de avaliação por visitadores externos onde } \\
\text { classificarão o nível do hospital. }\end{array}$ & 8 & - & - & - & - & - & 6 & - \\
\hline $\begin{array}{l}\text { Encerramento da auditoria em reunião conjunta com } \\
\text { avaliadores e membros da alta direção do hospital. }\end{array}$ & 9 & - & - & - & - & - & 7 & - \\
\hline $\begin{array}{l}\text { Relatório de visita e resultados da avaliação realizados } \\
\text { pelos avaliadores. }\end{array}$ & 10 & - & - & - & - & - & 8 & - \\
\hline Divulgação dos resultados para as áreas. & 11 & - & - & - & - & - & 9 & - \\
\hline $\begin{array}{l}\text { Estabelecimento de Planos de Ação para melhoria dos } \\
\text { problemas identificados. }\end{array}$ & 6 & - & - & - & - & - & 10 & - \\
\hline
\end{tabular}

(-) Não utilizou o instrumento MBAH 
A literatura relata que os programas de Qualidade tiveram seu início no período pós II Guerra Mundial e desenvolveram-se tendo como locus principal o segmento industrial. Dentro da área da saúde constata-se que as ações da Qualidade, organizadas como programas e sustentadas por sistemáticas específicas, constituem um caminho novo, de vida recente.

Esta idéia pode ser corroborada pelos dados apresentados pelos hospitais A, B, C, D, G e H, que responderam ao item 'Tempo de Implementação de Estratégias de Qualidade', do Quadro XVII: Situação da Qualidade nos Hospitais. Por estes dados, conclui-se que $65 \%$ dos hospitais, B, D, G e H, passaram por este processo há menos de oito anos, enquanto que apenas 35\% deles, A e C, o fizeram há mais de oito anos.

Mesmo ao constatar-se que esta implementação é recente na maioria dos hospitais, o Quadro XVII nos informa que a abrangência deste processo objetiva atingir a instituição em sua totalidade através de diferentes estratégias. Em cinco hospitais, $\mathrm{C}, \mathrm{D}, \mathrm{E}, \mathrm{F}$ e $\mathrm{H}$, foi relatado o envolvimento de todos os colaboradores em momentos diversos. Em dois hospitais, $\mathrm{A} \mathrm{e} \mathrm{G}$, coube às lideranças a responsabilidade da sensibilização, conscientização e efetiva implantação do processo de qualidade, inter e intra equipes.

Para a implantação dos programas de Qualidade, os hospitais optaram por diferentes mecanismos. Na questão destinada a identificação das ferramentas utilizadas, foram apresentados dados, que transformados no Quadro XVIII Ferramentas Adotadas para Implementar Estratégia de melhoria de Qualidade, demonstram que a mais utilizada foi o ciclo PDCA. Sendo que os hospitais A e C a utilizaram exclusivamente e o hospital $\mathrm{D}$ a aliou à ISO e à Joint Commission. O hospital G referiu aplicar, além do PDCA, o $5 \mathrm{~S}$ e debates internos com subsídios de leituras dirigidas, que visavam a aquisição de noções gerais de administração e Qualidade. As instituições B e E utilizaram, respectivamente, metodologia própria e ferramentas específicas para cada área.

A instituição $\mathrm{F}$ utilizou a gestão estratégica com o objetivo de direcionar as ações de Qualidade, tal abordagem contém em si diferentes possibilidades para a condução dos trabalhos com foco na melhoria contínua. 
O hospital $\mathrm{H}$ refere a utilização do Manual Brasileiro de Acreditação Hospitalar e do Consórcio Brasileiro de Acreditação Hospitalar.

Cabe ressaltar que no item 'Outros' do Quadro XVIII, os gestores dos hospitais $\mathrm{D}$ e $\mathrm{H}$ apontam como ferramentas a norma ISO, a Joint Commission, o CBA e o MBAH. Esta constatação gerou o seguinte questionamento: o conjunto de princípios que orienta a ISO, a Joint Commission, o CBA e o MBAH, faz com que eles se configurem como ferramentas ou como metodologia?

$\mathrm{Na}$ amostra pôde-se observar a utilização destas sendo referidas das duas formas. Vale ressaltar que Metodologia compreende o estudo científico dos métodos, guiados para a investigação da verdade (MICHAELIS 1998, p.1.368), e Método significa o conjunto dos meios, instrumento somado à técnica, dispostos convenientemente para alcançar um fim e, especialmente chegar a um conhecimento científico (MICHAELIS 1998, p.1.368). Identifica-se semelhança entre instrumento e ferramenta, sendo o primeiro entendido como todo meio para conseguir atingir um fim e chegar a um resultado; ou utensílio para levar a efeito uma operação. Dessa forma, pode-se concluir a utilização de diferentes conceitos com a mesma finalidade.

Assim, para os gestores entrevistados parece não haver diferenciação entre estes dois conceitos, Metodologia e Ferramenta, quando aplicados à norma ISO, à Joint Commission, ao CBA e ao MBAH. Esta discussão não possui consenso quando busca-se a literatura referida na 'Introdução' desta tese. Na prática evidenciase reflexo desta situação que pode ser ocasionado pela falta de clareza teórica. Como exemplo, observa-se o hospital $\mathrm{H}$ referindo, no Quadro XVIII a utilização do CBA como ferramenta e, no Quadro XIX, como metodologia.

Esta situação permite que cada instituição utilize a ISO, a Joint Commission, o CBA e o MBAH, conforme a compreensão pessoal dos gestores, que estabelecem e adequam os passos da implantação às necessidades institucionais. Portanto considera-se importante que esta discussão avance, podendo esclarecer esta questão de caráter teórico, mas que não se apresenta como fator limitante da prática atual. 
Quantó à sistemática utilizada o Quadro XIX: Metodologia de Avaliação, Certificação, Acreditação e Premiação adotadas mostra, de forma significativa, que cinco das oito instituições, A, B, C, D e G, relatam adoção da certificação da norma ISO.Destes cinco hospitais, três agregaram, em momentos diferentes, métodos de Acreditação $\mathrm{A}$ e $\mathrm{G} \rightarrow \mathrm{MBAH}$ e $\mathrm{D} \rightarrow$ JC. É importante ressaltar ainda que houve adesão dos hospitais C e G ao programa de Qualidade do $\mathrm{CQH}$.

Diante destes dados alguns apontamentos podem ser feitos. Os hospitais C e G relataram utilizar o instrumento do $\mathrm{CQH}$, Roteiro de Visitas, como passo inicial para implementação de ações de Qualidade. De acordo com a literatura, ao utilizar este instrumento a instituição mostra-se preocupada em definir seus indicadores e identificar seu status institucional, que são os quesitos avaliados para a obtenção do selo do CQH. Pode-se considerar que a adoção deste programa forneceu um primeiro diagnóstico da instituição, contribuindo para posterior aplicação de outras métodos de Qualidade. Sendo que, o passo seguinte nestes hospitais foi a implantação da ISO.

Como visto anteriormente, cinco hospitais adotaram a NBR ISO 9000:1994, que foi o método com maior adesão. Tal dado significativo instiga a reflexão sobre quais motivos contribuíram para esta escolha. Reportando-se à literatura, há evidência de que este mecanismo de certificação não significa nem a burocratização e nem a obtenção da Qualidade Total, mas está relacionado com: identificação, otimização, qualificação, padronização, monitoração, análise e crítica dos processos. A partir desta informação a ISO apresenta-se como um método orientador, que contribui para a organização dos hospitais. Padronizar vem ao encontro da minimização de erros, fato tão necessário nos hospitais, uma vez que qualquer procedimento realizado inadequadamente pode significar dor e sofrimento ao paciente, que é o foco da assistência de saúde.

Identificou-se também adesão de três hospitais, A,E e G ao MBAH, sendo este fato posterior à adesão da ISO. De acordo com Ministério da Saúde, no Manual Brasileiro de Acreditação Hospitalar 2002, a missão essencial das instituições hospitalares é: 
- "Atender os seus pacientes da forma mais adequada. Por isso, todo hospital deve preocupar-se com a melhoria permanente da Qualidade de sua gestão e assistência, buscando uma integração harmônica das áreas médicas, tecnológica, administrativa, econômica, assistencial e, se for o caso, de docência e pesquisa".

Este fato levaria ao seguinte questionamento: a adesão deste instrumento, posterior ao uso da NBR ISO 9000:1994, vem responder à busca de Qualidade Total, que esta última não prioriza?

Os dados apresentados no Quadro XIX levam a constatação da existência de uma lógica no tocante a escolha das sistemáticas adotadas. Isto gera reflexões da seguinte ordem: o gestor entende que há uma hierarquia a ser seguida quando decide pelo uso dos métodos escolhidos? Há, implicitamente, características nos métodos que favoreçam suas utilizações de maneira hierárquica?

$\mathrm{Na}$ implantação dos programas de Qualidade os hospitais contaram com diferentes apoios: externos (consultoria externa) e internos (institucional). O Quadro XX: Responsáveis pela Adaptação da Metodologia mostra que dos oito hospitais, apenas o F não buscou ajuda de consultoria externa, enquanto que todos os outros recorreram ao apoio de consultorias nacionais. Nestes últimos a faixa de tempo de prestação de serviços variou de um a trinta meses, e em cinco dos hospitais, A, B, C, D e H, observa-se uma maior concentração em períodos superiores há dezoito meses.

A busca de apoio externo, na implantação e acompanhamento das ações de Qualidade, reforça a idéia que vem sendo trabalhada, de que as instituições de saúde apresentam evolução em sua estrutura, organização e funcionamento, quando relacionadas com suas características originais. No entanto, seus avanços ainda são lentos e o apoio externo se faz necessário para alavancar estes processos.

Quanto ao apoio interno, todos contaram com algum tipo de ajuda para iniciar o processo de implantação do programa de Qualidade, diferenciando-se apenas quanto a origem da mesma. 
Não foi possível maior análise quanto aos colaboradores envolvidos, uma vez que a nomeação dos cargos difere, quando se compara instituições públicas e privadas, o que poderia resultar em análises impróprias.

As formas de trabalho escolhidas pelas instituições para orientação das ações de Qualidade encontram-se descritas no Quadro XXI: Estruturas Derivadas do Processo. Através dele nota-se a prevalência da formação dos Times de Melhoria, ocorrida nos hospitais A, C, D, F e H. Deve-se evidenciar que no caso do hospital $\mathrm{H}$ o time foi aliado às Comissões de Qualidade, e do $\mathrm{C}$ e $\mathrm{D}$, além das comissões, houve também a constituição da Força Tarefa. Os hospitais B e G optaram por formas distintas de organização. O primeiro relata a formação de comitês e o segundo a sensibilização e motivação dos profissionais. No hospital E foi utilizada apenas a força tarefa.

A constatação de que os hospitais optaram, predominantemente, pela formação de times de melhoria, poderia evidenciar a preocupação dos gestores da Qualidade no envolvimento de um maior número de colaboradores na discussão de questões institucionais, as quais merecem ser tratadas na busca de melhores resultados.

Essa forma de condução do trabalho parece aproximar os hospitais e gestores da meta de abrangência de todos o colaboradores nas ações e processos da Qualidade, como citado no Quadro XVII.

Pensando no critério adotado para formação dos grupos citados anteriormente, verifica-se através do Quadro XXII: Organização dos Grupos por Critério de Formação que a maioria deles, hospitais A, C, F, e H, foi formada tendo como pré-requisito a tarefa a ser desenvolvida. Nos hospitais D e E a função dos profissionais participantes foi relevante na constituição dos grupos. Enquanto que no hospital $\mathrm{B}$ este fator foi a área de trabalho, e no $\mathrm{G}$ o interesse pessoal dos profissionais envolvidos.

Retomando a questão dos métodos utilizados para implantação de programas de Qualidade, foram construídos os Quadros XXIII e XXIV. Os mesmos têm como intuito compreender especificamente as etapas do processo de implantação da ISO e do MBAH, para cada instituição que os adotou. 
O Quadro XXIII: Etapas para Implementação da ISO 9000, por ordem de prioridades institucionais apresenta passos que retratam uma possível forma de condução do processo de implementação. A ordem como foram apresentados não caracteriza uma hierarquia, esta por sua vez envolve a prioridade da atividade a ser desenvolvida. Sendo assim, os hospitais tinham total liberdade para defini-la.

A ordem de prioridades institucionais mostra que há uma concordância entre praticamente todos os hospitais, na consideração de que a 'Conscientização da Alta Direção' e a 'Organização do Planejamento do Trabalho' são passos iniciais na implementação desta certificação. Enquanto que os demais itens sofrem flutuação e variabilidade na ordem de eleição, influenciados e determinados pela cultura de cada instituição.

No caso do Quadro XXIV: Etapas para Implementação do Mamual Brasileiro de Acreditação Hospitalar conforme prioridades institucionais vale ressaltar que das três instituições, hospitais A, E e G, que adotaram o método MBAH, apenas duas, os hospitais A e G, relacionaram as etapas através das quais realizaram este processo. E estas por sua vez não apresentaram semelhanças na ordem das respostas. Tal lógica é semelhante aos princípios do Quadro XXIII.

Em ambos os casos, Quadros XXIII e XXIV, não há nenhuma referência literária que indique uma forma específica na implantação dos processos. O que se encontra são referenciais teóricos e um instrumental, que pode ser adaptado à diferentes instituições e aplicado segundo suas características organizacionais e funcionais.

\subsection{ANÁLISE DOS DADOS QUALITATIVOS}

No que se refere às questões de natureza qualitativa foi empregado o instrumento de análise do Discurso do Sujeito Coletivo para cada pergunta formulada. Nele foram descritas as Idéias Centrais do discurso de cada entrevistado, bem como as Expressões-Chave que sustentavam suas idéias. Cabe ressaltar que alguns deles apresentaram mais de uma Idéia Central para uma mesma pergunta. 
Estão listadas, no instrumento de análise do discurso, todas as Idéias Centrais e todas as Expressões-Chave para cada pergunta formulada (Anexo D). No DSC executou-se a transformação, agregação e encadeamento das várias Idéias Centrais e Expressões-Chave, listadas em uma só Idéia Central e em uma só expressão apenas um único indivíduo estivesse falando, isto é, um único discursosíntese. Destaca-se aqui que para uma mesma pergunta foram encontradas, muitas vezes, vários discursos coletivos, devido a existência de várias representações expressas pelos pesquisados.

O Quadro XXV: Síntese das Questões, Idéias Centrais e Ancoragens, a seguir, anuncia de maneira genérica, as questões abertas contidas no Formulário de Pesquisa e respondidas pelos entrevistados. Encontram-se nele as Idéias Centrais e Ancoragens classificadas por letras e que foram construídas a partir das ExpressõesChave, contidas no discurso dos sujeitos entrevistados. 


\section{QUADRO XXV - SÍNTESE DAS QUESTÕES, IDÉIAS CENTRAIS E}

ANCORAGENS

\begin{tabular}{|c|c|}
\hline $\begin{array}{l}\text { Em sua concepção, Qualidade na Saúde é? } \\
\text { A- Qualidade são Processos. } \\
\text { B- Qualidade é interação humana. } \\
\text { C- Qualidade é um instrumento de poder. } \\
\text { Conceitue Acreditação e quais benefícios / } \\
\text { melhorias este sistema pode gerar para os } \\
\text { hospitais, tanto ao consideramos clientes internos / } \\
\text { externos. } \\
\text { A- Acreditação sedimenta e desenvolve Qualidade } \\
\text { B- Acreditação é um instrumento medidor. } \\
\text { C- Acreditação desenvolve modelo de gestão. } \\
\text { D- Acreditação avalia o hospital como um todo. } \\
\text { E- Acreditação é a receita para fazer coisas básicas. } \\
\text { Conceitue Certificação e quais benefícios/ } \\
\text { melhorias este sistema pode gerar para os } \\
\text { hospitais, tanto ao considerarmos os clientes } \\
\text { internos/externos. } \\
\text { A- Certificação padroniza e normaliza } \\
\text { inicialmente definidos pela organização? (Ficha, } \\
\text { Produtividade, Diminuição de Defeitos, } \\
\text { Diminuição de Reclamações, Indicadores) } \\
\text { A- Indicadores Institucionais (Globais) } \\
\text { B- Indicadores de Desempenho (Áreas) } \\
\text { Qual a importância de um hospital desenvolver } \\
\text { um sistema de Qualidade? } \\
\text { C- Certificação é atestado de Qualidade. } \\
\text { romo mãonsurados os resultados dos }\end{array}$ & $\begin{array}{l}\text { A- Melhora a interação entre as pessoas. } \\
\text { B- Cria cultura da Qualidade, melhorando as } \\
\text { condições de trabalho. } \\
\text { C- Desenvolver marketing favorável no mercado. } \\
\text { Destaque as principais dificuldades do processo de } \\
\text { implantação? } \\
\text { A- Profissionais tomam questões de trabalho pelo } \\
\quad \text { lado pessoal. } \\
\text { B- Reunir equipes multiprofissionais. } \\
\text { C- Resistência a cultura da Qualidade. } \\
\text { D- Dificuldade para compreensão das metodologias } \\
\quad \text { de Qualidade. } \\
\text { E- Estabelecer indicadores de Qualidade. } \\
\text { Destaque os principais pontos a serem } \\
\text { melhorados. } \\
\text { A- Relação interna. } \\
\text { B- Estabelecer metas e medir indicadores. } \\
\text { C- Uniformizar ações e métodos. } \\
\text { D- Definir identidade institucional. } \\
\text { F- Qualidade alavanca processos de melhorias. } \\
\text { G- Qualidade cria metas e mede indicadores. } \\
\text { reconhecido no mercado. } \\
\text { diferenciada } \\
\text { B - Qualidade é o equilíbrio da organização. } \\
\text { D - Qualidade é prevenir. } \\
\text { dimensão de custo. } \\
\text { E- Qualidade é manter a imagem da instituição e ser } \\
\text { Analidade é tratar o paciente de forma }\end{array}$ \\
\hline
\end{tabular}


A seguir serão apresentados os Quadros do Discurso do Sujeito Coletivo resultantes das Expressões Chave, surgidas a partir dos depoimentos.

Inicialmente, está colocado em cor azul a questão formulada para o entrevistado. Imediatamente abaixo, encontra-se o quadro que contém as idéias centrais identificadas nos discursos dos sujeitos da amostra. Em seguida o próximo quadro oferece para cada idéia central em destaque e classificada por letras (A,B,C, etc), as Expressões Chave que conduzem à organização do DSC, que ocupa o lado direito dos quadros e está grafado em vermelho.

Este processo de construção da análise do Discurso do Sujeito Coletivo e as Ancoragens, estão disponiveis no Anexo D. Os passos para montagem do DSC foram elaborados seguindo o preconizado na metodologia. Os desdobramentos da fala dos sujeitos foram sendo trabalhados até a identificação do discurso predominante. A leitura do Anexo D poderá facilitar a compreensão dos quadros expostos na sequência. 


\section{EM SUA CONCEPÇÃO, QUALIDADE NA SAÚDE É ?}

\begin{tabular}{|l|}
\hline \multicolumn{1}{|c|}{ IDÉIAS CENTRAIS } \\
\hline A- Qualidade são Processos. \\
\hline B - Qualidade é interação humana. \\
\hline C- Qualidade é um instrumento de poder \\
\hline
\end{tabular}

\section{A - QUALIDADE SÃO PROCESSOS}

\begin{tabular}{|c|c|}
\hline Expressões Chave & DSC \\
\hline $\begin{array}{l}\text { - Falar de Qualidade na área da Saúde é } \\
\text { muito difícil,(...) o cliente vêm contra sua } \\
\text { vontade. Qualidade são processos que } \\
\text { buscam cada vez mais organizar tudo o } \\
\text { que o cliente precisa. } \\
\text { - Não podemos pensar que uma empresa que } \\
\text { presta serviços em atendimento médico / } \\
\text { Hospitalar, que não tenha a cultura, } \\
\text { conceitos e ferramentas da } \\
\text { Qualidade em sua gestão (...) estamos } \\
\text { tratando de vidas e é necessário que } \\
\text { tenhamos processos bem definidos, mão de } \\
\text { obra qualificada e equipamentos que } \\
\text { garantam os serviços prestados. } \\
\text { É ser capaz de definir, atuar e provar que } \\
\text { os processos assistenciais e os resultados } \\
\text { clínicos são compatíveis com padrões } \\
\text { legais, evidências científicas e custo- } \\
\text { efetivas. }\end{array}$ & $\begin{array}{l}\text { Falar de Qualidade na área da Saúde é muito } \\
\text { dificil, pois o cliente vêm contra sua vontade. } \\
\text { Portanto, Qualidade é ser capaz de definir, } \\
\text { atuar e provar que os processos assistenciais e } \\
\text { os resultados clínicos são compatíveis com } \\
\text { padrões legais, evidências científicas e custo- } \\
\text { efetivas. } \\
\text { Qualidade são processos que buscam cada vez } \\
\text { mais organizar tudo o cliente precisa, através } \\
\text { de conceitos e ferramentas da Qualidade em } \\
\text { sua gestão, mão de obra qualificada e } \\
\text { equipamentos que garantam os serviços } \\
\text { prestados. }\end{array}$ \\
\hline
\end{tabular}




\section{B - QUALIDADE É INTERAÇÃO HUMANA}

\begin{tabular}{|c|c|}
\hline Expressões Chave & DSC \\
\hline 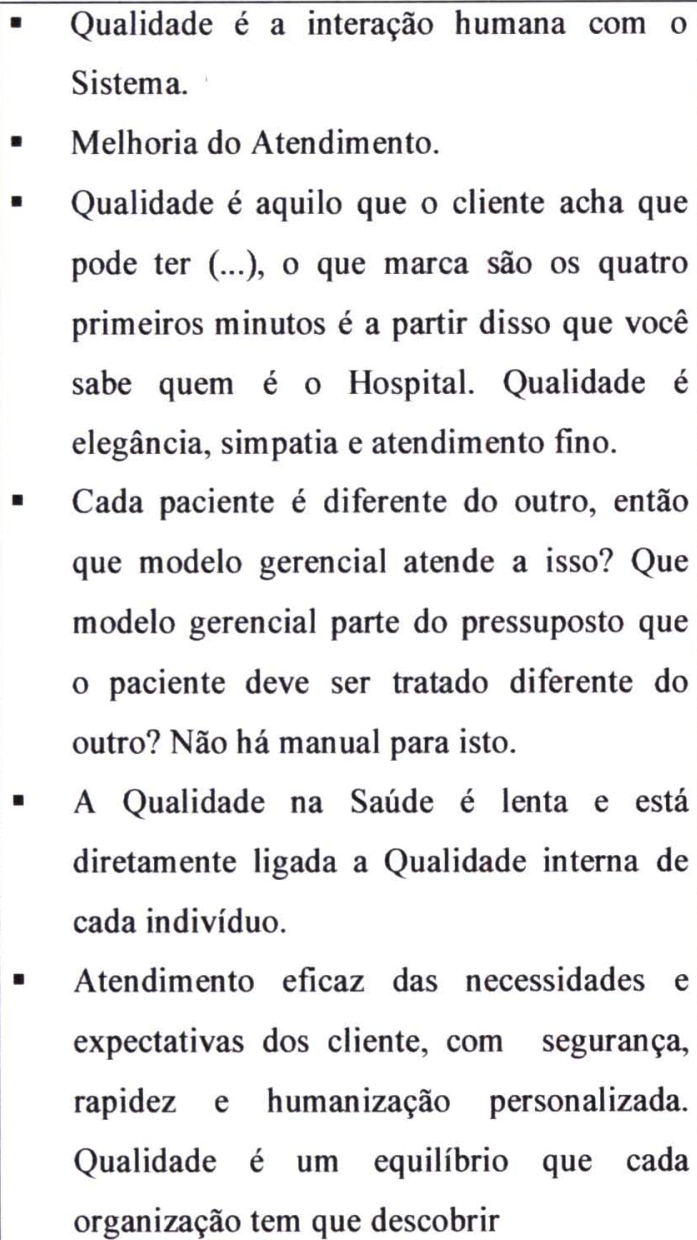 & $\begin{array}{l}\text { A Qualidade na Saúde é lenta e está } \\
\text { diretamente ligada a Qualidade interna de cada } \\
\text { indivíduo, por isso não há manual. } \\
\text { É a interação humana com o Sistema, um } \\
\text { equilíbrio que cada organização tem que } \\
\text { descobrir. } \\
\text { Atendimento eficaz das necessidades e } \\
\text { expectativas dos clientes, segurança, rapidez, } \\
\text { humanização personalizada, é aquilo que o } \\
\text { cliente acha que pode ter. } \\
\text { Qualidade é elegância, simpatia e atendimento } \\
\text { fino. }\end{array}$ \\
\hline
\end{tabular}




\section{C - QUALIDADE É UM INSTRUMENTO DE PODER}

\begin{tabular}{|l|l|}
\hline Expressões Chave & \multicolumn{1}{|c|}{ DSC } \\
\hline - Os médicos faziam os projetos das áreas, & Os médicos faziam os projetos das áreas, mas \\
mas queriam administrá-las também. Eles & queriam administrá-las também. Não davam \\
não davam autonomia para os profissionais & autonomia para os profissionais destas áreas e \\
destas áreas. Eles queriam controlar tudo, & queriam controlar tudo, inclusive as pessoas. \\
inclusive as pessoas. Os médicos não & Os médicos não entendem que melhorando o \\
entendem que melhorando o trabalho dos & trabalho dos outros profissionais aumenta a \\
outros profissionais aumenta a melhoria do & melhoria do seu próprio trabalho. A qualidade \\
trabalho deles. A qualidade passa a ser um & passa a ser um instrumento de poder. Apesar \\
instrumento de poder. Apesar de ter havido & de ter havido bons resultados no projeto da \\
bons resultados no projeto da Farmácia, a & Farmácia, a manutenção era dificil, pois os \\
manutenção dele era difícil, pois os & médicos agregaram um poder a mais. \\
médicos agregaram um poder a mais. & \\
\hline
\end{tabular}




\section{CONCEITUE ACREDITAÇÃO E QUAIS BENEFÍCIOS/MELHORIAS}

ESTE SISTEMA PODE GERAR PARA OS HOSPITAIS, TANTO AO

CONSIDERAMOS CLIENTES INTERNOS/EXTERNOS.

\begin{tabular}{|l|}
\hline \multicolumn{1}{|c|}{ IDÉIAS CENTRAIS } \\
\hline A- Acreditação sedimenta e desenvolve Qualidade \\
\hline B- Acreditação é um instrumento medidor. \\
\hline C- Acreditação desenvolve modelo de gestão. \\
\hline D- Acreditação avalia o hospital como um todo. \\
\hline E- Acreditação é a receita para fazer coisas básicas. \\
\hline
\end{tabular}

\section{A - ACREDITAÇÃO SEDIMENTA E DESENVOLVE QUALIDADE}

\begin{tabular}{|c|c|}
\hline Expressões Chave & DSC \\
\hline $\begin{array}{l}\text { - (...) a área da Qualidade se sedimentou } \\
\text { ainda mais. } \\
\text { - Vem para validar os esforços, consolida o } \\
\text { que se faz para a Qualidade. } \\
\text { - Atestado de Qualidade } \\
\text { Envolve aspectos relacionados ao } \\
\text { desenvolvimento da Qualidade em saúde, tais } \\
\text { como: o acesso e a garantia da continuidade do } \\
\text { atendimento; processos diagnósticos, } \\
\text { terapêuticos e de reabilitação; a segurança nos } \\
\text { procedimentos e atos médicos, o desempenho } \\
\text { dos recursos humanos e, ainda, as adequações } \\
\text { das instalações e equipamentos. }\end{array}$ & $\begin{array}{l}\text { Atestado de Qualidade que vem para validar } \\
\text { os esforços, consolidar e sedimentar o que se } \\
\text { faz para a Qualidade. } \\
\text { Envolve aspectos relacionados ao } \\
\text { desenvolvimento da Qualidade em saúde, tais } \\
\text { como: o acesso e a garantia da continuidade do } \\
\text { atendimento; processos diagnósticos, } \\
\text { terapêuticos e de reabilitação; a segurança nos } \\
\text { procedimentos e atos médicos, o desempenho } \\
\text { dos recursos humanos e, ainda, as adequações } \\
\text { das instalações e equipamentos. }\end{array}$ \\
\hline
\end{tabular}




\section{B - ACREDITAÇÃO É UM INSTRUMENTO MEDIDOR}

\begin{tabular}{|c|c|}
\hline ve & DSC \\
\hline $\begin{array}{l}\text { - São programas que visam avaliar os } \\
\text { diversos processos, legislações, normas, } \\
\text { etc... } \\
\text { - A Acreditação trabalha desde a estrutura } \\
\text { física, ampliou a CCIH, as precauções, a } \\
\text { área da Qualidade se sedimentou ainda } \\
\text { mais, complementando os métodos técnicos } \\
\text { de todas as áreas. Enquanto antes tinham } \\
\text { processos de rotina, hoje temos padrões } \\
\text { técnicos que padronizam, existem } \\
\text { indicadores de monitoramento, ação } \\
\text { preventiva que estabelecem indicadores } \\
\text { internos de avaliação. } \\
\text { Acreditação puxa para a melhor } \\
\text { sistemática. } \\
\text { Os beneficios decorrem de maior } \\
\text { profundidade dos padrões de Qualidade } \\
\text { para aquela área (Foco maior no processo } \\
\text { Técnico) } \\
\text { É um instrumento medidor do nível de } \\
\text { Qualidade, já existente em uma organização } \\
\text { hospitalar. }\end{array}$ & $\begin{array}{l}\text { É um instrumento medidor do nível de } \\
\text { Qualidade, já existente em uma organização } \\
\text { hospitalar. São programas que visam avaliar os } \\
\text { diversos processos, legislações, normas, etc... } \\
\text { Os benefícios decorrem de maior profundidade } \\
\text { dos padrões de Qualidade para aquela área, } \\
\text { puxando para melhor sistemática. } \\
\text { A Acreditação trabalha desde a estrutura física, } \\
\text { ampliou a CCIH, as precauções, a área da } \\
\text { Qualidade se sedimentou ainda mais, } \\
\text { complementando os métodos técnicos de todas } \\
\text { as áreas. Enquanto antes tinham processos de } \\
\text { rotina, hoje temos padrões técnicos que } \\
\text { padronizam, existem indicadores de } \\
\text { monitoramento, ação preventiva que } \\
\text { estabelecem indicadores internos de avaliação. }\end{array}$ \\
\hline
\end{tabular}




\section{C - ACREDITAÇÃO DESENVOLVE MODELO DE GESTÃo}

\begin{tabular}{|l|l|}
\hline Expressões Chave & \multicolumn{1}{|c|}{ DSC } \\
\hline - Os benefícios são quanto a ter um modelo & Os benefícios são quanto a ter um modelo de \\
de gestão, ter um controle dos requisitos & gestão, ter um controle dos requisitos exigidos \\
exigidos para o segmento, melhoria & para o segmento, melhoria contínua e e \\
contínua e principalmente melhoria no & principalmente melhoria no atendimento aos \\
atendimento aos pacientes e colaboradores. & pacientes e colaboradores \\
\hline
\end{tabular}

\section{D - ACREDITAÇÃO AVALIA O HOSPITAL COMO UM TODO}

\begin{tabular}{|c|c|}
\hline Expressões Chave & DSC \\
\hline $\begin{array}{l}\text { - A Acreditação visa aprimoramento } \\
\text { tecnológico e não de processo, tem que ser } \\
\text { sistema, ver o conjunto como um todo. } \\
\text { - A Acreditação avalia o hospital como um } \\
\text { todo, é global, usa termos mais adequados } \\
\text { às áreas, pois o hospital não pode ser } \\
\text { avaliado separadamente, os resultados da } \\
\text { Acreditação são palpáveis }\end{array}$ & $\begin{array}{l}\text { A Acreditação avalia o hospital como um todo, } \\
\text { é global, usa termos mais adequados às áreas, } \\
\text { pois o hospital não pode ser avaliado } \\
\text { separadamente, os resultados da Acreditação } \\
\text { são palpáveis. Visa o aprimoramento } \\
\text { tecnológico e não de processo. }\end{array}$ \\
\hline
\end{tabular}

\section{E - ACREDITAÇÃO É A RECEITA PARA FAZER COISAS BÁSICAS}

\begin{tabular}{|c|c|}
\hline Expressões Chave & DSC \\
\hline $\begin{array}{l}\text { - É a receita para fazer as coisas básicas, } \\
\text { alinhando para superar as dificuldades do } \\
\text { mínimo. } \\
\text { - Ela muito simplista. }\end{array}$ & $\begin{array}{l}\text { E muito simplista. } \dot{E} \text { a receita para fazer as } \\
\text { coisas básicas, alinhando para superar as } \\
\text { dificuldades do mínimo. }\end{array}$ \\
\hline
\end{tabular}


CONCEITUE CERTIFICAÇÃO E QUAIS BENEFÍCIOS/MELHORIA

ESTE SISTEMA PODE GERAR PARA OS HOSPITAIS, TANTO AO

CONSIDERARMOS OS CLIENTES INTERNOS/EXTERNOS

\begin{tabular}{|l|}
\hline \multicolumn{1}{|c|}{ IDÉIAS CENTRAIS } \\
\hline A- Certificação padroniza e normaliza procedimentos. \\
\hline B- Certificação gera confiança, credibilidade e reconhecimento. \\
\hline C- Certificação é atestado de Qualidade. \\
\hline
\end{tabular}

\section{A - CERTIFICAÇÃO PADRONIZA E NORMALIZA PROCEDIMENTOS}

\begin{tabular}{|l|l|}
\hline \multicolumn{1}{|c|}{ Expressões Chave } & \multicolumn{1}{|c|}{ DSC } \\
\hline - A norma é muito técnica, foi um aprender & São normas que visam certificar o sistema de \\
juntos, houve dificuldade com a equipe & Qualidade de uma empresa, através da \\
médica, e resistência dos funcionários e & padronização de processos e avaliações \\
gerencia. & sistêmicas, trazendo resultado nos controles \\
São normas que visam certificar o sistema & quanto a gestão de equipamentos, processos e \\
de Qualidade de uma empresa, através da & etc. \\
padronização de processos e avaliações & A norma é muito técnica, foi um aprender \\
sistêmicas, trazendo resultado nos controles & juntos, houve dificuldade com a equipe médica, \\
quanto a gestão de equipamentos, processos & e resistência dos funcionários e gerencia. \\
e etc. & Por outro lado, são extremamente burocráticas, \\
São extremamente burocráticas, desfoca do & desfoca do que precisa ter cuidado com \\
que precisa ter cuidado com Qualidade para \\
focar papel,
\end{tabular}




\section{B - CERTIFICAÇÃO GERA CONFIANÇA, CREDIBILIDADE E RECONHECIMENTO}

\begin{tabular}{|l|l|l|}
\hline \multicolumn{2}{|c|}{ Expressões Chave } & \multicolumn{1}{|c|}{ DSC } \\
\hline - Para o segmento hospitalar (...) traz & A certificação para o segmento hospitalar, traz \\
credibilidade junto a comunidade, sem & credibilidade e confiança do cliente para a \\
$\begin{array}{l}\text { desconsiderar o marketing institucional. } \\
\text { A certificação gera confiança e }\end{array}$ & $\begin{array}{l}\text { organização e junto a comunidade, sem } \\
\text { desconsiderar o marketing institucional., }\end{array}$ \\
$\begin{array}{l}\text { credibilidade do cliente para a organização, } \\
\text { gerando um aumento de clientes em busca } \\
\text { dos serviços nela prestados. }\end{array}$ & gerando um aumento de clientes em busca dos \\
serviços nela prestados.
\end{tabular}

\section{C-CERTIFICAÇÃo É ATESTADO DE QUALIDADE}

\begin{tabular}{|c|c|}
\hline Expressões Chave & DSC \\
\hline $\begin{array}{l}\text { - Atestado de Qualidade genérico, mais } \\
\text { voltado para gestão de Qualidade, menos } \\
\text { com a qualidade técnica. } \\
\text { - Selo de Qualidade }\end{array}$ & $\begin{array}{l}\text { É um Selo de Qualidade, atestado genérico, } \\
\text { mais voltado para gestão de Qualidade, menos } \\
\text { com a qualidade técnica. }\end{array}$ \\
\hline
\end{tabular}


COMO SÃO MENSURADOS OS RESULTADOS DOS PROGRAMAS DE QUALIDADE EM RELAÇÃO AOS OBJETIVOS INICIALMENTE DEFINIDOS PELA ORGANIZAÇÃO ? (FICHA, PRODUTIVIDADE, DIMINUIÇÃO DE DEFEITOS, DIMINUIÇÃO DE RECLAMAÇÕES, INDICADORES)

\begin{tabular}{|l|}
\hline \multicolumn{1}{|c|}{ IDÉIAS CENTRAIS } \\
\hline A- Indicadores Institucionais (Globais) \\
\hline B- Indicadores de Desempenho (Áreas) \\
\hline
\end{tabular}

\section{A - INDICADORES INSTITUCIONAIS (GLOBAIS)}

\begin{tabular}{|c|c|}
\hline Expressões Chave & DSC \\
\hline 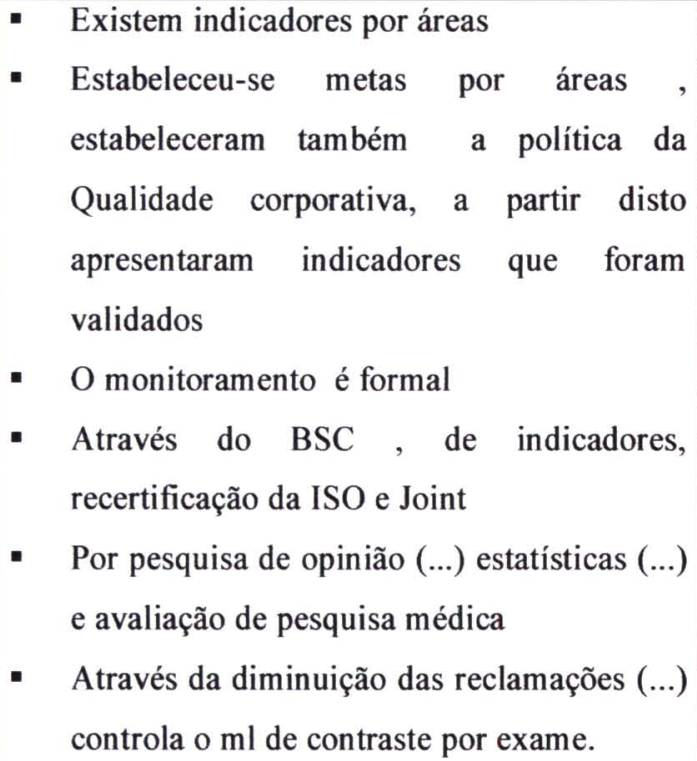 & $\begin{array}{l}\text { Estabeleceu-se metas e indicadores por áreas, } \\
\text { estabeleceram também a política da Qualidade } \\
\text { corporativa, a partir disto apresentaram } \\
\text { indicadores que foram validados. } \\
\text { Por pesquisa de opinião estatísticas e } \\
\text { avaliação de pesquisa médica Através da } \\
\text { diminuição das reclamações controla o ml de } \\
\text { contraste por exame. } \\
\text { O monitoramento de indicadores é formal. } \\
\text { Indicadores Institucionais são avaliados através } \\
\text { de BSC, recertificação da ISO e Joint, }\end{array}$ \\
\hline
\end{tabular}




\section{B - INDICADORES DE DESEMPENHO (ÁREAS)}

\begin{tabular}{|c|c|}
\hline Expressões Chave & DSC \\
\hline $\begin{array}{l}\text { - Indicadores de desempenho e Institucional, } \\
\text { Pesquisa de satisfação de clientes, controle } \\
\text { e tratamento de não conformidades, análise } \\
\text { crítica mensal por área, Auditorias Internas. } \\
\text { Indicadores de infecção hospitalar em } \\
\text { várias áreas. } \\
\text { Reuniões periódicas com análise de casos } \\
\text { práticos(...), Indicadores de satisfação do } \\
\text { cliente. (...) indicadores de complexidade } \\
\text { cirúrgica, (...) Índice de clima } \\
\text { organizacional, relatórios de Client Care, } \\
\text { etc... }\end{array}$ & $\begin{array}{l}\text { Indicadores de desempenho e Institucional, são } \\
\text { mensurados por: controle e tratamento de não } \\
\text { conformidades, análise crítica mensal por área, } \\
\text { Auditorias Internas. Indicadores de infecção } \\
\text { hospitalar em várias áreas. } \\
\text { Reuniões periódicas com análise de casos } \\
\text { práticos, Indicadores de satisfação do cliente. } \\
\text { Indicadores de complexidade cirúrgica, Índice } \\
\text { de clima organizacional, relatórios de Client } \\
\text { Care, etc... }\end{array}$ \\
\hline
\end{tabular}




\section{QUAL É A IMPORTÂNCIA DE UM HOSPITAL DESENVOLVER UM SISTEMA DE QUALIDADE?}

\section{IDÉIAS CENTRAIS}

A- Melhora a interação entre as pessoas.

B- Cria cultura da Qualidade, melhorando as condições de trabalho. C- Desenvolver marketing favorável no mercado.

\section{A - MELHORA A INTERAÇÃO ENTRE AS PESOAS}

\begin{tabular}{|c|c|}
\hline Expressões Chave & DSC \\
\hline $\begin{array}{l}\text { - A interação } \\
\text {.... Faz buscar continuamente a melhoria de } \\
\text { seu desempenho e adotar políticas, normas } \\
\text { e padrões metodológicos, visando a } \\
\text { interação das equipes multiprofissionais } \\
\text { existentes na Instituição }\end{array}$ & $\begin{array}{l}\text { Faz buscar continuamente a melhoria de seu } \\
\text { desempenho e adotar politicas, normas e } \\
\text { padrões metodológicos, visando a interação das } \\
\text { equipes multiprofissionais existentes na } \\
\text { Instituição. }\end{array}$ \\
\hline
\end{tabular}




\section{B - CRIA A CULTURA DA QUALIDADE, MELHORANDO AS CONDIÇÕES DE TRABALHO}

\begin{tabular}{|c|c|}
\hline Expressões Chave & DSC \\
\hline $\begin{array}{l}\text { - ..É criar mecanismos para atingir metas e } \\
\text { objetivos } \\
\text { - A definição de padrões de desempenho, } \\
\text { criar a cultura da Qualidade, melhorar as } \\
\text { condições globais para a excelência do } \\
\text { atendimento, dar garantias de condições de } \\
\text { trabalho aos médicos, ter credibilidade } \\
\text { junto aos clientes, médicos e comunidade, } \\
\text { investimento em equipamentos e } \\
\text { qualificação de mão de obra. } \\
\text { Um programa de qualidade alavanca para } \\
\text { um processo de melhoria } \\
\text { O sistema da qualidade faz com que o } \\
\text { hospital fique atento aos principais desejos } \\
\text { e anseios de seus clientes internos e } \\
\text { externos. Faz buscar continuadamente a } \\
\text { melhoria de seu desempenho e adotar } \\
\text { políticas, normas e padrões metodológicos, } \\
\text { visando a interação das equipes } \\
\text { multiprofissionais existentes na instituição } \\
\text { minimizando os defeitos da operação, além } \\
\text { da atenção aos custos operacionais. }\end{array}$ & $\begin{array}{l}\text { O sistema da qualidade faz com que o hospital } \\
\text { fique atento aos principais desejos e anseios de } \\
\text { seus clientes internos e externos. Faz buscar } \\
\text { continuadamente a melhoria de seu } \\
\text { desempenho e adotar políticas, normas e } \\
\text { padrões metodológicos, visando a interação das } \\
\text { equipes multiprofissionais existentes na } \\
\text { instituição minimizando os defeitos da } \\
\text { operação, além da atenção aos custos } \\
\text { operacionais. Cria mecanismos para atingir } \\
\text { metas e objetivos, valoriza a cultura da } \\
\text { Qualidade, melhora as condições globais para } \\
\text { excelência do atendimento, dá garantias de } \\
\text { condições de trabalho aos médicos, } \\
\text { credibilidade junto aos clientes, médicos e } \\
\text { comunidade, investindo em equipamentos e } \\
\text { qualificação de mão de obra }\end{array}$ \\
\hline
\end{tabular}

\section{C - DESENVOLVER MARKETING FAVORÁVEL NO MERCADO}

\begin{tabular}{|l|l|}
\hline \multicolumn{1}{|c|}{ Expressões Chave } & \multicolumn{1}{c|}{ DSC } \\
\hline - Ser capaz de provar que é bom. & É importante manter a imagem do hospital. É \\
$\begin{array}{l}\text { É importante manter a imagem do hospital. } \\
\text { mercado... }\end{array}$ & pensar que você será reconhecido no mercado e \\
\hline
\end{tabular}


DESTAQUE AS PRINCIPAIS DIFICULDADES DO PROCESSO DE IMPLANTAÇÃO ?

\begin{tabular}{|l|}
\hline \multicolumn{1}{|c|}{ IDÉIAS CENTRAIS } \\
\hline A- Profissionais tomam questões de trabalho pelo lado pessoal. \\
\hline B- Reunir equipes multiprofissionais. \\
\hline C- Resistência a cultura da Qualidade. \\
\hline D- Dificuldade para compreensão das metodologias de Qualidade. \\
\hline E- Estabelecer indicadores de Qualidade. \\
\hline
\end{tabular}

\section{A - PROFISSIONAIS TOMAM QUESTÕES DE TRABALHO PELO LADO PESSOAL}

\begin{tabular}{|l|l|}
\hline \multicolumn{1}{|c|}{ Expressões Chave } & \multicolumn{1}{|c|}{ DSC } \\
\hline ...O envolvimento das pessoas é algo que & $\mathrm{O}$ envolvimento das pessoas é algo que \\
dificulta, trabalhar as não conformidade na & dificulta, trabalhar as não conformidade na \\
integra (...) e o funcionário leva para o lado \\
pessoal.
\end{tabular}

\section{B- REUNIR EQUIPES MULTIPROFISSIONAIS}

\begin{tabular}{|l|l|}
\hline \multicolumn{1}{|c|}{ Expressões Chave } & \multicolumn{1}{c|}{ DSC } \\
\hline - $\begin{array}{l}\text { Conseguir reunir as equipes } \\
\text { multiprofissionais para um trabalho } \\
\text { adequado }\end{array}$ & Conseguir reunir as equipes multiprofissionais \\
para um trabalho adequado
\end{tabular}




\section{C - RESISTENCIA A CULTURA DA QUALIDADE}

\begin{tabular}{|c|c|}
\hline Expressões Chave & DSC \\
\hline 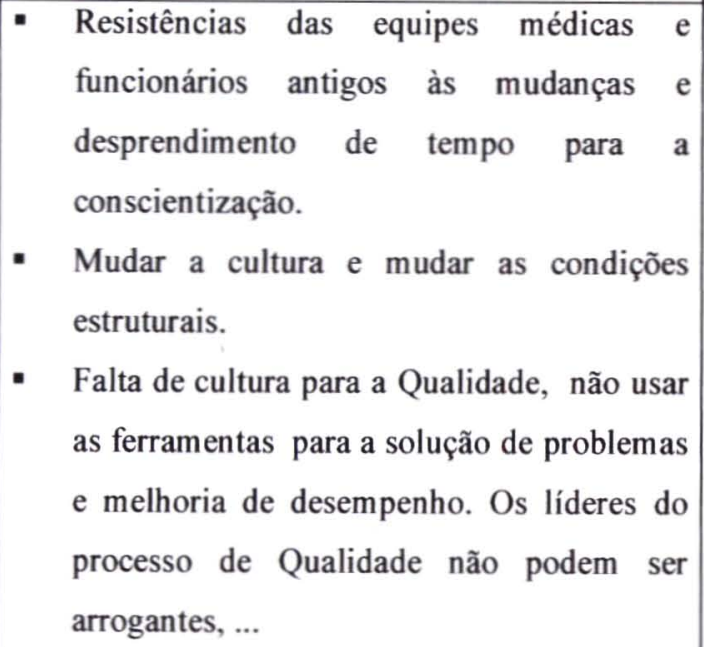 & $\begin{array}{l}\text { Mudar a cultura e mudar as condições } \\
\text { estruturais, causa resistências às mudanças das } \\
\text { equipes médicas e funcionários antigos. Há } \\
\text { também resistência ao desprendimento de } \\
\text { tempo para a conscientização; pela falta de } \\
\text { cultura para a Qualidade e, por não usar as } \\
\text { ferramentas para a solução de problemas, bem } \\
\text { como para melhoria de desempenho. } \\
\text { Para tanto os lideres do processo de Qualidade } \\
\text { não podem ser arrogantes. }\end{array}$ \\
\hline
\end{tabular}

D - DIFICULDADE PARA A COMPREENSÃO DAS METODOLOGIAS DE QUALIDADE

\begin{tabular}{|c|c|}
\hline Expressões Chave & DSC \\
\hline $\begin{array}{l}\text { - Na ISO a dificuldade foi a compreensão e } \\
\text { adaptação de linguagem e na Joint, } \\
\text { prontuário e corpo clínico. }\end{array}$ & $\begin{array}{l}\text { Na ISO a dificuldade foi a compreensão e } \\
\text { adaptação de linguagem e na Joint, prontuário e } \\
\text { corpo clínico. }\end{array}$ \\
\hline
\end{tabular}

\section{E - ESTABELECER INDICADORES DE QUALIDADE}

\begin{tabular}{|c|c|}
\hline Expressões Chave & DSC \\
\hline $\begin{array}{l}\text { - ... e acho também que uma dificuldade é ter } \\
\text { um indicador de Qualidade }\end{array}$ & $\begin{array}{l}\text { Uma das dificuldades é ter um indicador de } \\
\text { Qualidade. }\end{array}$ \\
\hline
\end{tabular}


DESTAQUE OS PRINCIPAIS PONTOS A SEREM MELHORADOS

\begin{tabular}{|l|}
\hline \multicolumn{1}{|c|}{ IDÉIAS CENTRAIS } \\
\hline A- Relação interna. \\
\hline B- Estabelecer metas e medir indicadores. \\
\hline C- Uniformizar ações e métodos. \\
\hline D- Definir identidade institucional. \\
\hline
\end{tabular}

\section{A - RELAÇÃO INTERNA}

\begin{tabular}{|c|c|}
\hline Expressões Chave & DSC \\
\hline $\begin{array}{l}\text { - Relação interna (...) e habilidade para } \\
\text { liderar } \\
\text { - A comunicação interna, o envolvimento dos } \\
\text { novos colaboradores e médicos das equipes } \\
\text { terceirizadas. } \\
\text { - (...) integração entre as áreas (...) } \\
\text { - Consciência das pessoas em relação à } \\
\text { Qualidade. }\end{array}$ & $\begin{array}{l}\text { A relação e comunicação interna, diz respeito a } \\
\text { integração entre as áreas, ao envolvimento dos } \\
\text { novos colaboradores e médicos das equipes } \\
\text { terceirizadas. } \\
\text { Ter mais recursos para treinar o pessoal, } \\
\text { habilidade para liderar e consciência das } \\
\text { pessoas em relação à Qualidade. }\end{array}$ \\
\hline
\end{tabular}




\section{B - ESTABELECER METAS E MEDIR INDICADORES}

\begin{tabular}{|c|c|}
\hline Expressões Chave & DSC \\
\hline $\begin{array}{l}\text { - ...Estabelecer indicadores internos, ações } \\
\text { preventivas incorporadas ao processo } \\
\text { - Criar metas e medir indicadores. } \\
\text { - Definir um norte para a organização, para a } \\
\text { obtenção de sinergia dos recursos e pessoas } \\
\text { que trabalham na instituição }\end{array}$ & $\begin{array}{l}\text { Definir um norte para a organização, para a } \\
\text { obtenção de sinergia dos recursos e pessoas que } \\
\text { trabalham na instituição. } \\
\text { Criar metas, medir, estabelecer indicadores e } \\
\text { ações preventivas incorporadas ao processo }\end{array}$ \\
\hline
\end{tabular}

\section{C - UNIFORMIZAR AÇÕES E MÉTODOS}

\begin{tabular}{|c|c|}
\hline Expressões Chave & DSC \\
\hline - $\quad$... a uniformização de ações e métodos & A uniformização de ações e métodos. \\
\hline
\end{tabular}

\section{D - DEFINIR IDENTIDADE INSTITUCIONAL}

\begin{tabular}{|l|l|}
\hline \multicolumn{1}{|c|}{ Expressões Chave } & \multicolumn{1}{c|}{ DSC } \\
\hline - $\quad$...e a identidade do hospital & A identidade do hospital. \\
\hline
\end{tabular}




\section{QUADROS DAS ANCORAGENS}

\begin{tabular}{|c|}
\hline $\begin{array}{c}\text { IDÉIAS CENTRAIS } \\
\text { OUALIDADF F́ TRATAR OPAIF NTF DF FORMA DIFFRFNCIUDA }\end{array}$ \\
\hline B - QUALIDADE É O EQUILÍBRIO DA ORGANIZAC̃̃O. \\
\hline C-QUALIDADE É PREVENIR. \\
\hline $\begin{array}{l}\text { D - QUALIDADE DEVE SER AVALIADA TANTO QUANTO A DIMENSÃO } \\
\text { DE CUSTO. }\end{array}$ \\
\hline $\begin{array}{l}\text { E - QUALIDADE É MANTER A IMAGEM DA INSTITUIÇÃO E SER } \\
\text { RECONHECIDO NO MERCADO. }\end{array}$ \\
\hline F - QUALIDADE ALAVANCA PROCESSOS DE MELHORIAS. \\
\hline G - QUALIDADE CRIA METAS E MEDE INDICADORES. \\
\hline
\end{tabular}

\section{A - QUALIDADE É TRATAR O PACIENTE DE FORMA DIFERENCIADA}

\begin{tabular}{|c|c|}
\hline Expressões Chave & DSC \\
\hline $\begin{array}{l}\text { - O hospital não pode ter um modelo } \\
\text { industrial, neste modelo as peças não } \\
\text { podem ter defeitos, elas devem ser todas } \\
\text { iguais. Mas cada pessoa é diferente da outra } \\
\text { e não se pode transformá-las em iguais. } \\
\text { - O Sistema de Qualidade faz com que o } \\
\text { hospital fique atento aos principais desejos } \\
\text { e anseios de seus clientes internos e } \\
\text { externos. }\end{array}$ & $\begin{array}{l}\text { O hospital não pode ter um modelo industrial, } \\
\text { neste modelo as peças não podem ter defeitos, } \\
\text { elas devem ser todas iguais. Mas cada pessoa é } \\
\text { diferente da outra e não se pode transformá-las } \\
\text { em iguais. } \\
\text { O Sistema de Qualidade faz com que o hospital } \\
\text { fique atento aos principais desejos e anseios de } \\
\text { seus clientes internos e externos. }\end{array}$ \\
\hline
\end{tabular}

\section{B - QUALIDADE É O EQUILÍBRIO DA ORGANIZAÇÃO}

\begin{tabular}{|l|l|l|l|}
\hline \multicolumn{2}{|c|}{ Expressões Chave } & \multicolumn{2}{|c|}{ DSC } \\
\hline $\begin{array}{l}\text { Qualidade é um equilíbrio que cada } \\
\text { organização tem que descobrir }\end{array}$ & $\begin{array}{l}\text { Qualidade é um equilíbrio que cada } \\
\text { organização tem que descobrir }\end{array}$ \\
\hline
\end{tabular}




\section{C - QUALIDADE É PREVENIR}

\begin{tabular}{|l|l|}
\hline \multicolumn{1}{|c|}{ Expressões Chave } & \multicolumn{1}{c|}{ DSC } \\
\hline $\begin{array}{l}\text { A área da Qualidade irá cobrar para saber } \\
\text { se houve ação preventiva. }\end{array}$ & $\begin{array}{l}\text { A área da Qualidade irá cobrar para saber se } \\
\text { houve ação preventiva. }\end{array}$ \\
\hline
\end{tabular}

\section{D - QUALIDADE DEVE SER AVALIADA TANTO QUANTO A DIMENSÃO DE CUSTO}

\begin{tabular}{|c|c|}
\hline Expressões Chave & DSC \\
\hline $\begin{array}{l}\text { - Desenvolver no mercado a percepção de } \\
\text { que boa Qualidade deve ser fator de } \\
\text { avaliação tão importante quanto a dimensão } \\
\text { de custos. }\end{array}$ & $\begin{array}{l}\text { Desenvolver no mercado a percepção de que } \\
\text { boa Qualidade deve ser fator de avaliação tão } \\
\text { importante quanto a dimensão de custos. }\end{array}$ \\
\hline
\end{tabular}

\section{E - QUALIDADE É MANTER A IMAGEM DA INSTITUIÇÃO E SER RECONHECIDO NO MERCADO}

\begin{tabular}{|l|l|}
\hline \multicolumn{1}{|c|}{ Expressões Chave } & \multicolumn{1}{c|}{ DSC } \\
\hline - É importante manter a imagem do hospital. & É importante manter a imagem do hospital. É \\
$\begin{array}{l}\text { É pensar que você será reconhecido no no } \\
\text { mercado, é marketing próprio. }\end{array}$ & pensar que você será reconhecido no mercado, \\
& é marketing próprio. \\
\hline
\end{tabular}

\section{F-QUALIDADE ALAVANCA PROCESSOS DE MELHORIAS}

\begin{tabular}{|c|c|}
\hline Expressões Chave & DSC \\
\hline $\begin{array}{l}\text { - Um programa de Qualidade alavanca para } \\
\text { um processo de melhorias. }\end{array}$ & $\begin{array}{l}\text { Um programa de Qualidade alavanca para um } \\
\text { processo de melhorias. }\end{array}$ \\
\hline
\end{tabular}

\section{G - QUALIDADE CRIA METAS E MEDE INDICADORES}

\begin{tabular}{|l|l|}
\hline \multicolumn{1}{|c|}{ Expressões Chave } & \multicolumn{1}{c|}{ DSC } \\
\hline - $\quad$ Estabelecer indicadores internos. & Criar metas, estabelecer e medir incadores. \\
\hline
\end{tabular}


A expansão dos estudos focados na área da Qualidade, em Instituições Hospitalares, nos provoca inquietação, no sentido de melhor entender como o tema vem sendo trabalhado neste universo.

Mapear como a Qualidade vem sendo praticada, com que instrumentos, identificar como os profissionais da saúde a compreendem e propor caminhos, constituiu o desafio desta pesquisa.

O estudo, permitiu a constatação da existência de ações de Qualidade sistemáticas, coordenadas por profissionais específicos, ligados diretamente com a alta direção.

A literatura evidencia a existência de instituições que já vem desenvolvendo ações voltadas à melhoria da Qualidade, em artigos publicados por, PITA (1992) e INOJOSA FARRAN (1994) citados por AKERMAN (1996). Aponta também, diversos significados para o conceito de Qualidade, onde cada autor conceitua, apresenta propostas e diferentes ferramentas.

Nas Idéias Centrais relativas a pergunta “Qualidade na Saúde é?”, encontramse três conceitos a destacar:

- Qualidade são processos;

- Qualidade é interação humana;

- Qualidade é um instrumento de poder.

Esses conceitos de Qualidade demonstram os diferentes olhares existentes no tocante à Qualidade na saúde. Os sujeitos da pesquisa, ao abordarem Qualidade como processo, concluem que "Qualidade é ser capaz de definir, atuar e provar que os processos assistenciais e os resultados clínicos são compatíveis com padrões legais, evidências científicas e custos efetivos".

Segundo MALIK "Outro mandamento da Qualidade, advém da percepção de que a experiência passada só é útil se transformada em dados" (1996a, p.22). 
Os argumentos presentes no DSC expressam que "Qualidade são processos que buscam cada vez mais organizar tudo o que o cliente precisa, através de conceitos e ferramentas da Qualidade em sua gestão, mão de obra qualificada e equipamentos que garantam os serviços prestados", o que vem ao encontro às idéias de BERWICK e col., que afirmam que "processos imprevisíveis não levam a uma Qualidade consistente e excelente. Controlar a Qualidade significa, em parte gerir os processos de forma que eles tornem-se previsíveis" (1994, p.40).

A área da saúde no Brasil vem buscando se desenvolver nestes aspectos, apesar disso, os resultados ainda são incipientes e muitos dos problemas encontrados decorrem da falta de sistematização e padrões no trabalho.

A imprevisibilidade dificulta avaliar o desempenho de um processo e a comparação deste com as novas situações alternativas que venham ser colocadas. No gerenciamento da Qualidade é necessário verificar os elementos componentes mais importantes do processo a ser avaliado para que haja o entendimento da variação que poderá ocorrer entre um processo e outro. É uma condição prévia necessária para o conhecimento sobre o desempenho.

TACHIZAWA e SCAICO afirmam que "(....) sem padronização não existe gestão de processos, tarefas ou atividades, pode-se ressaltar a importância da padronização para: estabelecer claramente responsabilidade e autoridade; estabilizar os processos; construir base para a melhoria contínua e, portanto, aumentar a produtividade; assegurar a qualidade; acumular o conhecimento tecnológico da empresa" (1997, p.95).

Na Idéia Central "Qualidade como interação humana" há valorização do "atendimento eficaz das necessidades e expectativas dos clientes, segurança, rapidez, humanização personalizada, é aquilo que o cliente acha que pode ter (....) é interação humana com o sistema, um equilíbrio que cada organização tem que descobrir". Conforme apontado pelos entrevistados. 
Segundo SACRAMENTO, "Buscar adequado nível de excelência, como saída final de um sistema que envolve a aplicação de princípios organizacionais sobre os processos e procedimentos, que transformam os recursos humanos, materiais e financeiros, na busca da prestação de um bom serviço de atendimento ao paciente, implica necessariamente na adoção de um processo de melhoria, associado ao desenvolvimento de programas de educação continuada, direcionado aos participantes das instituições de saúde, independentemente de seu nível hierárquico e técnico" (2001, p.140).

Estabelece-se assim um ciclo de excelência que, continuadamente, deve ser revisto e aprimorado, onde a participação das pessoas é de fundamental importância e a partir do qual cria-se um arcabouço gerencial eficiente, eficaz e efetivo.

Qualidade enquanto produto de trabalho de pessoas significa entendêla e conhecer sua interação com a organização, considerando sua percepção e a representação do trabalho para estes atores sociais.

O indivíduo, ao lado da organização, poderá realizar seus objetivos e enfrentar novos desafios.

A percepção do trabalhador a respeito dos fenômenos organizacionais contribui para seu desenvolvimento. Clareia sua visão sobre o trabalho abrindo questões que devem e precisam ser discutidas neste âmbito.

Tal como os indivíduos a organização também é dinâmica e passível de modificação pelo aprendizado adquirido.

A cultura das organizações retrata o conjunto de seus valores e crenças, que na interação com seus colaboradores, se transforma pelo conhecimento técnico e pelo comportamento.

MALIK (1992), TOLOVI Jr. (1994), WOOD Jr. e URDAN (1994), citados por AKERMAN, são unânimes em afirmar que "qualquer proposta de gestão de qualidade que não contemple em sua estratégia alterações na cultura organizacional tem grandes chances de falhar" $(1996, \mathrm{p} .85)$. 
Assim como falado no DSC “A Qualidade na Saúde é lenta e está diretamente ligada a Qualidade interna de cada indivíduo (....)".

MALIK afirma que "É necessário que as pessoas percebam que sempre há algo que elas ainda não sabem e podem aprender" (1996a, p.20).

Um componente fundamental para isso é a disponibilidade mental para o assunto. Quando os indivíduos buscam esclarecer e aprofundar sua visão pessoal, e ver a realidade objetivamente, desenvolvem competências para lidar com situações em diferentes aspectos da vida. Para tanto, é necessário disposição interna para confrontar pressupostos profundamente arraigados, que influenciam na forma de ver o mundo.

A relação do homem com o trabalho esta mediada pela consciência, identidade e emoções. Se tais aspectos não puderem ser refletidos na relação com o trabalho, o indivíduo não o estará transformando. Por tratar-se de um movimento individual, envolvendo a dinâmica de viver e estar no mundo, a tomada deste processo com suas próprias mãos, exige um redirecionamento existencial, por vezes lento, que refletirá nos demais papéis de sua vida, especialmente no trabalho.

Abordando a Idéia Central da Qualidade como instrumento de poder, evidencia-se o controle, o cerceamento dos colaboradores das áreas e as pessoas que interagem com os profissionais da Qualidade.

Segundo BERWICK e col., "o desafio de administrar a Qualidade não é o desafio do controle, mas da capacitação. As falhas da Qualidade geralmente não vem dos trabalhadores, mas dos sistemas em que estes trabalhadores são colocados pelos gerentes. Muitas vezes, os profissionais que detêm este poder, utilizam-se de elementos como culpa, punição e extorsão para obtenção de melhor Qualidade" (1994, p.61). 
Segundo DEJOURS, o medo e a ansiedade são os meios pelos quais se consegue fazer respeitar os preceitos hierárquicos. $\mathrm{O}$ eixo central da violência do poder, imputa medo e ansiedade no trabalhador, gerando um estado permanente sobre o indivíduo, de poder ser controlado. Esta disciplina é eficaz e traz os resultados esperados. $\mathrm{O}$ fato de poder ser controlado a qualquer momento é a forma como o controle é exercido, fazendo o indivíduo ficar sempre de prontidão. Trata-se da construção artificial de um autocontrole, Pois ter medo de ser vigiado é vigiar-se a si mesmo $(1987$, p.102).

Uma vez abordados os conceitos de Qualidade em seus diferentes aspectos, passa-se a discutir Acreditação e seus benefícios para os hospitais da amostra, considerando os clientes internos e externos. As Idéias Centrais presentes neste tópico, que revelam os principais aspectos envolvidos no tema são:

- Acreditação sedimenta e desenvolve Qualidade;

- Acreditação é um instrumento medidor;

- Acreditação desenvolve modelo de gestão;

- Acreditação avalia o hospital como um todo;

- Acreditação é a receita para fazer coisas básicas.

$\mathrm{Na}$ forma referida no DSC encontra-se que Acreditação é "atestado de Qualidade que vem para validar os esforços consolidados e sedimentar o que se faz para a Qualidade".

As organizações de saúde parecem ter maior grau de adesão aos Programas de Qualidade quando estes estabelecem ações sistematizadas e dirigidas.

Os esforços para implantação de Qualidade são melhor aceitos, quando orientados por metodologia clara que conduz a força de trabalho para objetivos comuns, compreendidos por todos. 
Para os pesquisados, Acreditação "envolve aspectos relacionados ao desenvolvimento da Qualidade em saúde, tais como: o acesso e a garantia da continuidade do atendimento; processos diagnósticos, terapêuticos e de reabilitação; a segurança nos procedimentos e atos médicos, o desempenho dos recursos humanos e, ainda, as adequações das instalações e equipamentos."

A Acreditação pressupõe avaliação do hospital como um todo, sistemática e encadeada, onde a inter-relação entre as áreas ocorre como um compromisșo essencial da metodologia.

A avaliação estabelece padrões de referência desejáveis e instrumentos que constatarão se estes padrões estão presentes na Instituição.

O entendimento encontrado no Discurso do Sujeito Coletivo dos pesquisados remete à identificação de semelhança e coerência com a teoria da Acreditação.

Para eles, Acreditação como instrumento medidor "trabalha desde a estrutura fisica, ampliou a $\mathrm{CClH}$, as precauções, a área da Qualidade se sedimentou ainda mais, complementando os métodos técnicos de todas as áreas. Enquanto antes tinham processos de rotina, hoje temos padrões técnicos que padronizam, existem indicadores de monitoramento, ação preventiva que estabelece indicadores internos de avaliação."

A Acreditação desenvolve modelo de gestão foi outra Idéia Central utilizada pelos pesquisados para mencionar os benefícios da Acreditação. Relatam que: "Os benefícios são quanto a ter um modelo de gestão, ter um controle dos requisitos exigidos para o segmento, melhoria contínua e principalmente melhoria no atendimento aos pacientes e colaboradores".

Toda a instituição hospitalar deve preocupar-se com a melhoria permanente, de tal forma que consiga uma interação harmônica das áreas, como se cada uma delas estivesse conectada a outra por fios invisíveis, que permitissem ações integradas. Dado o nobre caráter das instituições de saúde em sua missão a favor do ser humano, o cumprimento dessa premissa torna-se de elevada importância.

A Acreditação é um mecanismo que apoia os hospitais preocupados na promoção da saúde e prevenção das doenças, estimulando a avaliação dos resultados de sua interação com a comunidade. 
A proposta do trabalho da Acreditação não pretende avaliar um serviço ou área isoladamente, mas o seu conjunto, tanto que, se uma área for avaliada num nível mais baixo, toda a instituição também o será.

No DSC coloca-se que "a Acreditação avália o hospital como um todo, é global, usa termos mais adequados às áreas, pois o hospital não pode ser avaliado separadamente, os resultados da Acreditação são palpáveis. Visa o aprimoramento teórico e não de processos."

Este enfoque reforça o fato de que as estruturas do hospital estão interligadas e que o funcionamento de um componente interfere no resultado final.

Cada instituição deverá procurar meios para reduzir suas deficiências e desenvolver critérios para garantir a Qualidade.

Os avanços tecnológicos incorporados pela área da saúde são importantes e representam evolução para a instituição e, principalmente, para a melhoria dos serviços prestados. No entanto, o aprimoramento dos processos parecem ser, na verdade, a melhor forma de aperfeiçoamento. Ele envolve custos menores, melhoria no atendimento facilidades no acesso.

A citação no DSC, de que a Acreditação "visa o aprimoramento tecnológico e não de processo", suscita necessidade da revisão deste conceito, merecendo melhor entendimento dos propósitos da Acreditação.

A Acreditação evidencia pontos fortes e aspectos restritivos da organização, possibilitando o início de uma mudança gradual e planejada nas instituições. Os profissionais são estimulados a repensar seu trabalho, buscando aproximá-los de práticas e padrões reais aceitáveis, mobilizando-os para a superação dos pontos a serem corrigidos.

Os ítens de verificação propostos nos instrumentos de avaliação para Acreditação buscam identificar o status dos processos institucionais, revelando o nível em que o hospital se encontra. Cabe a este, apresentar evidências do cumprimento de seus propósitos.

Nas Idéias Centrais sobre Acreditação, a percepção dos pesquisados traduz-se em: "Acreditação é a receita para fazer coisas básicas e que é muito simplista", pressupondo implicitamente que já existe um mínimo de ações executadas pela Instituição. 
A percepção predominante é a do instrumento como um check-list. Ao ser aplicado, irá identificar a existência ou não do requisito solicitado, dos aspectos mais simples a serem verificados aos mais complexos.

$O$ instrumento de Acreditação pressupõe, principalmente, uma autoavaliação da instituição, e a identificação de seu status e, posteriormente serão visitados por especialistas que irão avaliar a performance institucional.

Para conceituar certificação e seus beneficios/melhorias, os pesquisadọs indicaram três linhas conceituais:

- Certificação padroniza e normaliza procedimentos.

- Certificação gera confiança, credibilidade e reconhecimento.

- Certificação é atestado de qualidade.

No DSC, cuja Idéia Central é: "Certificação padroniza e normaliza procedimentos", os pesquisados conceituam Certificação como "normas que visam certificar o sistema de qualidade de uma empresa, através de padronização de processos e avaliações sistêmicas, trazendo resultado nos controles quanto à gestão de equipamentos, processos, etc."

O objetivo deste método - ISO - é servir de guia às organizações que pretendem trabalhar com a gestão de Qualidade Total, sendo necessário uniformizar conceitos e procedimentos, fornecendo assim diretrizes para estabelecer, documentar e manter o sistema de Qualidade da instituição.

A aplicação deste método na área da saúde enfrentou algumas resistências dos profissionais envolvidos, por passar a exigir a padronização de processos, visando a garantia da qualidade dos serviços prestados.

Como relatado no DSC (....) "A norma é muito técnica, foi um aprender juntos, houve dificuldades com a equipe médica e resistência dos funcionários e gerências. Por outro lado, são extremamente burocráticas, desfoca do que precisa ter cuidado com qualidade para focar papel. A certificação ISO vale muito a pena nas áreas mais industriais, a medida que se padroniza e se normaliza procedimentos" 
Percebe-se que a resistência, relatada no DSC, ocorre quando se fala em qualidade no âmbito assistencial. Qualidade também é documentar os procedimentos para garantir que a assistência dada ao paciente tenha controle. A ISO, para estes profissionais, representa um esforço a mais, que os afasta da sua atividade principal. Nesta visão, identifica-se o distanciamento da equipe de saúde das metas definidas pela instituição.

Constata-se que, o desconhecimento do sistema de qualidade ISO reafirma $o$ preconceito sobre o método, reforçando o modelo mental destes profissionais, onde o paradigma do controle, da manutenção do status, do deixar como está, ainda permanece em evidência.

$O$ conceito de que "a certificação desfoca o que se precisa para a qualidade, para focar papel" deve ser revisto, tendo por base que qualidade é, segundo a ISO, "a totalidade de caracteristicas de uma entidade que lhe confere a capacidade de satisfazer as necessidades explícitas e implícitas"(PRAZERES 1996, p.65).

Além da Qualidade na prestação de serviços, uma instituição certificada fornece ao cliente a garantia de que seus requisitos serão atendidos.

Para os pesquisados, no DSC, "a certificação no segmento hospitalar, traz credibilidade e confiança do cliente para com a organização e junto a comunidade, que agregado ao marketing institucional, gera aumento de clientes, em busca dos serviços nela prestados".

Um dos grandes desafios de um programa de Qualidade é o de integrar diferentes visões. Buscar linguagem comum entre as pessoas da organização é o primeiro e principal passo para implantar um programa e estimular mentalidades orientadas para a qualidade. Assim, quando encontramos na área assistencial, profissionais voltados estritamente ao desenvolvimento de sua atuação técnica, constata-se o distanciamento da prática documental que acompanha sua atividade.

Este trabalho parcial, focado na assistência, reflete-se na cadeia do processo de prestação de serviço, podendo gerar prejuízo ao cliente final e à instituição. 
A sociedade tem buscado consenso, através do estabelecimento de sistemas de padronização, na tentativa de complementar os requisitos de produtos e serviços apresentando especificações técnicas feitas pelo cliente (CERQUEIRA NETO 1992).

A questão formulada e dirigida aos pesquisados: Como são mensurados os resultados dos programas de Qualidade em relação aos objetivos inicialmente definidos pela organização? (ficha, produtividade, diminuição de defeitos, diminuição de reclamações, indicadores); aborda a importância do estabelecimento de metas, indicadores por áreas e globais.

Segundo BURMESTER e col., “(....) indicadores são representações quantitativas ou não, de resultados, ocorrências ou eventos de um sistema. Constituem instrumento gerencial de mensuração, sem o qual é impossível a avaliação criteriosa de qualidade ou produtividade" (1993, p.1-27).

Verifica-se que sem a adoção de indicadores, a avaliação da qualidade ficará prejudicada. As variáveis que interferem no processo antes e depois não serão examinadas, ficando a instituição sem parâmetros comparativos.

Os indicadores permitem a avaliação de programas e serviços prestados à população, na área da saúde.

Diferentes racionalidades, acompanham a avaliação, desde sua utilização para tomada de decisão, até a verificação do cumprimento de objetivos dos programas.

BITTAR afirma que "Com auxílio de indicadores hospitalares e de saúde da comunidade, torna-se possivel avaliar se os programas e os serviços hospitalares estão influenciando de maneira positiva na saúde da população, ao mesmo tempo que também evidenciam a qualidade e a quantidade produzidas" (1996, p.86).

Segundo MALIK (1996b, p.22), "A área de saúde no Brasil trabalha geralmente mal a questão de dados e informações. Atualmente o discurso vem priorizando este setor, num movimento pendular, embora sem que os fatos correspondam a estas intenções". 
Os DSCs das Idéias Centrais: Indicadores Institucionais Globais e Indicadores de Desempenho, abordam vários exemplos de indicadores, referindo que seu uso é formal e monitorado sistematicamente. Pode-se destacar destas falas a utilização de métodos como a ISO, a Joint Comission e Balance Scored Card, como instrumentos que estimulam e dirigem as organizações e suas áreas para o estabelecimento de metas e indicadores.

Encontra-se na literatura, diversos autores que abordam o tema indicadores na saúde. Suas obras referem inúmeros exemplos de situações passíveis de mensuração, no entanto pouco encontramos de relatos vivenciais da aplicação destes. Tal fato surpreende e leva à reflexão sobre a utilização que é feita desta ferramenta.

$\mathrm{Na}$ visita aos hospitais, verificou-se a existência de indicadores organizados, retratando fragmentos da realidade institucional. No entanto, a utilização dos resultados obtidos parece não interferir na recondução das ações de Qualidade.

Os indicadores podem constituir instrumento de força e poder para mudar processos internos de trabalho, quando a coleta e os resultados são tratados adequadamente. Caso contrário, haverá volume de informações que não irão gerar melhorias ou revisões nos processos apontados, prejudicando o estabelecimento de ciclos de melhoria contínua. Pode-se verificar outra possibilidade no que tange aos resultados obtidos pelos indicadores, tratando a solução de problemas de maneira pontual e específica, sem a análise mais sistêmica.

Tal abordagem prejudica a instituição, à medida em que as ações passam a ser norteadas por características imediatistas, em oposição às preventivas, que poderiam resultar em mudanças estruturais.

Com relação a pergunta "Qual a importância de um hospital desenvolver um sistema de qualidade?" encontram-se três Idéias Centrais:

- Melhora a interação entre as pessoas;

- Cria a cultura da Qualidade melhorando as condições de trabalho;

- Desenvolve marketing favorável no mercado. 
Nos DSCs construidos a partir das Expressões- Chave verifica-se que com relação à interação entre as pessoas e os sistemas de Qualidade "faz buscar a melhoria de seu desempenho e, adotar políticas, normas, padrões metodológicos visando a interação das equipes multiprofissionais, existentes na instituição".

Segundo SIMIONI, "Os Recursos Humanos podem caracterizar-se como área viva dos sistemas de saúde, a partir de uma visão sistêmica de corte humanista. É a única que, no momento mesmo em que funciona, se representa, sendo capaz de pensar sobre si mesma e suas inter-relações, sobre o gerenciamento e as ações que realizam e que uma vez tomadas, "encarnam" os sistemas de saúde como algo além de uma máquina de produção de bens e serviços de saúde" $(1996$, p.3).

Portanto, é na interação do paciente com a equipe, que ocorre a ação de saúde, sobretudo na relação direta médico-paciente. $\mathrm{O}$ mesmo acontece no momento em que o farmacêutico dispensa o medicamento, ou quando a enfermeira orienta, ou quando o psicólogo o atende. Essas ações representam uma relação que é construída no exato momento do seu fazer, caracterizando-se como um produto intangivel, pois não é possível tocá-lo ou armazená-lo, destacando-se no seu exercício.

Os sistemas de Qualidade obterão sucesso junto aos atores da saúde, quando houver:

- Desejo de trabalhar de modo diferente e participativo;

- Desejo de ser reconhecido pelo desempenho;

- Reconhecimento do próprio empenho e dedicação;

- Possibilidades de melhoria no processo de trabalho;

- Possibilidade de expressar opiniões e idéias nas equipes. 
A visão do indivíduo como um ativo da organização, pessoa e não meramente um custo, é o desafio a ser superado. É o que possibilitará maior ou menor adesão aos programas de Qualidade.

Outra Idéia Central valoriza o desenvolvimento da cultura da Qualidade, que para os pesquisados "faz com que o hospital fique atento aos desejos e anseios de seus clientes internos e externos. Faz buscar continuamente a melhoria de seu desempenho (...). Valoriza a cultura da Qualidade, melhora as condições globais por excelência do atendimento, dá garantias de condições de trabalho aos médicos, credibilidade junto aos clientes, médicos e comunidade, investindo em equipamentos e qualificação da mão de obra".

Para MEZOMO, “Administrar mudanças é, portanto, estabelecer uma cultura de contínuo desenvolvimento, que permite à organização ser competitiva. Nenhum processo, serviço ou produto é intocável. É preciso desafiá-los permanentemente para que a Qualidade exista desde o princípio" (1992, p.61).

Mudar uma cultura organizacional implica em mudar padrões de comportamento, crenças, valores e todos os aspectos do trabalho e do pensamento que caracterizam as pessoas em grupo e as instituições. Isto é particularmente difícil na saúde, devido aos interesses profissionais, corporativos e setoriais, que conflitam freqüentemente com as diretrizes delas próprias.

A transformação individual é importante, mas não suficiente, pois o indivíduo não consegue transformar a organização do trabalho sozinho. As mudanças ocorrerão à medida em que percebam a si e ao mundo externo, trocando essas percepções e desejando mudanças.

Outra Idéia Central evidencia que sistemas de Qualidade na saúde, atuam sobre desenvolvimento de marketing. Em relação a este pressuposto, o pensamento predominante revela que: "É importante manter a imagem do hospital. É pensar que você será reconhecido no mercado e ser capaz de provar que é bom".

Conquistar boa reputação ou imagem no mercado, faz parte de um esforço que se obtém ao longo dos anos. "Ganhar e perder clientes é parte do negócio porém, as organizações trabalham para obter sua lealdade e confiança. Sabemos que custa mais caro a conquista de um novo cliente do que a sua manutenção". 
Também é reconhecido pelas organizações que, por vezes, sua marca constitui patrimônio mais valioso do que suas próprias instalações e equipamentos (AIDAR 1995, p.54).

Quando o cliente adquire um produto e/ou serviço, está inserido nele um valor agregado. Caso haja descontentamento, ocorrerá queda no referido valor, isto demonstra a importância do investimento na Qualidade.

Solicitou-se aos entrevistados que destacassem as principais dificuldades do processo de implantação. Expressaram conforme segue: "o envolvimento das pessoas é algo que dificulta trabalhar as não conformidades na íntegra e o funcionário leva para o lado pessoal."

Percebe-se na análise deste DSC que acaba ocorrendo o distanciamento do trabalhador de sua atividade, o que pode estar ocultando a ameaça de lidar com a extensão do medo, da impotência e da insatisfação, mas também oferece a compreensão para o não envolvimento com o trabalho e a desmotivação presente neste cenário.

Estes aspectos provocam sofrimento ao trabalhador, que por vezes não consegue identificar sua real dimensão.

Os trabalhadores percebem-se incapazes para manejar os processos do trabalho e sua energia psíquica está voltada para a realização do mesmo, de forma disciplinada, pelo temor de ser expropriado de sua atividade, o que impede de objetivar-se como ator social do trabalho.

Neste cenário, pode-se entender como este terreno se torna fértil ao estabelecimento de resistências, tanto do trabalhador quanto da instituição à cultura da Qualidade. Tal resistência tem natureza em questões estruturais quanto naquelas ligadas as equipes médicas e multiprofissionais.

$\mathrm{Na}$ seqüência do DSC, relatado anteriormente, é dito que (...) "pela falta de cultura para a Qualidade e, por não usar as ferramentas para solução de problemas, bem como para melhoria de desempenho. Para tanto os líderes do processo de Qualidade não podem ser arrogantes."

Assim, as crenças e valores tomados por verdadeiros por esses atores do processo vão se perpetuando, encontrando forte barreira para ser transposta. 
A conscientização para Qualidade pode ser uma aliada para a mudança dos modelos mentais, presentes nestas equipes de saúde. Este processo caminha lentamente, pois a adesão dos profissionais ocorre em diferentes momentos.

As generalizações, os pressupostos arraigados, ou mesmo as imagens que influenciam a forma de entender e agir dos indivíduos, são elementos que traduzem como ele está no mundo. Isto media a interação entre os indivíduos e grupos, expondo eficazmente seus próprios pensamentos, permitindo que estejam abertos a influência dos outros.

Nesta dinâmica, torna-se possível o questionamento de verdades, a partir das imagens internas que são constatadas e, que ao emergirem permitem novas visões.

Neste processo pode-se lançar novas luzes sobre o entendimento do trabalho, que passou a ser visto não mais como um meio para um determinado fim, ganhando dimensão de um espaço na vida dos indivíduos, agora resignificado pela agregação de diferentes aspirações.

Na pergunta - Destaque os principais pontos a serem melhorados - os DSCs abordam que "a relação e comunicação interna, diz respeito a integração entre as áreas, ao envolvimento dos novos colaboradores e médicos das equipes terceirizadas. Ter mais recursos para treinar o pessoal, habilidades para liderar e consciência das pessoas em relação à Qualidade".

Segundo AIDAR, "é importante lembrar que o efetivo desenvolvimento da Qualidade (do produto ou serviço) em qualquer organização, começa e termina pela Qualidade de suas relações internas

A forma como as pessoas interagem dentro da organização está diretamente ligada às crenças e valores por elas compartilhadas. Não podemos falar de mudanças profundas na empresa sem lidarmos com a questão da cultura organizacional" (1995, p.99). 
Outro aspecto relevante a ser considerado diz respeito à importância da habilidade dos indivíduos em descobrirem imagens compartilhadas, que estimulem o compromisso genuíno e o envolvimento, em lugar da mera aceitação.

Quando metas, valor e missão, são compartilhados pelos colaboradores, os propósitos da instituição são atingidos mais facilmente. $O$ suporte para isto acontecer encontra forte apoio nas ações de aprendizagem.

As pessoas, quando podem expandir continuamente sua capacidade de criar resultados, que realmente desejam, e são estimuladas a novos padrões de pensamentos, abrangentes e sistêmicos, passam a integrar a realidade e construir conexões com o todo.

Para KANAANE “ Um enfoque que valorize o despertar do potencial humano associado ao incremento à produtividade e à qualidade refere-se em última instância à perspectiva da administração centrada no individuo. Esta tende a assumir um papel mais abrangente quanto ao cultivo da potencialidade e capacidade humana, canalizando e fazendo frutificar valores e tendências facilitadores ao alcance dos objetivos organizacionais e dos desejos e metas individuais e/ou grupais" (1995, p.35).

De modo geral, as grandes instituições sociais partilham de visões obsoletas, cuja percepção da realidade é inadequada para lidar com um mundo interligado.

Um novo paradigma, importante no processo de gestão, é a adequação de visão sistêmica por parte dos gestores. Na maior parte das situações gerenciais há verdadeira alavancagem quando o gestor compreende a complexidade dinâmica da organização, não se prendendo aos detalhes. Dentro de uma visão sistêmica os problemas são vistos como diferentes facetas de uma única crise.

Os conceitos de Qualidade encontrados nas Idéias Centrais das ancoragens, referem-se às idéias circulantes na sociedade, particularmente nas organizações. 
Trata-se da representação social incorporada pelos indivíduos, que atribuem a elas significados próprios e valores. No entanto, esta compreensão passa por um filtro de cada indivíduo que seleciona os conteúdos que the são mais representativos.

Os indivíduos aderem e aplicam determinados métodos, segundo diagnóstico institucional previamente realizado ou em muitos casos, a opção da ferramenta se dá pelo conhecimento pontual dos gestores da Qualidade.

Outra observação em relação a este aspecto, diz respeito ao fato da escolha ser definida pela alta direção, devendo ser praticada pela liderança da Qualidade.

$\mathrm{O}$ aporte teórico dos pensadores da Qualidade mostra-se presente na Idéia Central das Ancoragens, acrescido de múltiplas informações, percepções e associações feitas pelos indivíduos, no decorrer de sua trajetória existencial, demonstrando que tiveram algum contato com essas Idéias, reinterpretando-as e adequando-as ao seu cotidiano.

A Idéia Central da Ancoragem - Qualidade é Prevenir - encontra apoio nos pensamentos de CROSBY (1992) que acredita que as despesas mais visíveis na Qualidade encontram-se na área da avaliação. CROSBY afirma que "O sistema que gera qualidade é a prevenção, não a ação" (1992, p.88).

As pessoas são uma poderosa força para descobrir problemas e gerar ações corretivas, minimizando o impacto dos erros. $O$ fato dos trabalhos nas organizações serem frequentemente desconexos e descontinuados, não executados em conjunto, torna difícil o desenvolvimento de uma visão sistêmica sobre as organizações e mais ainda para implementação de ações corretivas. Os profissionais das organizações ainda não desenvolveram uma mentalidade voltada para ações preventivas.

Os processos de avaliação são feitos normalmente após o fato ter ocorrido. Avaliação pressupõe a finalização do processo com mecanismos de checagem, triagem e separação do que já está feito, caracterizando-se portanto como um sistema dispendioso e não confiável na obtenção da Qualidade. Ao contrário deste conceito, a prevenção é algo feito no decorrer do processo baseando-se na compreensão deste. 
CROSBY (1992) relata que "O segredo da prevenção é examinar o processo e identificar as possibilidades de erro. Elas podem ser controladas” (p.81).

Qualidade alavanca processos de melhoria é outra Idéia Central presente na fala dos entrevistados. Encontra-se na literatura diversos autores que acreditam nesta afirmativa. DEMING (1990) coloca que a Qualidade deve existir desde a etapa do projeto de qualquer produto, que deve ser encarado como parte de um todo. Outra concepção marcante em relação ao tópico referenciado pelos sujeitos diz respeito à importância do trabalho em equipe, essencial para a alavancagem da melhoria contínua.

Projetos, planos, protocolos e especificações, devem traduzir aquilo que se pretende na tentativa de oferecer ao cliente a qualidade almejada. Este processo certamente irá gerar a redução contínua de desperdício e a constante melhoria da Qualidade. Vários fatores estão envolvidos nas melhorias dos processos, incluindo seleção de pessoal, especificações para os cargos a serem ocupados, treinamento, revisão de projetos, de modo a proporcionar a todos melhores oportunidades de conhecimento e aperfeiçoamento das suas habilidades. Melhorar um processo exige um estudo dos registros de trabalho afim de que se possa analisar, entender e introduzir alterações, observando seus efeitos.

Para JURAN (1988) "os melhoramentos de qualidade potencialmente mais importantes são de natureza multifuncional ou multidepartamental" (p.255). Outros tem natureza intradepartamental, podendo ser solucionados pelos próprios colaboradores da área, caso estes recebam a responsabilidade, o treinamento e a motivação. "A equipe sendo treinada para estudar os sintomas, elaborar teorias sobre as causas, testar as teorias, achar a causa, estimular um remédio, estabelecer controle para manter ganhos, poderá atuar favoravelmente para a melhoria dos processos institucionais" (JURAN 1988, p.257).

CROSBY (1992), aponta que vários passos devem ser seguidos para a obtenção das melhorias da qualidade. Propõe envolvimento das equipes de melhoria que estas façam medições dos processos, tendo por orientação o princípio absoluto de gerenciamento da Qualidade, que é o conceito de custo. Para a partir destas informações implementar ações corretivas. 
Na Idéia Central da Ancoragem - Qualidade deve ser avaliada tanto quanto a dimensão de custos - fica evidenciado que além da questão dos custos, que frequentemente é um dos elementos de maior atração e fixação nas organizações, aspectos relativos a avaliação da Qualidade, também devem ser tratados com relevância.

A dimensão do custo tem sido utilizada como forma de medir o desempenho de pessoas e processos, por vezes colocado como ítem ameaçador, ao invés de destacá-la como um ítem positivo.

A mesma atenção dirigida a este enfoque - dimensão de custo deveria ocorrer para a Qualidade, pois esta envolve a organização como um todo e seus resultados promovem efeitos no seu conjunto.

Segundo CROSBY (1992), "A conscientização da qualidade estendese através de todos os atos gerenciais. A maneira como o pessoal da gerência fala sobre qualidade é ponto importante. Quando a qualidade - como cumprimento dos requisitos - torna-se parte da linguagem da companhia, é que começa a exercer efeito" (p.136).

Enquanto CROSBY (1992) valoriza a forma como a alta gerência comunica a toda organização seus princípios de qualidade, BERWICK e col. (1994) coloca que inicialmente as equipes se engalfinham com os projetos em suas primeiras incursões no propósito de melhoria da Qualidade, e em seguida começavam.

BERWICK e col. relatam que "Essas experiências têm o sabor de exploração num território não cartografado: uma mistura de excitação e apreensão a princípio, depois alternadas oscilações de frustração e exaltação no curso da jornada. Acima de tudo, as equipes compartilharam um profundo sentimento de compromisso com a saúde e com a exploração de um novo campo repleto de promessas para tornar a saúde melhor" (1994, p.45). 
Em outro momento, BERWICK e col. ratificam que: "A melhoria da qualidade como método administrativo procura organizar a empresa de uma nova maneira - de forma que, de um modo ordeiro e planejado, todo mundo de todos os níveis possam desempenhar um papel ativo no sentido de compreender os problemas e os processos de trabalho subjacente aos mesmos, coletar e analisar dados sobre esses processos, gerar e testar hipóteses sobre as causas de falhas e projetar, implementar e testar soluções" (1990, p.48).

Na obra de JURAN (1988), encontra-se abordagem conceitual com ênfase no planejamento, controle e melhoramento da Qualidade.

Somando-se aos esforços dos autores referidos para conceituar, organizar e aplicar Qualidade de forma sistemática e dirigida, percebe-se crescente número de adeptos desta corrente, onde predomina a lógica da melhoria institucional pelos custos de seus processos. 


\section{CONSIDERAÇÕES FINAIS}

Qualidade é um termo utilizado por diversos especialistas, sob diferentes ópticas, tendo como ponto comum, identificar focos que promovam seu desenvolvimento. A busca de um conceito único torna-se algo dificil, especialmente na área da saúde.

A construção dos conceitos de Qualidade envolve uma multiplicidade de variáveis, assinalando setores e tendências predominantes, num dado contexto de trabalho.

Constata-se na pesquisa a existência de diferentes abordagens para Qualidade. Algumas valorizam a produtividade e o equilíbrio da organização, outras estão mais voltadas ao desenvolvimento do potencial humano. Tais tendências mostram-se presentes nos planos e ações das instituições que atuam neste segmento.

Ao escolher determinada teoria para embasar a prática da Qualidade, pode-se observar que o profissional busca inspiração naquela que mais se aproxima de seu sistema de crenças e valores, associando-o ao diagnóstico institucional, criando um elo entre teoria e prática. $\mathrm{O}$ sistema de crenças e valores dos indivíduos e da organização está embutido na escolha metodológica, que acaba por atender às expectativas das partes comprometidas no processo.

As ações dos gestores contém a representação social do conceito de trabalho e Qualidade, onde fica estabelecida a vinculação do fazer com aquilo que emana do social. Assim estas ações parecem ser mais dirigidas intuitivamente, do que embasadas num conhecimento construído teoricamente. Portanto, torna-se essencial que seus coordenadores busquem apoio na literatura, visando suporte e consistência na implementação de seus projetos, adequando-os às realidades de cada instituição. Este processo legitimará as práticas institucionais validando suas ações.

Vale ressaltar que as referências literárias atuais possuem limitações. Estas devem ser revistas com atenção, na tentativa de definições mais claras e consensuais. 
A sistemática escolhida pelos hospitais está vinculada a um conjunto de ações e posições sócio-culturais de seus gestores. Retrata relações estabelecidas entre eles, o processo de trabalho e seus grupos de referência, refletindo-se nas opções realizadas.

O sistema de crenças e valores dos indivíduos e da organização está embutido na escolha metodológica, que visa atender às expectativas das partes comprometidas no processo.

Dentre um dos objetivos deste estudo - mapear práticas de Qualidade, em instituições públicas e privadas de Saúde - identificou-se que a aplicação da norma ISO foi aquela que obteve maior destaque. Esta prática confere certificação cujo reconhecimento no mercado tem se mostrado crescente.

A possibilidade de sua aplicação parcial na instituição parece ser um elemento atraente para os gestores. Além do que, os passos preconizados na técnica, acabam por dirigir o trabalho dos colaboradores, impingindo ritmo ao processo e conduzindo-os às metas previstas.

A medida em que várias instituições participam do processo de certificação, percebe-se uma pressão no mercado para que outras também o façam.

Além disto, identifica-se que a preferência por este método pode estar vinculada ao momento social que as organizações estão vivendo. Muitas delas ainda não conseguem perceber-se sistemicamente e portanto, optam por instrumentos que possibilitam aplicação por setores. Provavelmente, a medida em que seus processos tornem-se interligados, haverá a utilização de métodos com caráter mais sistêmico.

Este movimento já é percebido no universo deste estudo quando algumas instituições, após alcançarem determinado grau de organização, inserem a aplicação de métodos mais abrangentes, que contribuem para o avanço das ações de Qualidade.

Os sistemas híbridos podem ser positivos e alavancadores de um desenvolvimento crescente e espiralado envolvendo cada vez mais os diversos níveis da instituição.

Em todos os hospitais pesquisados, a postura do gestor da Qualidade e da alta direção (superintendente e diretor executivo) demonstrou disposição para entrevista, o que poderia representar sinergia dessas duas esferas. 
No entanto, esta interação nem sempre ocorre com a força necessária para a consecução de um programa desta natureza.

Em algumas das instituições pôde-se constatar que o gestor da Qualidade ocupa lugar em esferas decisórias, fazendo parte do planejamento estratégico da organização e podendo integrar as metas da Qualidade aos objetivos macroinstitucionais.

Considera-se a aproximação da área técnica à estratégica essencial para o sucesso das ações de Qualidade, pois estas envolvem mudanças estruturais e paradigmáticas. Através deste movimento institucional a coletividade pode identificar e acompanhar o real apoio destinado aos programas de Qualidade. A transparência desse processo de aproximação interfere diretamente nos resultados daquelas ações, uma vez que os indivíduos aprendem, no decorrer de suas existências, a decodificar mensagens verdadeiras daquelas que manipulam o corpo funcional.

Os sistemas de Qualidade servem como guias, podendo ajudar na sinalização dos caminhos para a mudança. Os esforços para estabelecer Qualidade são imensos, tendo por base a melhoria contínua. No entanto, se as pessoas não estiverem dispostas a mudar e rever seus modos de ação, não será possível atingir os objetivos pretendidos, nem a cultura da instituição.

Este processo está relacionado à sistemas internos dos indivíduos e, por isso, entrar em contato com ele pode gerar algum tipo de retração e morosidade. As organizações tendem cristalizar-se no seu funcionamento. Resistem ao novo, através de barreiras criadas para manter o status vigente. Cabe a alta direção, estabelecer com clareza seus planos de mudanças, oferecendo diretrizes que orientem os colaboradores quanto ao novo caminho a ser trilhado e, projete esforços a serem empreendidos por todos.

O corpo funcional tem sido solicitado ao comprometimento com os trabalhos da Qualidade, por treinamentos ou ações orientadas ao cumprimento do método proposto. Porém, os treinamentos ministrados parecem priorizar aspectos da racionalidade. Assim pensar, agir e sentir, acabam não sendo trabalhados de forma integrada, o que impossibilita compreensão e adesão à abordagem sistêmica do processo. 
O resultado desta prática fragmentada é percebida no cotidiano, ao serem relatadas as resistências ao programa e à cultura da Qualidade.

Nas instituições pesquisadas, a adesão para Qualidade acontece parcialmente. Por vezes, encontra-se o colaborador respondendo a um papel que the foi atribuído, porém sem um exercício autônomo, realizando uma prática aparente e superficial.

Faz-se necessário que os gestores revejam a forma de condução dos processos da Qualidade, especialmente no que diz respeito ao envolvimento dos colaboradores. Encontrou-se nos dados quantitativos a citação de que todos os funcionários estão envolvidos nos programas de Qualidade, no entanto, na análise qualitativa é apontada a necessidade de melhoria neste envolvimento. Dessa forma, evidencia-se uma contradição que leva a pensar: "Por que os colaboradores não se sentem parte comprometida com este processo?"

O ciclo de excelência da Qualidade visa atingir constantes melhorias. Preocupa-se em integrar os colaboradores, definindo claramente seu papel institucional, fazendo fluir responsabilidade, adesão à cultura vigente $\mathrm{e}$ comprometimento. Este processo de co-participação, colaboradores e instituição, fortalece a organização e congrega seus integrantes a superarem crises e dificuldades comuns.

A apropriação da Qualidade se efetivará, com o autodesenvolvimento, o desenvolvimento interpessoal e das organizações. 


\section{CONCLUSÃo}

- O relato dos entrevistados denota diferenciação conceitual da Qualidade. Esta é constituída a partir da representação social dos gestores, e aliada às necessidades institucionais, interfere na prioridade das ações a serem tomadas.

- A maioria dos hospitais, inicialmente, optou por métodos de certificação, sendo o Sistema de Qualidade da Norma ISO 9000 o mais adotado. Este fato se deve a sua aplicação de caráter parcial, técnica e orientadora. Posteriormente, algumas instituições adotaram métodos onde ficou evidenciada a busca de uma visão sistêmica do hospital.

- A imprecisão das informações solicitadas, referentes a gestão de pessoas demonstram que a área de Recursos Humanos dos hospitais pesquisados carecem.de organização. Tal fato, reflete-se na falta de agilidade e fidedignidade das informações.

- Nos achados da pesquisa identificou-se dificuldade dos gestores na classificação das diferentes sistemáticas que objetivam o alcance da Qualidade. Evidencia-se então, a necessidade de contribuir com tal classificação. Sendo assim, este estudo propõe que Qualidade seja entendida como metodologia, e os métodos que a apoiam possam ser desdobrados em ferramentas e técnicas que permitirão sua realização com flexibilidade.

- Para eficiência dos Processos de Qualidade verifica-se a necessidade da aproximação entre as áreas técnicas e estratégicas 


\section{REFERÊNCIAS}

1. Aguilar MJ, Egg EA. Avaliação de serviços e programas sociais. Petrópolis: Vozes; 1994.

2. Aidar MM. Qualidade humana. 2a ed. São Paulo: Maltese;1996.

3. Akerman M. Gerência de qualidade nos hospitais paulistas. Cadernos FUNDAP ano 1996; n 19: 79-87.

4. Albuquerque LG. Importância e necessidade de pensar recursos humanos no nível estratégico. São Paulo; 1987.[Tese de Livre-Docência- FEA-USP].

5. Competitividade e recursos humanos. Rev Adm FEA-USP ano 1989; ano $27 \mathrm{n}^{\circ}$ 2: $40-42$ páginas.

6. Amaral JLG. O que você precisa saber sobre o sistema único de saúde: Cartilha SUS (2v). São Paulo: Associação Paulista de Medicina; 2000.

7. Angerami-Camon VA, organizador. A ética na saúde. São Paulo: Pioneira; 1997.

8. Barros CDA. Sensibilização para a qualidade. Rio de Janeiro: Qualitymark; 1992.

9. Berwick DM, Godfrey $\mathrm{AB}$, Roessner J. Melhorando a qualidade dos serviços médicos, hospitalares e da saúde. São Paulo: Makron Books; 1994.

10. Bittar OJNV. Metodologia para avaliação da produtividade em hospitais. $O$ Mundo da Saúde, 20 (7): 238-43, 1996.

11. . Hospital \& produtividade. São Paulo: Sarvier; 1997. 
12. . Gestão de processos e certificação para qualidade em saúde.

Rev. Ass. Med. Brasil, 46(1): 70-6, 2000.

13. . Produtividade em hospitais. São Paulo; 1994. [Tese de Livre

Docência - Departamento de Prática de Saúde Pública da Faculdade de Saúde Pública da Universidade de São Paulo].

14. Bonato de Souza VL, Procura de atendimento psicoterápico pelo trabalhador da saúde. São Paulo; 1994. [Dissertação de Mestrado Departamento de Psicologia Social da PUC-SP].

15. Algumas considerações sobre o conceito de saúde no trabalho. Rev Psicol Hosp 1995; 10: $40-43$.

16. , coordenadora Manual da qualidade: programa InCor da Qualidade. São Paulo (SP); InCor - Fundação Zerbini 1996.

17. Impacto de programas de qualidade em instituição hospitalar. In Qualimetria São Paulo, 82: 15 - 18, 1999.

18. Clientes: do desejo a satisfação. In Banas São Paulo: $48-50,2001$.

19. A qualidade no sistema público. In Banas Qualidade São Paulo: 20-29, 2003.

20. A saúde que dá certo no Brasil. In Controle da Qualidade São Paulo, 72: 44-45.

21. Boog GG. O desafio da competência: como enfrentar as dificuldades do presente e preparar sua empresa para o futuro. São Paulo: Best Seller; 1991. 
22. Borba VR. Administração hospitalar: princípios básicos. $3^{a}$ edição. São Paulo: Cedas, 1991.

23. Bourdieu P. Coisas ditas. São Paulo: Brasiliense; 1990.

24. Burmester $\mathrm{H}$ e col. Sistema de monitoração de indicadores de qualidade e produtividade de hospitais. Projeto BRA 93/11, São Paulo, 1993.

25. Camargo MO, Mello JB. Qualidade na saúde. São Paulo: Best Seller; 1998.

26. Carvalho L. Padrões mínimos de organização de hospitais. Porto Alegre: AHRGS/ Pontificia Universidade Católica do Rio Grande do Sul; 1979.

27. Castelar RM, Mordelet P, Grabois V, Gestão hospitalar: um desafio para o hospital brasileiro. Rennes (França): ENSP; 1995.

28. CBA - Conselho Brasileiro de Acreditação de Sistemas e Serviços de Saúde. Manual de acreditação hospitalar. Rio de Janeiro, 1999.

29. CQH - Controle de Qualidade do Atendimento Médico Hospitalar no Estado de São Paulo. Manual de orientação aos hospitais participantes. $2^{2}$ ed. São Paulo: Atheneu; 1998.

30. Crawford R. Na era do capital humano: o talento, a inteligência e o conhecimento como forças econômicas, seu impacto nas empresas e nas decisões: um guia que mostra como prosperar na economia. São Paulo: Atlas; 1994.

31. Crosby PB. Qualidade é investimento. $2^{\mathrm{a}}$ ed. Rio de Janeiro. José Olympio; 1986. 
32. . Integração: qualidade de recursos humanos para o ano de 2000. São Paulo: Makron Books; 1992.

33. Cruz LP. Qualidade em serviços. Manual InCor de Qualidade. São Paulo: Fundação Zerbini; 1996.

34. Cuenca MBC, Noronha DP, Ferraz MLEF, Andrade MTD. Guia de apresentação de teses. São Paulo: Biblioteca da Faculdade de Saúde Pública da Universidade de São Paulo, 1998.

35. Dejours C. A loucura do trabalho: estudo de psicopatologia do trabalho. $2^{\mathrm{a}}$ edição. São Paulo: 1987.

36. Deming EW. Qualidade: a revolução da administração. Rio de Janeiro: Marques Saraiva; 1990.

37. Donabedian A . The definition of Quality and approaches to its assessment: explorations in Quality assessment and monitoring, vol I. Ann Arbor, Health Administration Press, 1980.

38. Criteria, norms and standards of quality: what do they mean ? American Journal of Public Health , 1981, v.71, $\mathrm{n}^{\circ} 4$ : 409-412.

39. . The Epidemiology of Quality. Inquiry, 1985, v.22, n³:132140.

40. Veinte Años de Investigación en Torno a la Calidad de la Atención Médica, 1964-1984, Salud Pública de Mexico, 1988, v.30, nº 2: 202-215.

41. Encyclopaedia Britannica do Brasil Publicações Ltda. Enciclopédia Mirador Internacional. São Paulo: 1995, 21 v. 
42. Ferreira $\mathrm{ABH}$. Novo aurélio século XXI: o dicionário da língua portuguesa. $3^{\mathrm{a}}$ ed. São Paulo: Nova Fronteira; 1999.

43. FPNQ - Critérios de Excelência - $O$ estado da arte da gestão da qualidade Total. São Paulo: Fundação para o Prêmio Nacional da Qualidade; 1996.

44. Fortes PAC. Ética cidadania e busca da qualidade na administração dos serviços. dez 95: 49 - 50; mar 96: 48 - 49 .

45. . $O$ dilema bioético de selecionar quem deve viver: um estudo de microalocação de recursos escassos em saúde. São Paulo; 2000 [Tese de Livre Docência - Faculdade de Saúde Pública da Universidade de São Paulo].

46. Gastal FL. Controle estatístico de processos: um modelo para avaliação da qualidade de serviços de internação psiquiátrica. São Paulo; 1995 [Tese de doutorado - UNIFESP-EPM/SP].

47. Giddens A. As conseqüências da modernidade. $2^{a}$ ed. São Paulo: UNESP; 1991.

48. Gil AL. Qualidade total nas organizações: indicadores de qualidade, gestão econômica da qualidade, sistemas de qualidade. São Paulo: Atlas; 1993.

49. Gilmore CM; Novaes HM. Manual de gerência da qualidade. Washington, DC: OPAS; 1997.

50. Goldenberg M. A arte de pesquisar: como fazer pesquisa qualitativa em ciências sociais. $4^{\mathrm{a}}$ ed Rio de Janeiro: Record; 2000.

51. Gonçalves L. Conceitos fundamentais. São Paulo: EdUSP; 1994. 
52. Gonçalves EL. As funções do hospital moderno. In: Machline $\mathrm{C}$ et al., $\mathrm{O}$ Hospital e a visão administrativa contemporânea. São Paulo: Pioneria; 1989.

53. Hayes J; Shaw C. Implementing Accreditation System (23 may 1994, Treviso, Italy). International journal for quality in health care, v. $7 \mathrm{n}^{\circ} 2,175-177$.

54. Ishikawa K. Controle de qualidade total. Rio de Janeiro: Campos, 1997.

55. Joint Commission. Comprehensive Accreditation Manual for Hospitals. The Official Handbook. Oakbook Terrace; 1997.

56. How to achieve quality and accreditation in a hospital social work program. Oakbook Terrace; 1991.

57. - 1996 Accreditation Manual for hospitals. v1 Standards, Oakbook Terrace; 1996.

58. Orientation to the 1998 accreditation decision process. Oakbook Terrace; 1998.

59. Joint Commission International. Melhorando os cuidados com a saúde no mundo inteiro. Oakbook Terrace; 1998.

60. Junqueira LAP. Gestão de recursos humanos: uma utopia no setor público de saúde? Rev saúde pública em perspectiva, 6 (4): 9-14, 1992.

61. Juran JM. Juran planejando para a qualidade. $2^{\mathrm{a}}$ ed São Paulo: Pioneira; 1988.

62. . Juran na liderança para qualidade. São Paulo: Pioneira; 1990. 
63. Kanaane R. Comportamento humano nas organizações: o homem rumo ao século XXI. São Paulo: Atlas; 1995.

64. Kisil M, Paganinil JM. Avaliação para a transformação - desenvolvimento e fortalecimento dos sistemas locais de saúde. São Paulo: OPAS/ OMS/ Fundação Kellogg/ FSP-USP; 1995.

65. Lefevre e Lefevre F, Ana M. C., Jorge J. Vieira. Discurso do sujeito coletivo: uma nova abordagem metodológica em pesquisa qualitativa. 2000.

66. Malik AM (a). Qualidade em serviços de saúde nos setores público e privado in Cadernos Fundap. São Paulo, 19: 7 - 24, 1996.

67. (b). Avaliação, qualidade, gestão: para trabalhadores da área de saúde e outros interessados. São Paulo: SENAC; 1996.

68. Malik AM e Schiesari LM. Qualidade na gestão local de serviços e ações de saúde. Série Saúde e Cidadania v. 3. São Paulo: Peirópolis: Faculdade de Saúde Pública; 1998.

69. Massotti-Alves AJ. O debate contemporâneo sobre os paradigmas. In: Mazzotti-Alves AJ, Gewandsznajder F. O método nas ciências naturais e sociais: pesquisa quantitativa e qualitativa (cap.6). $2^{\mathrm{a}}$ ed São Paulo: Pioneira; 1999.

70. Mello JB, Camargo MO. Qualidade na saúde: práticas e conceitos, normas ISO nas áreas médico-hospitalar e laboratorial. São Paulo : Best Seller; 1998.

71. Mezomo JC. O administrador hospitalar: a caminho da eficiência. São Paulo : Cedas; 1991. 
72. Qualidade hospitalar: reinventando a administração do hospital. São Paulo: Cedas; 1992.

73. - Um hospital bem administrado: hospital, administração e saúde. São Paulo: Cedas; 1991.

74. Michaelis. Moderno dicionário da língua portuguesa. São Paulo: Cia Melhoramentos; 1998.

75. Minayo MCS. $\mathbf{O}$ desafio do conhecimento: pesquisa qualitativa em saúde. São Paulo: Hucitec; 2000.

76. Ministério da Saúde. Manual brasileiro de acreditação hospitalar. Brasília (DF); 1999.

77. Ministério do Planejamento. Prêmio qualidade do governo federal. Instrumento de avaliação da gestão pública - ciclo 2000. Programa Qualidade no Serviço Público; 2000.

78. Mirshawka V. Hospital: fui bem atendido, a vez do Brasil. São Paulo: Makron Books; 1994.

79. Negri B; Viana ALD. O sistema único de saúde em dez anos de desafio. São Paulo: Sobravime e Cealag; 2002.

80. Negri B; Giovanni GD. Brasil: radiografia da saúde. Campinas: NEPP; 2001.

81. Nogueira RP. Perspectivas da qualidade em saúde. Rio de Janeiro: Qualitymark; 1994.

82. Novaes HM; Paganini JM. Padrões e indicadores de qualidade para hospitais (Brasil). Washington (DC): Organização Pan-Americana de Saúde/ HSS; 94.05. 
83. Novaes HM; Motta PR. Manual protótipo de educação em administração hospitalar (v5) Rio de Janeiro. Fundação Kellogg; 1997.

84. Ortiz R. Pierre Bourdieu. São Paulo: Brasiliense; 1990.

85. Paganini JM; Novaes HM. Garantia de qualidade - acreditação de hospitais para a América Latina e Caribe. Brasília: OPAS; 1992. (OPAS - Série Silos, 13) 1990.

86. Pedreira ECN. Paradigmas da qualidade. Rio de Janeiro: Imagem; 1992.

87. Prazeres PM. Dicionário de termos da qualidade. São Paulo: Atlas; 1996.

88. Quick TL. Como desenvolver equipes bem sucedidas. Rio de Janeiro: Campus; 1995.

89. Quinto Neto A, Gastal FL. Acreditação hospitalar: proteção dos usuários, dos profissionais e das instituições de saúde. Porto alegre : DACASA/IAHC; 1997.

90. Ribeiro HP. O hospital: história e crise. São Paulo: Cortez; 1993.

91. Rutta AM; Pagliuso AT; Kanab MLZ. Critérios de excelência: o estado da arte da gestão para a excelência do desempenho e o aumento da competitividade. FPNQ; 2002.

92. Sacramento FJS, Identificação de fontes de desperdícios em instituições hospitalares. São Bernardo do Campo; 2001. [Dissertação de Mestrado Administração da Universidade Metodista de São Paulo]. 
93. Schiesari LMC. Cenário da acreditação hospitalar no Brasil: evolução histórica e referências externas. São Paulo; 1999. [Dissertação de mestrado Faculdade de Saúde Pública - USP].

94. Scrivens E. Accreditation: protecting the professional or the consumer ? Buckingham: Open University Press; 1995.

95. _. Policy issues in accreditation. International journal for quality in health care, 1998; 10:1-5.

96. Selltiz C, Jahada $M$, Deutsch $M$, Cook $S W$. Métodos de pesquisa nas reações sociais. $2^{\mathrm{a}}$ ed São Paulo: Herber/EdUSP; 1967.

97. Senge P. A quinta disciplina: arte e prática da organização de aprendizagem. $8^{2}$ ed. São Paulo: Best Seller; 1995.

98. Simioni AMC. O gerenciamento de recursos humanos em saúde como processo social . São Paulo,1996. [Dissertação de Mestrado - Faculdade de Saúde Pública da USP].

99. Singer P, Campos O. Prevenir e curar. Rio de Janeiro: Forense; 1988.

100. Tachizawa $T$, Scaico. Organização flexível: qualidade na gestão por processos. São Paulo: Atlas; 1997.

101. Teboul J. Gerenciando a dinâmica da qualidade Rio de Janeiro: Qualitymark; 1995.

102. Teixeira JMC. Sistemas médicos, técnicos e administrativos do hospital moderno: sua ordenação. In: Machline $C$ et al,, $O$ hospital e a visão administrativa contemporânea. $2^{\text {a }}$ ed São Paulo: Pioneira; 1989. 
103. Valle VF. Controle da qualidade total. $5^{\mathrm{a}}$ ed Belo Horizonte: UFMG/FCO; 1992.

104. Vieira MPA, Peixoto MRC, Khoury YMA. A pesquisa em História. $2^{\mathrm{a}}$ ed. São Paulo: Ática; 1991.

105. White $\mathrm{KC}$, Willians $\mathrm{TF}$ \& Greenburg BG. La ecologia de la atención médica. In: Investigaciones sobre Servicios de Salud: Uma Antologia, 1992, pp.240250. (Publicación científica n534, OPAS).

106. White $\mathrm{K}$ (Editor). Los servicios de salud. Washington, D.C.: OPS/OMS

107. Wood Jr T, Urdan FT. Gerenciamento da qualidade total: uma revisão crítica, In: Revista de Administração de Empresas, 34 (6), 46-59, 1994.

108. Zoboli ELCP. A interface entre a ética e a administração hospitalar. São Paulo; 2000. [Dissertação de mestrado - Faculdade de Saúde Pública da USP].

109. www.mct.gov.br/temas/info/dsi/qualidad/pnq.htm

110. www.saude.pr.gov.br/ftp/teses $\% 20$ ces/sus_tese $1 . d o c$ 


\section{ANEXO $\underline{\text { A }}$}

Termo de Consentimento 


\section{TERMO DE CONSENTIMENTO}

Ilmo Sr .

Diretor do Hospital

Prezado Sr,

Seu hospital foi selecionado para compor amostra da pesquisa "Programas de Qualidade em Hospitais de São Paulo", por estar dentro dos critérios definidos neste estudo.

A pesquisa em questão está sendo desenvolvida na Faculdade de Saúde Pública, da USP, no Departamento de Prática em Saúde Pública, na área de concentração da Administração Hospitalar, sob orientação da Prof. Dr. ${ }^{a}$ Vitória Kedy Cornetta.

O objetivo final será o mapeamento dos hospitais que implantaram Programas de Qualidade buscando conhecer os passos percorridos nestes processos, as escolhas metodológicas e a percepção dos pesquisados em relação aos resultados alcançados.

Tais objetivos nos colocaram frente a questões gerenciais que são fundamentais e determinantes para a implantação destas práticas de Qualidade e da melhoria dos serviços prestados.

Assim, solicito a VS a gentileza de indicar o nome, e-mail, telefone do profissional de sua instituição que poderá ser entrevistado por nós, colaborando assim com este trabalho.

Por exigência e norma da Comissão de Ética desta Universidade, este Consentimento deve ocorrer por escrito e ser enviado para:

\section{Instituto do Coração InCor HCFMUSP}

A/C Vera Lúcia Bonato de Souza

Av. Dr. Enéas de Carvalho Aguiar, $44-2^{\circ}$ andar SQ - InCor

Bairro: Cerqueira César - SP CEP: 05403-900

Email: sqvera@incor.usp.br Fone: 3069-5013

Asseguro que será mantido absoluto sigilo das informações fornecidas pelos hospitais participantes, assim como sua identificação.

Os resultados desta pesquisa fazem parte da linha de estudo citada, e seus resultados serão de conhecimento público.

Desde já agradeço.

Atenciosamente,

Prof ${ }^{2}$. Dr. ${ }^{2}$ Vitória Kedy Cornetta

Orientadora
Vera Lúcia Bonato de Souza

Coordenadora da Pesquisa/;Orientanda 


\section{ANEXO B}

Formulário de Pesquisa 
Instruções para preenchimento:

1. Trata-se de um questionário conduzido em forma de entrevista, que será aplicado por um pesquisador chefe que fará as orientações necessárias. Estará presente durante a entrevista um pesquisador colaborador cuja principal atividade será o registro das informações apresentadas.

2. Se por alguma razão (confidencialidade, informação incompleta ou quaisquer outras) uma questão não puder ser respondida, ignore- a, apenas solicitamos que não deixe de responder às demais, pois toda informação fornecida será essencial para o prosseguimento desta investigação.

3. Solicitamos anexar para fins de análise os estatutos, regulamentos, regimentos e normas da instituição.

4. As informações contidas neste instrumento serão mantidas sob sigilo.

\section{DADOS DE IDENTIFICAÇÃO DA INSTITUIÇÃO}

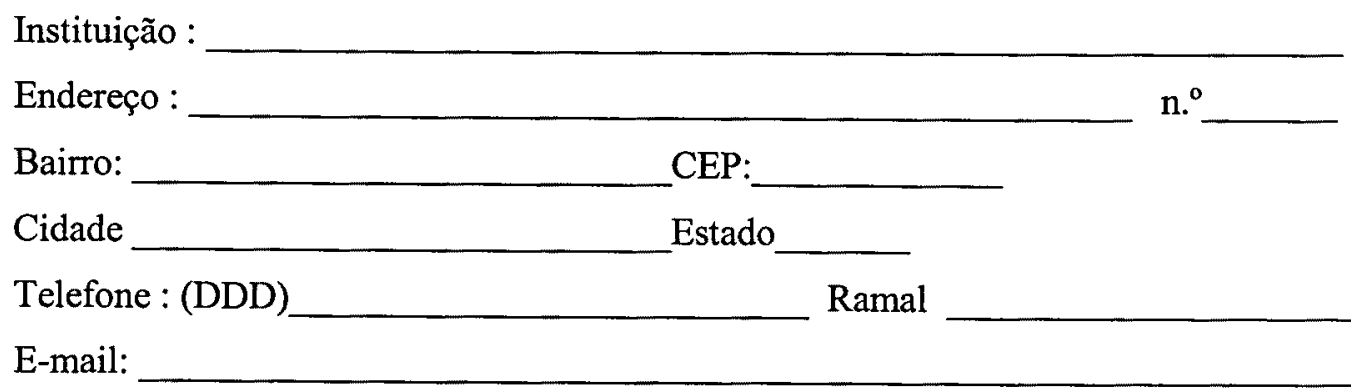

\section{DADOS DE IDENTIFICAÇÃO DO ENTREVISTADO}

Sexo: Idade:

Formação Profissional:

Cargo: Tempo na Instituição:

Tempo na área da Qualidade: 
1. Personalidade Jurídica:

\begin{tabular}{|c|c|c|c|}
\hline $\begin{array}{l}\square \text { Público } \\
\text { Fundação }\end{array}$ & $\begin{array}{l}\square \text { Federal } \\
\square \text { Estadual } \\
\square \text { Municipal }\end{array}$ & $\square$ Privado & $\begin{array}{l}\square \text { Universitário } \\
\square \text { Público e } \\
\square \text { Fundação } \\
\square \text { Filantrópico }\end{array}$ \\
\hline
\end{tabular}

2. Qual é o tipo da Instituição?:

$\square$ Geral $\square$ Especialidade

Qual?

3.Número de leitos:

4. Número de funcionários próprios:

$\square 200$ a $499 \square \quad \square$ de 500 a $999 \square 1000$ a $2499 \quad \square 2500$ ou mais

5. Número de funcionários por nível em relação a função exercida:

\begin{tabular}{|c|c|}
\hline Operacional & \\
\hline Técnico & \\
\hline Universitário & \\
\hline
\end{tabular}

6. Número de funcionários por grau de instrução:

$1^{\circ}$ grau completo

$2^{\circ}$ grau completo

$3^{\circ}$ grau completo

Mestrado: completo incompleto

Doutorado: completo incompleto

Especialização:

7. Quais estratégias foram utilizadas pela instituição para melhoria no atendimento ao cliente? 
8. Preencha o quadro abaixo considerando os treinamentos realizados no último ano:

\begin{tabular}{|l|l|l|}
\hline \multicolumn{1}{|c|}{ Treinamento } & Duração/h & $\begin{array}{c}\text { Público alvo } \\
\text { Número de } \\
\text { participantes/função }\end{array}$ \\
\hline$\square$ comportamental & & \\
\hline$\square$ técnico & & \\
\hline$\square$ administração & & \\
\hline$\square$ em Qualidade & & \\
\hline$\square$ Outros. Quais? & & \\
\hline & & \\
\hline & & \\
\hline
\end{tabular}

9. Relate as etapas mais importantes na implantação do Programa de Qualidade de sua instituição:

10. Há quanto tempo a organização vem desenvolvendo e implementando estratégias de Qualidade? (em anos)

$\square$ de 01 a $03 \quad \square$ de 04 a $05 \quad \square$ de 05 a $07 \quad \square$ mais de 08

11.Qual é a abrangência da implementação dessa estratégia:

$\square$ Uma área

$\square$ Algumas áreas

Quais?

Toda organização

12 Quantos funcionários foram envolvidos no processo de implementação de estratégias de Qualidade?

13. Sua organização adotou alguma metodologia específica para implementar sua estratégia de melhoria da qualidade?

$\square 5 \mathrm{~S}$

$\square$ PDCA

$\square 6$ Sigmas

$\square$ Outros. Quais? 
14. Conceitue Acreditação e quais beneficios / melhorias este sistema pode gerar para os hospitais, tanto ao considerarmos clientes internos/ externos:

15. Conceitue Certificação e quais benefícios / melhorias este sistema pode gerar para os hospitais, tanto ao considerarmos clientes internos/ externos:

16. Qual (is) metodologia(s) de avaliação, certificação, acreditação, premiação foi (foram) adotadas nesta instituição?

$\left(^{*}\right)$ Se for uma sintese de diferentes metodologias marcar aquelas utilizadas.

\begin{tabular}{|c|c|c|c|}
\hline$\square \mathrm{CQH}$ & $\square$ ISO & $\square$ Acreditação & $\square$ PQGF \\
\hline$\square$ Joint Comission & & $\square$ Própria Instituição & $\square$ \\
\hline
\end{tabular}

Outras

17. Houve apoio de consultoria externa?

$\square \operatorname{Sim} \square$ Não

Se positivo, de qual tipo?

$\square$ Nacional $\square$ Estrangeira

18. Quanto tempo a consultoria prestou serviços à organização?

$\square$ de 1 a 6 meses $\square$ de 6 a 12 meses $\square$ de 12 a 18 meses $\square$ de 18 a 24 meses

$\square$ de 24 a 30 meses

$\square$ Quando iniciou?

19. Houve alguém da organização responsável por adaptar a metodologia utilizada para as características do hospital?

$\square \operatorname{Sim}$

$\square$ Não

Em caso positivo, quais foram as pessoas (cargo e hierarquia) 
20. Quais estruturas foram derivadas neste processo:

$\square$ Times de melhoria

$\square$ Comissões de Qualidade

$\square$ Força tarefa

$\square$ Outros

21. Como os grupos foram organizados?

$\square$ por times

$\square$ por função

$\square$ por interesse pessoal

22. Caso tenham utilizado o SQ ISO 9000 , enumere de 1 a 20 , os passos seguidos conforme prioridades institucionais:

\begin{tabular}{|l|l|}
\hline Conscientização da Alta Administração & \\
\hline Organização do Planejamento do Trabalho & \\
\hline Diagnóstico dos Fluxos Operacionais pela Consultoria Externa & \\
\hline Mapeamento dos Macro - Processos e sua inter - relação & \\
\hline Treinamento ISO 9000 para Pessoal Operacional & \\
\hline Aprovação do Cronograma Geral e de Elaboração de Procedimentos & \\
\hline Visão de Processo para Gestores & \\
\hline Assessoria às áreas para Elaboração de Procedimentos & \\
\hline Procedimentos de Melhoria e Auditoria Interna & \\
\hline Estratégia para Melhoria Contínua & \\
\hline Sensibilização ISO 9000 e Política de Qualidade & \\
\hline Manual da Qualidade e Comunicação Interna & \\
\hline Monitoramento dos Objetivos da Qualidade & \\
\hline Realização de Auditoria Interna & \\
\hline Diagnóstico Independente & \\
\hline Análise Crítica pela Administração & \\
\hline Contratação - Contato com a Certificação & \\
\hline Realização da Pré Auditoria & \\
\hline Realização da Auditoria de Certificação & \\
\hline Reconhecimento aos Envolvidos & \\
\hline
\end{tabular}


23. Caso tenham utilizado o $\mathrm{MBAH}$, enumere de 1 a 11 , os passos seguidos conforme prioridades institucionais:

\begin{tabular}{|l|l|}
\hline $\begin{array}{l}\text { Definição institucional da aplicação do instrumento como metodologia de Qualidade } \\
\text { e integração institucional }\end{array}$ \\
\hline Manifestação institucional da alta direção da meta definida de aplicação do MBAH & \\
\hline $\begin{array}{l}\text { Sensibilização das áreas envolvidas no manual pela área da Qualidade, sobre a } \\
\text { importância de atender aos itens de verificação solicitados. }\end{array}$ & \\
\hline $\begin{array}{l}\text { Capacitação de avaliadores internos e gerentes pela Instituição Acreditadora ou } \\
\text { Entidades Associativas para liderar as atividades de preparação para visita e auditoria }\end{array}$ & \\
\hline $\begin{array}{l}\text { Auto avaliação das áreas, segundo os itens de verificação, liderado pelos } \\
\text { coordenadores locais do processo, com apoio da área da Qualidade, que poderá } \\
\text { funcionar como uma visita pré auditoria. }\end{array}$ & \\
\hline Marcação de visita dos avaliadores pelo hospital & \\
\hline Visita de avaliação por visitadores externos onde classificarão o nível do hospital. & \\
\hline $\begin{array}{l}\text { Encerramento da auditoria em reunião conjunta com avaliadores e membros da alta } \\
\text { direção do hospital. }\end{array}$ & \\
\hline Relatório de visita e resultados da avaliação realizados pelos avaliadores. & \\
\hline Divulgação dos resultados para as áreas. & \\
\hline Estabelecimento de Planos de Ação para melhoria dos problemas identificados. & \\
\hline
\end{tabular}

24. Eleja 5 passos considerados por você, como um conjunto de requisitos básicos e interrelacionados que possibilitaram a aplicação do PNQ em sua instituição.

25. Sua organização já vinha seguindo o modelo de gestão que facilitou a aplicação do PNQ? 
26. Como são mensurados os resultados dos Programas de Qualidade em relação aos objetivos inicialmente definidos pela Organização? (ficha, produtividade, diminuição de defeitos, diminuição de reclamações, indicadores)

27. Em sua concepção, Qualidade na Saúde é:

28. Qual a importância de um Hospital desenvolver um Sistema de Qualidade?

29. Destaque principais dificuldades do processo de implantação.

30. Destaque principais pontos a serem melhorados.

31. Este trabalho com ênfase na Qualidade trouxe alguma influência para sua vida fora do trabalho?

ロ $\operatorname{Sim}$ Não

32. Comentários Gerais: 
ANEXO $\underline{\mathbf{C}}$

Compilação dos Dados do Formulário

de Pesquisa e Entrevistas 


\section{PERFIL DOS HOSPITAIS}

Será apresentado, a seguir, os dados que permitiram entender os cenários internos dos Hospitais, a partir das informações relatadas.

Participaram das entrevistas nos Hospitais A, B, C, D, E, F, G e H, profissionais de diferentes formações, mas que têm como elemento comum a coordenação das ações de Qualidade das instituições pesquisadas. Assim, encontrase, atuando neste universo, profissionais como: Pedagogos, Advogados, Administradores, Médicos e Engenheiros.

\section{HOSPITAL A}

\section{Descrição da Instituição}

- Hospital Geral, Privado, de médio porte (85 leitos), atende convênios e particulares.

\section{Colaboradores}

- Número de Colaboradores: 200 a 499

Número de Colaboradores por Nível em relação a função exercida

- Operacional - 81

- Técnico - 132

- Universitário - 45

- Terceiros - não informado

Número de Colaboradores por Grau de Instrução

- $1^{\circ} \mathrm{Grau}$ Completo: 28

- $2^{\circ} \mathrm{Grau}$ Completo: 102

- $3^{\circ}$ Grau Completo: 30

- Especialização/Mestrado/Doutorado: não informado

\section{Identificação do Entrevistado}

- Sexo: Feminino

- Idade: 36 anos

- Formação Profissional: Pedagoga - Pós Graduada em RH

- Cargo: Assistente da Qualidade 
- Tempo na Instituição: 5 anos

- Tempo na área da Qualidade: 1 ano

Metodologia e Ações de Qualidade

Metodologia de Avaliação, Certificação, Acreditação

- ISO

- Acreditação

Responsáveis para a adaptação da Metodologia

- Gestores das áreas

Consultoria e tempo de prestação de serviços Nacional

- De 24 a 30 meses

Estruturas derivadas do Processo

- Times de Melhoria

Organização dos Grupos

- Por "times"

Metodologia para implementar estratégias de melhorias da Qualidade

- PDCA

Tempo de implementação de estratégias de Qualidade

- $>8$ anos

Abrangência

- Toda a organização

Colaboradores envolvidos

- 20

\section{Estratégias}

- Implantação do Sistema de Gestão da Qualidade e do Meio Ambiente.

Treinamentos (Número de colaboradores envolvidos e horas de treinamento)

- Comportamental: 284 colaboradores de todas as funções - 546 horas

- Técnico: 447 enfermagem - 912 horas

- Administrativo: não informado

- Qualidade: 346 colaboradores de todas as funções - 2496 horas

- Outros: 347 colaboradores de todas as funções - 803 horas

Etapas importantes na implantação do Programa de Qualidade

- Conscientização da ISO 9.002 e 14.000 
- Implantação da Política da Qualidade e Meio Ambiente

- Padronização e descrição dos processos

\section{Principais dificuldades do processo de implantação}

- “ O envolvimento das pessoas é algo que dificulta trabalhar as não conformidades na íntegra. A relação dar/receber uma não conformidade é muito complicada.

Todo profissional é movido por sentimentos. A não conformidade mostra o erro do outro e o funcionário leva para o lado pessoal. A ação preventiva, trabalha só corrigindo. As pessoas têm ações, mas ainda está estanque ao sistema. Acontecem nas ações, mas não trazem para o sistema. “"

Passos seguidos para implantação da ISO 9.000, conforme prioridades institucionais

1- Conscientização da Alta Administração

2- Organização do Planejamento do trabalho

3- Diagnóstico dos Fluxos Operacionais pela Consultoria Externa

4- Visão de Processo para Gestores

5- Aprovação do Cronograma Geral e de Elaboração de Procedimentos

6- Assessoria às áreas para Elaboração de Procedimentos

7- Manual da Qualidade e Comunicação Interna

8- Sensibilização ISO 9.000 e Política de Qualidade

9- Mapeamento dos Macroprocessos e suas inter-relações

10- Treinamento ISO 9.000 para Pessoal Operacional

11- Diagnóstico Independente

12- Análise Crítica pela Administração

13- Contratação - Contato com a Certificação

14- Realização da Pré-Auditoria

15- Realização da Auditoria de Certificação

16- Reconhecimento aos Envolvidos

17-Realização de Auditoria Interna

18-Monitoramento dos Objetivos da Qualidade

19-Procedimentos de melhoria e Auditoria Interna

20- Estratégia para Melhoria Contínua 
Passos seguidos para o MBAH, conforme prioridades institucionais:

1- Manifestação institucional da alta direção, da meta definida de aplicação do MBAH.

2- Definição institucional da aplicação do instrumento como metodologia de Qualidade e integração institucional.

3- Sensibilização das áreas envolvidas no manual pela área da Qualidade, sobre a importância de atender os ítens de verificação solicitados.

4- Capacitação de avaliadores internos e gerentes pela Instituição Acreditadora ou Entidades Associativas para liderar as atividades de preparação para visita e auditoria.

5- Auto-avaliação das áreas segundo os ítens de verificação, liderado pelos coordenadores locais do processo, com apoio da área da Qualidade, que poderá funcionar como uma visita pré-auditoria.

6- Estabelecimento de Planos de Ação para melhoria dos problemas identificados.

7- Marcação de visita dos avaliadores pelo hospital.

8- Visita de avaliação por visitadores externos onde classificarão o nível do hospital.

9- Encerramento da auditoria em reunião conjunta com avaliadores e membros da alta direção do hospital.

10-Divulgação dos resultados para as áreas.

\section{Passos para aplicação do PNQ}

- Não aplicado

\section{Mensuração de resultados dos Programas de Qualidade}

- É feita através de indicadores, objetivos e metas sistêmicas, ambientais e Qualidade, satisfação, horas de treinamento, "turn over", monitoramento dos indicadores mensais e objetivos organizacionais.

\section{Importância do hospital desenvolver um Sistema de Qualidade}

- A interação

\section{Pontos a serem melhorados}

- Relação interna, estabelecer indicadores internos, ações preventivas incorporadas ao processo, dar subsídios para trabalhar mais Qualidade e habilidade para liderar. 


\section{Conceituação/Benefícios e Melhorias}

- Qualidade: "São processos que buscam cada vez mais organizar tudo o que o cliente precisa, é a interação humana do profissional com o atendimento."

- Acreditação: "A Acreditação veio com o enfoque no cliente final e com a ISO trabalha-se processos, a Acreditação avalia desde a estrutura física, ampliou o $\mathrm{CCIH}$, com a Acreditação a área da Qualidade se sedimentou ainda mais, complementando os métodos técnicos de todas às áreas. Enquanto antes haviam processos de rotina, hoje contamos com padrões técnicos que padronizam. Existem indicadores internos de avaliação. A ISO tem ação corretiva e preventiva, porém acabamos agindo só corretivamente."

- Certificação: "Foi muito difícil a adaptação da ISO na área da saúde. A norma é muito técnica, houve dificuldade com a equipe médica, resistência dos funcionários e gerências." 


\section{HOSPITAL B}

\section{Descrição da Instituição}

- Hospital Geral/Fundação, de grande porte (220 leitos), atende SUS, convênios e particulares.

\section{Colaboradores}

- Número de Colaboradores: 500 à 999

Número de Colaboradores por Nível em relação a função exercida

- Operacional - 220

- Técnico - 369

- Universitário - 96

- Terceiros - não informado

Número de Colaboradores por Grau de Instrução

- $1^{\circ}$ Grau Completo: 47

- $2^{\circ}$ Grau Completo: 461

- $3^{\circ} \mathrm{Grau}$ Completo: 177

- Especialização: 41

Identificação do Entrevistado

- Sexo: Masculino

- Idade: 46 anos

- Formação Profissional: Direito - Pós Graduação em Administração Hospitalar

- Cargo: Superintendente

- Tempo na Instituição: 4 anos

- Tempo na Área da Qualidade: 4 anos

Metodologia e Ações de Qualidade

Metodologia de Avaliação, Certificação, Acreditação

- ISO 
Responsáveis para a adaptação da MetodologiaSuperintendente

Consultoria e tempo de prestação de serviços

- Nacional - De 18 a 24 meses

Estruturas derivadas do Processo

- Comitês

\section{Organização dos Grupos}

Por áreas

Metodologia para implementar estratégias de melhorias da Qualidade

- Metodologia própria (treinamentos, conscientização em relação ao atendimento)

Tempo de implementação de estratégias de Qualidade

- De 1 a 3 anos

\section{Abrangência}

- Seis áreas no momento, com previsão de em mais ou menos dois anos, certificar todo o hospital.

\section{Colaboradores envolvidos}

- Em média 250, no processo de Certificação.

\section{Estratégias}

- Foram usadas duas estratégias diferentes, uma com o corpo clínico isoladamente, outra com todo o quadro, focando a excelência no atendimento e satisfação do cliente.

Para isso foram utilizados filmes palestras de reciclagem, onde deu-se a metodologia ISO reuniões com os médicos, eventos de conscientização e motivação, além de treinamento com as supervisoras de enfermagem 2 vezes por semana, com carga horária de 60 horas.

Treinamentos (Número de colaboradores envolvidos e horas de treinamento)

- Comportamental: 610 colaboradores - 18 horas/funcionário

- Técnico: 4 colaboradores -35 horas/funcionário

- Administrativo: 46 colaboradores - 500 horas/funcionários

- Qualidade: 193 colaboradores - 396 horas/funcionário

- Outros: não informado

Etapas importantes na implantação do Programa de Qualidade 
- Para que se possa ter a Certificação e a garantia da Qualidade, o foco é na excelência do atendimento, ele faz a diferença, é a metodologia da ISO sistematizando o que já estava sendo feito.

Passos seguidos para implantação da ISO 9.000, conforme prioridades institucionais

1- Conscientização da Alta Administração

2- Organização do Planejamento do Trabalho

3- Diagnóstico dos Fluxos Operacionais pela Consultoria Externa

4- Treinamento ISO 9000 para Pessoal Operacional

5- Mapeamento dos Macroprocessos e sua inter-relação

6- Aprovação do Cronograma Geral e de Elaboração de Procedimentos

7- Assessoria às áreas para Elaboração de Procedimentos

8- Visão do Processo para Gestores

9- Procedimentos de melhoria e Auditoria Interna

10- Manual da Qualidade e Comunicação Interna

11 - Monitoramento dos Objetivos da Qualidade

12 - Realização de Auditoria Interna

13 - Diagnóstico Independente-Estratégia de Melhoria Contínua

14 - Contratação - Contato com a Certificação - Sensibilização ISO 9.000 e Política de Qualidade

15 - Realização da Pré-Auditoria

16 - Realização da Auditoria de certificação

17 - Análise Crítica pela Administração

18 - Reconhecimento aos Envolvidos

Passos seguidos para o MBAH, conforme prioridades institucionais

- Não foi utilizado MBAH.

Passos para aplicação do PNQ

- Não aplicado

Principais dificuldades do processo de implantação

Conseguir reunir as equipes multiprofissionais para um trabalho adequado 
Mensuração de resultados dos Programas de Qualidade

- Reclamações, indicadores da ISO, pesquisa de satisfação, treinamentos, indicadores corporativos validados institucionalmente, análise crítica por área com análise crítica geral

\section{Importância do hospital desenvolver um Sistema de Qualidade}

- Criar mecanismos para atingir metas e objetivos.

\section{Pontos a serem melhorados}

- Não chegaram a mensurar pontos críticos, as Áreas Certificadas estão com 100\% de satisfação do cliente e as demais áreas em torno de $90 \%$.

\section{Conceituação/Benefícios e Melhorias}

- Qualidade: Melhoria no atendimento.

- Acreditação: A Acreditação veio para validar os esforços, consolida o que se faz para se obter Qualidade existe uma diferença substancial, a Acreditação puxa para uma melhor sistemática, visa o aprimoramento tecnológico e não de processo, vê o sistema como um todo.

- Certificação: A Certificação ISO padroniza os procedimentos e exige uma melhoria contínua. 


\section{Descrição da Instituição}

- Hospital Geral Privado de Grande Porte (241 leitos), atende convênios e particulares.

\section{Colaboradores}

Número de Colaboradores

- 1000 a 2499

Número de Colaboradores por Nível em relação a função exercida

- Operacional - 1120

- Técnico - 155

- Universitário - 249

- Terceiros - não informado

Número de Colaboradores por Grau de Instrução

- $1^{\circ}$ Grau Completo: 207

- $2^{\circ} \mathrm{Grau}$ Completo: 587

- $3^{\circ} \mathrm{Grau}$ Completo: 223

- Mestrado: 34

Identificação do Entrevistado

- Sexo: Masculino

- Idade: 45 anos

- Formação Profissional: Administrador de Empresas

- Cargo: Gerente da Qualidade

- Tempo na Instituição: 13 anos

- Tempo na área da Qualidade: 8 anos

Metodologia e Ações de Qualidade

Metodologia de Avaliação, Certificação, Acreditação

- $\mathrm{CQH}$

- ISSO

Responsáveis para a adaptação da Metodologia

- Gerente da Qualidade 
Consultoria e tempo de prestação de serviços

- Nacional - De 24 a 30 meses

Estruturas derivadas do Processo

- Times de melhorias

- Comissões de Qualidade

- Força Tarefa

Organização dos Grupos

- Por áreas.

Metodologia para implementar estratégias de melhorias da Qualidade

- PDCA

Tempo de implementação de estratégias de Qualidade

- Mais de 8 anos

Abrangência

- Toda a organização

Colaboradores envolvidos

- 2.000

\section{Estratégias}

- Implantação do Programa de melhoria Contínua e de Acreditação.

Programas diversos de treinamentos, pesquisas de satisfação dos clientes (pacientes e médicos), padronização de processos e rotinas e adequação de recursos disponíveis.

Treinamentos (Número de colaboradores envolvidos e horas de treinamento)

- Comportamental: 2.124 colaboradores - 387 horas

- Técnico: 5.458 colaboradores -2.341 horas

- Administrativo: não informado

- Qualidade: 8.178 colaboradores -1.165 horas

- Outros: 530 integração - 658 horas

Etapas importantes na implantação do Programa de Qualidade

- Reestruturação de processos.

- Mudança na cultura da empresa quanto a Qualidade.

- Adequação PNQ para realidade do Hospital.

- Programas de treinamentos. 
- Programas de Acreditação.

- Programas de Geração de idéias.

- Reconhecimento dos colaboradores.

Passos seguidos para implantação da ISO 9.000, conforme prioridades institucionais

1- Conscientização da Alta Administração.

2- Diagnóstico dos Fluxos Operacionais pela Consultoria Externa.

3- Mapeamento dos Macroprocessos e sua inter-relação.

4- Organização do Planejamento do Trabalho.

5- Aprovação do cronograma Geral e da Elaboração de Procedimentos.

6- Visão de Processo para Gestores.

7- Treinamento ISO para Pessoal Operacional.

8- Estratégia para Melhoria Contínua.

9- Assessoria às áreas para Elaboração de Procedimentos.

10- Sensibilização ISO 9.000 e Política de Qualidade.

11- Contratação - Contato com a Certificação.

12- Monitoramento dos Objetivos da Qualidade.

13-Diagnóstico Independente.

14- Manual da Qualidade e Comunicação Interna.

15-Procedimentos de Melhoria e Auditoria Interna.

16- Análise Crítica pela Administração.

17-Realização de Auditoria Interna.

18- Realização da Pré-Auditoria.

19- Realização da Auditoria de Certificação.

20-Reconhecimento aos Envolvidos.

Passos seguidos para o MBAH, conforme prioridades institucionais

- Não foi utilizado MBAH.

Passos para aplicação do PNQ

- Não aplicado

Principais dificuldades do processo de implantação

- Resistências da equipe médica e funcionários antigos às mudanças, grande desprendimento de tempo para conscientização. 


\section{Mensuração de resultados dos Programas de Qualidade}

- Indicadores de desempenho e Institucional, pesquisas de satisfação dos clientes (pacientes e médicos), controle e tratamento de não conformidades, análise crítica mensal por área, auditorias internas, indicadores de infecção hospitalar e análise crítica geral.

\section{Importância do hospital desenvolver um Sistema de Qualidade}

- Definição de padrões de desempenho, criar uma cultura de Qualidade, melhorar condições globais para excelência no atendimento, dar garantias de condições de trabalho ao médico e paciente, ter credibilidade junto aos clientes, médicos e comunidade, investimento em equipamentos e qualificação de mão-de-obra.

\section{Pontos a serem melhorados}

- Comunicação interna, envolvimento dos novos colaboradores e médicos das equipes terceirizadas.

\section{Conceituação/Benefícios e Melhorias}

- Qualidade: "É essencial, hoje não podemos pensar que uma empresa que presta serviços em atendimento médico/hospitalar não tenha a cultura, conceitos e ferramentas da Qualidade em sua gestão.

Principalmente considerando que estamos tratando de vidas e é necessário que tenhamos processos bem definidos, mão de obra qualificada e equipamentos que garantam os serviços prestados."

- Acreditação: "São programas que visam avaliar os diversos processos, legislações, normas, etc., específicos de um segmento. Os benefícios são quanto a ter um modelo de gestão, ter um controle dos requisitos exigidos para o segmento clientes/pacientes e colaboradores."

- Certificação: "São Normas que visam certificar o Sistema de Qualidade de uma empresa, através da padronização de processos e avaliação sistêmicas, trazendo resultados nos controles quanto a gestão de equipamentos, processos, etc.

Para o segmento hospitalar, as certificações, além de todos os benefícios para o seu processo, trazem credibilidade junto à comunidade, sem desconsiderar o marketing institucional." 


\section{HOSPITAL D}

\section{Descrição da Instituição}

- Hospital Geral Privado/Filantrópico de Grande Porte (411 leitos), atende convênios e particulares.

Colaboradores

Número de Colaboradores:

- 2.500 ou mais

Número de Colaboradores por Nível em relação a função exercida

- Operacional - 1.144

- Técnico -1.436

- Universitário - 1.081

- Terceiros - não informado

Número de Colaboradores por Grau de Instrução

- $1^{\circ}$ Grau Completo: 897

- $2^{\circ}$ Grau Completo: 1.618

- $3^{\circ} \mathrm{Grau}$ Completo: 1.146

\section{Identificação do Entrevistado}

- Sexo: Masculino

- Idade: 29 anos

- Formação Profissional: Adm. de Empresas - Mestre em Adm. Hospitalar

- Cargo: Coordenador Administrativo

- Tempo na Instituição: 5 anos

- Tempo na Área da Qualidade: 5 anos

Metodologia e Ações de Qualidade

Metodologia de Avaliação, Certificação, Acreditação

- ISO

- "Joint Commission"

Responsáveis para a adaptação da Metodologia

- Coordenador administrativo

Consultoria e tempo de prestação de serviços

- Nacional - De 6 a 12 meses (ISO) e de 18 a 24 meses (JCI) 
Estruturas derivadas do Processo

- Times de Melhoria

- Comissões de Qualidade

- Força Tarefa

- Reorganização Institucional

Organização dos Grupos

- Função

Metodologia para implementar estratégias de melhorias da Qualidade

- PDCA / ISO 9.002 / "Joint Commission"

Tempo de implementação de estratégias de Qualidade

- De 5 a 7 anos

Abrangência

- Toda a organização

Colaboradores envolvidos

- Todos os colaboradores em diferentes momentos do processo

Estratégias

- Formação de grupos multiprofissionais para melhoria de processos

Treinamentos (Número de colaboradores envolvidos e horas de treinamento)

- Comportamental: não informado

- Técnico: não informado

- Administrativo: não informado

- Qualidade: não informado

- Outros: não informado

Etapas importantes na implantação do Programa de Qualidade

- Não informado.

Passos seguidos para implantação da ISO 9.000, conforme prioridades institucionais

1- Conscientização da Alta Administração.

2- Organização do Planejamento do Trabalho:

- Diagnóstico dos Fluxos Operacionais pela Consultoria Externa

- Mapeamento dos Macroprocessos e sua inter-relação

- Contratação - Contato com a Certificação 
3 - Treinamento ISO 9.000 para Pessoal Operacional:

- Aprovação do Cronograma Geral e de Elaboração de Procedimentos

- Visão de Processo para Gestores

4 - Assessoria às áreas para Elaboração de Procedimentos:

- Procedimentos de Melhoria e Auditoria Interna

- Estratégia para Melhoria Contínua

- Sensibilização ISO 9.000 e Política de Qualidade

- Manual da Qualidade e Comunicação Interna

- Análise Crítica pela Administração

5 - Monitoramento dos Objetivos da Qualidade

6 - Realização de Auditoria Interna

7 - Diagnóstico Independente

8 - Realização da Pré-Auditoria

9 - Realização da Auditoria de Certificação

10 - Reconhecimento aos Envolvidos

Passos seguidos para o MBAH, conforme prioridades institucionais

- Não foi utilizado MBAH.

Passos para aplicação do PNQ

- Não aplicado

Principais dificuldades do processo de implantação

- Na ISO a dificuldade de compreensão e adaptação da linguagem. Na "Joint Commission" a organização do prontuário e corpo clínico.

Mensuração de resultados dos Programas de Qualidade

- BSC / Indicadores Institucionais / Recertificações ISO / "Joint Commission" Importância do hospital desenvolver um Sistema de Qualidade

- Ser capaz de provar que é bom. Desenvolver no mercado a percepção de que a boa Qualidade deve ser fator de avaliação tão importante quanto a dimensão de custos.

\section{Pontos a serem melhorados}

- Estrutura de integração entre área, visando a uniformização das ações/métodos. 


\section{Conceituação/Benefícios e Melhorias}

- Qualidade: "Ser capaz de definir, atuar/provar que os processos assistências e os resultados clínicos são compatíveis com padrões legais, evidências científicas e custo-efetivas."

- Acreditação: “Atestado de Qualidade de órgãos especializados em setores dos padrões de Qualidade para aquela área (foco maior no processo técnico)."

- Certificação: "Atestado de Qualidade genérico mais voltado para a Gestão de Qualidade, menos com a Qualidade técnica." 


\section{HOSPITAL E}

\section{Descrição da Instituição}

- Hospital Geral, Privado, de Grande Porte (160 leitos), atende convênios e particulares.

Colaboradores

\section{Número de Colaboradores}

500 à 999

Número de Colaboradores por Nível em relação a função exercida

- Operacional - não informado

- Técnico - não informado

- Universitário - não informado

- Terceiros - não informado

Número de Colaboradores por Grau de Instrução

- $1^{\circ}$ Grau Completo: não informado

- $2^{\circ} \mathrm{Grau}$ Completo: não informado

- $3^{\circ} \mathrm{Grau}$ Completo: não informado

- Mestrado/Doutorado/Especialização: não informado

Identificação do Entrevistado

- Sexo: Masculino

- Idade: 43 anos

- Formação Profissional: Médico Cardiologista

- Cargo: Gerente Comercial

- Tempo na Instituição: 1 ano e 4 meses

- Tempo na área da Qualidade: 1 ano e 4 meses

Metodologia e Ações de Qualidade

Metodologia de Avaliação, Certificação, Acreditação

Responsáveis para a adaptação da Metodologia 
- Comissão

Consultoria e tempo de prestação de serviços

- Nacional - De 6 a 12 meses

Estruturas derivadas do Processo

- Força Tarefa

Organização dos Grupos

- Função

Metodologia para implementar estratégias de melhorias da Qualidade

- Cada área usou ferramentas próprias.

Tempo de implementação de estratégias de Qualidade

- Não informado

Abrangência

- Toda a Organização

Colaboradores envolvidos

- Todas as gerências, encarregados, $60 \%$ de multiplicadores e terceiros.

\section{Estratégias}

- Hospital tem como cliente principal o médico e para ele existe um centro de estudo, um centro cirúrgico, oferecendo boa infra-estrutura e logística, além de um sistema de rede onde o resultado do exame fique disponível pela internet.

Treinamentos (Número de colaboradores envolvidos e horas de treinamento)

- Comportamental: não informado

- Técnico: não informado

- Administrativo: não informado

- Qualidade: não informado

- Outros: não informado

Etapas importantes na implantação do Programa de Qualidade

- Não informado

Passos seguidos para implantação da ISO 9.000, conforme prioridades institucionais

- Não aplicado

Passos seguidos para o MBAH, conforme prioridades institucionais

- Não informado 


\section{Passos para aplicação do PNQ}

- Não aplicado

Principais dificuldades do processo de implantação

- Não houve dificuldades, todos tinham consciência do processo

Mensuração de resultados dos Programas de Qualidade

- Pesquisa de opinião

- Estatística / Definição de metas

- Avaliação da pesquisa médica

\section{Importância do hospital desenvolver um Sistema de Qualidade}

- É importante manter a imagem do hospital. É pensar que você será reconhecido no mercado, é "marketing" porque transmite para fora do hospital a capacidade de Qualidade.

\section{Pontos a serem melhorados}

- Consciência das pessoas em relação a Qualidade e a identidade do Hospital

Conceituação / Benefícios e Melhorias

- Qualidade: "Qualidade é aquilo que o cliente acha que pode ter, deve-se ter coerência no processo. As pessoas estão preocupadas em atender bem, o que marca são os 4 primeiros minutos, é a partir disso que você sabe quem é o hospital. Qualidade é elegância, simpatia e atendimento fino."

- Acreditação: "É a receita para fazer as coisas básicas, alinhando para superar as dificuldades do mínimo. A metodologia da ONA é didática e fácil de lidar sem omitir a documentação."

- Certificação: "São extremamente burocráticas, desfoca do que precisa ter cuidado com a Qualidade para focar papel, é uma maneira desgastante pois a burocracia sufoca." 


\section{HOSPITAL F}

\section{Descrição da Instituição}

- Hospital Pediátrico Público, de Médio Porte (119 leitos), atende SUS, convênios e particulares.

\section{Colaboradores}

Número de Colaboradores:

500 à 999

Número de Colaboradores por Nível em relação a função exercida

- Operacional - 203

- Técnico - 357

- Universitário - 340

- Terceiros - não informado

Número de Colaboradores por Grau de Instrução

- $1^{\circ} \mathrm{Grau}$ Completo: não informado

- $2^{\circ} \mathrm{Grau}$ Completo: não informado

- $3^{\circ} \mathrm{Grau}$ Completo: não informado

- Mestrado / Doutorado / Especialização: não informado

Identificação do Entrevistado

- Sexo: Masculino

- Idade: não informado

- Formação Profissional: não informado

- Cargo: não informado

- Tempo na Instituição: não informado

- Tempo na área da Qualidade: não informado

Metodologia e Ações de Qualidade

Metodologia de Avaliação, Certificação, Acreditação

- Própria

Responsáveis para a adaptação da Metodologia

- Diretor Executivo

Consultoria e tempo de prestação de serviços

- Não houve. 
Estruturas derivadas do Processo

- Times de Melhoria

Organização dos Grupos

- Times

Metodologia para implementar estratégias de melhorias da Qualidade

- Gestão Estratégica

Tempo de implementação de estratégias de Qualidade

- Nada consta

Abrangência

- Toda a Organização

Colaboradores envolvidos

- Todos os colaboradores em diferentes momentos do processo

\section{Estratégias}

- Mudança de modelos mentais, buscando uma mudança na forma dos gestores administrarem. Orienta o Hospital a trabalhar dentro de modelo biológico com sistema interativo, buscando reequilíbrio e reorganização, acha que a estratégia de Qualidade tem que ser sistêmica e focada nos usuários.

Exemplo.: Projetos com este foco - Humanização de alimentação

Treinamentos (Número de colaboradores envolvidos e horas de treinamento)

- Comportamental: 873 colaboradores - 29 horas

- Técnico: 550 colaboradores - horas não informadas

- Administrativo: 214 colaboradores -39 horas

- Qualidade: 1.290 colaboradores - 264 horas

- Outros: não informado

Etapas importantes na implantação do Programa de Qualidade

- Não informado

Passos seguidos para implantação da ISO 9.000, conforme prioridades institucionais

- Não foi utilizada ISO 9.000

Passos seguidos para o MBAH, conforme Prioridades Institucionais

- Não foi utilizado MBAH. 
Passos para aplicação do PNQ

- Não aplicado

Principais dificuldades do processo de implantação

- Não informado

Mensuração de resultados dos Programas de Qualidade

- Não informado

Importância do Hospital desenvolver um Sistema de Qualidade

- Não informado

Pontos a serem melhorados

- Não informado

Conceituação/Benefícios e Melhorias

- Qualidade: "Qualidade é o resultado final."

- Acreditação: "Não informado."

- Certificação: "Modelo de produção, que busca certezas e produz um modelo mental que não serve para o serviço hospitalar. Obriga a criação de manuais, sendo que não dá para avaliar o laboratório, se o porteiro não atende bem." 
Colaboradores: Descrição da Instituição

- Hospital Público/Fundação, especializado em Cardiologia de Grande Porte (247 leitos), atende SUS, convênios e particulares.

Número de Colaboradores

1.000 à 2.499

Número de Colaboradores por Nível em relação a função exercida

- Operacional - 309

- Técnico- 453

- Universitário - 329

- Terceiros -1.250

Número de Colaboradores por Grau de Instrução

- $1^{\circ}$ Grau Completo: 173 - Incompleto: 114

- $2^{\circ}$ Grau Completo: 331 - Incompleto: 62

- $3^{\circ}$ Grau Completo: 16 - Incompleto: 04

- Pós-Doutorado: 9 (Livre Docência)

\section{Identificação do Entrevistado}

- Sexo: Masculino

- Idade: 52 anos

- Formação Profissional: Médico

- Cargo: Assistente Técnico de Saúde

- Tempo na Instituição: 17 anos

- Tempo na área da Qualidade: 10 anos

Metodologia e Ações de Qualidade

Metodologia de Avaliação, Certificação, Acreditação

- $\mathrm{CQH}$

- ISO

- Acreditação

- 5S / PDCA 


\section{Responsáveis para a adaptação da Metodologia}

- Assistente Técnico de Saúde

Consultoria e tempo de prestação de serviços

- Nacional-De 1 a 6 meses

\section{Estruturas derivadas do Processo}

- Profissionais motivados, sensibilizados para processos de melhoria.

\section{Organização dos Grupos}

- Interesse Pessoal

Metodologia para implementar estratégias de melhorias da Qualidade

- $5 \mathrm{~S}$

- PDCA

- Funções gerais de administração e compra de livros

Tempo de implementação de estratégias de Qualidade

- De 5 a 7 anos

\section{Abrangência}

- Toda organização, menos os médicos.

\section{Colaboradores envolvidos}

- 80 (Diretores de serviço e chefes)

\section{Estratégias}

- Normalização, elaboração de rotinas, reuniões quinzenais sobre programas de Qualidade, aulas de PDCA. São utilizados:

- Discussão de filmes;

- Espinha de peixe Ishikawa;

- Discussão sobre economia de energia, troca de cartuchos, pedidos de modificação do programa;

- Caixa de informações/reclamações como ferramenta importante, porém sem um instrumento estruturado;

- Pesquisa de Opinião com o cliente interno e pesquisa para diminuição do tempo de atendimento ao paciente.

Treinamentos (Número de colaboradores envolvidos e horas de treinamento)

- Comportamental: 200 enfermagem/recepção - 50 horas

- Técnico: 300 enfermeiros / médicos / biomédicos / laboratório - 200 horas 
- Administrativo: 10 contabilidade - 30 horas

- Qualidade: 80 todos os colaboradores - 60 horas

- Outros: não informado

Etapas importantes na implantação do Programa de Qualidade

- Pesquisas internas com clientes internos e externos

- $5 \mathrm{~S}$ (70 servidores)

- PDCA ( Fundação Cristiano Otoni - 1998 retomou no ano 2000 com reuniões sistemáticas baseadas no livro "Qualidade e Produtividade”. Devido as demissões voluntárias o programa teve que ser interrompido, portanto o PDCA foi contratado e não pôde ser implantado.

Passos seguidos para implantação da ISO 9.000, conforme prioridades institucionais

1 - Conscientização da Alta Administração.

2 - Organização do Planejamento do Trabalho.

3 - Mapeamento dos Macro-Processos e suas inter-relações.

4 - Aprovação do Cronograma Geral e de Elaboração de Procedimentos.

5 - Manual da Qualidade e Comunicação Interna.

6 - Assessoria às áreas para Elaboração de Procedimentos.

7 - Realização de Auditoria Interna.

8 - Treinamento ISO 9.000 para Pessoal Operacional.

9 - Procedimentos de Melhoria e Auditoria Interna.

10 - Sensibilização ISO 9.000 e Política de Qualidade.

11 - Visão de Processo para Gestores.

12 - Estratégia para Melhoria Contínua.

13 - Monitoramento dos Objetivos da Qualidade.

14 - Diagnóstico Independente.

15 - Análise Crítica pela Administração.

Passos seguidos para o MBAH, conforme prioridades institucionais

1 - Definição institucional da aplicação do instrumento como metodologia de Qualidade e integração institucional

2 - Sensibilização das áreas envolvidas no manual pela área da Qualidade, sobre a importância de atender aos itens de verificação solicitados. 
3 - Capacitação de avaliadores internos e gerentes pela Instituição Acreditadora ou Entidades Associativas para liderar as atividades de preparação para visita e auditoria.

4 - Manifestação institucional da alta direção, da meta definida de aplicação do MBAH.

5 - Marcação de visita dos avaliadores pelo hospital

6 - Visita de avaliação por visitadores externos onde classificarão o nível do hospital.

7 - Encerramento da auditoria em reunião conjunta com avaliadores e membros da alta direção do hospital.

8 - Relatório de visita e resultados da avaliação realizados pelos avaliadores.

9 - Divulgação dos resultados para as áreas.

10 - Estabelecimento de planos de Ação para melhoria dos problemas identificados.

Passos para aplicação do PNQ

- Não aplicado

Principais dificuldades do Processo de Implantação

- Mudar a cultura, melhorar as condições estruturais, ampliar e envolver a Instituição como um todo.

Mensuração de resultados dos Programas de Qualidade

- Diminuição das reclamações.

- SAME centraliza manualmente as informações.

- laboratório controla $\mathrm{m} 1$ de contraste por exame.

Importância do Hospital desenvolver um Sistema de Qualidade

- Um Programa de Qualidade alavanca para um processo de melhoria.

Pontos a serem melhorados

- Ter mais recursos para treinar o pessoal, pois programa de Qualidade sem treinamentos não existe. Criar metas e medir indicadores.

\section{Conceituação/Benefícios e Melhorias}

- Qualidade: “A Qualidade na saúde é lenta e está ligada diretamente à Qualidade interna de cada indivíduo." 
- Acreditação: “A Acreditação avalia o hospital como um todo, é global não pode ser avaliado separadamente, os resultados da Acreditação são palpáveis, apesar de achar a elaboração da mesma muito simplista."

- Certificação: “A Certificação ISO vale muito a pena para as áreas mais industriais à medida que se padroniza e se normaliza procedimentos." 


\section{Descrição da Instituição}

- Hospital Geral, Privado, de Grande Porte (183 leitos), atende convênios e particulares.

\section{Colaboradores}

\section{Número de Colaboradores}

1.000 à 2.499

Número de Colaboradores por Nível em relação a função exercida

- Operacional - 200

- Técnico - 450

- Universitário - 350

- Terceiros - não informado

Número de Colaboradores por Grau de Instrução

- $1^{\circ} \mathrm{Grau}$ Completo: 200

- $2^{\circ}$ Grau Completo: 450

- $3^{\circ} \mathrm{Grau}$ Completo: 350

- Mestrado: 30

- Doutorado: 5

- Especialização: 50

\section{Identificação do Entrevistado}

- Sexo: Masculino

- Idade: 42 anos

- Formação Profissional: Engenheiro Mecânico Aeronáutico ITA/SJC, Pós Graduado em Administração de Empresas pela FGV/SP e Especialização em Gerenciamento de Negócios Internacionais IMD/Suíça

- Cargo: Superintendente Logístico

- Tempo na Instituição: 1 ano

- Tempo na Área da Qualidade: 10 anos

Metodologia e Ações de Qualidade

Metodologia de Avaliação, Certificação, Acreditação 
- Acreditação

Responsáveis para a adaptação da Metodologia

- Superintendentes e gerentes

Consultoria e tempo de prestação de serviços

- Nacional - De 18 a 24 meses

Estruturas derivadas do Processo

- Grupo facilitador

- Comissão de Qualidade

- Grupo Executivo

Organização dos Grupos

- Times

Metodologia para implementar estratégias de melhorias da Qualidade

- Manual de padrões de Acreditação Hospitalar - "Joint Commission" (CBA)

Tempo de implementação de estratégias de Qualidade

- 1 a 3 anos

Abrangência

- Toda a Organização

Colaboradores envolvidos

- 43 apoio, mais todos os colaboradores.

Estratégias

- Atendimento humanizado personalizado

- Foco em alta Qualidade e resolutividade da medicina

- Conduta ética e papel social

- Incentivo ao desenvolvimento e aperfeiçoamento da medicina

- Capacitação profissional de todos os colaboradores

Treinamentos (Número de colaboradores envolvidos e horas de treinamento)

- Comportamental: não informado

- Técnico: 400 enfermagem - 16.000 horas

- Administrativo: 683 linha de comando, secretarias e colaboradores - 39 horas

- Qualidade: 1.766 linha de comando, atendimento, médicos, grupos de facilitadores e corpo gerencial - 15.230 horas

- Outros: não informado 


\section{Etapas importantes na implantação do Programa de Qualidade}

- Agosto/2000 -Apresentação da proposta de Acreditação

- Setembro/Outubro 2000 - Educação ao grupo facilitador e ao grupo executivo sem os padrões preconizados no Manual de Acreditação Hospitalar JCI/CBA

- Novembro/Dezembro 2000 - Disseminação do Programa de Acreditação.

- Janeiro 2001 - Preparação do grupo facilitador para a etapa de auto-avaliação.

- Fevereiro/Março 2001 - Auto-Avaliação.

- Abril/2001 - Confecção de relatório de auto-avaliação.

- Maio/Julho 2001 - Análise e discussão geral das conformidades e não conformidades e proposta de mudança na metodologia CBA.

- Agosto/Setembro 2001 - Classificação/ priorização das não conformidades, proposta workshop - "Educação para a Qualidade “.

- Outubro/2001 - Workshop "Educação para a Qualidade”- Corpo Gerencial.

- Novembro/Dezembro 2001 - Workshop "Educação para a Qualidade" - Grupo Facilitador.

- Janeiro/Fevereiro 2002 - Workshop “Educação para a Qualidade" - Linha de Comando, Corpo Médico e Terceiros.

- Fevereiro/2002 - Avaliação externa simulada realizada pelo CBA.

- Março/ 2002 - Avaliação do clima organizacional e proposta de melhorias pelos gestores de áreas.

- Abril/2002 - Definição do Plano diretor da Qualidade Corporativa.

Passos seguidos para implantação da ISO $\mathbf{9 . 0 0 0 ,}$ conforme prioridades institucionais

- Não foi utilizada a ISO 9.000.

Passos seguidos para o MBAH, conforme Prioridades Institucionais

- Não informado.

\section{Passos para aplicação do PNQ}

- Não aplicado

\section{Principais dificuldades do processo de implantação}

- Falta de cultura para Qualidade 
- Não saber usar as ferramentas para solução de problemas e melhorias de desempenho

- Líderes do processo de Qualidade não ser "arrogante"

- Qualidade é ter um equilíbrio que cada organização tem que descobrir. Nenhum plano/programa de Qualidade ensina/orienta o como fazer. Ficam só no QUE fazer e QUAIS padrões devem ser seguidos.

\section{Mensuração de resultados dos Programas de Qualidade}

- Reuniões periódicas com análise de casos práticos da Assistência à Saúde, indicadores de satisfação do cliente SAC, melhoria nos indicadores de complexidade cirúrgica, índice do clima organizacional, relatórios do setor de "client care", etc

\section{Importância do hospital desenvolver um Sistema de Qualidade}

- Sistema de Qualidade faz com que o hospital fique atento aos principais desejos/anseios de seus clientes internos e externos. Faz buscar continuamente a melhoria de seu desempenho e adotar políticas, normas e padrões metodológicos, visando a interação das equipes multiprofissionais existentes na Instituição, visando atingir o máximo da satisfação de seus clientes, minimizando os defeitos da operação, além da atenção aos custos operacionais.

\section{Pontos a serem melhorados}

- Definir um "Norte" para organização, para a obtenção de sinergia dos recursos e pessoas que trabalham na Instituição. Os demais pontos são técnicos, fáceis de detectar.

\section{Conceituação/Benefícios e Melhorias}

- Qualidade: O Sistema de Qualidade faz com que o hospital fique atento aos principais desejos/anseios de seus clientes internos e externos. Faz buscar continuamente a melhoria de seu desempenho e adotar políticas, normas e padrões metodológicos, visando a interação das equipes multiprofissionais existentes na Instituição, visando atingir o máximo da satisfação de seus clientes, minimizando os defeitos da operação, além da atenção aos custos operacionais.

- Acreditação: É um instrumento medidor do nível de Qualidade já existente em uma organização hospitalar. Envolve aspectos relacionados no desenvolvimento da Qualidade em saúde, tais como: o acesso e a garantia da continuidade do 
atendimento, processos diagnósticos, terapêuticos e de reabilitação, a segurança dos procedimentos e atos médicos, o desempenho dos recursos humanos e ainda, as adequações das instalações e equipamentos.

Podemos ter como beneficios:
a) referências de boas práticas;
b) melhorias de segurança e atendimento aos clientes;
c) documentação adequada e responsabilidades definidas;
d) sinergias organizacionais com otimização dos recursos.

- Certificação: A Certificação é executada por entidade especificamente designada para tal, com base em requisitos previamente estabelecidos $\mathrm{e}$ documentados, podendo ou não resultar em emissão de certificados. Gera confiança e credibilidade do cliente para organização, gerando um aumento de clientes em busca dos serviços nela prestados. Como benefícios:

- Reconhecimento de outras Instituições;

- Melhorias de negociação com fornecedores e clientes;

- Selo de Qualidade reconhecido por todos no meio hospitalar. 
ANEXO D

Quadro Das Expressões-Chave, Idéias

Centrais e Ancoragens 


\section{QUADROS DAS EXPRESSÕES CHAVE, IDÉIAS CENTRAIS E \\ ANCORAGENS}

\section{EM SUA CONCEPÇ̃̃O, QUALIDADE NA SAÚDE É?}

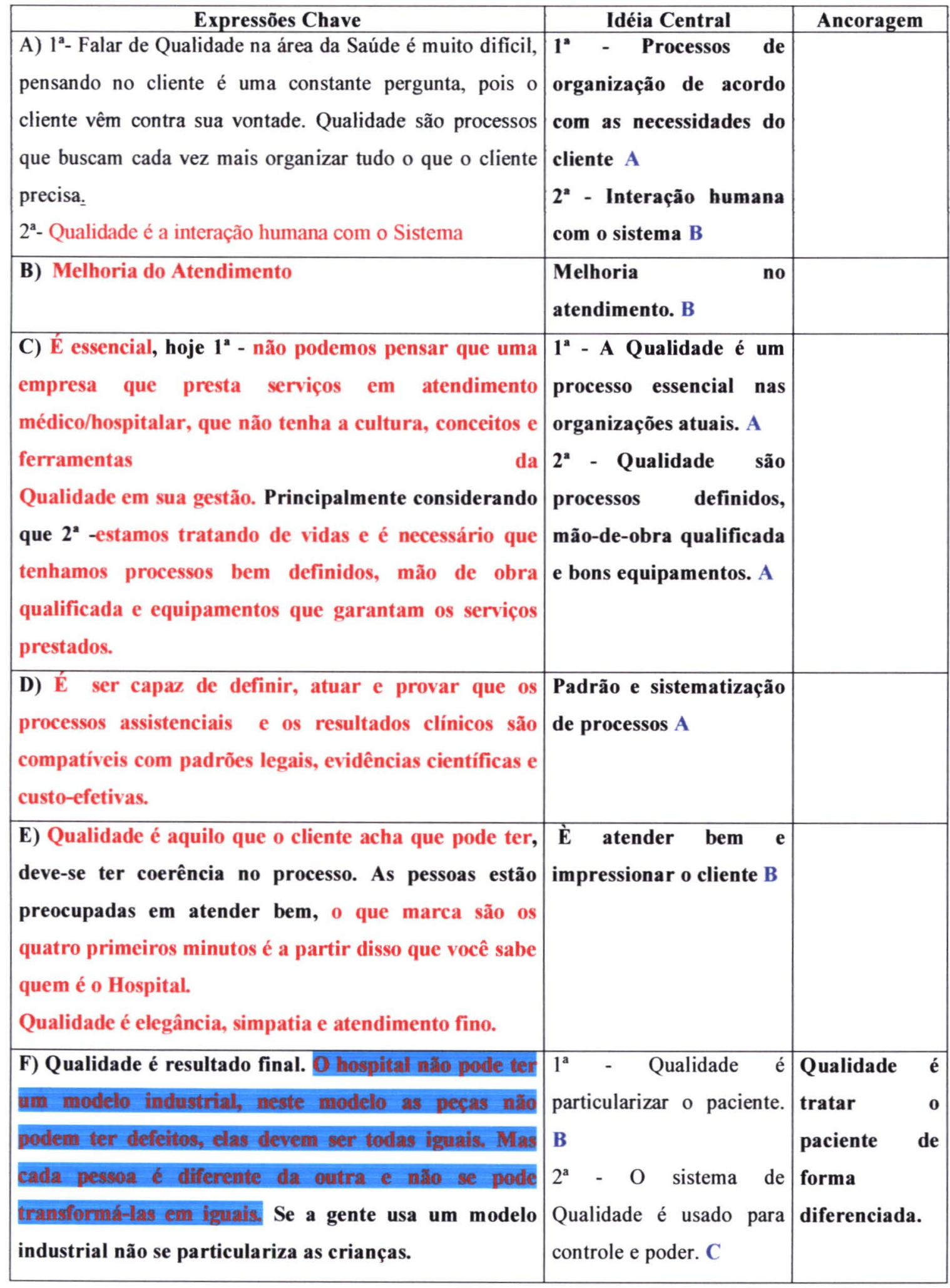




\begin{tabular}{|c|c|c|}
\hline 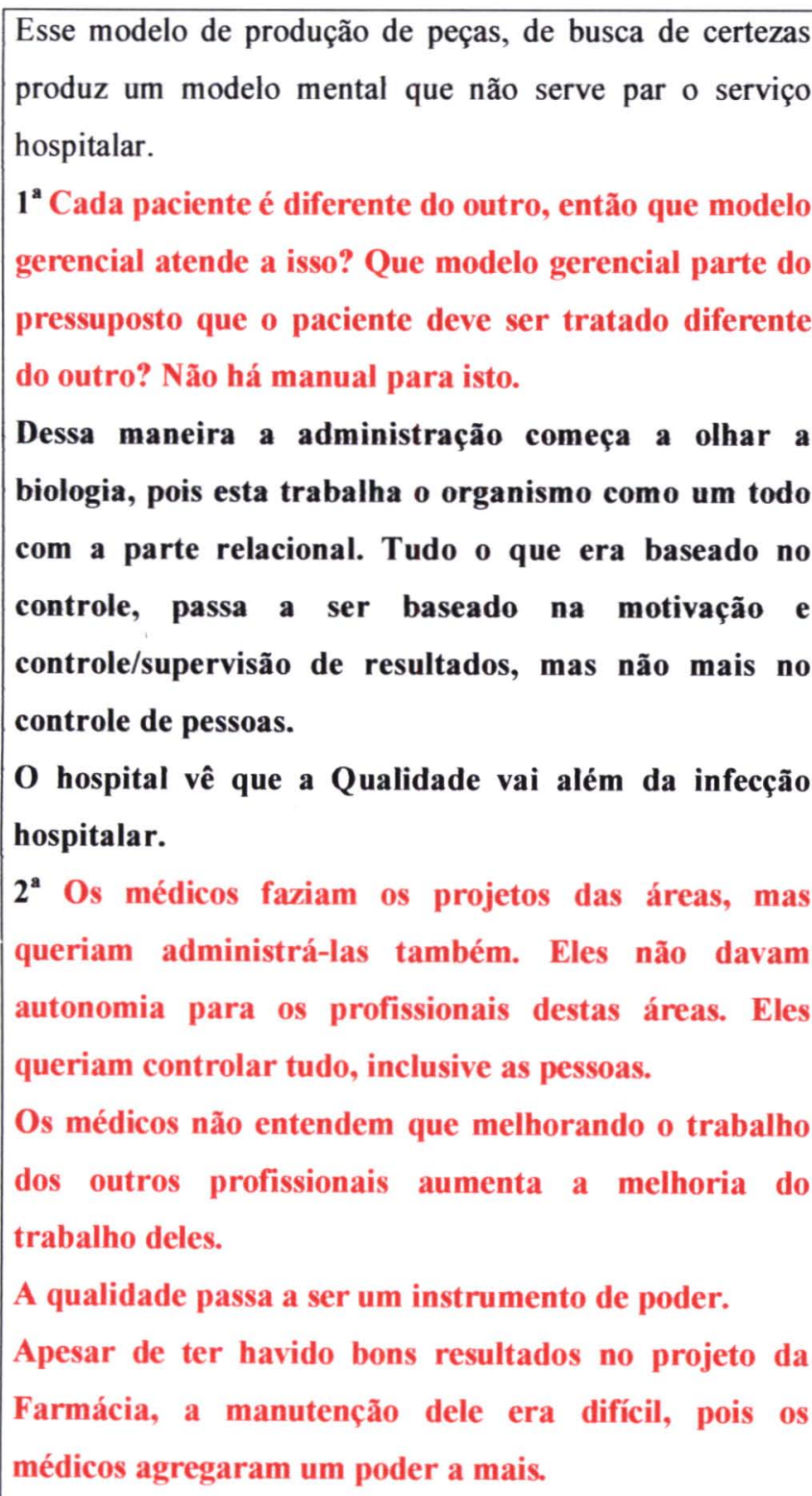 & & \\
\hline $\begin{array}{l}\text { G) A Qualidade na Saúde é lenta e está diretamente } \\
\text { ligada a Qualidade interna de cada indivíduo. }\end{array}$ & $\begin{array}{l}\text { Qualidade em saúde é } \\
\text { lenta e depende das } \\
\text { referências pessoais. B }\end{array}$ & \\
\hline $\begin{array}{l}\text { H) Atendimento eficaz das necessidades e expectativas } \\
\text { dos cliente, com segurança, rapidez e humanização } \\
\text { personalizada. } \\
\text { Qualidade é um equallibrio que cadla organizaçîno tem } \\
\text { que descobrir }\end{array}$ & $\begin{array}{l}\text { Qualidade está ligada às } \\
\text { necessidades } \\
\text { expectativas do } \\
\text { B cliente. }\end{array}$ & $\begin{array}{l}\text { Qualidade é o } \\
\text { equilíbrio da } \\
\text { organização. }\end{array}$ \\
\hline
\end{tabular}

Categorias:
A - Qualidade são Processos
B - Qualidade é Interação Humana
C - Qualidade é um instrumento de Poder 


\begin{tabular}{|c|c|c|}
\hline Expressões Chave & Idéia Central & Ancoragem \\
\hline 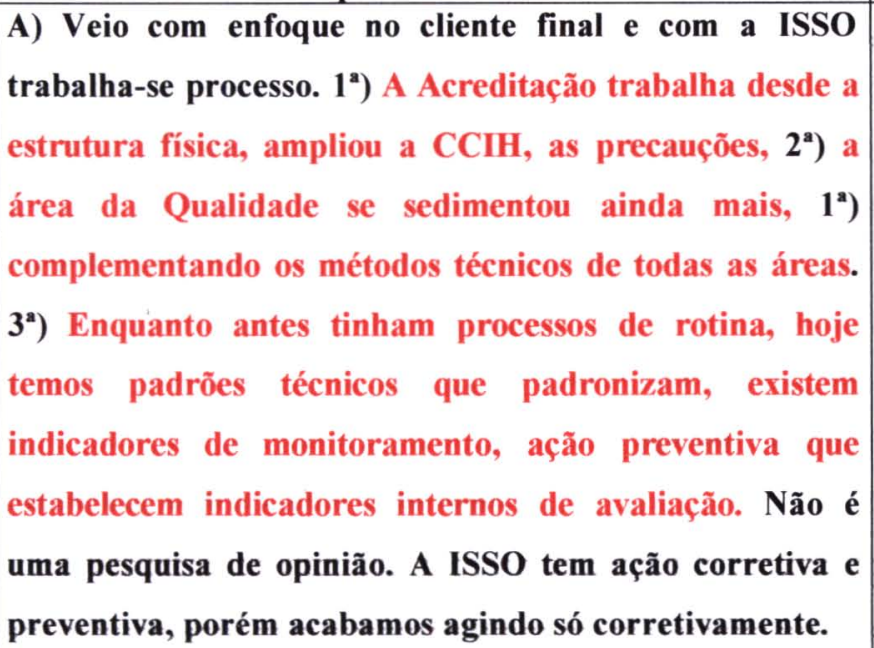 & 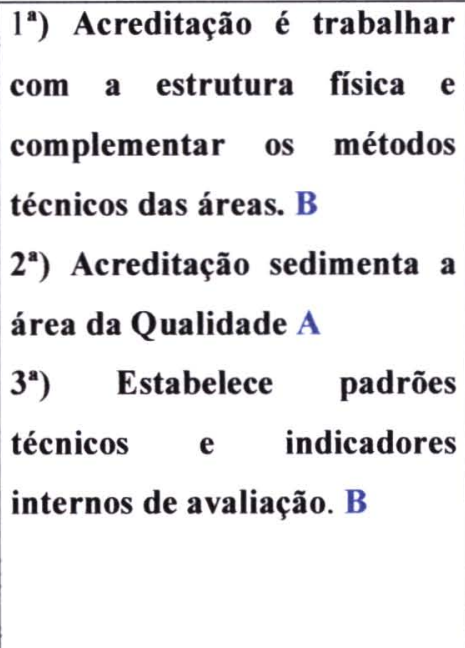 & \\
\hline $\begin{array}{l}\text { B) } 1^{2} \text { ) Vem para validar os esforços, consolida o que se } \\
\text { faz para a Qualidade. Existe uma diferença substancial } \\
\text { para a Certificação ISO que padroniza procedimentos e } \\
\text { a } \\
2^{\text {a }} \text { ) Acreditação puxa para a melhor sistemática. } 3^{\text {an }} \text { A } \\
\text { Acreditação visa aprimoramento tecnológico e não de } \\
\text { processo, tem que ser sistema, ver o conjunto como um } \\
\text { todo. Participando de um seminário simularam uma } \\
\text { Acreditação no Centro Cirúrgico e conseguiram nível 3, } \\
\text { a partir deste momento passaram a participar do } \\
\text { conceito de Acreditação. } \\
\text { Trabalharão preferencialmente nos pontos da } \\
\text { Acreditação Hospitalar e o objetivo é fazer Acreditação. }\end{array}$ & $\begin{array}{l}\text { 1ª) Acreditação consolida a } \\
\text { Qualidade A } \\
\text { 2 }^{\mathrm{a}} \text { ) Acreditação melhora a } \\
\text { sistemática B } \\
\text { 3 }^{\mathrm{a}} \text { ) Acreditação é um sistema } \\
\text { que visa o todo D }\end{array}$ & \\
\hline $\begin{array}{l}\left.\text { C) } 1^{a}\right) \text { São programas que visam avaliar os diversos } \\
\text { processos, legislações, normas, etc... específicos de um } \\
\text { segmento. } 2^{a} \text { ) Os benefícios são quanto a ter um modelo } \\
\text { de gestão, ter um controle dos requisitos exigidos para o } \\
\text { segmento, melhoria contínua e principalmente melhoria } \\
\text { no atendimento aos pacientes e colaboradores. }\end{array}$ & $\begin{array}{l}1^{\text {a}} \text { ) Acreditação são programas } \\
\text { que avaliam processos, } \\
\text { legislações e normas. B } \\
2^{a} \text { Acreditação desenvolve } \\
\text { um modelo de gestão, visando } \\
\text { a melhoria no atendimento } \\
\text { aos clientes internos e } \\
\text { externos. C }\end{array}$ & \\
\hline
\end{tabular}




\begin{tabular}{|c|c|}
\hline $\begin{array}{l}\text { D) } 1^{a} \text { ) Atestado de Qualidade de órgãos especializados } \\
\text { em setores específicos. } 2^{a} \text { ) Os benefícios decorrem de } \\
\text { maior profundidade dos padrões de Qualidade para } \\
\text { aquela área (Foco maior no processo Técnico) }\end{array}$ & $\begin{array}{l}\text { 1ª) Atestado de Qualidade A } \\
\text { 2a) Profundidade nos padrões } \\
\text { de Qualidade B }\end{array}$ \\
\hline $\begin{array}{l}\text { E) } 1^{\text {a }) ~ E ́ ~ a ~ r e c e i t a ~ p a r a ~ f a z e r ~ a s ~ c o i s a s ~ b a ́ s i c a s, ~ a l i n h a n d o ~} \\
\text { para superar as dificuldades do mínimo. A metodologia } \\
\text { da ONA é didática e fácil de lidar sem omitir a } \\
\text { documentação. }\end{array}$ & $\begin{array}{l}\text { 1ª } \text { É a receita para fazer as } \\
\text { coisas básicas E }\end{array}$ \\
\hline F) & \\
\hline 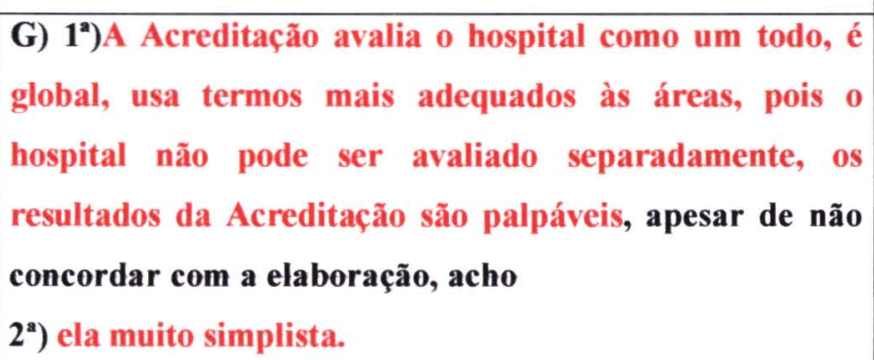 & $\begin{array}{l}\text { 1ª) Acreditação é global com } \\
\text { resultados palpáveis. D } \\
\left.2^{a}\right) \text { Ela é muito simplista. E }\end{array}$ \\
\hline 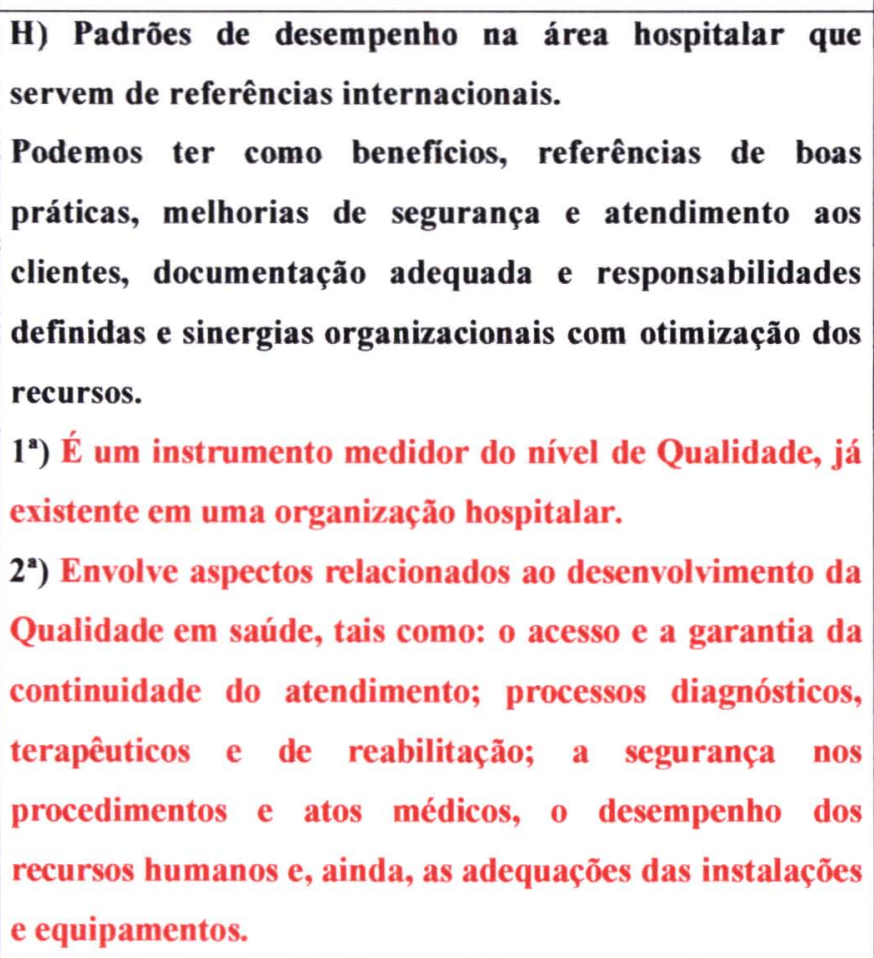 & $\begin{array}{lcc}\left.1^{\mathrm{a}}\right) & \text { Acreditação é } & \text { um } \\
\text { instrumento medidor. B } & \\
\left.2^{\mathrm{a}}\right) \quad \text { Está relacionado } & \text { ao } \\
\text { desenvolvimento } & \text { da } \\
\text { Qualidade na saúde. A } & \end{array}$ \\
\hline
\end{tabular}

\section{Categorias:}

A - Acreditação sedimenta e desenvolve Qualidade.

B - Acreditação é um instrumento medidor.

C - Acreditação desenvolve modelo de gestão.

D - Acreditação avalia o hospital como um todo.

E - Acreditação é a receita para fazer coisas básicas. 


\begin{tabular}{|c|c|c|}
\hline Expressões Chave & Idéia Central & Ancoragem \\
\hline $\begin{array}{l}\text { A) Antes o trabalho da Qualidade estava a nível de } \\
\text { gerencia e diretoria, que haviam feito cursos e estavam } \\
\text { passando por uma fase de padronização dos processos. } \\
\text { Foi muito difícil a adaptação da ISO na área da saúde. } \\
\text { A norma é muito técnica, foi um aprender juntos, } \\
\text { houve dificuldade com a equipe médica, e resistência } \\
\text { dos funcionários e gerencia. A diretoria administrativa } \\
\text { diz que todas as vezes que vêm ao Hospital sente uma } \\
\text { receptividade muito grande. A diretoria acompanha a } \\
\text { inspeção. }\end{array}$ & $\begin{array}{l}\text { A norma é muito } \\
\text { técnica. } A\end{array}$ & \\
\hline $\begin{array}{l}\text { B) A norma é muito técnica, foi um aprender juntos, } \\
\text { houve dificuldade com a equipe médica, e resistência } \\
\text { dos funcionários e gerencia }\end{array}$ & $\begin{array}{l}\text { Padronização } \text { de } \\
\text { procedimentos para } \\
\text { melhoria contínua. A }\end{array}$ & \\
\hline $\begin{array}{l}\text { C) } 1^{a} \text { ) São normas que visam certificar o sistema de } \\
\text { Qualidade de uma empresa, através da padronização } \\
\text { de processos e avaliações sistêmicas, trazendo resultado } \\
\text { nos controles quanto a gestão de equipamentos, } \\
\text { processos e etc... } 2^{\mathrm{a}} \text { ) Para o segmento hospitalar, as } \\
\text { certificações, além de todos os beneficios para o seu } \\
\text { processo, traz credibilidade junto a comunidade, sem } \\
\text { desconsiderar o marketing institucional. }\end{array}$ & $\begin{array}{l}1^{\text {an }} \text { São normas que } \\
\text { certificam através de } \\
\text { padronização } \\
\text { processos e avaliações } \\
\text { sistêmicas. A } \\
2^{\text {a })} \text { Traz credibilidade } \\
\text { junto a comunidade. B }\end{array}$ & \\
\hline $\begin{array}{l}\text { D) Atestado de Qualidade genérico, mais voltado para } \\
\text { gestão de Qualidade, menos com a qualidade técnica }\end{array}$ & $\begin{array}{l}\text { Atestado de Qualidade } \\
\text { genérico. C }\end{array}$ & \\
\hline $\begin{array}{l}\text { E) São extremamente burocráticas, desfoca do que } \\
\text { precisa ter cuidado com Qualidade para focar papel, é } \\
\text { uma maneira desgastante, pois a burocracia sufoca. }\end{array}$ & $\begin{array}{l}\text { São extremamente } \\
\text { burocráticas e focam } \\
\text { papéis. A }\end{array}$ & \\
\hline
\end{tabular}




\begin{tabular}{|c|c|}
\hline F) & \\
\hline $\begin{array}{l}\text { G) A certificação ISO vale muito a pena nas área mais } \\
\text { industriais, a medida que se padroniza e se normaliza } \\
\text { procedimentos }\end{array}$ & $\begin{array}{l}\text { A certificação padroniza } \\
\text { er normaliza } \\
\text { procedimentos. A }\end{array}$ \\
\hline $\begin{array}{l}\text { H) } 1^{2} \text { ) Selo de Qualidade, sendo reconhecido por todos } \\
\text { do meio hospitalar. } 2^{a} \text { ) Podemos ter como benefícios o } \\
\text { reconhecimento de outras instituições, e melhorias de } \\
\text { negociação com fornecedores e clientes. } \\
\text { A certificação da qualidade é executada por entidade } \\
\text { especificamente designada para tal, com base em } \\
\text { requisitos previamente estabelecidos e documentados, } \\
\text { podendo ou não resultar em emissão de certificados. } 2^{a} \text { ) } \\
\text { A certificação gera confiança e credibilidade do cliente } \\
\text { para a organização, gerando um aumento de clientes } \\
\text { em busca dos serviços nela prestados. }\end{array}$ & 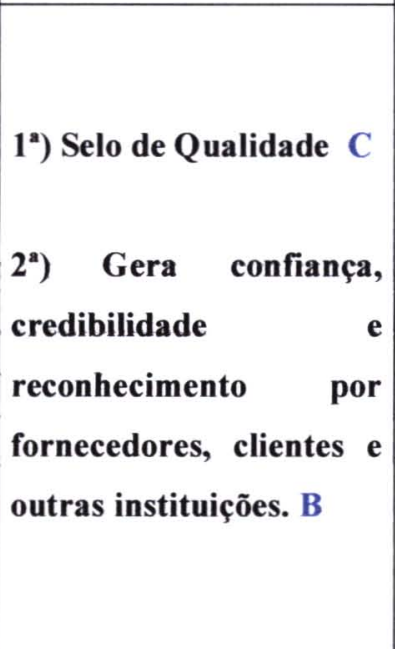 \\
\hline
\end{tabular}

Categorias:

A - Certificação padroniza e normaliza procedimentos.

B - Certificação gera confiança, credibilidade e reconhecimento

C - Certificação é atestado de Qualidade 


\begin{tabular}{|c|c|c|}
\hline Expressões Chave & Idéia Central & Ancoragem \\
\hline $\begin{array}{l}\text { A) Indicadores, objetivos, metas sistêmicas, ambientais e } \\
\text { Qualidade, satisfação, horas de treinamento, turn over, } \\
\text { monitoramento dos indicadores mensal, e objetivos } \\
\text { organizacionais. Existem indicadores por área, mas não } \\
\text { entram no processo ISO . No âmbito geral não estamos } \\
\text { conseguindo uma melhoria contínua, por isso } \\
\text { estabelecemos indicadores externos. }\end{array}$ & Indicadores por área $\mathbf{A}$ & \\
\hline $\begin{array}{l}\text { B) Reclamações, indicadores da ISSO, ferramentas como } \\
\text { a pesquisa de satisfação e treinamentos. Quando } \\
\text { estabeleceu-se metas nas áreas, estableceram também a } \\
\text { política da Qualidade coorporativa, a partir disso } \\
\text { apresentaram indicadores que foram validados . } \\
\text { Análise crítica por área com análise crítica geral. }\end{array}$ & $\begin{array}{l}\text { Definiram metas nas } \\
\text { áreas, politica da } \\
\text { Qualidade coorporativa e } \\
\text { indicadores. } A\end{array}$ & \\
\hline $\begin{array}{l}\text { C) } \mathbf{1}^{\text {a }} \text { Indicadores de desempenho e Institucional, } \\
\text { Pesquisa de satisfação de clientes, controle e tratamento } \\
\text { de não conformidades, análise crítica mensal por área, } \\
\text { Auditorias Internas. Indicadores de infecção hospitalar } \\
\text { em várias áreas, } 2^{a} \text { ) indicadores de satisfação do cliente, } \\
\text { que para a Instituição é o mais importante. } \\
\text { Já existia no conceito de Qualidade uma pesquisa junto } \\
\text { aos pacientes, mas a amostragem era pequena e não } \\
\text { satisfazia, foi então perguntado qual era o melhor } \\
\text { momento para o paciente responder a pesquisa e } \\
\text { percebeu-se que seria na casa dele. Foi então criada uma } \\
\text { pesquisa que abrange desde o momento da internação } \\
\text { até a alta, este instrumento é um questionário que se } \\
\text { baseia em três pontos: nota de acordo com o fluxo, } \\
\text { satisfação do cliente e críticas, sugestões e elogios. Esta } \\
\text { pesquisa é feita no setor de telemerketing e serviu como } \\
\text { indicador de qualidade. }\end{array}$ & 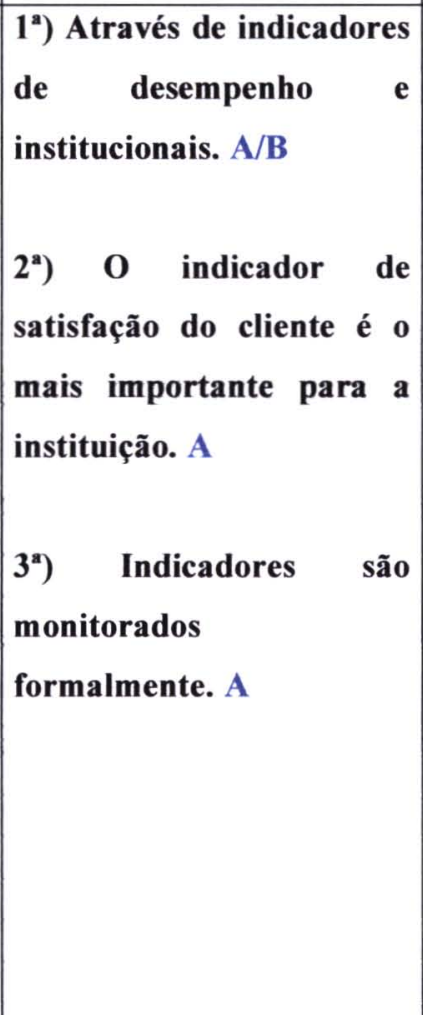 & $\begin{array}{l}\text { Qualidade } \\
\text { é prevenir. }\end{array}$ \\
\hline $\begin{array}{l}\text { Quando a nota for acima de três, não se investiga e é } \\
\text { enviado para a área imediatamente. } A \text { área investiga e }\end{array}$ & & \\
\hline
\end{tabular}




\begin{tabular}{|c|c|}
\hline $\begin{array}{l}\text { toma as decisões em relação ao ocorrido e no final do } \\
\text { mês é gerado um relatório que é acompanhado pelo } \\
\text { gerente de Qualidade e diretores que irão acompanhar o } \\
\text { andamento. } \\
\left.3^{a}\right) 0 \text { monitoramento, além do organograma da empresa ( } \\
\text { gerentes/ diretores ) é formal e a área da Qualidade irá } \\
\text { cobrar para saber se houve ação preventiva. A } \\
\text { Qualidade tem interação direta e se houve alguma } \\
\text { gravidade, de imediato é tomado uma providência, a } \\
\text { resposta tem que vir do gerente de área. }\end{array}$ & \\
\hline $\begin{array}{l}\text { D) Através do BSC, de Indicadores, recertificações ISO } \\
\text { e Joint }\end{array}$ & $\begin{array}{l}\text { Através do BSC, } \\
\text { indicadores, recertificação } \\
\text { ISO e Joint. A }\end{array}$ \\
\hline $\begin{array}{l}\text { E) Por pesquisa de opinião que é preenchida na alta, } \\
\text { estatísticas, definição de metas, de onde o hospital quer } \\
\text { chegar e como está hoje para aumentar eficiência e } \\
\text { diminuir desperdício e avaliação de pesquisa médica. } \\
\text { A Pesquisa cliente e paciente é feita pelo hospital e pela } \\
\text { gerencia do atendimento onde se pega os pontos } \\
\text { apontados e verifica-se o que pode ter acontecido, sem } \\
\text { esquecer que existe fantasia por parte do paciente, pois } \\
\text { existem coisas que não podem ser feitas. }\end{array}$ & $\begin{array}{l}\text { Pesquisa de Opinião, } \\
\text { estatística e avaliação de } \\
\text { pesquisa médica. A }\end{array}$ \\
\hline F) & \\
\hline $\begin{array}{l}\text { G) Através da diminuição das reclamações, o SAME } \\
\text { centraliza manualmente as informações e o laboratório } \\
\text { controla ml de contraste por exame. }\end{array}$ & $\begin{array}{l}\text { Diminuição de } \\
\text { reclamações e controle de } \\
\text { ml de contraste por } \\
\text { exame. A }\end{array}$ \\
\hline $\begin{array}{l}\text { H) Reuniões periódicas com análise de casos práticos de } \\
\text { Assistência à Saúde, Indicadores de satisfação do cliente. } \\
\text { 0 SAC, melhoria nos indicadores de complexidade } \\
\text { cirúrgica, mais clientes e mais médicos, com situações } \\
\text { complexas, vindo atuar no hospital, Índice de clima } \\
\text { organizacional, relatórios de Client Care, etc... }\end{array}$ & 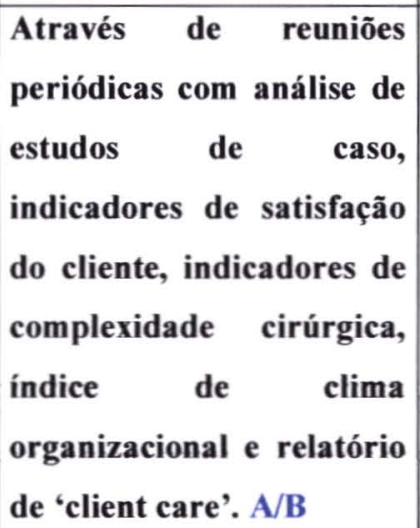 \\
\hline
\end{tabular}

Categorias: A - Indicadores institucionais (Globais)

B - Indicadores de desempenho ( áreas) 


\begin{tabular}{|c|c|c|}
\hline Expressões Chave & Idéia Central & Ancoragem \\
\hline A) $\mathrm{A}$ interação. & Interação A & \\
\hline $\begin{array}{l}\text { B) Dentro do hospital é criar mecanismos para atingir } \\
\text { metas e objetivos. }\end{array}$ & $\begin{array}{l}\text { Criar mecanismos para } \\
\text { atingir metas e } \\
\text { objetivos. B }\end{array}$ & \\
\hline $\begin{array}{l}\text { C) A definição de padrões de desempenho, criar a } \\
\text { cultura da Qualidade, melhorar as condições globais } \\
\text { para a excelência do atendimento, dar garantias de } \\
\text { condições de trabalho aos médicos, ter credibilidade } \\
\text { junto aos clientes, médicos e comunidade, investimento } \\
\text { em equipamentos e qualificação de mão de obra. }\end{array}$ & $\begin{array}{l}\text { Criar uma cultura de } \\
\text { Qualidade, visando } \\
\text { melhoria das condições } \\
\text { globais (equipamentos e } \\
\text { mão de obra), excelência } \\
\text { no atendimento, } \\
\text { garantia de condições de } \\
\text { trabalho aos médicos, } \\
\text { buscando credibilidade } \\
\text { junto aos clientes } \\
\text { internos e externos.B }\end{array}$ & \\
\hline $\begin{array}{l}\text { D) Ser capaz de provar que é bom. Desenvolver no } \\
\text { mercado a percepção de que boa Qualidade deve ser } \\
\text { fator de avaliação tão importante quanto a dimensão } \\
\text { de custos. }\end{array}$ & $\begin{array}{l}\text { Provar que é bom para o } \\
\text { mercado C }\end{array}$ & $\begin{array}{ll}\text { Qualidade } & \text { é } \\
\text { avaliação } & \text { e } \\
\text { custo. } & \end{array}$ \\
\hline $\begin{array}{l}\text { E) } \hat{E} \text { importante mamter a imagemt do lhospital, } \\
\text { pensar que você será reconhecido no mercado, ế } \\
\text { marketing próprio. Transmitir para fora do hospital a } \\
\text { capacidade de Qualidade. }\end{array}$ & $\begin{array}{ll}\text { Manter a imagem do } \\
\text { hospital para ser } \\
\text { reconhecido } & \text { no } \\
\text { mercado. } C & \end{array}$ & $\begin{array}{l}\text { È manter a } \\
\text { imagem da } \\
\text { instituição e } \\
\text { ser } \\
\text { reconhecidoo } \\
\text { no mercado. }\end{array}$ \\
\hline \multicolumn{3}{|l|}{ F) DESCARTADA } \\
\hline $\begin{array}{l}\text { G) Um programa de Qualidade allavamea para um } \\
\text { processo de melhorias. }\end{array}$ & $\begin{array}{l}\text { Alavanca para um } \\
\text { processo de melhorias. } B\end{array}$ & $\begin{array}{l}\text { Qualidade é } \\
\text { alavancar um } \\
\text { processo de } \\
\text { melhorias. }\end{array}$ \\
\hline
\end{tabular}




\begin{tabular}{|c|c|c|}
\hline $\begin{array}{l}\text { H) } 1^{\text {a }) ~} 0 \text { Sisterna de Qualidade fac com que o hospital } \\
\text { fique atento as principais desejos e anselos de seus } \\
\text { clientes internos e extermos } \mathbf{2}^{\mathrm{a}} \text { ) Faz buscar } \\
\text { continuadamente a melhoria de seu desempenho e } \\
\text { adotar políticas, normas e padrões metodológicos, } \\
\text { visando a interação das equipes multiprofissionais } \\
\text { existentes na Instituição, visando atingir o máximo da } \\
\text { satisfação de seus clientes, } 3^{\mathrm{a}} \text { ) minimizando os defeitos } \\
\text { da operação, além da atenção aos custos operacionais. }\end{array}$ & 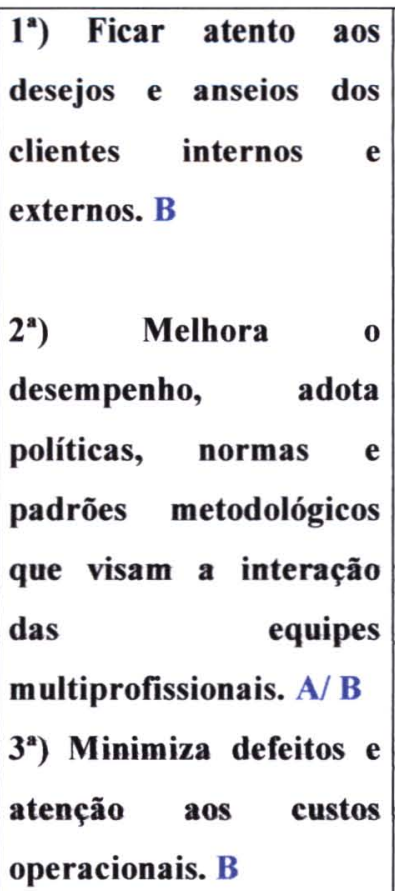 & $\begin{array}{l}\text { Qualidade é } \\
\text { tratar } \\
\text { paciente de } \\
\text { forma } \\
\text { diferenciada. }\end{array}$ \\
\hline
\end{tabular}

Categorias:

A - Melhora a interação entre as pessoas

B - Cria Cultura da Qualidade, melhorando as condições de trabalho

C - Desenvolver marketing favorável no mercado 


\begin{tabular}{|c|c|c|}
\hline Expressões Chave & Idéia Central & Ancoragem \\
\hline $\begin{array}{l}\text { A) Apesar de conseguir bons resultados, o } \\
\text { envolvimento das pessoas é algo que dificulta, } \\
\text { trabalhar as não conformidades na íntegra, a } \\
\text { relação de dar e receber uma não conformidade é } \\
\text { muito complicada. Todo profissional é movido de } \\
\text { sentimentos, a não conformidade mostra o erro do } \\
\text { outro e o funcionário leva para o lado pessoal. }\end{array}$ & $\begin{array}{l}\text { As pessoas se envolvem } \\
\text { pessoalmente } \\
\text { processo e quando levam } \\
\text { uma não conformidade } \\
\text { não aceitam. A }\end{array}$ & \\
\hline $\begin{array}{l}\text { B) Conseguir reunir as equipes multiprofissionais para } \\
\text { um trabalho adequado. }\end{array}$ & $\begin{array}{l}\text { Reunir equipes } \\
\text { multiprofissionais para } \\
\text { um trabalho adequado. } \\
\text { B }\end{array}$ & \\
\hline $\begin{array}{l}\text { C) } \mathbf{1}^{\mathbf{a}} \text { ) Resistência das Equipes Médicas e funcionários } \\
\text { antigos às mudanças e grande desprendimento } \mathbf{2}^{\mathrm{a}} \text { ) de } \\
\text { tempo para conscientização. }\end{array}$ & 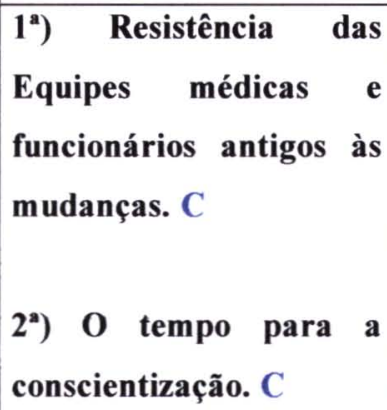 & \\
\hline $\begin{array}{l}\text { D) } \mathbf{1}^{\mathbf{a}} \text { ) Na ISO a dificuldade foi a compreensão e } \\
\text { adaptação de linguagem e na } \mathbf{2}^{\mathrm{a}} \text { ) Joint prontuário e } \\
\text { corpo clínico. }\end{array}$ & 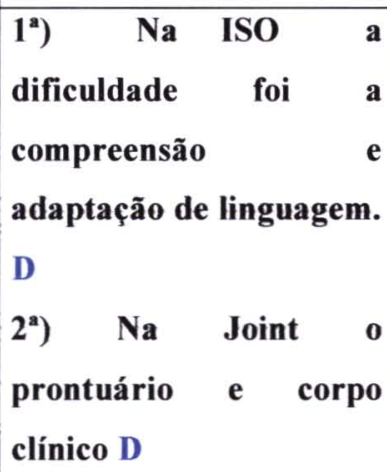 & \\
\hline $\begin{array}{l}\text { E) Não houve dificuldade, todos tinha conhecimento do } \\
\text { processo. }\end{array}$ & Não houve dificuldade. & \\
\hline F) & & \\
\hline
\end{tabular}




\begin{tabular}{|c|c|}
\hline $\begin{array}{l}\text { G) } 1^{2} \text { ) Mudar a cultura, } 2^{2} \text { ) melhorar as condições } \\
\text { estruturais, ampliar e envolver a instituição como um } \\
\text { todo. }\end{array}$ & 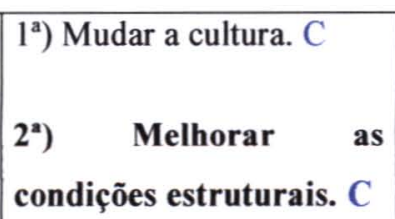 \\
\hline $\begin{array}{l}\text { H) } 1^{\text {a }} \text { ) Falta de cultura para a Qualidade, não usar as } \\
\text { ferramentas para a solução de problemas e melhoria de } \\
\text { desempenho. Os líderes do processo de Qualidade não } \\
\text { podem ser arrogantes, } 2^{\text {a }} \text { ) e acho também que uma } \\
\text { dificuldade é ter um Indicador de Qualidade. } \\
\text { Devemos respeitar a natureza de cada organização, e } \\
\text { fazer o melhor possível, dentro do seu momento e } \\
\text { recursos disponíveis. Nenhum plano ou programa de } \\
\text { Qualidade, ensina ou orienta o como fazer. Ficam só } \\
\text { no que fazer e quais padrões devem ser seguidos. }\end{array}$ & $\begin{array}{l}\text { 1") A falta de cultura } \\
\text { para Qualidade. C } \\
\text { 2 }^{\mathrm{a}} \text { ) Dificuldade de ter } \\
\text { um indicador de } \\
\text { Qualidade. E }\end{array}$ \\
\hline
\end{tabular}

Categorias:

A - Profissionais tomam questões de trabalho pelo lado pessoal

B - Reunir equipes multiprofissionais

C - Resistência a cultura da Qualidade

D - Dificuldade para a compreensão das metodologias de Qualidade

E - Estabelecer indicadores de Qualidade 


\begin{tabular}{|c|c|c|}
\hline Expressões Chave & Idéia Central & \\
\hline $\begin{array}{l}\text { A) } \mathbf{1}^{\mathbf{a}} \text { ) Relação interna, } \mathbf{2}^{\mathbf{a}} \text { ) estabelecer indlicadores } \\
\text { internos, } \mathbf{3}^{\mathbf{a}} \text { ) ações preventivas incorporadas ao } \\
\text { processo, dar subsídios para trabalhar mais } \\
\text { Qualidade, habilidade para liderar. }\end{array}$ & $\begin{array}{l}\text { 1 }^{\text {a })} \text { Melhorar a relação } \\
\text { interna e habilidade para } \\
\text { liderar A } \\
\text { Estabelecer } \\
\text { 2 }^{\text {a }} \text { indicadores internos. B } \\
\text { 3a Ações preventivas } \\
\text { incorporadas no } \\
\text { processo. B }\end{array}$ & $\begin{array}{l}\text { Estabelecer } \\
\text { indicadores } \\
\text { internos }\end{array}$ \\
\hline $\begin{array}{l}\text { B) Não chegaram a mensurar pontos críticos, as áreas } \\
\text { certificadas estão } 100 \% \text { de satisfação do cliente e as } \\
\text { demais áreas em torno de } 90 \%\end{array}$ & $\begin{array}{l}\text { Não há pontos a serem } \\
\text { melhorados. }\end{array}$ & \\
\hline $\begin{array}{l}\text { C) A comunicação interna, o envolvimento dos novos } \\
\text { colaboradores e médicos das equipes terceirizadas. }\end{array}$ & $\begin{array}{l}\text { A comunicação interna, } \\
\text { o envolvimento de novos } \\
\text { colaboradores e médicos } \\
\text { das equipes } \\
\text { terceirizadas. A }\end{array}$ & \\
\hline $\begin{array}{l}\text { D) A estrutura } \text { de }^{a} \text { ) integração entre áreas, visando } \\
2^{a} \text { ) a uniformização das ações e métodos. }\end{array}$ & $\begin{array}{l}1^{\text {a) }} \text { A integração das áreas. } \\
\text { A } \\
2^{\text {a) }} \text { A uniformização das } \\
\text { ações e métodos. C }\end{array}$ & \\
\hline 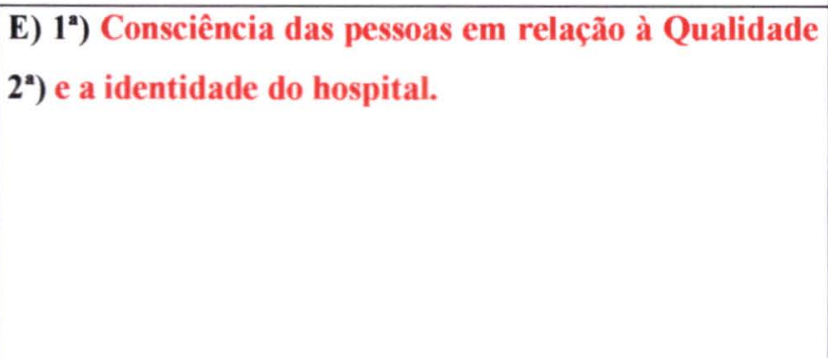 & $\begin{array}{l}1^{\text {a }} \text { Consciência das } \\
\text { pessoas em relação da } \\
\text { Qualidade. A } \\
2^{\text {a }} \text { A identidade do } \\
\text { hospital. D }\end{array}$ & \\
\hline F) & & \\
\hline
\end{tabular}




\begin{tabular}{|c|c|c|}
\hline 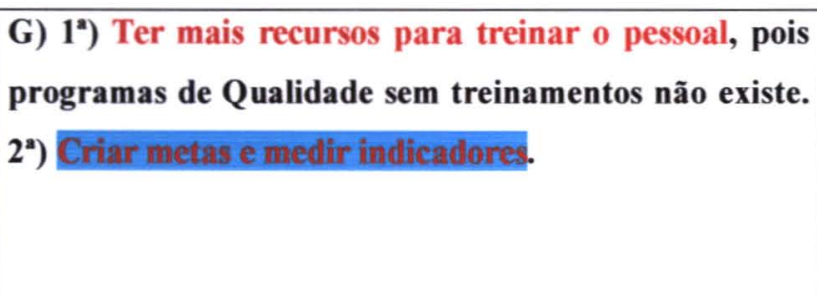 & $\begin{array}{l}1^{\text {a })} \text { Ter recursos para } \\
\text { treinar o pessoal. A } \\
\text { 2a) Criar metas e medir } \\
\text { indicadores. B }\end{array}$ & $\begin{array}{l}\text { Criar metas e } \\
\text { medir } \\
\text { indicadores. }\end{array}$ \\
\hline $\begin{array}{l}\text { H) Definir um "NORTE" para a organização, para a } \\
\text { obtenção de sinergia dos recursos e pessoas que } \\
\text { trabalham na instituição. } \\
\text { Os demais pontos, são pontos técnicos, fáceis de } \\
\text { detectar. }\end{array}$ & $\begin{array}{l}\text { Definir onde a } \\
\text { instituição quer chegar, } \\
\text { direcionando os recursos } \\
\text { e as pessoas. B }\end{array}$ & \\
\hline
\end{tabular}

Categorias:
A - Relação interna
B - Estabelecer metas e medir indicadores
C - Uniformizar ações e métodos
D - Definir identidade institucional 